\title{
Translational control \\ by the ribosomal protein Asc1p/Cpc2p in Saccharomyces cerevisiae
}

\author{
Dissertation \\ zur Erlangung des Doktorgrades \\ der Mathematisch-Naturwissenschaftlichen Fakultäten \\ der Georg-August-Universität zu Göttingen
}

vorgelegt von

Nicole Rachfall

aus

Göttingen

Göttingen 2010 
Die vorliegende Arbeit wurde von September 2006 bis September 2010 in der Abteilung Molekulare Mikrobiologie und Genetik unter Anleitung von Prof. Dr. Gerhard H. Braus am Institut für Mikrobiologie und Genetik der Georg-August-Universität zu Göttingen angefertigt.

Teile dieser Arbeit wurden veröffentlicht in:

Valerius, O., Kleinschmidt, M., Rachfall, N., Schulze, F., López Marín, S., Hoppert, M., Streckfuss-Bömeke, K., Fischer, C., and Braus, G. H. (2007) The Saccharomyces homolog of mammalian RACK1, Cpc2/Asc1p, is required for FLO11-dependent adhesive growth and dimorphism. Mol Cell Proteomics 6 (11), 1968-1979.

Rachfall, N., Heinemeyer, I., and Valerius, O. (2009) 5'TRUE: Die wahre Translation? BIOspektrum 2, 169-171.

Rachfall, N., Heinemeyer, I., Morgenstern, B., Valerius, O., and Braus, G. H. (2010) 5'TRU: Identification and analysis of translationally regulative 5'untranslated regions in amino acid starved yeast cells. Mol Cell Proteomics (under revision).

D7

Referent: $\quad$ Prof. Dr. G.H. Braus

Korreferent: Prof. Dr. S. Pöggeler

Tag der mündlichen Prüfung: 27.10.2010 


\section{DANKSAGUNG}

Zunächst möchte ich mich bei Prof. Dr. Gerhard H. Braus bedanken, der es mir ermöglicht hat, diese Arbeit in seiner Abteilung anzufertigen und mich in meiner wissenschaftlichen Ausbildung unterstützt hat.

Frau Prof. Dr. Stefanie Pöggeler danke ich herzlich für das Interesse an meiner Dissertation und die Übernahme des Korreferats.

Ein ganz besonderer Dank geht an Ole der mich seit meiner Diplomarbeit auf meinem Weg begleitet hat. Unsere enge Zusammenarbeit bei der Entwicklung der Projekte hat wesentlich zum Erfolg dieser Arbeit beigetragen und mich in meiner wissenschaftlichen Denkweise nachhaltig geprägt. Ich werde unsere Gespräche und Diskussionen sehr vermissen! Bei meinen übrigen Laborkollegen Britta, Verena und Ingo möchte ich mich für die tolle Zeit im Labor bedanken. Ihr hattet immer ein offenes Ohr für mich und besonders Verena war eine große Unterstützung bei der Umsetzung der Experimente.

Ihr alle seit mir über die letzten Jahre wirklich sehr ans Herz gewachsen und zu echten Freunden geworden, die ich hoffentlich nie aus den Augen verlieren werde!

Viel Dank gebührt auch Franzi, Susanne, Marc und Ingo, die durch ihre Diplomarbeiten und Praktika einen wichtigen Beitrag zu meiner Arbeit geleistet haben. Recht herzlich danke ich auch Rebekka für das Korrekturlesen dieser Arbeit und Stefan I. für die hilfreichen Anmerkungen und experimentelle Ideengebung. Ebenfalls möchte ich allen nicht namentlich erwähnten Mitgliedern der Abteilung für die angenehme Arbeitsatmosphäre sowie hilfreiche Diskussionen und Anregungen danken.

Mein ausdrücklicher Dank gilt meinen Eltern, die mich immer in all meinen Vorhaben unterstiutzt und an mich geglaubt haben. Es ist schön zu wissen, dass ich mich immer auf euch verlassen kann.

Finally, I'd like to thank Donnie who never had the slightest doubt in my abilities and supported me throughout the whole process. Even at times when I was not too happy about how things were going, he always found a way to make me smile. 



\section{TABle OF ConTents}

$\begin{array}{ll}\text { SUMMARY } & 1\end{array}$

$\begin{array}{ll}\text { ZUSAMMENFASSUNG } & 3\end{array}$

$\begin{array}{ll}\text { CHAPTER I } & 5\end{array}$

Introduction $\quad \mathbf{5}$

1. The regulation of gene expression in Saccharomyces cerevisiae 5

1.1 Transcriptional regulation 5

1.2 Regulation through messenger RNA 9

$\begin{array}{lll}1.3 & \text { Translational regulation } & 10\end{array}$

1.3.1 Translation initiation $\quad 11$

1.3.2 Translation elongation and termination $\quad 15$

2. Gene expression upon amino aid starvation 18

3. WD40-proteins 21

3.1 The WD40-protein Asc1p/Cpc2p 21

$\begin{array}{lll}3.1 .1 & \text { Structure and localization } & 21\end{array}$

3.1.2 Asc1p interactions and functions known in Saccharomyces cerevisiae 23

3.1.3 Asc1p orthologues 26

4. Aim of this work 27

$\begin{array}{lr}\text { References } & 29\end{array}$

$\begin{array}{ll}\text { Chapter II } & 47\end{array}$

5'TRU: Identification and analysis of translationally regulative

$\begin{array}{ll}\text { 5'untranslated regions in amino acid starved yeast cells } & 47\end{array}$

$\begin{array}{ll}\text { Abstract } & 47\end{array}$

$\begin{array}{ll}\text { Introduction } & 48\end{array}$

$\begin{array}{lr}\text { Materials and Methods } & 50\end{array}$

$\begin{array}{ll}\text { Results } & 57\end{array}$

$\begin{array}{ll}\text { Discussion } & 72\end{array}$ 
$\begin{array}{ll}\text { Acknowledgement } & 74\end{array}$

$\begin{array}{ll}\text { References } & 75\end{array}$

$\begin{array}{lr}\text { ChaPTER III } & 79\end{array}$

Asc1p, a ribosomal protein in the abyss of cellular signaling $\quad 79$

$\begin{array}{ll}\text { Abstract } & 79\end{array}$

Introduction $\quad 80$

Materials and Methods $\quad 82$

Results $\quad 89$

Discussion 110

$\begin{array}{ll}\text { Acknowledgement } & 116\end{array}$

$\begin{array}{ll}\text { References } & 117\end{array}$

$\begin{array}{ll}\text { CHAPTER IV } & 127\end{array}$

Asc1p mediates the regulation of translation elongation and balances $\begin{array}{lr}\text { eIF5A and eEF2 expression } & 127\end{array}$

$\begin{array}{ll}\text { Abstract } & 127\end{array}$

$\begin{array}{ll}\text { Introduction } & 128\end{array}$

Materials and Methods 130

Results 132

$\begin{array}{ll}\text { Discussion } & 140\end{array}$

Acknowledgement 142

$\begin{array}{ll}\text { References } & 143\end{array}$

$\begin{array}{ll}\text { CHAPTER V } & 147\end{array}$

Does Asc1p/RACK1 talk the signal into the ribosome? - A conclusive $\begin{array}{ll}\text { model } & 147\end{array}$

$\begin{array}{ll}\text { References } & 151\end{array}$

$\begin{array}{lr}\text { ChaPTER VI } & 155\end{array}$

$\begin{array}{ll}\text { Supplementary Material } & 155\end{array}$

$\begin{array}{ll}\text { CURRICULUM VITAE } & 187\end{array}$ 


\section{SUMMARY}

The mRNA-specific control of translation is of great importance for the adjustment to environmental changes, as e.g. amino acid limitations. It is especially mediated through the mRNA-5' untranslated regions (5'UTRs), containing a variety of translationally regulatory elements. This work presents a method to identify and analyze translationally regulative 5'UTRs (5'TRU) in Saccharomyces cerevisiae. Herein, a de novo proteome-based approach in conjunction with transcriptome data revealed thirteen proteins, whose biosynthesis is up-regulated post-transcriptionally under amino acid starvation conditions. The assessment of the corresponding 5'UTRs by a newly developed testing system proposes a translational up-regulation upon amino acid starvation for Enolp, Fba1p and Tpilp through their respective 5'UTR sequence. The strongest effects were observed for the unstructured and A-rich TPI1-5'UTR. Bioinformatical analyses helped to determine these features to be beneficial for an efficient translation when amino acids are scarce.

The highly conserved ribosomal protein Asc1p/Cpc2p has been described to be involved in several cellular processes, including translational regulation and angiogenesis for mammalian RACK1. The first comprehensive proteome and transcriptome analyses of this protein revealed a requirement for Asc1p in iron uptake and energy metabolism, especially apparent in a respiration deficiency of $\Delta a s c 1$ cells. Additionally, Asc1p can be linked to the MAP kinase-associated networks of invasive/filamentous growth, pheromone response and cell wall integrity through the derived transcriptome data as well as its post-transcriptional/translational regulation of the transcription factors Ste12p, Phd1p, Tec1p, Rap1p and Flo8p. Based on these data, we propose that Asc1p is involved in signal transduction pathways by controlling the translation of transcriptional regulators.

Several previous studies have described Asc1p to specifically alter translation initiation. This work provides first evidence for the involvement of Asc1p in translation elongation through the translation factors eIF5A and eEF2, both participating in this process. Further evidence is given by the enhanced sensitivity for the translation elongation inhibitors sordarin and anisomycin as well as the elevated expression of the +1 frameshifting-dependent protein Oazlp in the $\Delta$ ascl strain. Furthermore, the synergistic regulation of eIF5A and eEF2 by ASC1 and GCN2, coding for the kinase directly involved in the regulation of translation initiation, suggests a superordinate role for Asc1p in translation initiation and elongation. 



\section{ZUSAMMENFASSUNG}

Die mRNA-spezifische Kontrolle der translationellen Regulation ist von hoher Wichtigkeit für die Anpassung an umweltbedingte Veränderungen, wie z.B. Aminosäuremangel. Sie wird insbesondere durch die 5' untranslatierten Regionen (5'UTRs) der mRNA vermittelt, welche verschiedene translationell regulatorische Elemente enthalten können. Diese Arbeit präsentiert eine Methode, um translationell regulative 5' $\underline{\text { UTRs }}$ (5'TRU) in Saccharomyces cerevisiae zu identifizieren und zu analysieren. Der auf einem de novo Proteom basierende Ansatz führte in Verbindung mit Transkriptom-Daten zu der Identifizierung von dreizehn Proteinen, deren Biosynthese post-transkriptionell unter Aminosäuremangel erhöht ist. Die Untersuchung der zugehörigen 5'UTRs mittels eines eigens entwickelten Testsystems deutet auf eine 5’UTR-vermittelte erhöhte Translationsrate für Eno1p, Fba1p und Tpilp hin. Die stärksten Effekte wurden hierbei für die unstrukturierte und A-reiche TPI1-5'UTR beobachtet. Mit Hilfe von bioinformatischen Analysen konnten diese Charakteristika als vorteilhaft für eine effiziente Translation unter Aminosäuremangel ermittelt werden.

Für das hoch-konservierte ribosomale Protein Asc1p/Cpc2p wurde eine Beteiligung an verschiedenen zellulären Prozessen beschrieben, einschließlich translationeller Regulation und Angiogenese für RACK1 aus Säugern. Die erste übergreifende Proteom- und TranskriptomAnalyse für dieses Protein zeigte, dass Asc1p für die Eisen-Aufnahme sowie den Energiemetabolismus benötigt wird, was sich insbesondere in dem eingeschränkten Atmungsvermögen einer $\Delta a s c 1$ Mutante äußert. Zusätzlich weisen die erstellten TranskriptomDaten sowie die post-transkriptionelle/translationelle Regulation der Transkriptionsfaktoren Ste12p, Phd1p, Tec1p, Rap1p und Flo8p auf eine Verbindung von Asc1p mit den MAP Kinaseassoziierten Netzwerken des invasiven/Pseudohyphenwachtums, der Pheromon-Antwort und der Zellwand-Integrität hin. Gestützt auf diese Daten, vermuten wir den Einfluss von Asc1p auf Signaltransduktionswege, indem es die Translation transkriptioneller Regulatoren kontrolliert.

In früheren Studien wurde Asc1p insbesondere in der Regulation der Translationsinitiation beschrieben. Diese Arbeit liefert erste Beweise für einen Einfluss von Asc1p auf die Translationselongation über die Translationsfaktoren eIF5A und eEF2, welche beide an diesem Prozess beteiligt sind. Weitere Hinweise liefern eine gesteigerte Sensitivität für die Translationselongations-Inhibitoren Sordarin und Anisomycin sowie eine erhöhte Expression des +1 frameshifting-abhängigen Proteins Oazlp in einem $\Delta$ ascl Stamm. Zusätzlich lässt eine synergistische Regulation von eIF5A und eEF2 durch ASC1 und GCN2, welches für die direkt an der Translationsinitiation beteiligte Kinase kodiert, eine übergeordnete Funktion von Asc1p in Translationsinitiation und- elongation vermuten. 



\section{Chapter I}

\section{Introduction}

\section{The regulation of gene expression in Saccharomyces cerevisiae}

Gene expression is regulated at various stages within the cell, which allows for a precise response upon changing environmental and cellular conditions, as e.g. nutrient limitations, oxygen availability or heat shock (Carlson, 1997; Holcik and Sonenberg, 2005). The processes involved include transcription, messenger RNA (mRNA) processing and translation (Day and Tuite, 1998). Regulation at these crucial points of gene expression is the basis of cellular differentiation and morphogenesis of any organism and provides for its versatility and adaptability.

\subsection{Transcriptional regulation}

Transcription confers the first step in gene expression from genetic information, in form of DNA, to the final gene product, carrying out its cellular function. The superordinate role in the involved regulatory mechanisms is taken over by chromatin and the RNA-polymerase II (Kornberg, 1999).

Chromatin describes the arrangement in which the chromosomal DNA is complexed. It is divided in the silent heterochromatin (condensed) and the euchromatin (extended), depicting the actively transcribed genes. The localization of chromatin in relation to the nuclear-pore structures within the nuclear envelope has been described to decide over silencing or activation (Akhtar and Gasser, 2007). Whereas euchromatin is found in close proximity to nuclear-pore components, heterochromatin localizes to non-pore sites. The packaging of the DNA is mediated by histones, the major protein component of chromatin (van Holde and Zlatanova, 1996). The five known major classes of histones function in the assembly of nucleosomes, consisting of a distinct histone complex around which the DNA is spooled. Nucleosomes are linked together by a linker-histone, which serves in compacting the nucleosomes to chromatin fibers (Figure 1) (Georgel and Hansen, 2001). 
chromosome

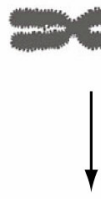

chromatin, (condensed)

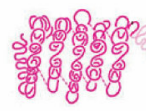

1

chromatin,

(extended) sobo00000

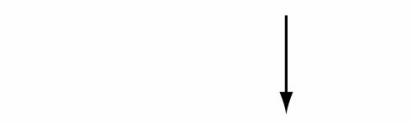

chromatin

fiber
Figure 1. Scheme of transcriptional regulation of gene expression. DNA is stored in the nucleus in the form of chromosomes, consisting of chromatin. Chromatin fibers are layers of nucleosomes composed of DNA wrapped around complexes of histone proteins.

The regulation of transcription is mediated through modifications of histones, leading to chromatinremodeling, and the binding of transcription factors (trans- factors) to upstream activation (UAS) or repression sites (URS) (cis-elements) in the promoter of genes. Additionally the transcription rate is determined by the interaction of the RNA-polymerase II-associated mediator complex with transcription factors as well as enhancers and silencers.

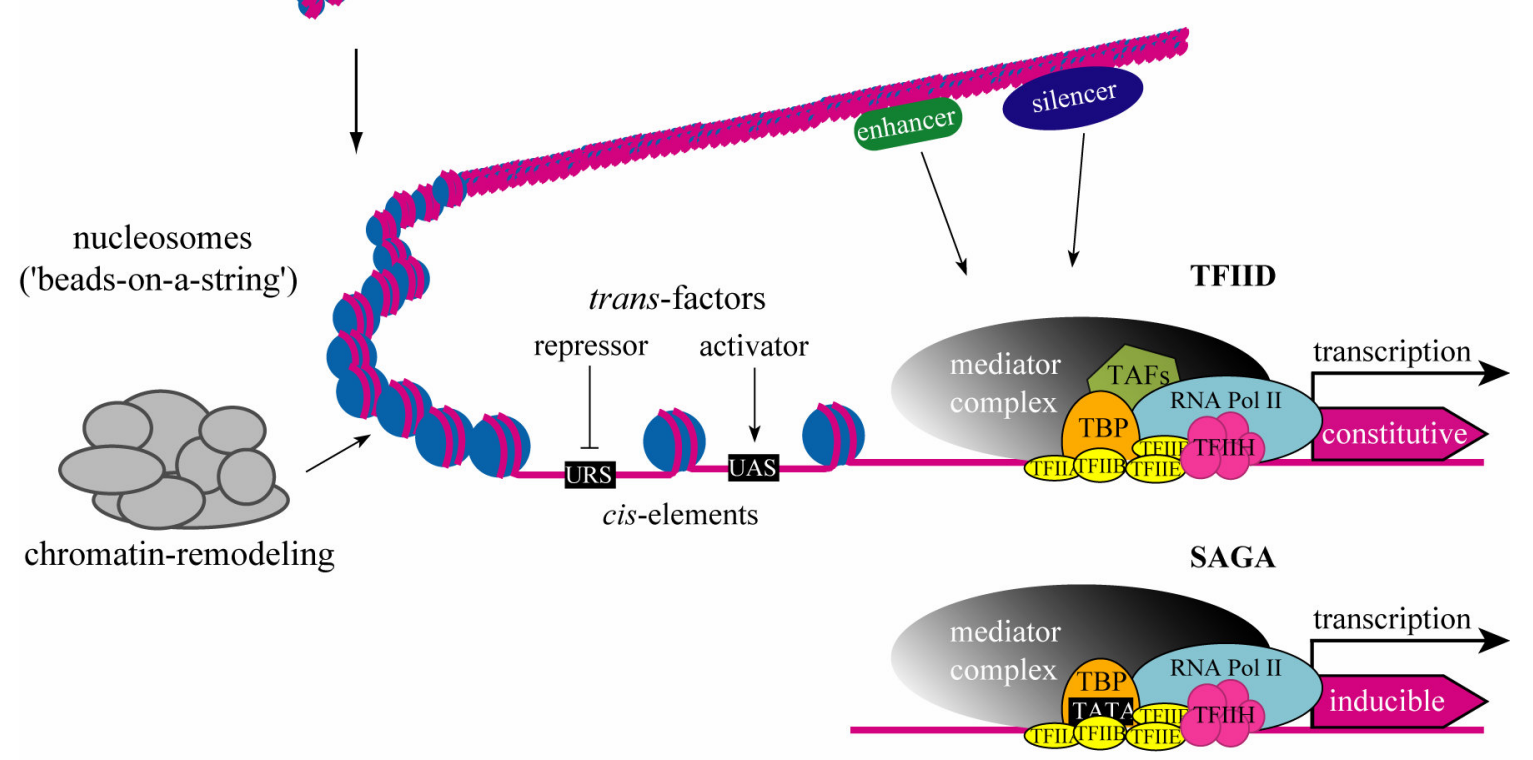

Several modifications of histones have been described, including acetylations, phosphorylations, ubiquitinations and methylations (Lo et al., 2000; Lee et al., 2010). Furthermore histone modifications can act combinatorially in a context-dependent manner to facilitate or repress transcription, as e.g. shown for the requirement of the monoubiquitination of histone H2B for proper H3 methylation (Shilatifard, 2006), a process highly conserved among eukaryotes (Kim et al., 2009). The entity of post-translational modifications results in the remodeling of the chromatin structure and 
thereby regulates gene expression by changes in the accessibility of the DNA for the RNA-polymerase II (Grewal and Moazed, 2003; Shilatifard, 2006).

RNA-polymerase II is a multi-subunit enzyme that is acting in the transcription of protein-coding genes in eukaryotes (Figure 1). Early work established the directed accurate transcription initiation by RNA polymerase II to be mediated by a distinct element in the promoter region of a gene. The so-called TATA-box with the consensus sequence TATA(A/T)A was regarded as the predominant DNA element of core promoters (Struhl, 1987). More recently it was shown that a TATA-box is actually absent in most ( $80 \%)$ RNA-polymerase II-driven promoters (Basehoar et al., 2004). Hereby stress responsive and highly-regulated genes (inducible) are regulated by a TATA-containing promoter, whereas the predominant TATA-less promoter is found for housekeeping genes (constitutive) (Figure1) (Basehoar et al., 2004; Huisinga and Pugh, 2004).

In both cases the first step in the assembly of the transcription pre-initiation complex (PIC) on the core promoter requires the TATA-binding protein (TBP) (Kim and Iyer, 2004). It is delivered to TATA-less promoters by the general transcription factor (GTF) TFIID and to TATA-containing promoters by the $\underline{\text { Spt}} \underline{-} \underline{A} d a-\underline{G} c n 5$ acetyltransferase (SAGA) complex (Basehoar et al., 2004; Huisinga and Pugh, 2004). Subsequently the TBP-associated factors (TAFs) assemble on the promoter, which have been shown to be required for TFIID- but not SAGA-mediated transcription initiation (Huisinga and Pugh, 2004). PIC assembly is completed via incorporation of further GTFs, the mediator complex and the RNA-polymerase II in a stepwise fashion (Ranish et al., 1999; Johnson and Carey, 2003). Whereas the two distinct multi-protein complexes TFIID and SAGA partially act on the same promoters, $90 \%$ of the genome was shown to be regulated through the delivery of TBP by TFIID, which corresponds to the significantly higher number of TATA-less promoters in the genome associated with TFIID function (Huisinga and Pugh, 2004).

Furthermore it was proposed that the turnover rates for TBP are significantly faster on SAGA-dependent/TATA-containing promoters than on TFIID-dependent/TATA-less promoters (van Werven et al., 2009), resulting in only a few rounds of transcription for stress-response genes (TATA-containing) and multiple rounds for housekeeping genes (TATA-less) (Morachis et al., 2010). At the same time PIC assembly on stress-induced genes is a rapid process but very inefficient on the TATA-less promoters of housekeeping genes (Morachis et al., 2010). Thus, it was concluded that the incorporation of a TATA 
element in the promoters of stress-responsive genes is critical for their optimal regulation (Sugihara et al., 2010).

Upon the successful assembly of the PIC at the core promoter, the entire complex is directed to the transcription start site and transcription initiation is prepared (Stargell et al., 2000). The rate of transcription initiation is determined by several factors and serves as the fundamental control point in the transcriptional regulation of gene expression (Struhl, 1995). For example, it was shown that the transcription factor Rap1p binds to subunits of TFIID (Taf4, Taf5 and Taf12) and that these interactions drive the transcription of genes encoding for ribosomal proteins (Layer et al., 2010).

A further regulatory potential is given by the distance between TBP-binding site and transcription initiation site, which is significantly larger and more variable in Saccharomyces cerevisiae than in other eukaryotes (Struhl, 1995). Variances in this promoter region define the promoter strength and therefore the expression rate of the corresponding gene by influencing the binding-capabilities of the PIC to the promoter (Struhl, 1995). Additionally, control elements of about 10-30bp in length approximately 200bp upstream of the initiation site (upstream control elements, UCE) work in an orientation independent manner to regulate gene transcription. These cis-elements act as target sequences for specific DNA binding transcription factors (trans-factors) (Struhl, 1995), which are subdivided in activators, binding to upstream activation sites (UAS) and repressors, attaching to upstream repression sites (URS) (Figure 1) (Sumrada and Cooper, 1987; Rai et al., 1988). They influence the transcription initiation rate by increasing or diminishing the promoter-affinity of the RNA-polymerase II-including PIC, respectively (Figure 1). Some genes are additionally controlled by cis-acting DNA regulatory elements, namely enhancers and silencers, which can be found thousands of base pairs upstream or downstream of the transcription initiation site (Banerji et al., 1981; Blackwood and Kadonaga, 1998). Their denomination results from an interaction with transcriptional activators and repressors, respectively (Barolo and Posakony, 2002). The effects of the interactions of trans-factors with UCEs and enhancer/silencer elements on transcription initiation are conveyed by the mediator complex (Barberis et al., 1995; Björklund and Gustafsson, 2005). 
The mediator complex consists of 21 subunits and is a functional component of the PIC, binding to the C-terminal domain of the RNA-polymerase II (Thompson et al., 1993; Kim et al., 1994)

The regulation of nearly all RNA-polymerase II-dependent genes in S. cerevisiae requires the presence of the mediator complex and the post-translational modification of its subunits have been suggested to globally affect gene transcription (Balciunas et al., 2003; Björklund and Gustafsson, 2005). Furthermore it was shown that the mediator complex is required for the recruitment of the chromatin-remodeling complex Swi/Snf to the UAS of the GAL1-promoter to induce efficient gene transcription (Lemieux and Gaudreau, 2004).

\subsection{Regulation through messenger RNA}

Simultaneously to the transcription process the nascent pre-mRNA molecules are processed by specific processing factors. They mediate the excision of intron sequences from pre-mRNAs as well as the addition of the 7-methylguanosine cap $\left(\mathrm{m}^{7} \mathrm{G}\right)$ structure on the mRNA-5' end and the poly(A) tail, consisting of up to 200 adenine residues and

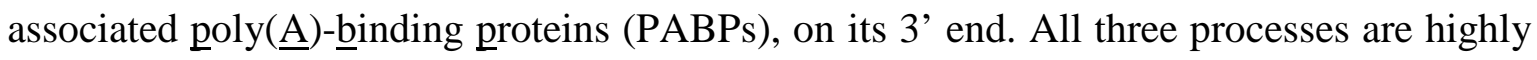
conserved among eukaryotes and not only affect each other but are also influenced by the momentary transcriptional activity of the corresponding gene (Proudfoot et al., 2002). A specific regulatory function for splicing has been shown for the transcription factor Hac1p, mediating the transcriptional up-regulation of genes as a consequence of the unfolded protein response (UPR). The 5' untranslated region (5'UTR) of the HAC1-mRNA contains a non-conventional intron, which prevents its translation due to the formation of a stemloop structure. Upon UPR-stress this inhibitory intron in the HACl-mRNA is spliced out and translation is facilitated (Ruegsegger et al., 2001).

Cap-structure formation as well as poly-adenylation are also of importance for the initiation of translation and protect the mRNA from degradation (Shatkin et al., 1976; Furuichi et al., 1977). mRNA-stability is further conferred through internal mRNA-sequences in the 5'UTR, the coding region and the 3'UTR of an mRNA molecule (Herrick and Jacobson, 1992; Muhlrad and Parker, 1992; Pierrat et al., 1993).

Further co-transcriptional processes include the packaging of the mature transcripts in messenger ribonucleoproteins (mRNPs) and mRNP-export through the nuclear pore 
complex. The assembly of mRNPs, their translocation to the cytoplasmic side of the nuclear pore and the final release of the mRNAs for translation are complex processes, coordinated by a multitude of factors (Kohler and Hurt, 2007; Tran et al., 2007; Luna et al., 2008). Stress-induced disturbances of this processing have been described to induce changes in gene expression (Bond, 2006). To prevent the translation of improper mRNAs and subsequent negative cellular implications, eukaryotic cells have developed multiple nuclear and cytosolic mRNA quality control mechanisms (Doma and Parker, 2007), which function in specifically detecting and destroying faulty transcripts by an evolutionary conserved riboexonuclease machinery, the exosome (Schmid and Jensen, 2008).

mRNA-decay is further induced when translation initiation is inhibited. The mRNAs exit translation and convert into translationally repressed mRNPs. mRNPs then assemble with the decapping enzyme and several accessory proteins of the mRNA degradation machinery in cytoplasmic foci, referred to as processing-bodies (P-bodies). Despite the prevailing function of P-bodies in mRNA-decay evidence has been provided that mRNA molecules can return to translation after assembling to P-bodies (Brengues et al., 2005). Additionally, the existence of EGP-bodies in S. cerevisiae was described, named after their so far only known protein constituents eIF4E, eIF4G, and $\underline{P}$ ab1p. They are functionally and spatially distinct from P-bodies but resemble stress granules (SG) known in higher eukaryotes (Hoyle et al., 2007). In contrast to P-bodies, EPG-bodies do not harbor components of the degradation machinery and are proposed to serve as sites for mRNA storage during periods of translation inactivity (Hoyle et al., 2007).

In comparison to prokaryotes exhibiting an mRNA half-life of 1-5 minutes, the evolution of the diverse set of regulatory mechanisms described in eukaryotes results in distinct variances in the stability of different mRNAs, which adds to the ability of eukaryotic cells to adjust to changing environmental conditions (Day and Tuite, 1998).

\subsection{Translational regulation}

The process of translation has particular significance on gene expression since it represents the last step in the conversion of genetic information to polypeptide chain. It enables a quick and reversible adaptation, especially needed for efficient stress response (Holcik and Sonenberg, 2005). The translational process is subdivided in three subsequent phases. 
Translation initiation describes the step in which the ribosomal subunits are directed to the AUG start codon of the mRNA (Pain, 1996). During translation elongation the mRNA is translated in the polypeptide chain and the termination of translation is determined by the stop codon (UAA, UAG or UGA) of the mRNA, resulting in the release of the nascent protein and the ribosomal subunits (Stansfield et al., 1995; Merrick and Hershey, 1996). Even though all stages of translation are strictly regulated by the interplay of various translation factors and are subject to regulatory mechanisms, the initiation of translation is considered as the most critical and rate limiting step in protein biosynthesis (Marintchev and Wagner, 2004; Ingolia et al., 2009).

\subsubsection{Translation initiation}

Several translation initiation factors (eIFs) are involved in mediating the initiation process. Initially the ternary complex is formed consisting of the heterotrimeric complex eIF2 bound to GTP and the initiator transfer RNA (tRNA) Met-tRNA ${ }_{i}^{\text {Met }}$ (eIF2-GTPMet-tRNA ${ }_{i}{ }^{\text {Met }}$ ) (Figure 2). Mediated by eIF1 and eIF1A the $43 \mathrm{~S}$ pre-initiation complex is assembled by the addition of eIF3 and the small 40S ribosomal subunit to the ternary complex. Subsequently the $43 \mathrm{~S}$ pre-initiation complex binds to the 7-methylguanosine cap $\left(\mathrm{m}^{7} \mathrm{G}\right)$ structure on the 5 , end of the mRNA and assembles with additional eIFs to the 48S pre-initiation complex, which scans the mRNA-5'UTR for the AUG start codon (Figure 2). Both steps are facilitated by eIF4F, the stable heterotrimeric cap-binding complex, consisting of the cap-binding protein eIF4E, the DEAD-box helicase eIF4A, and the central multi-scaffold protein eIF4G, which possesses additional binding sites for the poly(A)-binding protein Pab1p (PABP) (Merrick and Hershey, 1996). Pab1p binding enables the interaction of the 5' cap with the $3^{\prime}$ poly(A) tail of the mRNA to create a circularized complex with regulatory potential towards translation initiation (Wells et al., 1998).

Correct base pairing between the Met-tRNA ${ }_{i}{ }^{\text {Met }}$ anticodon and the AUG codon by the $48 \mathrm{~S}$ complex is mediated through eIF5, which also functions as GTPase-activating protein (GAP) in hydrolyzing eIF2-GTP of the ternary complex to eIF2-GDP, its inactive state (Huang et al., 1997). It was further shown that start site selection triggers the interaction of eIF5 and eIF1A, which is presumed to demonstrate the switch from the scanning- 
competent to the scanning-incompetent state of the $48 \mathrm{~S}$ pre-initiation complex (Maag et al., 2006). eIF2-GDP is thereupon recycled to its active state by the guanine exchange factor (GEF) eIF2B, enabling the anew formation of ternary complex for translation initiation (Figure2). It was demonstrated by Singh et al. (2006) that the guanine nucleotide exchange by eIF2B is antagonized by a complex formation of eIF2 and eIF5. eIF2/eIF5 is proposed to serve as a cytoplasmic reservoir for eIF2 and to function in translational control by affecting the rate-limiting step of GDP-GTP exchange.

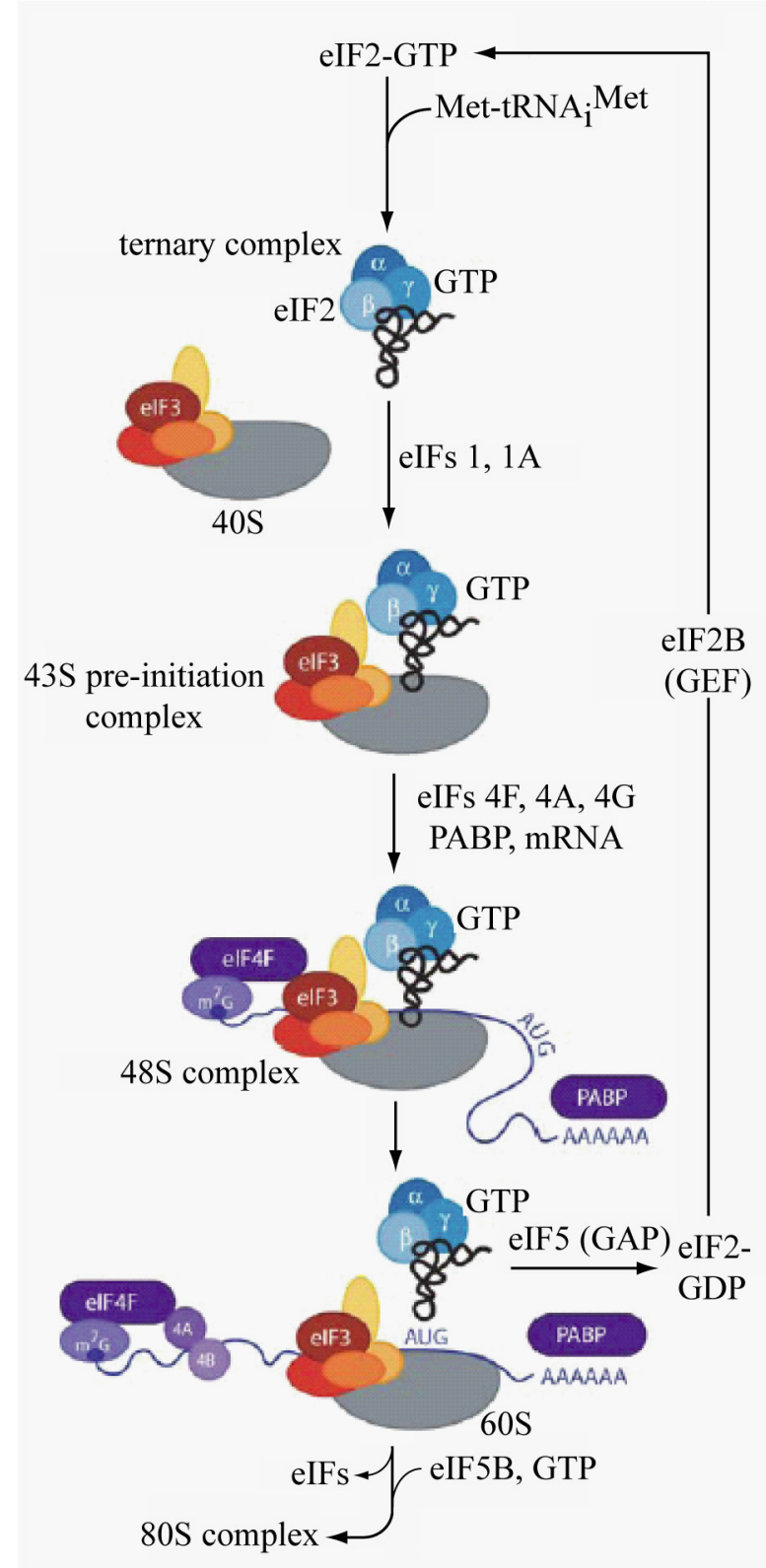

Figure 2. Cap-dependent initiation of translation (modified from Hinnebusch, 2005). The ternary complex (eIF2-GTP-Met-tRNA ${ }_{i}^{\text {Met }}$ ) is assembled and associates with eIF3 and the $40 \mathrm{~S}$ ribosomal subunit to the 43S pre-initiation complex.

Mediated by several eIFs the 43S complex binds to the cap-structure of the mRNA to assemble the $48 \mathrm{~S}$ preinitiation complex that scans in 3' direction for the AUG start codon. Subsequently eIF5A mediates AUG recognition and GTP hydrolysis. eIF2-GDP is recycled by eIF2B to eIF2GTP to enable the anew formation of ternary complex.

After binding of the 60S ribosomal subunit the eIFs are released and elongation on the joined 80S complex can begin. 
The dissociation of the ternary complex as well as eIF5 and eIF1 leads to the disaggregation of the pre-assembled eIFs and the formation of the 40S initiation complex. The second guanine nucleotide-binding protein, eIF5B, then stimulates joining of the $60 \mathrm{~S}$ subunit with the $40 \mathrm{~S}$ initiation complex under the consumption of GTP to form the 80S complex. Polypeptide chain elongation thereupon starts from the methionine linked to the 80S initiation complex (Merrick and Hershey, 1996).

The process of translation initiation can generally be affected by global or mRNA-specific control mechanisms. Global changes are mainly induced in the response to different stressors, resulting in a reduction of the translation initiation rate to conserve energy but also to prevent the synthesis of faulty proteins (Hinnebusch et al., 2004; Holcik and Sonenberg, 2005). The required rearrangements of the translational machinery can be mediated though post-translational modifications of general eIFs or changes in their abundance within the cell (Day and Tuite, 1998; Gebauer and Hentze, 2004). Thus, the amount of ternary complex has been shown to directly depend on eIF2 phosphorylation (Price and Proud, 1994) and the amount of eIF4E is regulated through the 4E-binding protein p20 in yeast (Altmann et al., 1997).

Despite a reduced general translation initiation rate upon stress conditions, certain mRNAs, e.g. coding for stress response proteins, still have to be sufficiently translated. This is mediated through the mRNA-specific control, regulated by sequential or structural characteristics of the respective mRNA. Especially the 5'UTRs of mRNAs seem to be of specific importance for the regulation of translation initiation since they have been described to harbor a variety of elements with regulatory properties (Figure 3) (Kozak, 1986; Day and Tuite, 1998). Especially purine bases within 5' leaders have been speculated to enhance translation initiation in eukaryotes (Baim and Sherman, 1988). This is supported by the finding that the elevated translation of the transcription factor Flo8 $p$ upon glucose-limitation depends on an unstructured poly(A) tract region in its 5'UTR. In this case translation initiation is independent of the cap-structure or eIF4E-binding but is mediated by eIF4G and recruitment of the poly(A)-binding protein (Pab1) to the A-rich sequence within the 5' leader (Gilbert et al., 2007). This internal ribosome entry site (IRES) allows efficient translation of the FLO8-mRNA even when canonical cap-dependent translation is reduced due to global translational adaptations upon stress conditions (Figure 3) (Merrick, 2004). Even though most IRES are found in 5'UTRs in 
close proximity to the translation initiation site, they have also been described as integral components of the coding regions of mRNAs, as shown for the URE2-mRNA in $S$. cerevisiae. Mediated by a simultaneous cap-dependent and cap-independent translational initiation on the URE2-mRNA two distinct polypeptide chains are synthesized of $42 \mathrm{kDa}$ and $30 \mathrm{kDa}$, respectively (Komar et al., 2003). The shorter protein is synthesized through IRES-mediated translation and was shown to be preferentially expressed under heat shock conditions. Correspondingly, IRES have been described to predominantly facilitate translation of proteins that are specifically required under stress conditions (Bonnal et al., 2003). Additionally, the majority of IRES elements found so far in eukaryotic mRNAs are involved in development, differentiation, cell cycle, cell growth, apoptosis and stress (Hellen and Sarnow, 2001).

mRNA

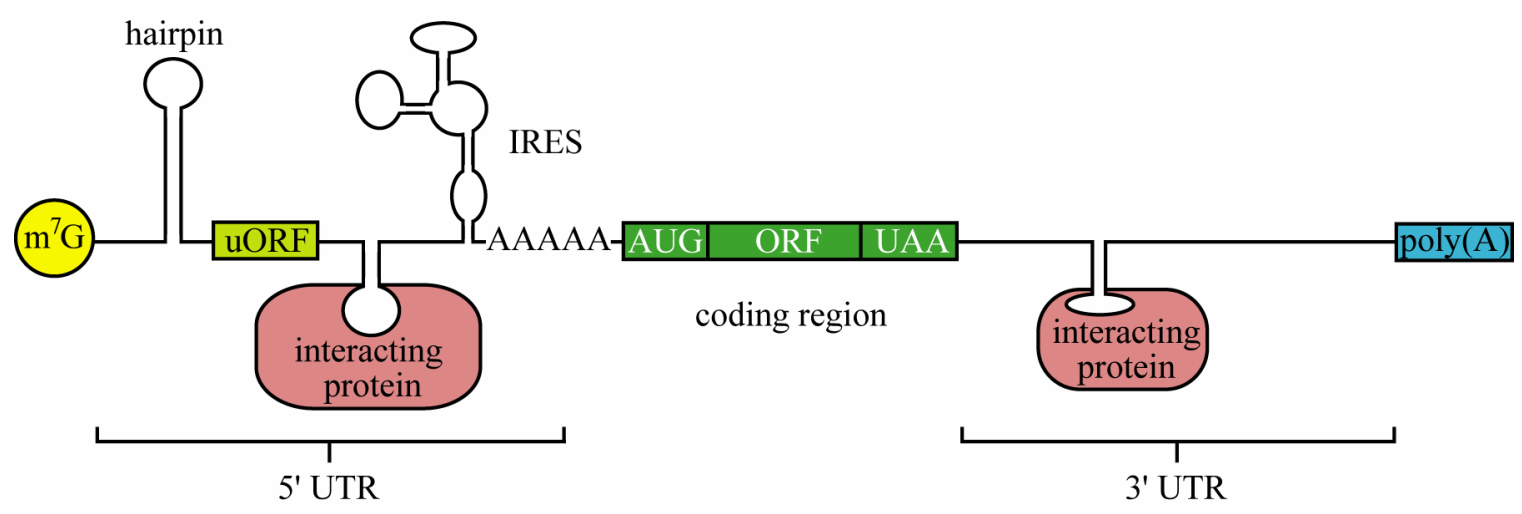

Figure 3. Scheme of an mRNA, harboring possible post-transcriptionally regulative elements. A eukaryotic mRNA is composed of the coding region (green) as well as the 5' and 3' untranslated regions (UTR) upstream and downstream of the coding region. Secondary hairpin structure formation, upstream open reading frames (uORFs), internal ribosome entry sites (IRES) and the interaction with proteins are features that can influence the translation rate of a specific mRNA.

It is to mention that in contrast to viral IRES, whose enhancement of translational activity is structure-based, strong eukaryotic IRES have been linked to weak secondary structures (Xia and Holcik, 2009). In agreement secondary structure formation has predominantly been shown to the inhibit translation initiation. Secondary structures in the 5'UTRs of mRNAs can form so-called hairpin structure, which can block the scanning process of the 
48S pre-initiation complex. Hereby, the degree of the inhibitory effect is determined by the stability of the hairpin structure and its distance from the AUG start codon with the effects being more severe upon closer proximity to the initiation codon (Baim and Sherman, 1988; Vega Laso et al., 1993; Day and Tuite, 1998).

Apart from these constitutive effects of secondary structures, they can also take over regulatory function, e.g. by serving as binding sites for interacting proteins (Figure 3) (Wilkie et al., 2003). Many regulatory proteins function by altering the association of the small ribosomal subunit to the mRNA. By steric inhibitions they disturb the interaction of the cap-binding complex eIF4F with the cap-structure, thereby preventing the formation of the 43S pre-initiation complex (Kozak, 1991). Another implication for protein-mRNA interaction is described for the mRNA-binding protein Tis $11 \mathrm{p}$, conserved in plants and mammals. The protein is up-regulated in response to iron-limitation and binds to specific AU-rich elements in the 3'UTRs of mRNAs, coding for proteins that participate in the consumption of iron, and targets them for degradation (Puig et al., 2005).

Further elements known to regulate translation initiation are upstream open reading frames (uORF) (Figure 3). A uORF describes the presence of another AUG start codon in the 5'leader of the mRNA that can be recognized by the $48 \mathrm{~S}$ pre-initiation complex and serve as translation start site. The paradigm for a uORF-containing mRNA is the one of the transcription factor Gcn4p, containing four uORFs in its 5'UTR. Beside GCN4, 24 other S. cerevisiae genes have been identified to harbor one or more uORFs in their mRNAs, such as LYS12, PCL5 and WSC3 (Zhang and Dietrich, 2005). Translation initiation at a uORF element can cause the synthesis of a cis-acting peptide that causes stalling of the translational machinery and therefore prevents the translation of the actual coding region of the mRNA. In other cases the positioning within the 5'UTR or other features of the uORF can determine the efficiency with which the pre-initiation complex reinitiates downstream of the uAUG (Vilela and McCarthy, 2003).

\subsubsection{Translation elongation and termination}

The process of translation elongation requires the involvement of considerably less translation factors than the initiation process. The substrates for elongation are aminoacylated tRNAs (aa-tRNA), which are synthesized by aminoacyl tRNA synthetases 
via esterification of their specific amino acid to its compatible cognate tRNA (Moldave, 1985). The elongation process is initiated by the binding of the initiator aa-tRNA $\left(\right.$ Met-tRNA ${ }_{i}{ }^{\text {Met }}$ ) to the P-site of the $80 \mathrm{~S}$ ribosome after subunit joining, which opens the A-site for the entry of the next aa-tRNA. Translation elongation factor 1A (eEF1A) assembles to a ternary complex with the aa-tRNA and GTP (eEF1A-GTP-aa-tRNA) to deliver the aa-tRNAs to the ribosomal A-site (Carvalho et al., 1984). Upon codonanticodon match in the A-site of the ribosome, GTP within the ternary complex is hydrolyzed, resulting in the inactive GDP-bound form of eEF1A. The recycling of eEF1A for the next elongation cycle via GDP-GTP exchange is mediated by the GEF eEF1B (Slobin and Möller, 1978). Additionally to its function in the transfer of aa-tRNAs to the ribosome, a role of eEF1A in the re-export of tRNAs from the nucleus into the cytoplasm has been proposed (Murthi et al., 2010).

In the next step the $60 \mathrm{~S}$ ribosomal subunit mediates the peptidyl transferase activity required for the formation of the peptide bond between the initiator amino acid/polypeptide chain attached to the peptidyl-tRNA in the ribosomal P-site and the new amino acid carried by the aa-tRNA in the A-site of the ribosome. Hereby the initiator amino acid methionine/polypeptide chain is transferred from the peptidyl-tRNA in the P-site to the aa-tRNA in the A-site. Finally, the deacylated empty tRNA in the P-site is ejected from the ribosome and the new peptidyl-tRNA, carrying the polypeptide chain is moved from the A- to the P-site. This translocation step is mediated in a GTP-dependent manner by the G-protein eEF2 and simultaneously induces the ribosome to advance one triplet in the reading frame towards the 3 ' end of the mRNA to the next codon. A characteristic in yeast and other fungi is the existence of a third translation elongation factor, eEF3. It is essential for translation elongation and facilitates the release of the deacylated tRNA from the E-site during A-site occupation under ATP-consumption (Triana-Alonso et al., 1995).

The termination of the process is induced by a stop codon (UAA, UAG, UGA) in the mRNA sequence and is mediated by the heterodimeric realease factor (RF) complex, consisting of eRF1 and eRF3 (Stansfield et al., 1995). eRF1 is involved in stop codon recognition and initiates the release of the peptidyl-tRNA from the P-site of the ribosome (Frolova et al., 1994). This reaction is catalyzed by the GTPase eRF3 (Frolova et al., 1994). Subsequently, the polypeptide chain is released from the peptidyl-tRNA and the ribosome disassociates in its $40 \mathrm{~S}$ and $60 \mathrm{~S}$ subunits. 
A very crucial process during translation elongation is the translocation step, in which the ribosome moves one triplet in the reading frame of the mRNA. Slippage of the translational machinery in this process can cause a shift in the reading frame by one nucleotide in $3^{\prime}$ or 5 ' direction of the mRNA, referred to as -1 and +1 frameshifting, respectively. Implications of such errors in translational elongation may be premature translation termination or the misreading of termination codons (nonsense read-through) (Raman et al., 2006). On the other hand ribosomal frameshifting is required for the translation of other mRNAs, as e.g. for transposable elements in yeast. Additionally, three proteins in $S$. cerevisiae have been demonstrated to require +1 frameshifting for their protein biosynthesis, namely Oaz1p, Abp140p and Est3p (Asakura et al., 1998; Palanimurugan et al., 2004; Taliaferro and Farabaugh, 2007). This requirement is described as programmed +1 ribosomal frameshifting and is induced by the sequential or structural features of the corresponding mRNAs, which program ribosomes for frequent translational errors (Farabaugh, 1996). Recently the translation factor eIF5A has been linked to the process of ribosomal frameshifting by the reduction of +1 ribosomal frameshifting in a ts-eIF5A-variant (Saini et al., 2009). Thus, the involvement of eIF5A in the process of translation elongation is proposed through a functional interaction with eEF2 after it was originally identified to promote translation initiation via in vitro assay (Park et al., 1991). Also, eIF5A is highly conserved and essential in all eukaryotes, as well shown for its unique modification resulting in the integration of the rare amino acid hypusine (Park, 2006).

In mammalian cells the phosphorylation of eEF1A and eEF1B as well as eEF2 has been demonstrated (Carlberg et al., 1990; Kielbassa et al., 1995; Chang and Traugh, 1998). Whereas the phosphorylation of eEF1A and eEF1B is proposed to enhance translation rates, the eEF2 kinase-mediated phosphorylation strongly inhibits translation in mammalian cells (Carlberg et al., 1990). In yeast two phoyphorylation sites in the amino acid sequence of eEF2 have been identified, one displying a motif for the cAMPdependent protein kinase (PKA). Mutations in these sites render yeast cells less capable of coping with various stress conditions (www.phosphogrid.org). Further a stimulation of eEF2 by the Ser/Thr protein kinase Rck2p has been proposed, which is dependent on Rck2p-phosphorylation by the osmostress-activated protein kinase Hog1p, thereby connecting MAP kinase signaling and regulation of protein synthesis (Teige et al., 2001). 


\section{Gene expression upon amino acid starvation}

Amino acids are the essential building blocks for protein biosynthesis, which confers a great importance to the amino acid pool within the cell. The amino acid supply is dependent on the uptake from the environment (Donaton et al., 2003), recycling of amino acids by autophagy (Alvers et al., 2009) and the de novo biosynthesis of all 20 amino acids. Especially the biosynthesis of amino acids is highly regulated in fungi, described as the general amino acid control (GAAC) (Braus et al., 2004).

The central element in this regulatory control mechanism is the transcription factor Gen $4 \mathrm{p}$, which controls the expression of hundreds of genes, of which 50 are involved in different amino acid biosynthesis pathways (Hinnebusch, 1988; Hinnebusch and Natarajan, 2002). In response to the limitation in only one of the 20 amino acids, the synthesis of aa-tRNA for that distinct amino acid is compromised, which results in a lack of this specific aa-tRNA during the translation elongation process and activates the GAAC, a cross pathway regulation of amino acid biosynthesis (Hinnebusch, 1992). To investigate the implication of amino acid starvation under laboratory conditions it is possible to omit a specific amino acid from the growth medium or to induce amino acid starvation conditions by specific drugs. The most commonly used drug is the histidine analog 3-amino-1,2,4-triazole (3AT), a competitive inhibitor of Imidazoleglycerol-phosphate dehydratase (His3p), which catalyzes the sixth step in histidine biosynthesis (Hilton et al., 1965).

In the course of the GAAC, unloaded tRNAs accumulate in the cell and are detected by the sensor kinase Gcn2p, which contains a typical protein kinase domain and a C-terminal histidyl-tRNA synthetase (HisRS) related domain (Wek et al., 1995). Upon binding to unloaded tRNAs the protein kinase domain of Gcn2p is activated and mediates the phosphorylation of eIF2 on serin 51 of its $\alpha$ subunit (Figure 4) (Dever et al., 1992). The phosphorylated form of eIF2 acts as a competitive inhibitor for the GEF eIF2B, preventing the recycling step from eIF2-GDP to eIF2-GTP. This in turn inhibits the formation of the ternary complex by active eIF2 and the initiator methionyl-tRNA (eIF2-GTPMet-tRNA ${ }_{i}{ }^{\text {Met }}$ ), thereby diminishing translation initiation and amino acid consumption (Hinnebusch, 2000). Additionally to conserving scarce amino acids by the reduction in overall de novo protein biosynthesis, the limited amount of ternary complex induces the translation of the GCN4-mRNA, coding for the chief transcriptional regulator of the 
GAAC. This opposite behaviour to most other mRNAs is mediated through four small uORFs in the 5'UTR of the GCN4-mRNA, whereas uORF1 and uORF4 seem to play the decisive role in the translational regulation of GCN4 (Figure 4) (Mueller and Hinnebusch, 1986).
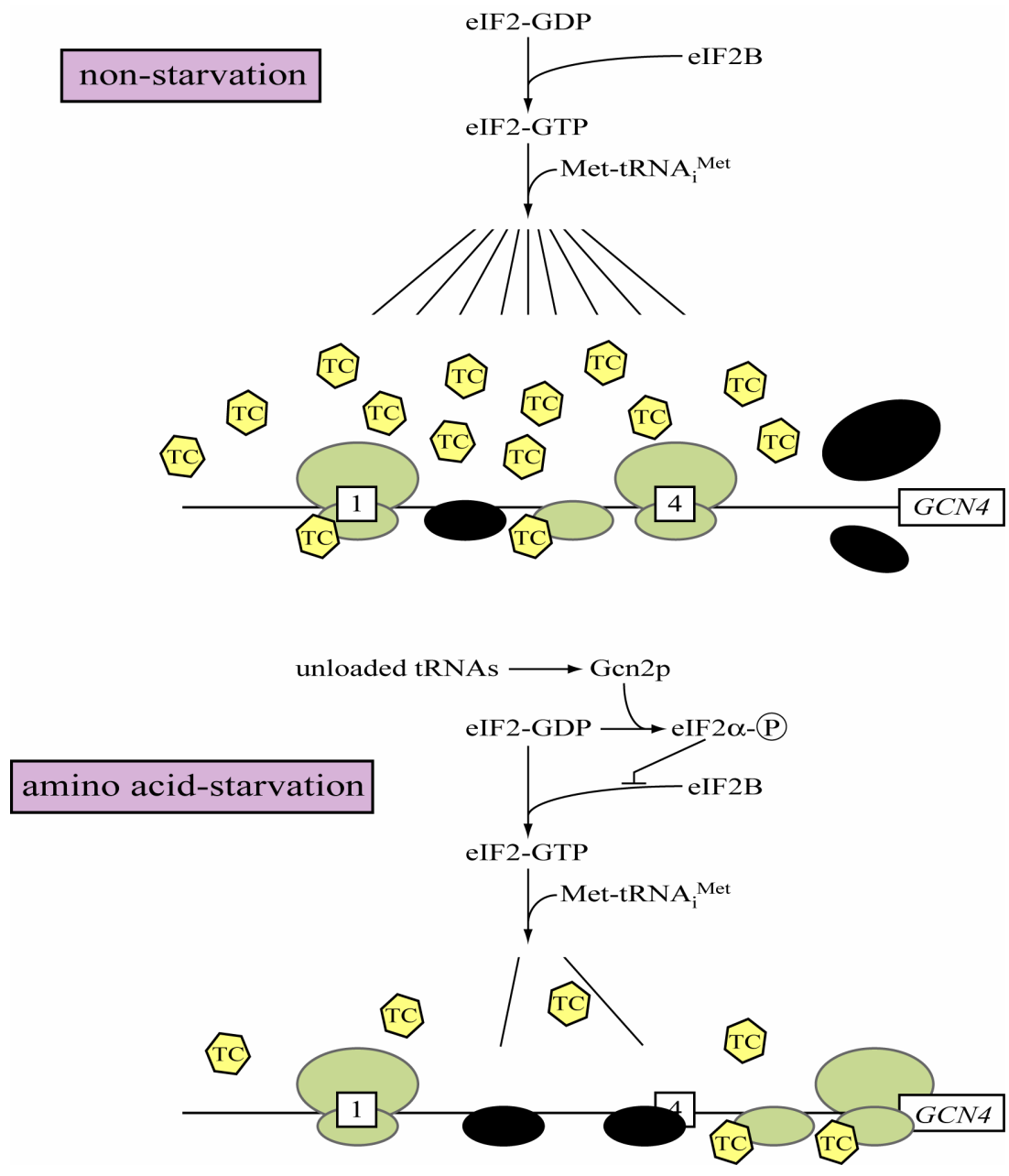

Figure 4. Scheme for the translational control of GCN4. The GCN4-mRNA is depicted with uORF1 and uORF4 in its 5'UTR. Under non-starvation conditions large amounts of ternary complex (TC) are available. This enables translation initiation on uORF1 and uORF4 but prevents re-initiation on the GCN4-ORF. When amino acids are scarce unloaded tRNAs accumulate in the cell and are detected by the Gcn2p kinase. Gcn2p in turn phosphorylates eIF2 on its $\alpha$ subunit, which inhibits the GDP-GTP exchange by eIF2B and results in a reduction in TC-formation. Hence, the process of translation initiation slows down, which results in the 40S ribosomal subunit to scan past uORF4. Re-initiation can take place on the GCN4-ORF. 
In a genomewide study of uORFs in a set of mapped 5'UTRs, it was proposed that uORFs are rather rare but more common in genes which are apparently translationally up-regulated. Additionally, most genes translationally up-regulated upon stressors have longer 5' UTRs, which applies for GCN4 with a rather long 5'UTR of approximately $600 \mathrm{nt}$, clearly exceeding the length of less than 50nt determined for the majority of yeast 5'UTRs (Lawless et al., 2009). Generally uORFs are regarded to function as translational barriers by reducing the efficiency of re-initiation downstream of the uORF (Kozak, 1983). This is confirmed by the repressing effect of the uORFs on GCN4-translation under conditions when amino acids are plentiful. Under those conditions the fraction of phosphorylated eIF2 is small and the ternary complex can be assembled unhindered to the $40 \mathrm{~S}$ ribosomal subunit to initiate translation on uORF1 in the GCN4-5'UTR. Due to the abundance of ternary complex a subsequent re-initiation on uORF4 can take place, which inhibits the 40S subunit from remaining attached to the mRNA and re-initiating at the AUG start codon of the coding region of GCN4. Under amino acid starvation conditions the phosphorylation of eIF2 is induced causing a reduced availability of ternary complex for translation initiation. This reduction leads to a less rapid re-initiation process, resulting in more of the $40 \mathrm{~S}$ ribosomal subunits to scan past uORF4 before anew binding of ternary complex and re-initiation of translation at the GCN4-ORF instead, thereby conferring a derepression of GCN4-expression (Hinnebusch, 2005).

An analogous translational regulation was found for the mammalian transcriptional activator ATF4 (Harding et al., 2000). The ATF4-mRNA harbors two uORFs in its 5'UTR, whereas the second uORF overlaps the actual ATF4-ORF, preventing ATF4-translation when ternary complex is abundant. When the amount of ternary complex is reduced the second uORF is skipped and re-initiation of translation occurs on the AUG of the ORF (Lu et al., 2004; Vattem and Wek, 2004). Elevated translation rates under amino acid starvation conditions have further been described for the mammalian arginine/lysine-transporter cat-1 through an internal ribosome entry site (IRES) in its 5'UTR. The cap-independent translation initiation at the IRES-element is mediated by eIF2-phosphorylation and the translation of a small uORF in the cat-1-leader (Fernandez et al., 2002). 


\section{WD40-proteins}

WD40-proteins are a large family of proteins with a common architecture, characterized by a very stable $\beta$-propeller structure consisting of a various number of blades (Lambright $e t$ al., 1996; Sondek et al., 1996). The number of propeller blades is determined by the number of WD40-repeats within the sequence of the protein (Lambright et al., 1996).

Each WD-repeat consists of 40 amino acids with a certain variance, which defines the propeller blade. The boundaries of each WD-repeat are characterized by a glycinehistidine-dipeptide 11-24 amino acids downstream of the N-terminus and the C-terminal amino acids tryptophan and aspartate (WD-motif) (Neer et al., 1994; Smith et al., 1999; Li and Roberts, 2001). It is assumed that the specific propeller structure of WD40-proteins serves as a rigid scaffold for the binding of other proteins, resulting in the formation of reversible complexes (Smith et al., 1999). The interaction partners for a WD40-protein are determined through its number of propeller blades as well as its variance in the 40 amino acids of each blade. Additionally, the flanking regions of the WD-repeats seem to add to the specificity of a WD-protein and determine its localization and function within the cell (Smith et al., 1999).

WD40-proteins are involved in a variety of cellular processes including signal transduction through transcriptional regulation, vesicular trafficking, cell cycle control and apoptosis (Keleher et al., 1992; Vaisman et al., 1995; Saxena et al., 1996; Adrain et al., 1999; Chen and Kaiser, 2003). In the yeast Saccharomyces cerevisiae 60 WD40-repeat proteins have been identified so far and their important physiological role was described for all eukaryotes, including their involvement in human diseases ( $\mathrm{Li}$ and Roberts, 2001). Examples for complexes formed through protein interaction with WD40-proteins are G proteins and the E3 ubiquitin ligase (Smith et al., 1999; Li and Roberts, 2001).

\subsection{The WD40-protein Asc1p/Cpc2p}

\subsubsection{Structure and localization}

The protein encoded by $A S C 1 / C P C 2$ is a WD40-repeat protein, consisting of seven WD-repeats, which is characteristic for the category of G $\beta$-like WD-proteins (Smith et al., 
1999). It has recently been shown that the seven-bladed $\beta$-propeller of Asc1p is characterized by a specific asymmetric structure (Coyle et al., 2009). Its crystal structure revealed two distinct large loop insertions between blade 3 and 4 and additionally between blade 6 and 7 (Figure 5). The bulging away from the propeller structure by this loop formation in Asc1p and its orthologues in other organisms is distinct from all other G $\beta$-like proteins.

The loop between blades 6 and 7 is described to fold into a knob-like structure (Figure 5). Even though the amino acids stabilizing this structure formation only show a limited conservation in eukaryotes an insertion of some sort at this position is universal among RACK1 sequences (McCahill et al., 2002).

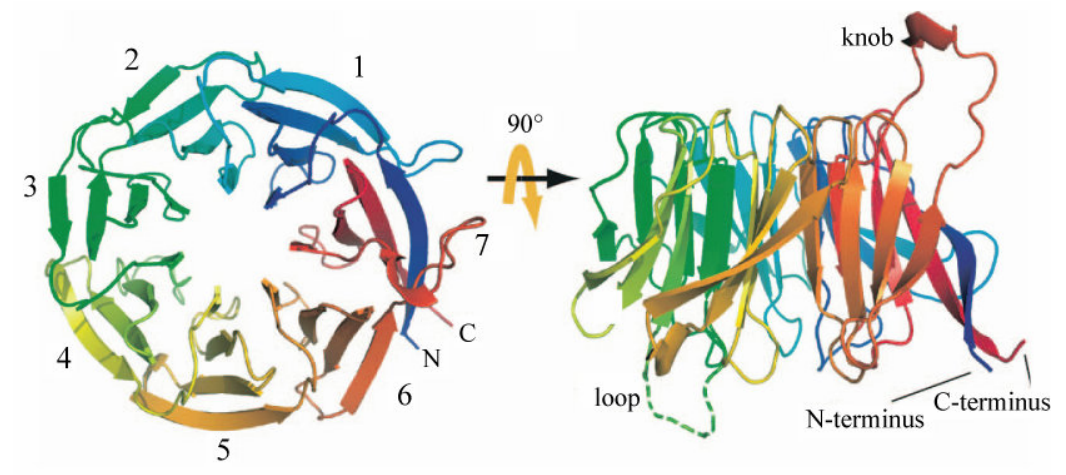

Figure 5. Crystal structure of Asc1p (modified from Coyle et al., 2009). The top view illustrates the seven blades of the $\beta$-propeller labeled 1-7. The side view demonstrates the two distinct loop structures and the knob contained in the loop between blade 6 and 7 .

The unusual features of the $\beta$-propeller for RACK1-species might contribute to its functional and binding-specificities since accessory loops or unusual surfaces of $\beta$-propellers often serve as platforms for interactions with other proteins (Neer et al., 1994; Smith et al., 1999; Chaudhuri et al., 2008).

Due to the binding properties of Asc1p and the ribosomal structure, Asc1p could be placed at the head of the $40 \mathrm{~S}$ ribosomal subunit in close proximity to the mRNA exit tunnel (Figure 6) (Coyle et al., 2009). Although the structured knob lies along the binding interface, it is not required for Asc1p ribosome-association, indicating its function in mediating protein interactions in close proximity to the ribosome (Coyle et al., 2009).

Despite its foremost ribosomal association it has also been suggested that a small fraction of Asc1p exists as a ribosome-free protein in the cell, supported by the functional analysis 
of an Asc1p-variant partially compromised in ribosome-binding (Coyle et al., 2009). Additionally, a shuttling of Asc1p from ribosome-bound to unbound form has been discussed on the basis of an elevated amount of cytosolic Asc1p during stationary phase (Baum et al., 2004).

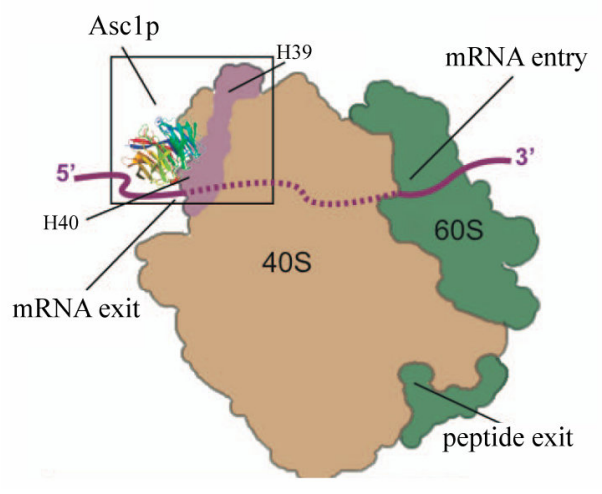

Figure 6. The localization of Asc1p on the ribosome (modified from Coyle et al., 2009). Asc1p resides on the $40 \mathrm{~S}$ ribosomal subunit near the mRNA exit tunnel in close proximity to helices 39 and 40 of the $18 \mathrm{~S}$ rRNA. The part of the protein containing the knob-structure faces the ribosome, whereas the remaining part of the protein is accessible.

Additionally to encoding for Asc1p, the ASCl gene belongs to the 5\% of yeast genes containing an intron in their open reading frame (ORF). This rather small amount of genes has been described to be responsible for the bulk of mRNA in the cell, which is also reflected in high levels of ASC1 expression, resulting in 330,000 Asc1p molecules per cell (Ares et al., 1999; Ghaemmaghami et al., 2003). The ASCl intron consists of 273 nucleotides in the proximity to the 3' end of the ASC1-ORF and codes for the small C/D box nucleolar RNA (snoRNA) U24 (Tyc and Steitz, 1989; Maxwell and Fournier, 1995). It is involved in ribosome biogenesis through post-transcriptional site-specific 2 '-O-methylation of the $28 \mathrm{~S}$ rRNA and is the only snoRNA that is required for more than two such modifications (Kiss-László et al., 1998; Schattner et al., 2004).

\subsubsection{Asc1p interactions and functions known in Saccharomyces cerevisiae}

The exposed positioning of Asc1p on the ribosome and its asymmetric seven-bladed propeller structure is conserved from yeast to human and results in its interaction with a multitude of proteins and ligands (Gavin et al., 2002; Gavin et al., 2006; Coyle et al., 2009). For example it has been shown that Asc1p physically interacts with the MAP kinase Slt2p of the Pkc1p cell wall integrity pathway (Breitkreutz et al., 2010). An 
additional implication of Asc1p in this pathway is given by the enhanced phosphorylation of Slt2p in the absence of Asc1p (Chasse et al., 2006) and a higher sensitivity of a $\Delta a s c l$ strain for the cell wall drugs calcofluor white and zymolyase (Valerius et al., 2007). Despite the described interaction with PKC in mammalian cells with the Asc1p orthologue RACK1 ( Receptor of Activated protein $\underline{\text { Kinase }} \underline{\mathrm{C}}$ ), it has been shown for Asc1p in yeast that it specifically influences cell wall integrity near bud sites by a Pkc1p-independent mechanism (Melamed et al., 2010).

Another interaction of Asc1p was described with the mRNA-binding protein Scp160p and furthermore that this interaction is required for the recruitment of Scp160p and its associated messages to the ribosome (Baum et al., 2004). Subsequently an extended Asc1p network (Smy2p, Eap1p, Scp160p and Asc1p; SESA network) has been identified to specifically inhibit the translation initiation of the POM34-mRNA, encoding an integral membrane protein of the nuclear pore complex (Sezen et al., 2009). In agreement, earlier studies have described Asc1p as a translational repressor (Gerbasi et al., 2004). Its first discovery linked Asc1p to the process of translation initiation in context with heme-deficient growth as its deletion suppressed a heml'cypl- absence of growth phenotype (Chantrel et al., 1998). Further evidence for an inhibitory effect of Asc1p on translation initiation is the enhanced phosphorylation of the translation initiation factors eIF4A and eIF2 (Valerius et al., 2007), the latter inhibiting the formation of the ternary complex required for the initiation process (Dever et al., 1992; Voorma et al., 1994). Additionally, ASC1 genetically interacts with GCN2, encoding the eIF2 kinase. The additional deletion of $A S C 1$ suppresses the absence of growth phenotype of a $\Delta g c n 2$ strain on amino acid starved medium (Hoffmann et al., 1999).

Whereas resistance to calcofluor white and the Scp160p interaction with the ribosome have been identified as processes dependent on Asc1p as ribosomal constituent, another described function for Asc1p in cell signaling is suggested to be independent of its ribosome-association (Zeller et al., 2007; Coyle et al., 2009). According to structural investigations via crystallization studies the organization of Asc1p on the ribosomal interface excludes simultaneous binding to the G $\alpha$-protein Gpa2p involved in the pathway of invasive and pseudohyphal growth (Coyle et al., 2009). Asc1p has been described as a repressor of this pathway, which serves to alter $S$. cerevisiae cell morphology in response to changes in nutrient-availabilities (Figure 7) (Mösch et al., 1999; Zeller et al., 2007). 
Limitations in nitrogen and glucose induce the pathway and result in diploid pseudohyphal growth and haploid invasive growth, respectively (Gimeno et al., 1992; Cullen and Sprague, 2000), through the expression of FLO11, coding for a GPI-anchored cell wall flocculin (Lo and Dranginis, 1998; Rupp et al., 1999).

The pathway is divided in two signaling cascades, the cAMP-dependent protein kinase (PKA) pathway and the mitogen-activated protein kinase (MAPK) pathway, which both have been shown to be inhibited by Asc1p (Figure 7) (Zeller et al., 2007).

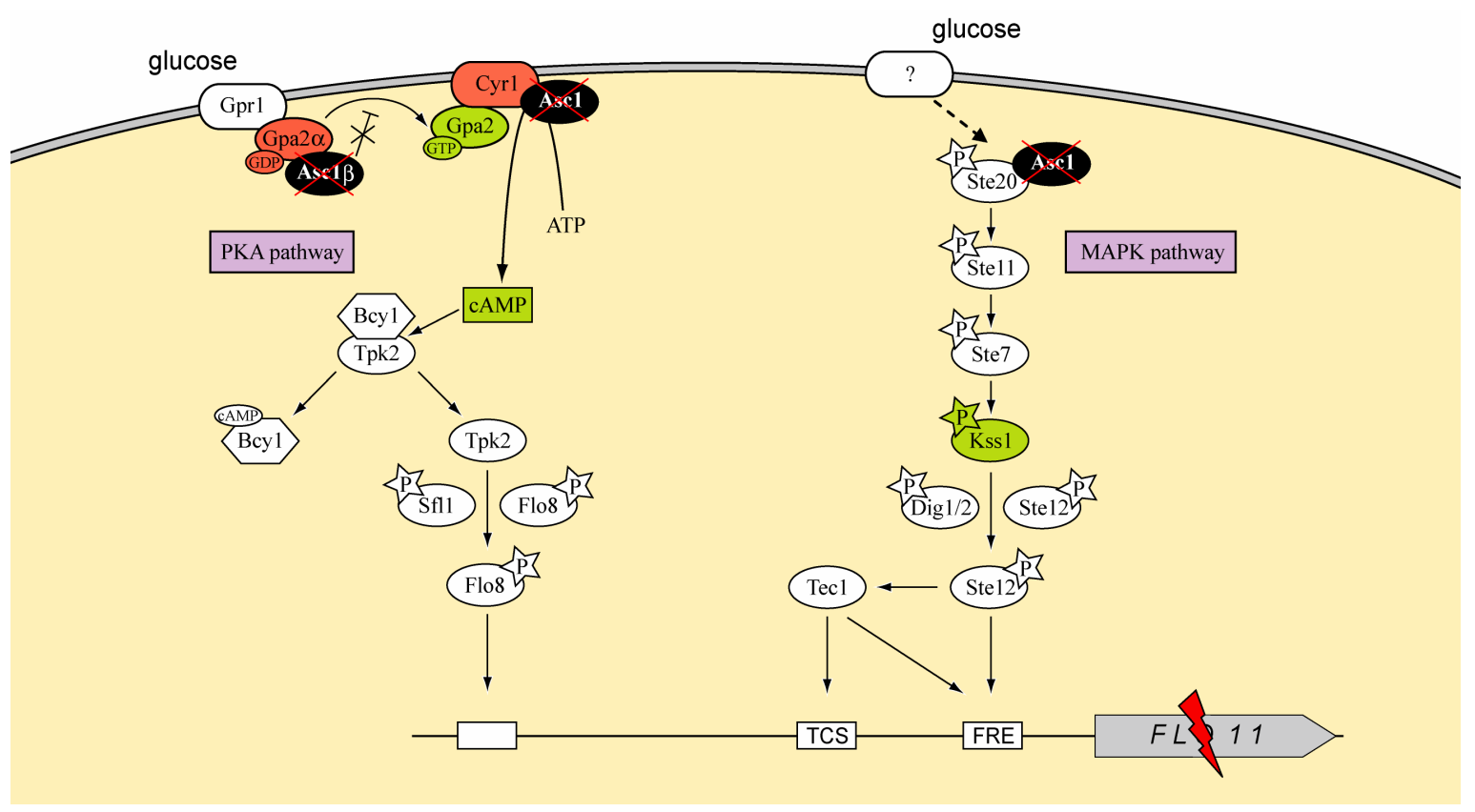

Figure 7. Scheme of signaling pathway of invasive/pseudohyphal growth. PKA pathway as well as MAPK pathway are illustrated. In the PKA pathway Gpr1p functions as glucose-sensor in the plasma membrane. Upon glucose-limitation it interacts with the heterotrimeric G protein $\alpha$ subunit, Gpa2p, to activate the adenylate cyclase Cyr1p, which in turn elevates cAMP-levels within the cell. cAMP activates the cAMP-dependent protein kinase (PKA), which results in the release of Tpk2p and subsequent phosphorylation of the transcriptional repressor Sfl1p and activator Flo8p to induce FLO11-expression (Pan et al., 2002). The MAPK pathway is induced by glucose-limitation through an unknown sensor, which results in the phosphorylation of Ste20p. The phosphorylation is passed on through the MAPK cascade to the transcription factor Ste12p and its inhibitors Dig1p/Dig2p, resulting in the release of Ste12p and subsequent activation of the transcription factor Tec1p (Elion et al., 1993; Tedford et al., 1997). The activated transcription factors then bind to the FLO11-promoter at Tec1p-binding sites (TCS) or filamentous response-elements (FRE) to induce transcription (Baur et al., 1997; Madhani and Fink, 1997; Madhani and Fink, 1998). The physical interactions of Asc1p and the described phenotypes for a $\Delta$ ascl strain are illustrates in red and green according to Valerius et al., 2007 and Zeller et al., 2007. 
The MAP kinase cascade, including Ste20p, Ste11p, Ste7p, and Kss1p, is activated by glucose through binding to an unknown receptor (Mösch et al., 1996; Mösch et al., 1999). The inhibitory influence of Asc1p on this pathway was demonstrated through the elevated phosphorylation of the MAP kinase Kss1p when ASCl is deleted. Additionally, Asc1p-binding to Ste20p was shown (Zeller et al., 2007).

In the second branch of the signaling pathway, glucose binds to the plasma membrane glucose-sensor Gpr1p (Lemaire et al., 2004), which activates the heterotrimeric G protein $\alpha$ subunit Gpa2p. This in turn activates the adenylate cyclase Cyr1p (Colombo et al., 1998; Kraakman et al., 1999), which leads to increased cellular concentrations of cAMP (Kataoka et al., 1985). Asc1p has been found to interact with the GDP-bound form of Gpa2p as G $\beta$ subunit and inhibits the Gpa2p guanine nucleotide exchange activity, as required for proper inducability of the signaling cascade. Additionally, its physical interaction with Cyr1p was shown and an enhanced Cyr1p-dependent cAMP-production was observed in a $\Delta$ ascl strain background (Zeller et al., 2007).

Contradictory to these findings pointing to an enhanced activity of the signaling pathway of invasive/pseudohyphal growth in a $\Delta a s c 1$ strain, cells lacking Asc1p are not able to undergo the expected physiological changes in response to outside stimuli. Neither glucose starvation-induced invasive growth nor pseudohyphal differentiation in response to nitrogen-limitation can be observed in $\Delta a s c 1$ cells (Valerius et al., 2007; Zeller et al., 2007). These growth phenotypes could be traced back to a reduced expression of FLO11, resulting in a drastic reduction in mRNA as well as protein levels of Flo11p in the $\Delta$ ascl strain (Valerius et al., 2007) (Figure 7).

\subsubsection{Asc1p orthologues}

Asc1p is a highly conserved protein and its orthologues have been described to be required early on in cell development, suggesting its role in differentiation (Guillemot et al., 1989). Cellular functions, influenced by Asc1p/RACK1 are diverse, including root formation and flowering in Arabidopsis thaliana (Guo and Chen, 2008; Guo et al., 2009) and sexual differentiation in Schizosaccharomyces pombe (McLeod et al., 2000; Paul et al., 2009). In Cryptococcus neoformans the Asc1p orthologue Gib2p has been identified as G $\beta$ protein, functioning in cAMP-signaling associated with virulence (Palmer et al., 2006). RACK1 of 
Drosophila melanogaster has been shown to be expressed in many tissues throughout multiple steps of development (Kadrmas et al., 2007). Furthermore mammalian RACK1 is involved in the regulation of cell proliferation and cell cycle control (Hermanto et al., 2002). It has been shown to be involved in apoptosis and contributes to tumor growth in vivo (Zhang et al., 2008; Mamidipudi and Cartwright, 2009). In this role it was determined as up-regulated during angiogenesis and in colon carcinoma, non-small cell lung carcinoma (Berns et al., 2000) and melanomas (López-Bergami et al., 2005).

The diversity of processes affected by Asc1p and its orthologues throughout the eukaryotic kingdom underlines its presumed role as a versatile scaffold protein, functioning as central nexus for various signal transduction pathways. In mammalian, the interaction of RACK1 with activated protein kinase $\mathrm{C}$ results in the phosphorylation of eIF6. The resulting dissociation of eIF6 from the 60S ribosomal subunit is required for subsequent translation (Ceci et al., 2003). Additionally, RACK1 interacts with the G protein transducin to repress gene expression and to regulate G1/S progression by suppressing Src kinase activity (Dell et al., 2002; Kraus et al., 2006; Liu et al., 2010).

RACK1 therefore links signal transduction pathways directly to the ribosome, which allows translation to be regulated in response to environmental changes. Accordingly it has been proposed to function as a link between signal transduction and the translational machinery (Nilsson et al., 2004).

These findings illustrate the importance of Asc1p/RACK1 especially in higher eukaryotes, where its ubiquitous expression is essential. In contrast, $A S C 1$ in yeast is not essential but the role of Asc1p in differentiation is still evident. This and the functional interchangeability of RACK1 and Asc1p within the yeast ribosome (Gerbasi et al., 2004) makes yeast a valuable model organism to study the cellular function of RACK1.

\section{Aim of this work}

Translational regulation has a significant influence on the adaptability of an organism. It enables a rapid response upon diverse cellular and environmental changes by altering protein biosynthesis directly at the ribosome. One aim of this work was to identify proteins that are more efficiently synthesized under amino acid starvation conditions due to a translational regulation mediated by their respective 5'UTR. Therefore a proteome analysis 
was conducted to identify protein-spots that are up-regulated under amino acid starvation conditions. The subsequent comparison with pre-existing transcriptome data of amino acid starved yeast cells revealed several post-transcriptionally regulated proteins. The 5'UTRs of their corresponding mRNAs were analyzed bioinformatically according to their sequential and structural characteristics. Additionally, a lacZ-reporter system was developed to determine the translationally regulative properties of the 5'UTR sequences upon amino acid starvation. Protein levels of candidates, whose corresponding 5'UTRs could successfully enhance lacZ-expression upon the induction of amino acid starvation were determined.

Furthermore, the ribosomal protein Asc1p was analyzed according to its cellular impact and its influence on translational regulation. The major cellular processes influenced by Asc1p were determined in a comprehensive analysis of the proteome and the transcriptome of a $\Delta$ ascl strain, combined with corresponding phenotypical characterizations. The transcription factors inducing the majority of the observed transcriptional changes in the $\Delta$ ascl mutant were analyzed according to their abundance changes in response to the deletion of ASC1. Additionally, their corresponding 5'UTRs were assessed in regard to their ability to mediate translational changes in the $\Delta a s c l$ strain distinct from wt via the previously mentioned lacZ-reporter system.

In a third project the effect of Asc1p on the process of translation elongation was investigated. Therefore growth on elongation inhibitors was examined and the translation elongation influencing factors eIF5A and eEF2 were analyzed in regard to their abundance as well as the hypusination modification of eIF5A in a $\triangle a s c 1$ strain. Further, protein levels of eIF5A, eEF2 and the transcription factors Rap1p and Tec1p were assessed in a $\Delta a s c 1 \Delta g c n 2$ double mutant. Also the +1 frameshifting-dependent expression of Oaz1p was determined in a $\Delta a s c 1$ strain. 


\section{References}

Adrain, C., Slee, E. A., Harte, M. T., and Martin, S. J. (1999) Regulation of apoptotic protease activating factor-1 oligomerization and apoptosis by the WD-40 repeat region. J Biol Chem 274 (30), 20855-20860.

Akhtar, A., and Gasser, S. M. (2007) The nuclear envelope and transcriptional control. Nat Rev Genet 8 (7), 507-517.

Altmann, M., Schmitz, N., Berset, C., and Trachsel, H. (1997) A novel inhibitor of capdependent translation initiation in yeast: p20 competes with eIF4G for binding to eIF4E. EMBO J 16 (5), 1114-1121.

Alvers, A. L., Fishwick, L. K., Wood, M. S., Hu, D., Chung, H. S., Dunn, W. A., Jr., and Aris, J. P. (2009) Autophagy and amino acid homeostasis are required for chronological longevity in Saccharomyces cerevisiae. Aging Cell 8 (4), 353-369.

Ares, M., Jr., Grate, L., and Pauling, M. H. (1999) A handful of intron-containing genes produces the lion's share of yeast mRNA. RNA 5 (9), 1138-1139.

Asakura, T., Sasaki, T., Nagano, F., Satoh, A., Obaishi, H., Nishioka, H., Imamura, H., Hotta, K., Tanaka, K., Nakanishi, H., and Takai, Y. (1998) Isolation and characterization of a novel actin filament-binding protein from Saccharomyces cerevisiae. Oncogene 16 (1), 121-130.

Baim, S. B., and Sherman, F. (1988) mRNA structures influencing translation in the yeast Saccharomyces cerevisiae. Mol Cell Biol 8 (4), 1591-1601.

Balciunas, D., Hallberg, M., Bjorklund, S., and Ronne, H. (2003) Functional interactions within yeast mediator and evidence of differential subunit modifications. J Biol Chem 278 (6), 3831-3839.

Banerji, J., Rusconi, S., and Schaffner, W. (1981) Expression of a $\beta$-globin gene is enhanced by remote SV40 DNA sequences. Cell (27), 299-308.

Barberis, A., Pearlberg, J., Simkovich, N., Farrell, S., Reinagel, P., Bamdad, C., Sigal, G., and Ptashne, M. (1995) Contact with a component of the polymerase II holoenzyme suffices for gene activation. Cell 81 (3), 359-368.

Barolo, S., and Posakony, J. W. (2002) Three habits of highly effective signaling pathways: principles of transcriptional control by developmental cell signaling. Genes Dev 16 (10), 1167-1181. 
Basehoar, A. D., Zanton, S. J., and Pugh, B. F. (2004) Identification and distinct regulation of yeast TATA box-containing genes. Cell 116 (5), 699-709.

Baum, S., Bittins, M., Frey, S., and Seedorf, M. (2004) Asc1p, a WD40-domain containing adaptor protein, is required for the interaction of the RNA-binding protein Scp160p with polysomes. Biochem J (380), 823-830.

Baur, M., Esch, R. K., and Errede, B. (1997) Cooperative binding interactions required for function of the Ty1 sterile responsive element. Mol Cell Biol 17 (8), 4330-4337.

Berns, H., Humar, R., Hengerer, B., Kiefer, F. N., and Battegay, E. J. (2000) RACK1 is up-regulated in angiogenesis and human carcinomas. FASEB $J 14$ (15), $2549-2558$.

Björklund, S., and Gustafsson, C. M. (2005) The yeast Mediator complex and its regulation. Trends Biochem Sci 30 (5), 240-244.

Blackwood, E. M., and Kadonaga, J. T. (1998) Going the distance: a current view of enhancer action. Science 281 (5373), 60-63.

Bond, U. (2006) Stressed out! Effects of environmental stress on mRNA metabolism. FEMS Yeast Res 6 (2), 160-170.

Bonnal, S., Boutonnet, C., Prado-Lourenco, L., and Vagner, S. (2003) IRESdb: the Internal Ribosome Entry Site database. Nucleic Acids Res 31 (1), 427-428.

Braus, G. H., Pries, R., Düvel, K., and Valerius, O. (2004) Molecular biology of fungal amino acid biosynthesis regulation. Kück, U. (ed.), The Mycota II: Genetics and Biotechnology (2nd edition). Springer Verlag Berlin-Heidelberg, 239-269.

Breitkreutz, A., Choi, H., Sharom, J. R., Boucher, L., Neduva, V., Larsen, B., Lin, Z. Y., Breitkreutz, B. J., Stark, C., Liu, G., Ahn, J., Dewar-Darch, D., Reguly, T., Tang, X., Almeida, R., Qin, Z. S., Pawson, T., Gingras, A. C., Nesvizhskii, A. I., and Tyers, M. (2010) A global protein kinase and phosphatase interaction network in yeast. Science 328 (5981), 1043-1046.

Brengues, M., Teixeira, D., and Parker, R. (2005) Movement of eukaryotic mRNAs between polysomes and cytoplasmic processing bodies. Science 310 (5747), 486-489.

Carlberg, U., Nilsson, A., and Nygard, O. (1990) Functional properties of phosphorylated elongation factor 2. Eur J Biochem 191 (3), 639-645. 
Carlson, M. (1997) Genetics of transcriptional regulation in yeast: connections to the RNA polymerase II CTD. Annu Rev Cell Dev Biol 13, 1-23.

Carvalho, M. D., Carvalho, J. F., and Merrick, W. C. (1984) Biological characterization of various forms of elongation factor 1 from rabbit reticulocytes. Arch Biochem Biophys 234 (2), 603-611.

Ceci, M., Gaviraghi, C., Gorrini, C., Sala, L. A., Offenhauser, N., Marchisio, P. C., and Biffo, S. (2003) Release of eIF6 (p27 $7^{\mathrm{BBP}}$ ) from the $60 \mathrm{~S}$ subunit allows 80S ribosome assembly. Nature 426 (6966), 579-584.

Chang, Y. W., and Traugh, J. A. (1998) Insulin stimulation of phosphorylation of elongation factor 1 (eEF-1) enhances elongation activity. Eur J Biochem 251 (1-2), 201-207.

Chantrel, Y., Gaisne, M., Lions, C., and Verdière, J. (1998) The transcriptional regulator Hap1p (Cyp1p) is essential for anaerobic or heme-deficient growth of Saccharomyces cerevisiae: Genetic and molecular characterization of an extragenic suppressor that encodes a WD repeat protein. Genetics 148 (2), 559-569.

Chasse, S. A., Flanary, P., Parnell, S. C., Hao, N., Cha, J. Y., Siderovski, D. P., and Dohlman, H. G. (2006) Genome-scale analysis reveals Sst2 as the principal regulator of mating pheromone signaling in the yeast Saccharomyces cerevisiae. Eukaryot Cell 5 (2), 330-346.

Chaudhuri, I., Soding, J., and Lupas, A. N. (2008) Evolution of the $\beta$-propeller fold. Proteins 71 (2), 795-803.

Chen, E. J., and Kaiser, C. A. (2003) LST8 negatively regulates amino acid biosynthesis as a component of the TOR pathway. J Cell Biol 161 (2), 333-347.

Colombo, S., Ma, P., Cauwenberg, L., Winderickx, J., Crauwels, M., Teunissen, A., Nauwelaers, D., de Winde, J. H., Gorwa, M. F., Colavizza, D., and Thevelein, J. M. (1998) Involvement of distinct G-proteins, Gpa2 and Ras, in glucose- and intracellular acidification-induced cAMP signalling in the yeast Saccharomyces cerevisiae. EMBO J 17 (12), 3326-3341.

Coyle, S. M., Gilbert, W. V., and Doudna, J. A. (2009) Direct link between RACK1 function and localization at the ribosome in vivo. Mol Cell Biol 29 (6), 1626-1634.

Cullen, P. J., and Sprague, G. F., Jr. (2000) Glucose depletion causes haploid invasive growth in yeast. Proc Natl Acad Sci U S A 97 (25), 13619-13624. 
Day, D. A., and Tuite, M. F. (1998) Post-transcriptional gene regulatory mechanisms in eukaryotes: an overview. J Endocrinol 157 (3), 361-371.

Dell, E. J., Connor, J., Chen, S., Stebbins, E. G., Skiba, N. P., Mochly-Rosen, D., and Hamm, H. E. (2002) The $\beta \gamma$ subunit of heterotrimeric G proteins interacts with RACK1 and two other WD repeat proteins. J Biol Chem 277 (51), 49888-49895.

Dever, T. E., Feng, L., Wek, R. C., Cigan, A. M., Donahue, T. F., and Hinnebusch, A. G. (1992) Phosphorylation of initiation factor $2 \alpha$ by protein kinase Gcn2 mediates gene-specific translational control of GCN4 in yeast. Cell 68 (3), 585-596.

Doma, M. K., and Parker, R. (2007) RNA quality control in eukaryotes. Cell 131 (4), 660-668.

Donaton, M. C., Holsbeeks, I., Lagatie, O., Van Zeebroeck, G., Crauwels, M., Winderickx, J., and Thevelein, J. M. (2003) The Gap1 general amino acid permease acts as an amino acid sensor for activation of protein kinase A targets in the yeast Saccharomyces cerevisiae. Mol Microbiol 50 (3), 911-929.

Elion, E. A., Satterberg, B., and Kranz, J. E. (1993) Fus3 phosphorylates multiple components of the mating signal transduction cascade: evidence for Ste12 and Far1. Mol Biol Cell 4 (5), 495-510.

Farabaugh, P. J. (1996) Programmed translational frameshifting. Microbiol Rev 60 (1), 103-134.

Fernandez, J., Bode, B., Koromilas, A., Diehl, J. A., Krukovets, I., Snider, M. D., and Hatzoglou, M. (2002) Translation mediated by the internal ribosome entry site of the cat-1 mRNA is regulated by glucose availability in a PERK kinase-dependent manner. J Biol Chem 277 (14), 11780-11787.

Frolova, L., Le Goff, X., Rasmussen, H. H., Cheperegin, S., Drugeon, G., Kress, M., Arman, I., Haenni, A. L., Celis, J. E., Philippe, M., and et al. (1994) A highly conserved eukaryotic protein family possessing properties of polypeptide chain release factor. Nature 372 (6507), 701-703.

Furuichi, Y., LaFiandra, A., and Shatkin, A. J. (1977) 5'-terminal structure and mRNA stability. Nature 266 (5599), 235-239.

Gavin, A. C., Aloy, P., Grandi, P., Krause, R., Bösche, M., Marzioch, M., Rau, C., Jensen, L. J., Bastuck, S., Dümpelfeld, B., Edelmann, A., Heurtier, M. A., Hoffman, V., Hoefert, C., Klein, K., Hudak, M., Michon, A. M., Schelder, M., 
Schirle, M., Remor, M., Rudi, T., Hooper, S., Bauer, A., Bouwmeester, T., Casari, G., Drewes, G., Neubauer, G., Rick, J. M., Kuster, B., Bork, P., Russell, R. B., and Superti-Furga, G. (2006) Proteome survey reveals modularity of the yeast cell machinery. Nature 440 (7084), 631-636.

Gavin, A. C., Bösche, M., Krause, R., Grandi, P., Marzioch, M., Bauer, A., Schultz, J., Rick, J. M., Michon, A. M., Cruciat, C. M., Remor, M., Höfert, C., Schelder, M., Brajenovic, M., Ruffner, H., Merino, A., Klein, K., Hudak, M., Dickson, D., Rudi, T., Gnau, V., Bauch, A., Bastuck, S., Huhse, B., Leutwein, C., Heurtier, M. A., Copley, R. R., Edelmann, A., Querfurth, E., Rybin, V., Drewes, G., Raida, M., Bouwmeester, T., Bork, P., Seraphin, B., Kuster, B., Neubauer, G., and Superti-Furga, G. (2002) Functional organization of the yeast proteome by systematic analysis of protein complexes. Nature 415 (6868), 141-147.

Gebauer, F., and Hentze, M. W. (2004) Molecular mechanisms of translational control. Nat Rev Mol Cell Biol 5 (10), 827-835.

Georgel, P. T., and Hansen, J. C. (2001) Linker histone function in chromatin: dual mechanisms of action. Biochem Cell Biol 79 (3), 313-316.

Gerbasi, V. R., Weaver, C. M., Hill, S., Friedman, D. B., and Link, A. J. (2004) Yeast Asc1p and mammalian RACK1 are functionally orthologous core 40S ribosomal proteins that repress gene expression. Mol Cell Biol 24 (18), 8276-8287.

Ghaemmaghami, S., Huh, W. K., Bower, K., Howson, R. W., Belle, A., Dephoure, N., O'Shea, E. K., and Weissman, J. S. (2003) Global analysis of protein expression in yeast. Nature 425 (6959), 737-741.

Gilbert, W. V., Zhou, K., Butler, T. K., and Doudna, J. A. (2007) Cap-independent translation is required for starvation-induced differentiation in yeast. Science 317 (5842), 1224-1227.

Gimeno, C. J., Ljungdahl, P. O., Styles, C. A., and Fink, G. R. (1992) Unipolar cell divisions in the yeast $S$. cerevisiae lead to filamentous growth: regulation by starvation and RAS. Cell 68 (6), 1077-1090.

Grewal, S. I., and Moazed, D. (2003) Heterochromatin and epigenetic control of gene expression. Science 301 (5634), 798-802. 
Guillemot, F., Billault, A., and Auffray, C. (1989) Physical linkage of a guanine nucleotide-binding protein-related gene to the chicken major histocompatibility complex. Proc Natl Acad Sci U S A 86 (12), 4594-4598.

Guo, J., and Chen, J. G. (2008) RACK1 genes regulate plant development with unequal genetic redundancy in Arabidopsis. BMC Plant Biol 8, 108.

Guo, J., Wang, J., Xi, L., Huang, W. D., Liang, J., and Chen, J. G. (2009) RACK1 is a negative regulator of ABA responses in Arabidopsis. J Exp Bot 60 (13), 3819-3833.

Harding, H. P., Novoa, I., Zhang, Y., Zeng, H., Wek, R., Schapira, M., and Ron, D. (2000) Regulated translation initiation controls stress-induced gene expression in mammalian cells. Mol Cell 6 (5), 1099-1108.

Hellen, C. U., and Sarnow, P. (2001) Internal ribosome entry sites in eukaryotic mRNA molecules. Genes Dev 15 (13), 1593-1612.

Hermanto, U., Zong, C. S., Li, W., and Wang, L. H. (2002) RACK1, an insulin-like growth factor I (IGF-I) receptor-interacting protein, modulates IGF-I-dependent integrin signaling and promotes cell spreading and contact with extracellular matrix. Mol Cell Biol 22 (7), 2345-2365.

Herrick, D., and Jacobson, A. (1992) A coding region segment is necessary, but not sufficient for rapid decay of the HIS3 mRNA in yeast. Gene 114 (1), 35-41.

Hilton, J. L., Kearney, P. C., and Ames, B. N. (1965) Mode of action of the herbicide, 3-amino-1,2,4-triazole(amitrole): inhibition of an enzyme of histidine biosynthesis. Arch Biochem Biophys 112 (3), 544-547.

Hinnebusch, A. G. (1988) Mechanisms of gene regulation in the general control of amino acid biosynthesis in Saccharomyces cerevisiae. Microbiol Rev 52 (2), 248-273.

Hinnebusch, A. G. (1992) General and pathway-specific regulatory mechanisms controlling the synthesis of amino acid biosynthetic enzymes in Saccharomyces cerevisiae. Broach, J. R., Jones, E. W., and Pringle, J. R. (eds.), The Molecular and Cellular Biology of the Yeast Saccharomyces cerevisae: Gene Expression. Cold Spring Harbor Laboratory Press, 319-414.

Hinnebusch, A. G. (2000) Mechanism and regulation of initiator methionyl tRNA binding to ribosomes. Sonenberg, N., Hershey, J. W. B., and Mathews, M. B. (eds.), Translational Control of Gene Expression. Cold Spring Harbor Laboratory Press, $185-243$. 
Hinnebusch, A. G. (2005) Translational regulation of GCN4 and the general amino acid control of yeast. Annu Rev Microbiol 59, 407-450.

Hinnebusch, A. G., Asano, K., Olsen, D. S., Phan, L., Nielsen, K. H., and Valasek, L. (2004) Study of translational control of eukaryotic gene expression using yeast. Ann N Y Acad Sci 1038, 60-74.

Hinnebusch, A. G., and Natarajan, K. (2002) Gcn4p, a master regulator of gene expression, is controlled at multiple levels by diverse signals of starvation and stress. Eukaryot Cell 1 (1), 22-32.

Hoffmann, B., Mösch, H. U., Sattlegger, E., Barthelmess, I. B., Hinnebusch, A., and Braus, G. H. (1999) The WD protein Cpc2p is required for repression of Gcn4 protein activity in yeast in the absence of amino-acid starvation. Mol Microbiol 31 (3), 807-822.

Holcik, M., and Sonenberg, N. (2005) Translational control in stress and apoptosis. Nat Rev Mol Cell Biol 6 (4), 318-327.

Hoyle, N. P., Castelli, L. M., Campbell, S. G., Holmes, L. E., and Ashe, M. P. (2007) Stress-dependent relocalization of translationally primed mRNPs to cytoplasmic granules that are kinetically and spatially distinct from P-bodies. J Cell Biol 179 (1), 65-74.

Huang, H. K., Yoon, H., Hannig, E. M., and Donahue, T. F. (1997) GTP hydrolysis controls stringent selection of the AUG start codon during translation initiation in Saccharomyces cerevisiae. Genes Dev 11 (18), 2396-2413.

Huisinga, K. L., and Pugh, B. F. (2004) A genome-wide housekeeping role for TFIID and a highly regulated stress-related role for SAGA in Saccharomyces cerevisiae. Mol Cell 13 (4), 573-585.

Ingolia, N. T., Ghaemmaghami, S., Newman, J. R., and Weissman, J. S. (2009) Genome-wide analysis in vivo of translation with nucleotide resolution using ribosome profiling. Science 324 (5924), 218-223.

Johnson, K. M., and Carey, M. (2003) Assembly of a mediator/TFIID/TFIIA complex bypasses the need for an activator. Curr Biol 13 (9), 772-777.

Kadrmas, J. L., Smith, M. A., Pronovost, S. M., and Beckerle, M. C. (2007) Characterization of RACK1 function in Drosophila development. Dev Dyn 236 (8), 2207-2215. 
Kataoka, T., Broek, D., and Wigler, M. (1985) DNA sequence and characterization of the $S$. cerevisiae gene encoding adenylate cyclase. Cell (43), 493-505.

Keleher, C. A., Redd, M. J., Schultz, J., Carlson, M., and Johnson, A. D. (1992) Ssn6-Tup1 is a general repressor of transcription in yeast. Cell 68 (4), 709-719.

Kielbassa, K., Müller, H. J., Meyer, H. E., Marks, F., and Gschwendt, M. (1995) Protein kinase $\mathrm{C}_{\delta}$-specific phosphorylation of the elongation factor eEF-alpha and an eEF-1 alpha peptide at threonine 431. J Biol Chem 270 (11), 6156-6162.

Kim, J., Guermah, M., McGinty, R. K., Lee, J. S., Tang, Z., Milne, T. A., Shilatifard, A., Muir, T. W., and Roeder, R. G. (2009) RAD6-Mediated transcription-coupled $\mathrm{H} 2 \mathrm{~B}$ ubiquitylation directly stimulates $\mathrm{H} 3 \mathrm{~K} 4$ methylation in human cells. Cell 137 (3), 459-471.

Kim, J., and Iyer, V. R. (2004) Global role of TATA box-binding protein recruitment to promoters in mediating gene expression profiles. Mol Cell Biol 24 (18), 8104-8112.

Kim, Y. J., Björklund, S., Li, Y., Sayre, M. H., and Kornberg, R. D. (1994) A multiprotein mediator of transcriptional activation and its interaction with the C-terminal repeat domain of RNA polymerase II. Cell 77 (4), 599-608.

Kiss-László, Z., Henry, Y., and Kiss, T. (1998) Sequence and structural elements of methylation guide snoRNAs essential for site-specific ribose methylation of pre-rRNA. EMBO J 17 (3), 797-807.

Kohler, A., and Hurt, E. (2007) Exporting RNA from the nucleus to the cytoplasm. Nat Rev Mol Cell Biol 8 (10), 761-773.

Komar, A. A., Lesnik, T., Cullin, C., Merrick, W. C., Trachsel, H., and Altmann, M. (2003) Internal initiation drives the synthesis of Ure2 protein lacking the prion domain and affects [URE3] propagation in yeast cells. EMBO J 22 (5), 1199-1209.

Kornberg, R. D. (1999) Eukaryotic transcriptional control. Trends Cell Biol 9 (12), M46-49.

Kozak, M. (1983) Comparison of initiation of protein synthesis in procaryotes, eucaryotes, and organelles. Microbiol Rev 47 (1), 1-45.

Kozak, M. (1986) Influences of mRNA secondary structure on initiation by eukaryotic ribosomes. Proc Natl Acad Sci U S A 83 (9), 2850-2854.

Kozak, M. (1991) Structural features in eukaryotic mRNAs that modulate the initiation of translation. J Biol Chem 266 (30), 19867-19870. 
Kraakman, L., Lemaire, K., Ma, P., Teunissen, A. W., Donaton, M. C., Van Dijck, P., Winderickx, J., de Winde, J. H., and Thevelein, J. M. (1999) A Saccharomyces cerevisiae G-protein coupled receptor, Gpr1, is specifically required for glucose activation of the cAMP pathway during the transition to growth on glucose. Mol Microbiol 32 (5), 1002-1012.

Kraus, S., Gioeli, D., Vomastek, T., Gordon, V., and Weber, M. J. (2006) Receptor for activated $\mathrm{C}$ kinase 1 (RACK1) and Src regulate the tyrosine phosphorylation and function of the androgen receptor. Cancer Res 66 (22), 11047-11054.

Lambright, D. G., Sondek, J., Bohm, A., Skiba, N. P., Hamm, H. E., and Sigler, P. B. (1996) The $2.0 \AA$ A crystal structure of a heterotrimeric G protein. Nature 379 (6563), 311-319.

Lawless, C., Pearson, R. D., Selley, J. N., Smirnova, J. B., Grant, C. M., Ashe, M. P., Pavitt, G. D., and Hubbard, S. J. (2009) Upstream sequence elements direct post-transcriptional regulation of gene expression under stress conditions in yeast. BMC Genomics 10, 7.

Layer, J. H., Miller, S. G., and Weil, P. A. (2010) Direct transactivator-transcription factor IID (TFIID) contacts drive yeast ribosomal protein gene transcription. J Biol Chem 285 (20), 15489-15499.

Lee, J. S., Smith, E., and Shilatifard, A. (2010) The language of histone crosstalk. Cell 142 (5), 682-685.

Lemaire, K., Van de Velde, S., Van Dijck, P., and Thevelein, J. M. (2004) Glucose and sucrose act as agonist and mannose as antagonist ligands of the $\mathrm{G}$ protein-coupled receptor Gpr1 in the yeast Saccharomyces cerevisiae. Mol Cell 16 (2), 293-299.

Lemieux, K., and Gaudreau, L. (2004) Targeting of Swi/Snf to the yeast GAL1 UAS requires the Mediator, $\mathrm{TAF}_{\mathrm{IIs}}$, and RNA polymerase II. EMBO J 23 (20), 4040-4050.

Li, D., and Roberts, R. (2001) WD-repeat proteins: structure characteristics, biological function, and their involvement in human diseases. Cell Mol Life Sci 58 (14), 2085-2097.

Liu, Q., Wang, X., Liu, Y., Lu, R., Yuan, Q., Yang, B., Zhou, J., Wang, Y., and Wang, Z. (2010) RACK1 inhibits morphine re-exposure via inhibition of Src. Neurol Res, Epub. 
Lo, W. S., and Dranginis, A. M. (1998) The cell surface flocculin Flo11 is required for pseudohyphae formation and invasion by Saccharomyces cerevisiae. Mol Biol Cell 9 (1), 161-171.

Lo, W. S., Trievel, R. C., Rojas, J. R., Duggan, L., Hsu, J. Y., Allis, C. D., Marmorstein, R., and Berger, S. L. (2000) Phosphorylation of serine 10 in histone $\mathrm{H} 3$ is functionally linked in vitro and in vivo to Gcn5-mediated acetylation at lysine 14. Mol Cell 5 (6), 917-926.

López-Bergami, P., Habelhah, H., Bhoumik, A., Zhang, W., Wang, L. H., and Ronai, Z. (2005) RACK1 mediates activation of JNK by protein kinase C [corrected]. Mol Cell 19 (3), 309-320.

Lu, P. D., Harding, H. P., and Ron, D. (2004) Translation reinitiation at alternative open reading frames regulates gene expression in an integrated stress response. J Cell Biol 167 (1), 27-33.

Luna, R., Gaillard, H., Gonzalez-Aguilera, C., and Aguilera, A. (2008) Biogenesis of mRNPs: integrating different processes in the eukaryotic nucleus. Chromosoma 117 (4), 319-331.

Maag, D., Algire, M. A., and Lorsch, J. R. (2006) Communication between eukaryotic translation initiation factors 5 and $1 \mathrm{~A}$ within the ribosomal pre-initiation complex plays a role in start site selection. J Mol Biol 356 (3), 724-737.

Madhani, H. D., and Fink, G. R. (1997) Combinatorial control required for the specificity of yeast MAPK signaling. Science 275 (5304), 1314-1317.

Madhani, H. D., and Fink, G. R. (1998) The control of filamentous differentiation and virulence in fungi. Trends Cell Biol 8 (9), 348-353.

Mamidipudi, V., and Cartwright, C. A. (2009) A novel pro-apoptotic function of RACK1: suppression of Src activity in the intrinsic and Akt pathways. Oncogene 28 (50), 4421-4433.

Marintchev, A., and Wagner, G. (2004) Translation initiation: structures, mechanisms and evolution. Q Rev Biophys 37 (3-4), 197-284.

Maxwell, E. S., and Fournier, M. J. (1995) The small nucleolar RNAs. Annu Rev Biochem 64, 897-934. 
McCahill, A., Warwicker, J., Bolger, G. B., Houslay, M. D., and Yarwood, S. J. (2002) The RACK1 scaffold protein: a dynamic cog in cell response mechanisms. Mol Pharmacol 62 (6), 1261-1273.

McLeod, M., Shor, B., Caporaso, A., Wang, W., Chen, H., and Hu, L. (2000) Cpc2, a fission yeast homologue of mammalian RACK1 protein, interacts with Ran1 (Pat1) kinase to regulate cell cycle progression and meiotic development. Mol Cell Biol 20 (11), 4016-4027.

Melamed, D., Bar-Ziv, L., Truzman, Y., and Arava, Y. (2010) Asc1 supports cell-wall integrity near bud sites by a Pkc1 independent mechanism. PLoS One 5 (6), e11389.

Merrick, W. C. (2004) Cap-dependent and cap-independent translation in eukaryotic systems. Gene 332, 1-11.

Merrick, W. C., and Hershey, J. W. B. (1996) The pathway and mechanism of eukaryotic protein synthesis. Hershey, J. W. B., Mathews, M. B., Sonenberg, N. (eds.), Tanslational control. Cold Spring Harbor Laboratory Press, 31-70.

Moldave, K. (1985) Eukaryotic protein synthesis. Annu Rev Biochem 54, 1109-1149.

Morachis, J. M., Murawsky, C. M., and Emerson, B. M. (2010) Regulation of the p53 transcriptional response by structurally diverse core promoters. Genes Dev 24 (2), 135-147.

Mösch, H. U., Kübler, E., Krappmann, S., Fink, G. R., and Braus, G. H. (1999) Crosstalk between the Ras $2 \mathrm{p}$-controlled mitogen-activated protein kinase and cAMP pathways during invasive growth of Saccharomyces cerevisiae. Mol Biol Cell 10 (5), 1325-1335.

Mösch, H. U., Roberts, R. L., and Fink, G. R. (1996) Ras2 signals via the Cdc42/Ste20/mitogen-activated protein kinase module to induce filamentous growth in Saccharomyces cerevisiae. Proc Natl Acad Sci U S A 93 (11), $5352-5356$.

Mueller, P. P., and Hinnebusch, A. G. (1986) Multiple upstream AUG codons mediate translational control of GCN4. Cell 45 (2), 201-207.

Muhlrad, D., and Parker, R. (1992) Mutations affecting stability and deadenylation of the yeast MFA2 transcript. Genes Dev 6 (11), 2100-2111. 
Murthi, A., Shaheen, H. H., Huang, H. Y., Preston, M. A., Lai, T. P., Phizicky, E. M., and Hopper, A. K. (2010) Regulation of tRNA bidirectional nuclear-cytoplasmic trafficking in Saccharomyces cerevisiae. Mol Biol Cell 21 (4), 639-649.

Neer, E. J., Schmidt, C. J., Nambudripad, R., and Smith, T. F. (1994) The ancient regulatory-protein family of WD-repeat proteins. Nature 371 (6495), 297-300.

Nilsson, J., Sengupta, J., Frank, J., and Nissen, P. (2004) Regulation of eukaryotic translation by the RACK1 protein: a platform for signalling molecules on the ribosome. EMBO Rep 5 (12), 1137-1141.

Pain, V. M. (1996) Initiation of protein synthesis in eukaryotic cells. Eur J Biochem 236 (3), 747-771.

Palanimurugan, R., Scheel, H., Hofmann, K., and Dohmen, R. J. (2004) Polyamines regulate their synthesis by inducing expression and blocking degradation of ODC antizyme. EMBO J 23 (24), 4857-4867.

Palmer, D. A., Thompson, J. K., Li, L., Prat, A., and Wang, P. (2006) Gib2, a novel G $\beta$-like/RACK1 homolog, functions as a G $\beta$ subunit in cAMP signaling and is essential in Cryptococcus neoformans. J Biol Chem 281 (43), 32596-32605.

Pan, X., and Heitman, J. (2002) Protein kinase A operates a molecular switch that governs yeast pseudohyphal differentiation. Mol Cell Biol 22 (12), 3981-3993.

Park, M. H. (2006) The post-translational synthesis of a polyamine-derived amino acid, hypusine, in the eukaryotic translation initiation factor 5A (eIF5A). J Biochem 139 (2), 161-169.

Park, M. H., Wolff, E. C., Smit-McBride, Z., Hershey, J. W., and Folk, J. E. (1991) Comparison of the activities of variant forms of eIF-4D. The requirement for hypusine or deoxyhypusine. J Biol Chem 266 (13), 7988-7994.

Paul, S. K., Oowatari, Y., and Kawamukai, M. (2009) A large complex mediated by Moc1, Moc2 and Cpc2 regulates sexual differentiation in fission yeast. FEBS $J 276$ (18), 5076-5093.

Pierrat, B., Lacroute, F., and Losson, R. (1993) The 5' untranslated region of the PPRI regulatory gene dictates rapid mRNA decay in yeast. Gene 131 (1), 43-51.

Price, N., and Proud, C. (1994) The guanine nucleotide-exchange factor, eIF-2B. Biochimie 76 (8), 748-760. 
Proudfoot, N. J., Furger, A., and Dye, M. J. (2002) Integrating mRNA processing with transcription. Cell 108 (4), 501-512.

Puig, S., Askeland, E., and Thiele, D. J. (2005) Coordinated remodeling of cellular metabolism during iron deficiency through targeted mRNA degradation. Cell 120 (1), 99-110.

Rai, R., Genbauffe, F. S., and Cooper, T. G. (1988) Structure and transcription of the allantoate permease gene (DAL5) from Saccharomyces cerevisiae. J Bacteriol 170 (1), 266-271.

Raman, A., Guarraia, C., Taliaferro, D., Stahl, G., and Farabaugh, P. J. (2006) An mRNA sequence derived from a programmed frameshifting signal decreases codon discrimination during translation initiation. RNA 12 (7), 1154-1160.

Ranish, J. A., Yudkovsky, N., and Hahn, S. (1999) Intermediates in formation and activity of the RNA polymerase II preinitiation complex: holoenzyme recruitment and a postrecruitment role for the TATA box and TFIIB. Genes Dev 13 (1), 49-63.

Ruegsegger, U., Leber, J. H., and Walter, P. (2001) Block of HACl-mRNA translation by long-range base pairing is released by cytoplasmic splicing upon induction of the unfolded protein response. Cell 107 (1), 103-114.

Rupp, S., Summers, E., Lo, H. J., Madhani, H., and Fink, G. (1999) MAP kinase and cAMP filamentation signaling pathways converge on the unusually large promoter of the yeast FLO11 gene. EMBO J 18 (5), 1257-1269.

Saini, P., Eyler, D. E., Green, R., and Dever, T. E. (2009) Hypusine-containing protein eIF5A promotes translation elongation. Nature 459 (7243), 118-121.

Saxena, K., Gaitatzes, C., Walsh, M. T., Eck, M., Neer, E. J., and Smith, T. F. (1996) Analysis of the physical properties and molecular modeling of Sec13: A WD repeat protein involved in vesicular traffic. Biochemistry 35 (48), 15215-15221.

Schattner, P., Decatur, W. A., Davis, C. A., Ares, M., Jr., Fournier, M. J., and Lowe, T. M. (2004) Genome-wide searching for pseudouridylation guide snoRNAs: analysis of the Saccharomyces cerevisiae genome. Nucleic Acids Res 32 (14), 4281-4296.

Schmid, M., and Jensen, T. H. (2008) The exosome: a multipurpose RNA-decay machine. Trends Biochem Sci 33 (10), 501-510. 
Sezen, B., Seedorf, M., and Schiebel, E. (2009) The SESA network links duplication of the yeast centrosome with the protein translation machinery. Genes Dev 23 (13), 1559-1570.

Shatkin, A. J., Banerjee, A. K., Both, G. W., Furuichi, Y., and Muthukrishnan, S. (1976) Dependence of translation on 5'-terminal methylation of mRNA. Fed Proc 35 (11), 2214-2217.

Shilatifard, A. (2006) Chromatin modifications by methylation and ubiquitination: implications in the regulation of gene expression. Annu Rev Biochem 75, 243-269.

Singh, C. R., Lee, B., Udagawa, T., Mohammad-Qureshi, S. S., Yamamoto, Y., Pavitt, G. D., and Asano, K. (2006) An eIF5/eIF2 complex antagonizes guanine nucleotide exchange by eIF2B during translation initiation. EMBO J 25 (19), 4537-4546.

Slobin, L. I., and Möller, W. (1978) Purification and properties of an elongation factor functionally analogous to bacterial elongation factor Ts from embryos of Artemia salina. Eur J Biochem 84 (1), 69-77.

Smith, T. F., Gaitatzes, C., Saxena, K., and Neer, E. J. (1999) The WD repeat: a common architecture for diverse functions. Trends Biochem Sci 24 (5), 181-185.

Sondek, J., Bohm, A., Lambright, D. G., Hamm, H. E., and Sigler, P. B. (1996) Crystal structure of $\mathrm{a}_{\mathrm{A}}$ protein $\beta \gamma$ dimer at 2.1 $\mathrm{A}$ resolution. Nature 379 (6563), 369-374.

Stansfield, I., Jones, K. M., and Tuite, M. F. (1995) The end in sight: terminating translation in eukaryotes. Trends Biochem Sci 20 (12), 489-491.

Stargell, L. A., Moqtaderi, Z., Dorris, D. R., Ogg, R. C., and Struhl, K. (2000) TFIIA has activator-dependent and core promoter functions in vivo. J Biol Chem 275 (17), 12374-12380.

Struhl, K. (1987) Promoters, activator proteins, and the mechanism of transcriptional initiation in yeast. Cell 49 (3), 295-297.

Struhl, K. (1995) Yeast transcriptional regulatory mechanisms. Annu Rev Genet 29, 651-674.

Sugihara, F., Kasahara, K., and Kokubo, T. (2010) Highly redundant function of multiple AT-rich sequences as core promoter elements in the TATA-less RPS5 promoter of Saccharomyces cerevisiae. Nucleic Acids Res, Epub. 
Sumrada, R. A., and Cooper, T. G. (1987) Ubiquitous upstream repression sequences control activation of the inducible arginase gene in yeast. Proc Natl Acad Sci U S A 84 (12), 3997-4001.

Taliaferro, D., and Farabaugh, P. J. (2007) An mRNA sequence derived from the yeast EST3 gene stimulates programmed +1 translational frameshifting. RNA 13 (4), 606-613.

Tedford, K., Kim, S., Sa, D., Stevens, K., and Tyers, M. (1997) Regulation of the mating pheromone and invasive growth responses in yeast by two MAP kinase substrates. Curr Biol 7 (4), 228-238.

Teige, M., Scheikl, E., Reiser, V., Ruis, H., and Ammerer, G. (2001) Rck2, a member of the calmodulin-protein kinase family, links protein synthesis to high osmolarity MAP kinase signaling in budding yeast. Proc Natl Acad Sci U S A 98 (10), $5625-5630$.

Thompson, C. M., Koleske, A. J., Chao, D. M., and Young, R. A. (1993) A multisubunit complex associated with the RNA polymerase II CTD and TATA-binding protein in yeast. Cell 73 (7), 1361-1375.

Tran, E. J., Zhou, Y., Corbett, A. H., and Wente, S. R. (2007) The DEAD-box protein Dbp5 controls mRNA export by triggering specific RNA: protein remodeling events. Mol Cell 28 (5), 850-859.

Triana-Alonso, F. J., Chakraburtty, K., and Nierhaus, K. H. (1995) The elongation factor 3 unique in higher fungi and essential for protein biosynthesis is an E site factor. J Biol Chem 270 (35), 20473-20478.

Tyc, K., and Steitz, J. A. (1989) U3, U8 and U13 comprise a new class of mammalian snRNPs localized in the cell nucleolus. EMBO J 8 (10), 3113-3119.

Vaisman, N., Tsouladze, A., Robzyk, K., Ben-Yehuda, S., Kupiec, M., and Kassir, Y. (1995) The role of Saccharomyces cerevisiae Cdc40p in DNA replication and mitotic spindle formation and/or maintenance. Mol Gen Genet 247 (2), 123-136.

Valerius, O., Kleinschmidt, M., Rachfall, N., Schulze, F., López Marín, S., Hoppert, M., Streckfuss-Bömeke, K., Fischer, C., and Braus, G. H. (2007) The Saccharomyces homolog of mammalian RACK1, Cpc2/Asc1p, is required for FLO11-dependent adhesive growth and dimorphism. Mol Cell Proteomics 6 (11), 1968-1979. 
van Holde, K., and Zlatanova, J. (1996) Chromatin architectural proteins and transcription factors: a structural connection. Bioessays 18 (9), 697-700.

van Werven, F. J., van Teeffelen, H. A., Holstege, F. C., and Timmers, H. T. (2009) Distinct promoter dynamics of the basal transcription factor TBP across the yeast genome. Nat Struct Mol Biol 16 (10), 1043-1048.

Vattem, K. M., and Wek, R. C. (2004) Reinitiation involving upstream ORFs regulates ATF4 mRNA translation in mammalian cells. Proc Natl Acad Sci U S A 101 (31), $11269-11274$.

Vega Laso, M. R., Zhu, D., Sagliocco, F., Brown, A. J., Tuite, M. F., and McCarthy, J. E. (1993) Inhibition of translational initiation in the yeast Saccharomyces cerevisiae as a function of the stability and position of hairpin structures in the mRNA leader. J Biol Chem 268 (9), 6453-6462.

Vilela, C., and McCarthy, J. E. (2003) Regulation of fungal gene expression via short open reading frames in the mRNA 5'untranslated region. Mol Microbiol 49 (4), 859-867.

Voorma, H. O., Thomas, A. A., and Van Heugten, H. A. (1994) Initiation of protein synthesis in eukaryotes. Mol Biol Rep 19 (3), 139-145.

Wek, S. A., Zhu, S., and Wek, R. C. (1995) The histidyl-tRNA synthetase-related sequence in the eIF-2 $\alpha$ protein kinase Gen2 interacts with tRNA and is required for activation in response to starvation for different amino acids. Mol Cell Biol 15 (8), 4497-4506.

Wells, S. E., Hillner, P. E., Vale, R. D., and Sachs, A. B. (1998) Circularization of mRNA by eukaryotic translation initiation factors. Mol Cell 2 (1), 135-140.

Wilkie, G. S., Dickson, K. S., and Gray, N. K. (2003) Regulation of mRNA translation by 5'- and 3'-UTR-binding factors. Trends Biochem Sci 28 (4), 182-188.

Xia, X., and Holcik, M. (2009) Strong eukaryotic IRESs have weak secondary structure. PLoS One 4 (1), e4136.

Zeller, C. E., Parnell, S. C., and Dohlman, H. G. (2007) The RACK1 ortholog Asc1 functions as a G-protein $\beta$ subunit coupled to glucose responsiveness in yeast. J Biol Chem 282 (34), 25168-25176. 
Zhang, W., Cheng, G. Z., Gong, J., Hermanto, U., Zong, C. S., Chan, J., Cheng, J. Q., and Wang, L. H. (2008) RACK1 and CIS mediate the degradation of BimEL in cancer cells. J Biol Chem 283 (24), 16416-16426.

Zhang, Z., and Dietrich, F. S. (2005) Identification and characterization of upstream open reading frames (uORF) in the 5' untranslated regions (UTR) of genes in Saccharomyces cerevisiae. Curr Genet 48 (2), 77-87. 



\title{
Chapter II
}

\section{5'TRU: Identification and analysis of translationally regulative 5'untranslated regions in amino acid starved yeast cells}

\begin{abstract}
This work describes a method to identify and analyze translationally regulative 5'UTRs (5'TRU) in Saccharomyces cerevisiae. 2D-analyses of ${ }^{35} \mathrm{~S}$-methionine metabolically labeled cells revealed thirteen genes/proteins, whose protein biosynthesis is post-transcriptionally up-regulated upon amino acid (aa) starvation. The 5'UTRs of the candidates' respective mRNAs were further investigated. A plasmid-based reporter-testing system was developed to analyze their capability to influence translation dependent on aa-availability. Most of the thirteen candidate-5'UTRs are able to enhance translation independently of amino acids. Two 5'UTRs generally repressed translation, and the 5'UTRs of ENO1, FBAI and TPII specifically up-regulated translation when cells were starved for amino acids. The strongest effects in the testing system were achieved with the TPI1-5'UTR. Elevated Tpi1p-levels in aa-starved cells reflected this effect. Bioinformatical analyses support that an unstructured A-rich 5'leader is beneficial for efficient translation when amino acids are scarce.
\end{abstract}




\section{Introduction}

Gene expression is efficiently controlled by several regulatory mechanisms of protein biogenesis to adapt to changing endogenous and environmental conditions. They include transcription, mRNA-processing, translation, and post-translational modifications (Day and Tuite, 1998). Translational regulation has particular significance since it represents the last step in the conversion of genetic information to a polypeptide chain. It enables a quick and reversible adaptation, especially needed for efficient stress response (Holcik and Sonenberg, 2005). Stresses often induce global control mechanisms leading to the reduction of overall protein biosynthesis. This is mediated by post-translational modifications of one or more translation initiation factors (eIFs), e.g. by phosphorylations or changes in their abundance (Day and Tuite, 1998; Gebauer and Hentze, 2004). An example is the response to amino acid starvation (aa-starvation) conditions. A lack of amino acids leads to an increased amount of unloaded tRNAs within the cell. This is detected by the sensor kinase Gcn2p, which phosphorylates the translation initiation factor eIF2 on its $\alpha$ subunit. The phosphorylated form of eIF2 acts as competitive inhibitor for the guanine nucleotide exchange factor $(\mathrm{GEF})$ eIF2B, preventing the recycling reaction from eIF2-GDP to the GTP-bound form. This results in a reduced translation rate since only eIF2-GTP is able to form the ternary complex (eIF2-GTP-Met-tRNA ${ }_{i}{ }^{\text {Met }}$ ) needed for translation initiation (Hinnebusch, 2000). This global control can be overruled by mRNAspecific control mechanisms to ensure sufficient translation of specific mRNAs even when overall protein biosynthesis is reduced. Those mechanisms are especially directed by elements in the 5' untranslated regions (5'UTRs) of mRNAs (Day and Tuite, 1998). The paradigm of an mRNA more efficiently translated under aa-starvation conditions encodes Gen $4 p$, which is the global regulator of amino acid biosynthesis (Hinnebusch, 2005). The GCN4-mRNA contains four short upstream open reading frames (uORFs) in its 5'UTR, which repress translation under non-starvation conditions. The induction of aastarvation results in eIF2 phosphorylation, reducing the amount of ternary complex. As a consequence the ribosome does not reinitiate translation at the fourth uORF, but preferentially initiates at the GCN4-start codon and thereby derepresses GCN4-translation (Hinnebusch, 1993). Such a regulative mechanism is conserved from yeast to the mammalian activating transcription factor 4 (ATF4), whose mRNA carries two uORFs in 
its 5'UTR (Harding et al., 2000; Vattem and Wek, 2004). Another feature known to regulate translation efficiency is the presence of internal ribosome entry sites (IRES) in the 5'UTR of mRNAs. They enable sufficient translation for specific mRNAs under conditions when canonical cap-dependent translation is inhibited. IRES directly recruit the ribosome to the vicinity of the initiation codon, thus bypassing the cap-structure and its associated eIFs (Holcik and Sonenberg, 2005). The mammalian transporter for the essential amino acids arginine and lysine, cat-1, features an IRES in its 5'UTR with an incorporated uORF. Induction of IRES activity requires the translation of the UORF, unfolding an inhibitory structure in the cat-1-5'UTR, leading to a conformational change (Yaman et al., 2003). A necessity for cap-independent translation via IRES has been shown for starvation-induced differentiation in yeast. In contrast to the structure-based viral IRES-activity the activation in yeast is mediated by unstructured A-rich elements via recruitment of the poly(A) binding protein (Pab1p) (Gilbert et al., 2007). In accordance it has recently been shown that strong IRES possess weak secondary structures and are predominantly located immediately upstream of the mRNA-initiation codon (Xia and Holcik, 2009). The formation of stronger secondary structures on the other hand can influence translation efficiency via hairpin structures. They inhibit scanning of the 43S pre-initiation complex or binding of regulative proteins (Day and Tuite, 1998; Gebauer and Hentze, 2004).

In spite of an increasing research interest in translational regulation there are still only a few proteins for which a translational regulation has been described. In this context the high density of available microarray data generated under various growth conditions is immensely valuable. In a combination with proteomics it enables the distinction between transcriptional and post-transcriptional regulation.

Here, we describe a proteome-based approach to identify 5'UTRs regulating translation in dependence of aa-availability. Bioinformatical analyses of respective 5'UTRs disclosed a noticeable accumulation of adenine bases and their predicted secondary structures to be specifically weak or not present. The introduction of the 5'UTR sequences in a reporter-testing vector revealed three 5'UTRs that significantly increased translation when aa-starvation was induced. The strongest effects could be monitored for the unstructured TPI1-5'UTR. In conjunction with the up-regulation of total Tpilp in cells starved for amino acids, this strongly suggests its 5'UTR-mediated translational regulation. 


\section{Materials and Methods}

Yeast strains and growth conditions - The Saccharomyces cerevisiae strain RH2817

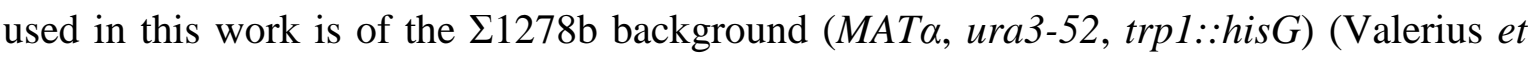
al., 2007). The strains RH3384 and RH3385 were generated by C-terminally tagging ENOI and FBAI with 3xmyc, respectively, according to Janke and colleagues (2004). Transformations were carried out according to the lithium acetate method (Ito et al., 1983). Cultures were grown at $30^{\circ} \mathrm{C}$ overnight in $10 \mathrm{ml}$ liquid minimal medium (YNB) containing respective supplements (amino acids, uracil), diluted and cultivated in main cultures to midlog phase before isolation of protein extracts or total RNA. Experiment-specific growth conditions are given in the respective paragraphs.

Plasmid construction - All plasmids used in this study are listed in Table 1. To construct the plasmid pME3680 (testing vector) the PGK1-promoter was amplified with the primers 5'-GATAGATCTGCACGTGGCCTCTTATCGAG-3' and 3'-CGAAAGAAAAAGAGAA AAAATGTCTAGTAGTTCCTTCGGATCCATGTGGAGATCTTC-5' resulting in the $P G K 1$-promoter fragment flanked by $B g l \mathrm{II}$ restriction sites including a $\mathrm{BamHI}$ restriction site and ATG start codon downstream of the promoter. The BglII restriction sites enable the introduction of the $P G K 1$-promoter fragment into BamHI restricted Yep355. To construct plasmids 'pME3681 - pME3694' respective 5'UTRs (Supplementary Table 1, David et al., 2006) were amplified by PCR inserting BglII restriction sites on both ends and ligated with pME3680 utilizing the BamHI restriction site previously introduced by PCR. Plasmids were amplified in the Escherichia coli strain DH5 $\alpha$ in LB medium with $100 \mu \mathrm{g} / \mathrm{ml}$ ampicillin.

Table 1. Plasmids used in this work

\begin{tabular}{|c|c|c|}
\hline Plasmid & Description & Reference \\
\hline Yep355 & $7.94 \mathrm{~kb}$ vector, $a m p^{R}($ bla $)$, lacZ, ori, $2 \mu m, U R A 3$ & $\begin{array}{l}\text { ATCC, The Global } \\
\text { Bioresource Center }^{\mathrm{TM}} \\
\text { (Wesel, Germany) }\end{array}$ \\
\hline pME3680 & $\begin{array}{l}\text { Yep355 containing }{ }^{\text {prom }} P G K 1 \text { followed by BamHI restriction site and } \\
\text { ATG start codon (testing vector) }\end{array}$ & This work \\
\hline pME3681 & $\begin{array}{l}\text { pME3680 with } G C N 4-5 \text { 'UTR introduced between }{ }^{\text {prom }} P G K 1 \text { and ATG } \\
\text { start codon }\end{array}$ & This work \\
\hline
\end{tabular}


Table 1. Continued.

\begin{tabular}{|c|c|c|}
\hline pME3682 & $\begin{array}{l}\text { pME3680 with } P G K 1-5 \text { 'UTR introduced between }{ }^{\text {prom }} P G K 1 \text { and ATG } \\
\text { start codon }\end{array}$ & This work \\
\hline pME3683 & $\begin{array}{l}\text { pME3680 with ASC1-5'UTR introduced between }{ }^{\text {prom }} P G K 1 \text { and ATG } \\
\text { start codon }\end{array}$ & This work \\
\hline pME3684 & $\begin{array}{l}\text { pME3680 with } G R X 1-5 \text { 'UTR introduced between }{ }^{\text {prom }} P G K 1 \text { and ATG } \\
\text { start codon }\end{array}$ & This work \\
\hline pME3685 & 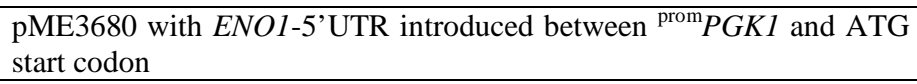 & This work \\
\hline pME3686 & $\begin{array}{l}\text { pME3680 with TRP5-5'UTR introduced between }{ }^{\text {prom }} P G K 1 \text { and ATG } \\
\text { start codon }\end{array}$ & This work \\
\hline pME3687 & $\begin{array}{l}\text { pME3680 with ILV5-5'UTR introduced between }{ }^{\text {prom }} P G K 1 \text { and ATG } \\
\text { start codon }\end{array}$ & This work \\
\hline pME3688 & $\begin{array}{l}\text { pME3680 with IPP1-5'UTR introduced between }{ }^{\text {prom }} P G K 1 \text { and ATG } \\
\text { start codon }\end{array}$ & This work \\
\hline pME3689 & $\begin{array}{l}\text { pME3680 with FBA1-5'UTR introduced between }{ }^{\text {prom }} P G K 1 \text { and ATG } \\
\text { start codon }\end{array}$ & This work \\
\hline pME3690 & $\begin{array}{l}\text { pME3680 with } R H R 2-5 \text { 'UTR introduced between }{ }^{\text {prom }} P G K 1 \text { and ATG } \\
\text { start codon }\end{array}$ & This work \\
\hline pME3691 & $\begin{array}{l}\text { pME3680 with } A H P 1-5 \text { 'UTR introduced between }{ }^{\text {prom }} P G K 1 \text { and ATG } \\
\text { start codon }\end{array}$ & This work \\
\hline pME3692 & $\begin{array}{l}\text { pME3680 with } A L D 6-5 \text { 'UTR introduced between }{ }^{\text {prom }} P G K 1 \text { and ATG } \\
\text { start codon }\end{array}$ & This work \\
\hline pME3693 & $\begin{array}{l}\text { pME3680 with FPR1-5'UTR introduced between }{ }^{\text {prom }} P G K 1 \text { and ATG } \\
\text { start codon }\end{array}$ & This work \\
\hline pME3694 & $\begin{array}{l}\text { pME3680 with TPII-5'UTR introduced between }{ }^{\text {prom }} P G K 1 \text { and ATG } \\
\text { start codon }\end{array}$ & This work \\
\hline
\end{tabular}

De novo proteome and 2D-PAGE analysis - To induce amino acid starvation conditions $50 \mathrm{ml}$ yeast cultures were grown to midlog phase $\left(\mathrm{OD}_{600}=0.8\right)$ in minimal medium prior to the addition of the histidine analog 3-amino-1,2,4-triazole (3AT) to a final concentration of $10 \mathrm{mM}$ (Hilton et al., 1965) and further incubated for $30 \mathrm{~min}$ at $30^{\circ} \mathrm{C}$. Then $450 \mu \mathrm{Ci}$ Met- $\left[{ }^{35} \mathrm{~S}\right]$-label (Hartmann Analytik, Braunschweig, Germany) were added and the cultures incubated for an additional hour. The time period of 30min prior to the addition of ${ }^{35} \mathrm{~S}$-methionine ensured proper induction of aa-starvation conditions before the effects on the de novo protein biosynthesis are monitored. Cells were harvested and washed in wash buffer (0.1M Tris, $\mathrm{pH} 8.0$ with $1 \%$ DMSO and $1 \mathrm{mM}$ PMSF). Protein extracts were obtained by lysing cells with Y-PER ${ }^{\circledR}$ Plus reagent (\#78999, Pierce, Rockford, IL, USA) containing cOmplete Protease Inhibitor Cocktail (Roche Diagnostics GmbH, Mannheim, Germany) and purification by methanol-chloroform extraction (Wessel and Flügge, 1984). Protein concentrations were determined via BCA Protein Assay kit from Pierce (\#23227). $100 \mu \mathrm{g}$ of purified protein extracts were used in 2D-PAGE analyses. For the first dimension the protein samples were applied to Immobiline Drystrips (pH 4-7, 18cm, \#17-1233-01, GE Healthcare Europe GmbH Freiburg, Germany) via rehydration loading. The $\mathrm{pH}$ range 
of 4-7 was chosen to achieve a satisfying separation of protein-spots in this dense area, facilitating subsequent identification of single proteins. The separation was carried out in the Ettan IPGphor Isoelectric focusing system (GE Healthcare) at $20^{\circ} \mathrm{C}$ and a maximum of $50 \mu \mathrm{A} /$ strip with the following program: $70 \mathrm{~V}$ for $12 \mathrm{~h}$ (step-n-hold), $500 \mathrm{~V}$ for $1 \mathrm{~h}$ (step-n-hold), 1000V for $1 \mathrm{~h}$ (step-n-hold), $8000 \mathrm{~V}$ for $1 \mathrm{~h}$ (gradient), $8000 \mathrm{~V}$ for $4 \mathrm{~h}$ (step-nhold). The strips were thereafter equilibrated in equilibration buffer $(50 \mathrm{mM}$ Tris- $\mathrm{HCl}, \mathrm{pH}$

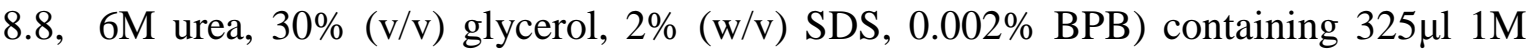
DTT or $125 \mathrm{mg}$ Iodacetamide and incubated for 30min, respectively. The second dimension separation was executed on $12.5 \%$ polyacrylamide gels in Protean ${ }^{\circledR}$ II xi vertical electrophoresis cells (1mm spacers, 20x20cm glass plates) (Bio-Rad Laboratories GmbH, Munich, Germany). Electrophoresis was performed at $30 \mathrm{~mA}$ per gel. Gels were silver-stained according to Blum et al. (1987), vacuum dried and exposed on imaging plates (Fuji, Tokyo, Japan) for two weeks. The protein-spots in the resulting autoradiographies were quantified with the analysis software PDQuest ${ }^{\mathrm{TM}}$ (Bio-Rad, Munich, Germany). To excise relevant protein-spots from the corresponding gels, the autoradiographies were transferred to transparency film and matched with the gels by overlay. The analysis was performed for five biologically independent replicates.

LC-MS/MS Protein Identification - Excised polyacrylamide gel pieces of silver-stained protein-spots were digested with trypsin according to Shevchenko et al. (1996). Tryptic peptides extracted from each gel piece were injected onto a reverse-phase liquid chromatographic column (Dionex-NAN75-15-03-C18 PM) utilizing the ultimate HPLC system (Dionex, Idstein, Germany) to further reduce sample complexity prior to mass analyses with an LCQ DecaXP mass spectrometer (Thermo Scientific, San Jose, CA, USA), equipped with a nano-electrospray ion source. Cycles of MS spectra with $\mathrm{m} / \mathrm{z}$ ratios of peptides and four data-dependent MS2 spectra were recorded by mass spectrometry. The "peak list" was created with extractms provided with the Xcalibur software package (BioworksBrowser 3.3.1, Thermo Scientific). The MS2 spectra with a total ion current higher than 10,000 were used to search for matches against a yeast genome protein sequence database from the National Center for Biotechnology Information (NCBI) Saccharomyces Genome Database (Stanford, CA, USA, 6882 sequences, March 2005, plus 180 sequences of the most commonly appearing contaminants, as e.g. keratins and proteases, provided with the BioworksBrowser package) using the TurboSEQUEST 
algorithm (Eng et al., 1994) of the Bioworks software (Version 3.3.1, Thermo Scientific). The search parameters based on the TurboSEQUEST software included: (i) precursor ion mass tolerance less than $1.4 \mathrm{amu}$, (ii) fragment ion mass tolerance less than $1.0 \mathrm{amu}$, (iii) up to three missed tryptic cleavages allowed and (iv) fixed cysteine modifications by carboxyamidomethylation (plus $57.05 \mathrm{amu}$ ) and variable modifications by methionine oxidation (plus $15.99 \mathrm{amu}$ ) and phosphorylation of serine, threonine or tyrosine (plus 79.97 $\mathrm{amu}$ ). At least two matched peptide sequences of identified proteins must pass the following criteria: (i) the cross-correlation scores (XCorr) of matches must be greater than 2.0, 2.5 or 3.0 for peptide ions of charge state 1, 2 and 3, respectively, (ii) $\Delta \mathrm{Cn}$ values of the best peptide matches must be at least 0.4 and (iii) the primary scores (Sp) were at least 600. Peptides of identified proteins were individually blasted against the Saccharomyces genome database (SGD) (BLASTP at http://seq.yeastgenome.org/cgi-bin/blast-sgd.pl against the dataset Protein Encoding Genes) to ensure their unambiguous assignment to the TurboSEQUEST-specified protein.

Scintillation counting - Cells were cultivated and harvested as for 2D-PAGE analysis and lysed via Y-PER ${ }^{\circledR}$ Plus reagent. The metabolically labeled protein extracts were separated from free Met- $\left[{ }^{35} \mathrm{~S}\right]$-isotope by methanol-chloroform extraction and the sediment resuspended in $400 \mu \mathrm{l}$ Y-PER ${ }^{\circledR}$ Plus reagent. $200 \mu \mathrm{l}$ were mixed with $5 \mathrm{ml}$ of ULTIMA GOLD XR LCS-Cocktail (Perkin Elmer, Boston, MA, USA) and subjected to scintillation counting. The measured counts per minute $(\mathrm{cpm})$ were related to the concentration of the protein extracts determined via BCA Protein Assay kit from Pierce. The insoluble fraction was washed in wash buffer and incubated in Y-PER ${ }^{\circledR}$ Plus reagent overnight. After washing in $\mathrm{H}_{2} \mathrm{O}$ the pellet was weight and resuspended in $1 \mathrm{ml}_{2} \mathrm{O} .100 \mu$ of this suspension were added to $5 \mathrm{ml}$ of ULTIMA GOLD XR LCS-Cocktail followed by scintillation counting. The relative activities were determined by normalization to respective pellet masses.

$\boldsymbol{\beta}$-galactosidase assay - Assays were performed with extracts of cells grown in liquid minimal medium. $10 \mathrm{ml}$ pre-cultures were grown overnight at $30^{\circ} \mathrm{C}$ and $1 \mathrm{ml}$ was used to inoculate $10 \mathrm{ml}$ main cultures. For non-starvation conditions cells were harvested after $6 \mathrm{~h}$. To induce amino acid starvation conditions, 3AT was added to a final concentration of $10 \mathrm{mM}$ and cells were incubated at $30^{\circ} \mathrm{C}$ for $8 \mathrm{~h}$ to compensate for a reduced growth rate 
under aa-starvation conditions. Specific $\beta$-galactosidase activities were normalized to the total protein amount (Bradford, 1976) in each extract and calculated according to Rose and Botstein (1983) ( $\mathrm{A}_{415} \mathrm{x}$ 0.3)/(0.0045 x protein concentration $\mathrm{x}$ extract volume $\mathrm{x}$ time).

Determination of plasmid copy numbers - Cells were grown as for $\beta$-galactosidase assays and total DNA was isolated via Smash and Grab method (Hoffman and Winston, 1987). 20ng/ $\mu$ l DNA was used in Real-Time-PCR (RT-PCR) performed with LightCycler ${ }^{\circledR}$ FastStart DNA Master ${ }^{\text {PLUS }}$ SYBR Green I in the LightCycler ${ }^{\circledR} 2.0$ Instrument (Roche, Mannheim, Germany). The fragment used for determination of plasmid copy numbers via RT-PCR corresponds to a $158 \mathrm{bp}$ long non-coding region of the testing vector sequence. For normalization the housekeeper genes $A C T 1$ and $C D C 28$ were used with a PCR product length of 159 and $168 \mathrm{bp}$, respectively. Plasmid copy numbers were determined relative to the empty testing vector (pME3680) by $2^{-\Delta \Delta C}$ method (Livak and Schmittgen, 2001).

5' rapid amplification of cDNA ends (5'RACE) - Yeast cultures were grown according to the conditions used for $\beta$-galactosidase assays. Total RNA was isolated with the High Pure RNA Isolation Kit from Roche (Mannheim, Germany). $3 \mu \mathrm{g}$ of total RNA were used to amplify the $5^{\prime}$ ends of respective mRNAs with the Gene Racer ${ }^{\mathrm{TM}}$ kit from Invitrogen (\#L1502-01, Karlsruhe, Germany). Reverse transcription was performed using the SuperScript ${ }^{\mathrm{TM}}$ III reverse transcriptase and a gene-specific primer. To amplify the $5^{\prime}$ ends of the cDNA, the Platinum ${ }^{\circledR}$ Taq DNA Polymerase High Fidelity (Invitrogen) was used with the Gene Racer 5' primer and a nested gene-specific primer. The amplification product was purified using S.N.A.P. ${ }^{\mathrm{TM}}$ columns provided with the Gene Racer $^{\mathrm{TM}}$ kit and cloned using the TOPO TA Cloning ${ }^{\circledR}$ kit for Sequencing (Invitrogen, provided with Gene Racer $^{\text {TM }}$ kit). Sequencing was done by the Göttingen Genomics Laboratory (G2L, Göttingen, Germany).

Western hybridization analysis - Cell main cultures were grown in 50ml minimal media at $30^{\circ} \mathrm{C}$ to midlog phase $\left(\mathrm{OD}_{600}=0.8\right)$ before further incubation with or without $10 \mathrm{mM} 3 \mathrm{AT}$ for $1.5 \mathrm{~h}$. Protein extraction was performed as previously described for the 2D-PAGE analysis and proteins were blotted onto nitrocellulose membrane subsequently of separation by 1D- or 2D-PAGE. After incubation of membranes with polyclonal rabbit anti-eIF2 $\alpha$-P (BIOSOURCE, Nivelles, Belgium), polyclonal rabbit anti-eIF2 $\alpha$ (kindly provided by Thomas Dever and Alan Hinnebusch, NIH, Bethesda, MD, USA), monoclonal 
mouse anti-myc (\#sc-40, Santa Cruz Biotechnology, Heidelberg, Germany), polyclonal rabbit anti-Cdc28 (\#sc-28550, Santa Cruz Biotechnology, Heidelberg, Germany) or rabbit anti-Tpi1 (kindly provided by Jürgen Dohmen, University of Cologne, Köln, Germany) antibodies and subsequent incubation with polyclonal peroxidase-coupled goat anti-mouse (\#115-035-003, Dianova, Hamburg, Germany) or goat anti-rabbit (\#G21234, MoBiTec, Göttingen, Germany) secondary antibodies, proteins were visualized by ECL technology (Amersham Biosciences, Munich, Germany). The quantification was carried out via PDQuest $^{\mathrm{TM}}$ analysis software (Bio-Rad, Munich, Germany).

Northern hybridization analysis - Yeast cultures were cultivated according to western hybridization protocol. Total RNA from yeast was isolated following the protocol described by Cross and Tinkelenberg (1991). The RNA samples were denatured and separated on a $1.4 \%$ agarose gel containing $3 \%$ formaldehyde and transferred onto nylon membranes by capillary blotting. Gene specific probes were labeled radioactively with $\left[\alpha-{ }^{32} \mathrm{P}\right] \mathrm{dATP}$ utilizing the Prime-It ${ }^{\circledR}$ II Random Primer Labeling Kit from Stratagene (\#300385, La Jolla, CA, USA). A Fuji Film BAS-1500 Phosphor-Imaging scanner (Fuji, Tokyo, Japan) and Aida Image Analyzer software (Version 4.22.034, raytest, Straubenhardt, Germany) were used for quantification of signals.

\section{Detection of local, thermodynamically optimal RNA secondary structures -} RNALFOLD from the VIENNA Package 1.8.2 (Hofacker et al., 2004) was used for the detection of local, thermodynamically optimal RNA secondary structures in 5'UTRs and the computation of their minimal free energy (MFE). The program was called with the options "-noLP" and "-L 100". The first option inhibits lonely base pairs and the second restrains the maximal local structure size to 100 bases.

Calculation of the z-score - The z-score is a measure for the stability of an RNA secondary structure in comparison with the stability of secondary structures of random sequences with similar sequence properties as the target sequence. It is computed for each subsequence in each 5'UTR with a local, thermodynamic optimal RNA secondary structure. The $\mathrm{z}$-score is defined as: $\mathrm{z}=(\mathrm{m}-\mu): \sigma$, whereby $\mathrm{m}$ is the MFE of the secondary structure of the target sequence $S, \mu$ is the mean and $\sigma$ the standard deviation of the MFE-values of the RNA secondary structures of random sequences with the same length 
and dinucleotide composition as $\mathrm{S}$. The creation of random sequences with similar properties as the target sequence is done by DISHUFFLE (Clote et al., 2005). The program permutes a given RNA sequence but preserves its dinucleotide composition. For each target sequence 100 random sequences are computed. For each of the random sequences the secondary structure is predicted with RNAFOLD also from the VIENNA Package 1.8.2 (Hofacker et al., 1994). Then, for each target sequence the mean $\mu$ and standard deviation $\sigma$ of the MFE-values of the random sequences and the $\mathrm{z}$-score are computed. 


\section{Results}

In our analysis, we are aiming to find 5' UTRs that specifically enhance the translation of their respective mRNA under aa-starvation conditions induced by the histidine analog 3-amino-1,2,4-triazole (3AT). 3AT is a competitive inhibitor of Imidazoleglycerolphosphate dehydratase (His3p), which catalyzes the sixth step in histidine biosynthesis (Hilton et al., 1965). The strategy to identify regulatory 5'UTRs is based on (i) the $2 \mathrm{D}$-analysis of ${ }^{35} \mathrm{~S}$-methionine labeled de novo proteomes generated under differential conditions. The next steps of the analysis consist of (ii) identification of protein-spots regulated under the chosen condition, (iii) comparison of the obtained proteome data with pre-existing transcriptome data generated under similar conditions (Kleinschmidt et al., 2005), (iv) evaluation of the candidate-5'UTRs via reporter-testing system presented in this study and (v) sequential and structural analysis of 5'UTRs by bioinformatical means (overview in Figure 1).

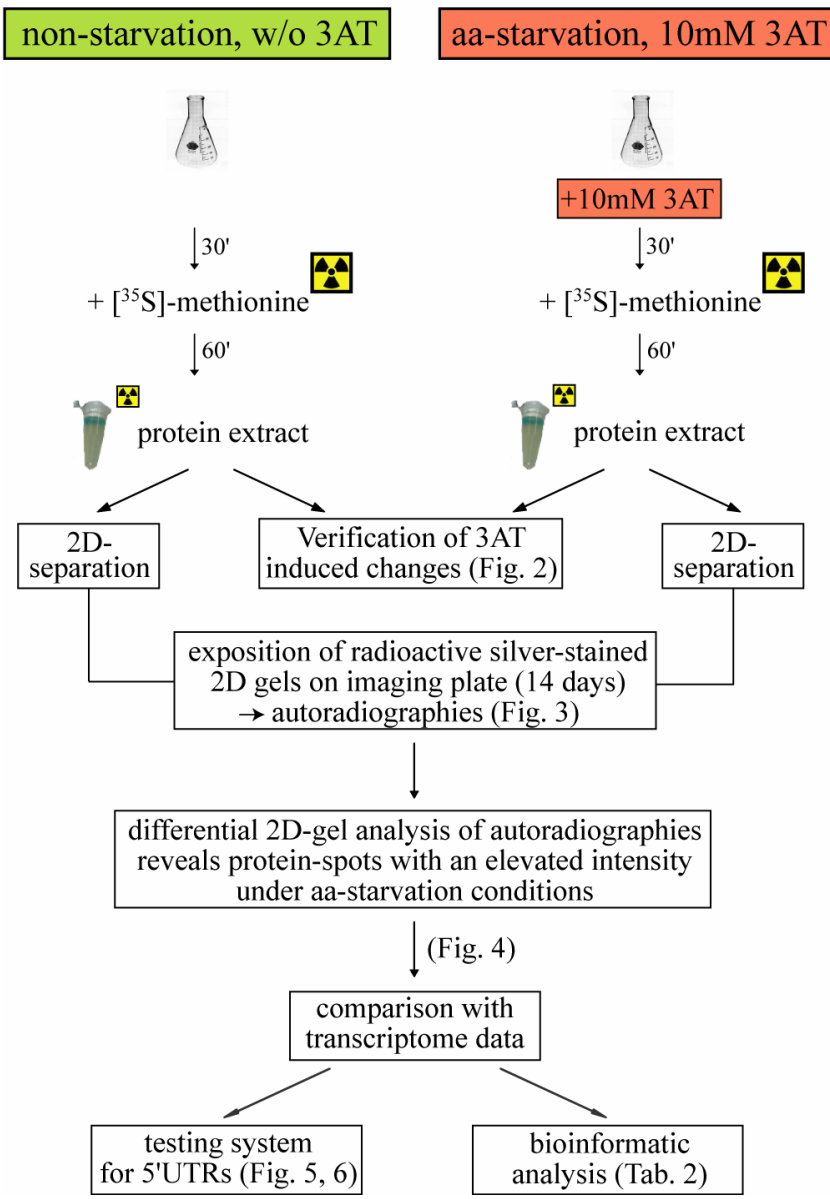

Figure 1. Flow chart of experiments to identify mRNA-5'UTRs potentially involved in translational control upon amino acid starvation. Protein extracts were isolated from cultures grown in the presence (aa-starvation) or absence (non-starvation) of the histidine analog 3-amino-1,2,4-triazole (3AT) for $90 \mathrm{~min}$. After $30 \mathrm{~min}{ }^{35} \mathrm{~S}$-labeled methionine was added. A 2D-PAGE analysis of the autoradiographies, corresponding to the generated 2D-gels, revealed proteins more efficiently synthesized under aa-starvation conditions (Figure 4). Proteins whose corresponding mRNA-levels were not regulated upon aa-starvation or even showed a decrease were determined and subjected to further investigations (Figure 4, top part of chart). The 5'UTRs of those respective candidate-mRNAs were analyzed in a lacZ-reporter assay (Figures 5A and 6) and by bioinformatic tools (Table 2). 


\section{The de novo biosynthesis of various abundant proteins is up-regulated post- transcriptionally upon amino acid-starvation}

Wild type cells of the $\Sigma 1278$ background were cultivated in the absence or presence of $10 \mathrm{mM} 3 \mathrm{AT}$ for 30 minutes. After the addition of ${ }^{35} \mathrm{~S}$-methionine the cultures were incubated for an additional hour. This enables the visualization of the effects of aa-starvation on de novo protein biosynthesis in S. cerevisiae. The evaluation of a de novo proteome in comparison to a conventional steady-state proteome has the advantage to illustrate the effects of translational rearrangements taking place in response to environmental changes more directly. The effective induction of aa-starvation conditions by $10 \mathrm{mM} 3 \mathrm{AT}$ was verified at the level of translational regulation via eIF2-phosphorylation (Figure 2A). The amount of phosphorylated eIF2 $\alpha$ was determined to be four times higher under aa-starvation than non-starvation conditions. The data was normalized against the total eIF2 amount in the cell. The consequential reduction in overall protein biosynthesis and successful incorporation of radioactively labeled methionine during translation could be monitored via scintillation counting (Figure 2B). Cell lysis by Y-PER ${ }^{\circledR}$ Plus reagent resulted in a soluble and insoluble fraction. For both fractions aa-starvation leads to a reduction in de novo protein biosynthesis by approximately $50 \%$.

A

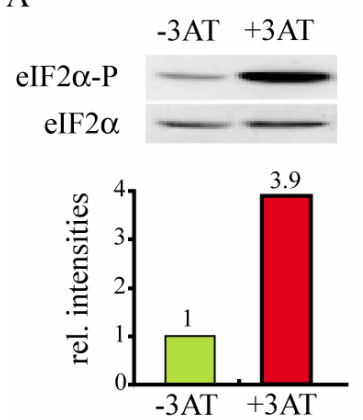

B

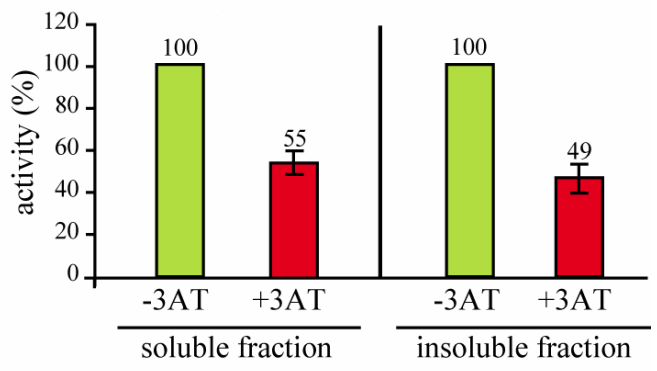

Figure 2. Verification of aa-starvation induced eIF2-phosphorylation and reduced protein biosynthesis by supplementation with $10 \mathrm{mM} 3 \mathrm{AT}$. (A) Immuno-detection of phosphorylated eIF $2 \alpha$. eIF $2 \alpha-\mathrm{P}$ was detected by specific antibody. Signals were quantified and normalized against total eIF2 $\alpha$ levels detected with anti-eIF2 $\alpha$ antibody under non-starvation (-3AT) and aa-starvation (+3AT) conditions. (B) Scintillation counting. Relative activities of protein-incorporated radioactive ${ }^{35} \mathrm{~S}$-methionine were measured. The activity for the soluble fraction was normalized against the total protein content of the respective extract as determined by BCA protein assay. The activity of the insoluble fraction was normalized against the mass of the respective pellet. The data shown results from five independent experiments. 
The radioactive labeling of proteins by ${ }^{35} \mathrm{~S}$-methionine during translation enables the generation of autoradiographies from 2D-gels (Figure 3). In comparison to the silver-stained gels, the autoradiographies only illustrate proteins that were synthesized when aa-starvation conditions were already induced. Their analysis therefore results in a more precise image of the changes in protein biosynthesis mediated by the addition of 3AT since the effects are not diluted by the proteome present prior to the induction of starvation.
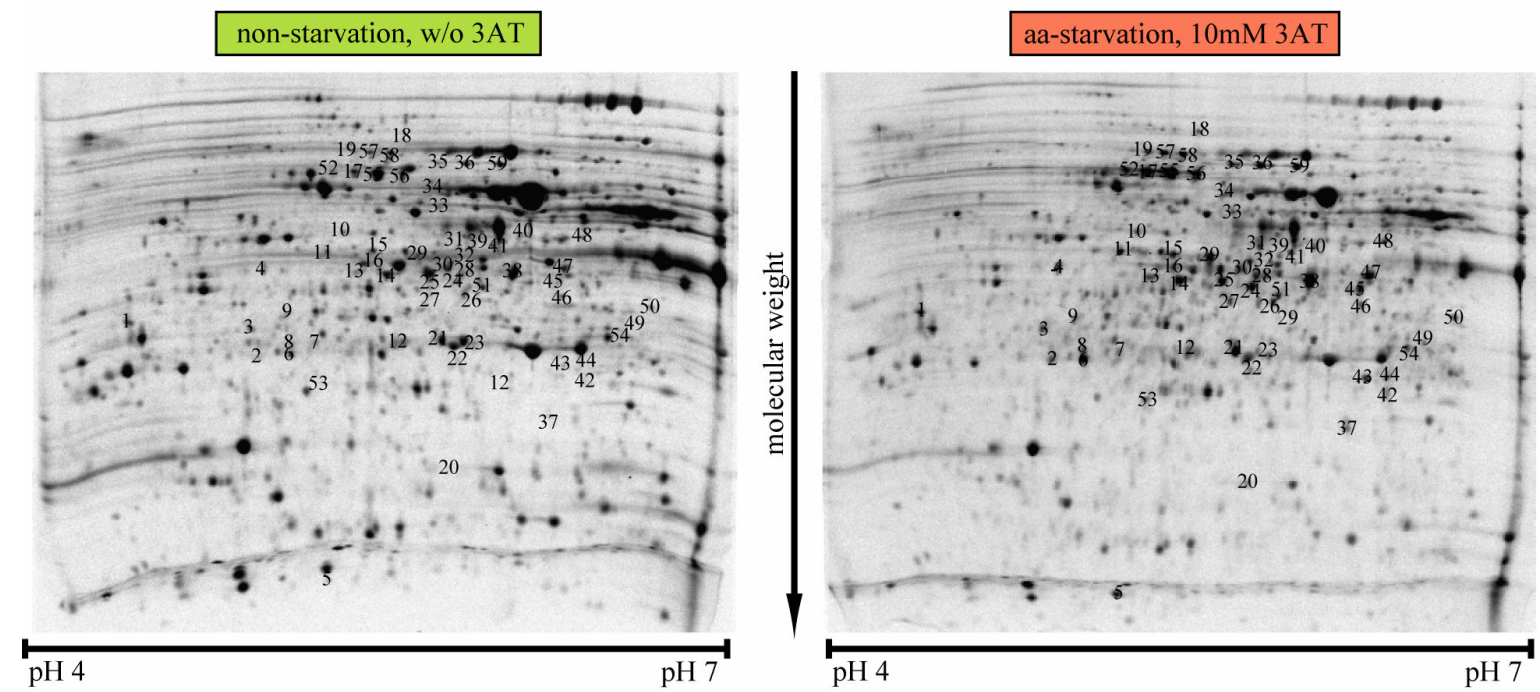

Figure 3. De novo proteome of the soluble cell fraction obtained under non-starvation (w/o 3AT) and aa-starvation (10mM 3AT). Autoradiographies corresponding to 2D-PAGE (Supplementary Figure 1) of ${ }^{35} \mathrm{~S}$-methionine radioactively labeled proteins. The numbers indicate excised protein-spots with an enhanced intensity under aa-starvation conditions.

Our 2D-analysis was conducted on the basis of five biological replicates. It revealed a total number of 31 proteins, which showed an up-regulation under aa-starvation conditions (Figure 4). The corresponding proteins can be assigned to several biological functions and take part in cellular processes like amino acid biosynthesis, glycolysis, oxidative stress response, and cell biogenesis. The fold changes $\left({ }^{+3 \mathrm{AT}} /-3 \mathrm{AT}\right)$ for the up-regulated protein-spots were determined by the analysis of the autoradiographies via PDQuest ${ }^{\mathrm{TM}}$ and range from 1.10 for Grx1p to 9.93 for Bnalp. The obtained proteome data was compared with transcriptome data generated under similar conditions of non-starvation and aa-starvation (10mM 3AT, 8h) (Kleinschmidt et al., 2005) (Figure 4). 


\begin{tabular}{|c|c|c|c|c|}
\hline \multirow[t]{2}{*}{ candidate } & \multicolumn{3}{|c|}{ transcriptome $^{\mathrm{a}}$} & \multirow{2}{*}{$\begin{array}{c}\text { confidence } \\
\text { factor } \\
\text { proteome/transcriptome } \\
x \\
\text { frequency }\end{array}$} \\
\hline & $+3 \mathrm{AT} /-3 \mathrm{AT}$ & $\log _{10}$ & $+3 \mathrm{AT} /-3 \mathrm{AT}$ & \\
\hline Tpi1 & 0.87 & $-0.06 \square$ & 3.76 & 25.9 \\
\hline Cpc2/Asc1 & 0.76 & $-0.12 \longleftarrow$ & 4.23 & 22.3 \\
\hline Fba1 & 1.00 & $\boldsymbol{C}^{0.79}$ & 6.22 & 12.4 \\
\hline Ipp1 & 0.99 & 0.34 & 2.19 & 8.9 \\
\hline Ald6 & 0.77 & $-0.11 \sqsubset$ & 3.21 & 8.3 \\
\hline Rhr2 & 0.87 & $-0.06 \sqrt{-1}$ & 4.47 & 5.1 \\
\hline Ilv5 & 0.93 & -0.03 口" & 2.15 & 4.6 \\
\hline Pgk1 & 0.60 & $\mathbf{C}^{0.40}$ & 2.54 & 4.2 \\
\hline Fpr1 & 0.89 & -0.05 口 & 3.37 & 3.8 \\
\hline Trp5 & 0.83 & $-0.08 \square$ & 1.54 & 1.9 \\
\hline Ahp1 & 0.97 & -0.01 年 & 1.70 & 1.8 \\
\hline Eno1 & 0.79 & $-0.10 \sqsubset \square^{0.10}$ & 1.25 & 1.6 \\
\hline Grx1 & 0.99 & ${ }_{0} \boldsymbol{P}^{0.04}$ & 1.10 & 1.1 \\
\hline Tdh3 & 1.24 & $\nabla 0.09$ & 4.21 & 34.0 \\
\hline Rib5 & 1.23 & 0.65 & 4.48 & 32.8 \\
\hline Arg1 & 1.65 & $\begin{array}{ll} & 0.22 \\
\end{array}$ & 3.09 & 31.8 \\
\hline Aro8 & 1.45 & $\Longrightarrow 0.16$ & 3.39 & 28.1 \\
\hline Bna1 & 2.08 & ${ }^{1.0}$ & 9.93 & 19.1 \\
\hline Yhr029c & 2.16 & ${ }^{0.91}$ & 8.08 & 18.7 \\
\hline His7 & 3.28 & 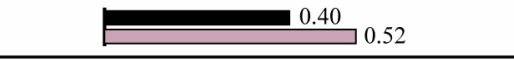 & 2.49 & 9.8 \\
\hline Ecm 40 & 1.28 & $\square_{0.20} 0.36$ & 2.30 & 7.2 \\
\hline Thr1 & 1.43 & $\square_{0.16}^{0.33}$ & 2.13 & 6.0 \\
\hline Hor2 & 1.29 & $\square 0.11$ & 3.41 & 5.3 \\
\hline Ccp1 & 1.72 & $\begin{array}{r}0.24 \\
\end{array}$ & 1.96 & 3.4 \\
\hline Ubc13 & 1.13 & $\square_{0.05}^{0.25}$ & 1.79 & 3.2 \\
\hline Sod2 & 1.22 & $\square_{0.11}^{0.37}$ & 2.34 & 1.9 \\
\hline Bmh2 & 1.13 & $\square_{0.05} 0.26$ & 1.83 & 1.6 \\
\hline Pdc1 & 1.04 & $\overline{\square_{0.02}} 0.17$ & 1.47 & 1.4 \\
\hline His1 & 1.60 & 0.20 & 2.23 & 1.4 \\
\hline Ade 1 & 2.04 & $0.31{ }^{0.45}$ & 2.80 & 1.4 \\
\hline Gev3 & 1.83 & 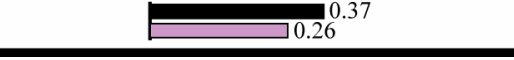 & 2.37 & 1.3 \\
\hline
\end{tabular}

Figure 4. Comparison of proteome and transcriptome data generated to monitor effects of aa-starvation conditions. All candidates listed were found to be up-regulated upon aa-starvation in the proteome analyses (see Supplementary Table 2 for corresponding protein names/functions and 
Supplementary Table 3 for data on protein sequence identification). The transcriptome data used in this comparison has been obtained under similar conditions ( ${ }^{a}$ Kleinschmidt et al., 2005). Transcriptome as well as proteome changes induced by aa-starvation conditions are displayed as the quotient of spot-intensity under aa-starvation to spot-intensity under non-starvation conditions $\left({ }^{+3 \mathrm{AT}} /-3 \mathrm{AT}\right)$. To clearly illustrate up- and downregulation, transcriptome and proteome changes are visualized logarithmically in a horizontal histogram. The last column represents the 'confidence factor' which is composed of the fold change $\left({ }^{+3 \mathrm{AT}} / \mathrm{-}_{-3 \mathrm{AT}}\right)$ of the proteome relative to that of the transcriptome and further including the frequency to which a candidate has been identified within the proteome analysis.

For more than half of the candidates with elevated protein-spot intensities under aa-starvation conditions an up-regulation could also be found on their mRNA-level (Figure 4, bottom part of chart). This comparison shows that the underlying regulation for these candidates is most likely to be found on the level of transcription even though an additional post-transcriptional regulation is not excluded. For the remaining thirteen identified proteins a comparison of their proteome fold change with the fold change of their mRNA levels $\left({ }^{+3 \mathrm{AT} /} / \mathrm{-AT}_{\mathrm{AT}}\right)$ revealed that a post-transcriptional regulation can be assumed. Their spot-intensities are elevated under aa-starvation conditions, whereas their corresponding mRNA levels either stay the same or are down-regulated when aa-starvation is induced (Figure 4, top part of chart). Due to this discrepancy in the transcriptome and proteome changes, these candidates are of specific interest in this study and define the base for further investigations. A 'confidence factor' is created as a means to facilitate the assessment of a candidate's potential to be post-transcriptionally regulated. It factors in the determined de novo proteome changes under aa-starvation conditions in context with the transcriptome changes. Furthermore the frequency by which a protein could be identified in the five biologically independent replicates is accounted for since a candidate's reliability enhances with the number of its identifications. When applying the confidence factor to rank the identified proteins, Tpilp can be found on top of the list of post-transcriptionally up-regulated candidates with a confidence factor of 25.9. In part this is due to its identification in most of the five replicates. In some analyses multiple proteinspots corresponded to Tpilp, indicating that various processed forms of Tpilp are more abundant under aa-starvation conditions. Fba1p on the other hand shows the highest de novo proteome changes among post-transcriptionally regulated candidates $\left({ }^{+3 \mathrm{AT}} / \mathrm{-}_{-3 \mathrm{AT}}=6.22\right)$ but could only be identified from two protein-spots in the analyses. This is reflected by its confidence factor of 12.4 , which reduces its rank. 


\section{Novel testing system to monitor translational regulation mediated by 5'UTRs}

Translational control of individual mRNAs often depends upon the sequential characteristics and/or structural features of the transcript itself. Primarily 5'UTRs are known to contain a variety of elements with a regulatory effect on the translation of their mRNAs (Day and Tuite, 1998). This encouraged us to develop a straightforward testing system to enable the identification of 5'UTR sequences altering translation (Figure 5A).

A
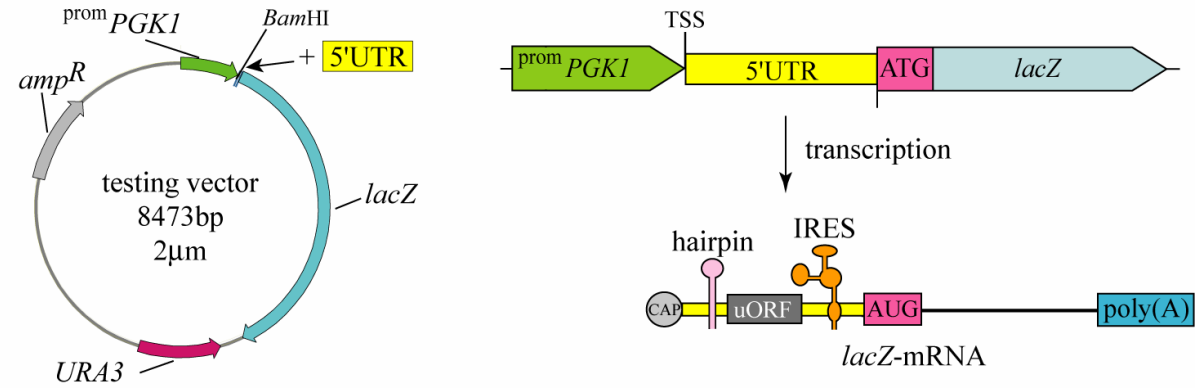

B

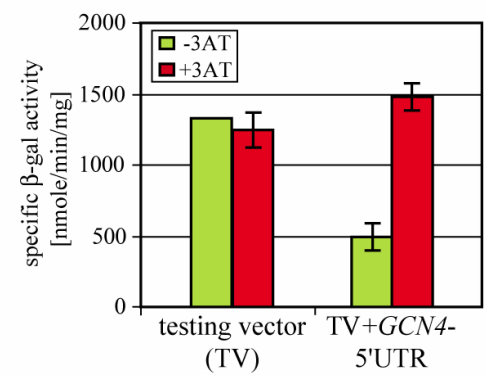

Figure 5. Reporter-testing system to analyze 5'UTRs regarding their impact on translational regulation of lacZ-expression measured by $\boldsymbol{\beta}$-galactosidase assay. (A) Scheme of testing system. The testing vector is a $2 \mu \mathrm{m}$ yeast-E.coli shuttle vector carrying selectable marker genes for E. coli and yeast $\left(a m p^{R}\right.$ and $U R A 3$, respectively), the constitutive $P G K 1$-promoter with a defined transcription start site (TSS) and a lacZ-reporter gene. A BamHI restriction site in between promoter and reporter gene facilitates the integration of arbitrary 5'UTRs. Possible incorporated translationally regulative elements are depicted within the 5'UTR of the lacZ-mRNA, such as hairpin structures, upstream open reading frames (uORFs) and internal ribosome entry sites (IRES). (B) Proof-of-principle for the testing system. $\beta$-galactosidase assay performed with yeast cells carrying the empty testing vector (standard control) or the testing vector with incorporated GCN4-5'UTR (functional control). Cells were grown in the presence (+3AT) or absence (-3AT) of $10 \mathrm{mM} 3 \mathrm{AT}$. 
Translational changes are monitored via $\beta$-galactosidase assay. 5'UTRs of interest can be inserted in between the constitutive $P G K 1$-promoter and the lacZ-reporter gene of the testing vector via restriction site. Subsequent transcription consequently results in a lacZ-mRNA carrying the incorporated 5'UTR as its own (Figure 5A). A well-studied example of an mRNA being regulated translationally according to the availability of amino acids is the transcript of GCN4. Its 5'UTR contains four uORFs responsible for a repressed translation of the GCN4-mRNA under non-starvation conditions, whereas they lead to an enhanced translation under aa-starvation conditions when overall translation is compromised (Hinnebusch, 1993). This aa-dependent regulation enables the usage of the GCN4-5'UTR as functional control in the $\beta$-galactosidase assays performed with the described testing system. We could successfully transfer the effects on translation described for the GCN4-5'UTR on its own mRNA to the lacZ-reporter mRNA by incorporating the GCN4-5'UTR in the testing vector (TV) (Figure 5B). Its introduction leads to a reduced $\beta$-galactosidase activity under non-starvation conditions (-3AT) compared to the empty TV without 5'UTR. This impeding effect is derepressed upon the induction of aa-starvation $(+3 \mathrm{AT}, 10 \mathrm{mM})$, resulting in an enhanced $\beta$-galactosidase activity. No aa-dependent differences in $\beta$-galactosidase activity could be monitored for the empty TV (w/o 5'UTR, standard control) (Figure 5B). This shows that the effects observed by the testing system can be clearly assigned to the introduced 5'UTR sequence alone.

The 5'UTRs to be analyzed via the testing system are composed of the thirteen candidates post-transcriptionally up-regulated in their biosynthetic activity upon aa-starvation conditions (Figure 4, top part). The lengths of the respective candidate-5'UTRs were determined according to a previously generated tiling array transcriptome analysis of Saccharomyces cerevisiae (David et al., 2006) (www.ebi.ac.uk/huber-srv/queryGene, Table 2). The cloned 5'UTR sequences were sequenced and are displayed in Supplementary Table 1. For most of the 5'UTR sequences inserted in the TV an increase in $\beta$-galactosidase activity can be monitored under non-starvation (-3AT) as well as under aa-starvation (+3AT) conditions. It reaches up to sixteen-fold relative to the empty TV suggesting a general promotion of translation by the respective 5'UTRs (representative 5'UTR effects shown in Figure 6A and C). 
A

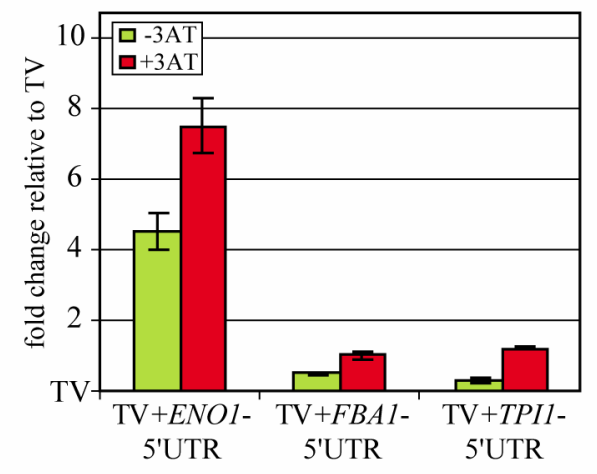

B

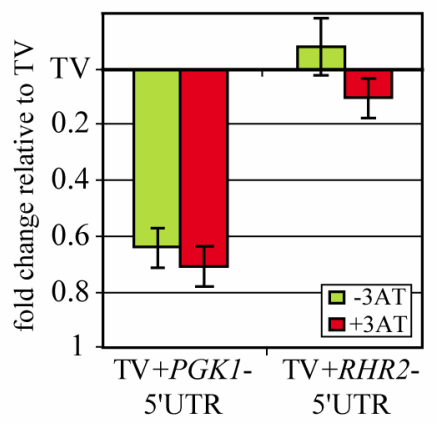

C

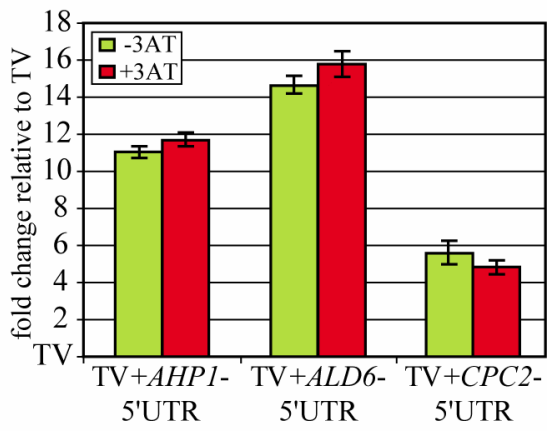

Figure 6. $\beta$-galactosidase assays displaying the effects of candidate-5'UTRs on lacZ-reporter activity dependent on aa-availability. The three observed effects on lacZ-expression are illustrated in (A) enhanced expression $\mathrm{w} /$ additional positive 3AT effect, (B) reduced expression w/o significant 3AT effect and (C) enhanced expression w/o significant 3AT effect. $\beta$-galactosidase activities were normalized to respective plasmid copy numbers (Supplementary Figure 2) and are displayed relative to the testing vector without 5 'UTR under the respective conditions.

The plasmid copy numbers of each construct incorporated in the wild type yeast cells were determined under non-starvation and aa-starvation conditions (Supplementary Figure 2). The resulting numbers were incorporated in the $\beta$-galactosidase assay data shown for the empty TV (Figure 5B) and respective 5'UTRs inserted (Figure 5B and 6) to account for any differences. The TSS for each vector including controls (TV w/o 5'UTR, TV+GCN45'UTR) were mapped by 5'RACE under both aa-availability conditions (Figure 7). This ensures that the differential $\beta$-galactosidase activities for the integrated ENO1-, FBA1-and TPI1-5'UTR are not due to the utilization of different transcription start sites (TSS) favored under the respective condition. The main TSS for the empty TV (w/o 5'UTR) was mapped at -7 related to the last base of the $P G K 1$-promoter sequence set to $0 .-7$ also serves as main TSS for the TV with the GCN4- and ENO1-5'UTR inserted. A TSS at -7 or 
in its proximity could also be found when the FBAl- and TPII- 5'UTR were inserted in the TV but it is not used as main TSS. Under non-starvation and aa-starvation conditions the main TSS for both constructs was mapped within their 5'UTR sequence, for FBA1 around position +33 and for the TPI1-5'UTR-construct around position +16 .

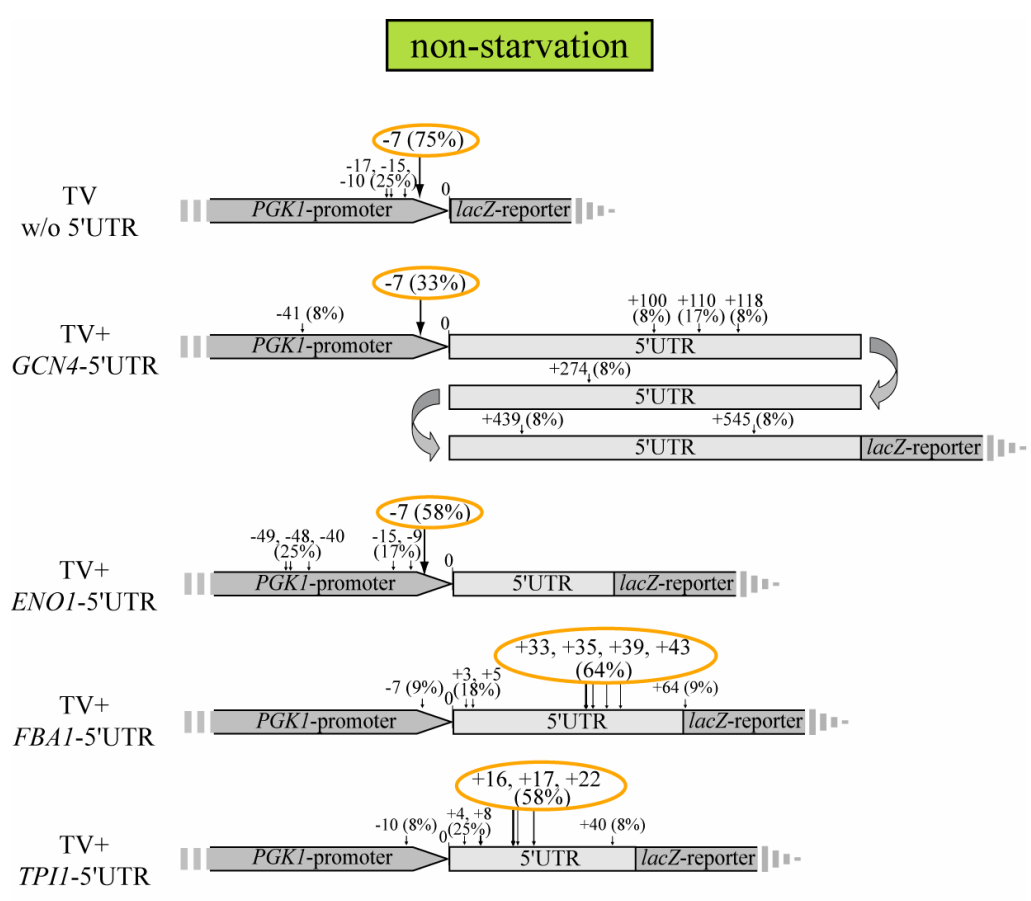

aa-starvation (10mM 3AT)

TV

w/o 5'UTR
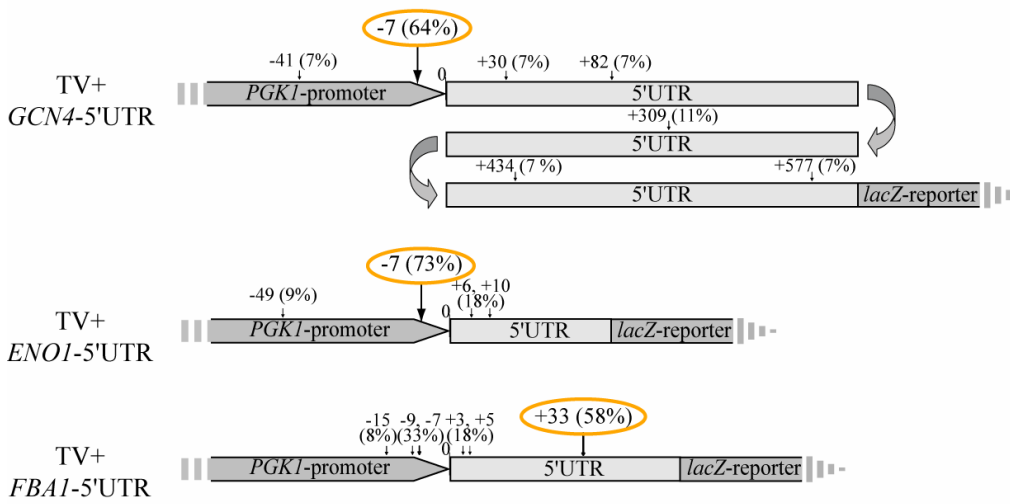

$\mathrm{TV}+$ TPI1-5'UTR
Figure 7. Illustration of transcription start sites (TSS) mapped by 5'RACE. Determination of the lacZreporter-gene TSS was performed for the testing vector without 5'UTR as well as for the reporter constructs with the respective 5'UTRs. The cells hosting the vectors were grown under non-starvation conditions or aa-starvation induced by $10 \mathrm{mM}$ 3AT. Each construct is displayed with the 5'UTR lengths as cloned for the evaluation via testing system (see Table 2).

The experimentally mapped TSS by 5'RACE are indicated by arrows with the percentages by which they were found and their exact position in relation to the last bp of the promoter (set to 0 ) and the first bp of the respective 5'UTR (set to 1). The main TSS determined for each construct and condition is encircled. 
Although there is not one common main TSS for all constructs, the respective main TSS mapped are independent of aa-availability. This results in the identical mRNAs entering translation under non-starvation as well as under aa-starvation conditions for the respective construct. These findings argue for a translational regulation underlying the measured increase of $\beta$-galactosidase activity from non-starvation to aa-starvation for the 5'UTRs of ENOI, FBAI and TPII.

\section{Correlation between de novo biosynthesis and total protein amount of candidate- proteins within the cell}

In this study we chose the method of metabolically labeling proteins by ${ }^{35} \mathrm{~S}$-methionine in the course of translation. The successive analysis of the respective autoradiographies discloses changes in the de novo protein biosynthesis dependent on aa-availability. This represents a very sensitive approach that enables the visualization of even subtle changes in the de novo biosynthesis for a specific protein. At this time point changes in its total protein amount within the cell might not be detectable yet. Among the proteins identified to be more efficiently synthesized under aa-starvation conditions are Eno1p, Fba1p and Tpi1p (Figure 8).

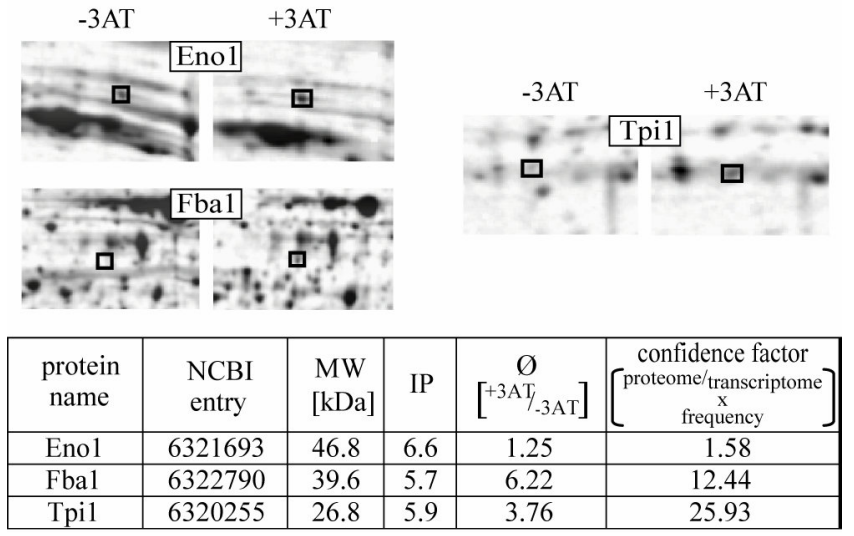

Figure 8. Autoradiographies of 2D-spots of candidates showing a significant aa-specific effect in $\boldsymbol{\beta}$-galactosidase assays. Close-up views of radioactive protein-spots assigned to the noted protein identified by LC-MS/MS, illustrating their relative changes upon induction of aa-starvation by $3 \mathrm{AT}$. For each of the displayed proteins an average value of the relative quantification $\left(\varnothing\left[{ }^{+3 \mathrm{AT}} / \mathrm{-}_{-3 \mathrm{AT}}\right]\right)$ resulting from five independent analyses is given along with information about molecular weight (MW) and isoelectric point (IP). The 'confidence factor' results from data displayed in Figure 4. 
The results obtained via testing system further suggest an underlying translational regulation mediated by their respective 5'UTR. They were found to positively influence lacZ-expression when amino acids are scarce. In a next step we were interested in how strong these translational changes are and whether they might already be reflected in elevated total protein amounts of Eno1p, Fba1p, and Tpilp after 90min of aa-starvation. It is to mention that these candidates are proteins of high abundance. Changes in their de novo biosynthesis might be masked for quite some time by the immense amount of protein already present in the cell before their impact is detectable by conventional western hybridization. In the performed 2D-western experiments several processed forms can be detected for all three proteins. All forms seem to underlie the same regulatory effect upon aa-starvation according to their uniform change in abundance (Figure 9A).

A
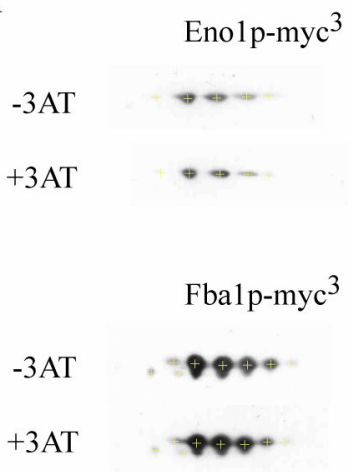

Tpilp

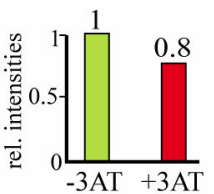

B
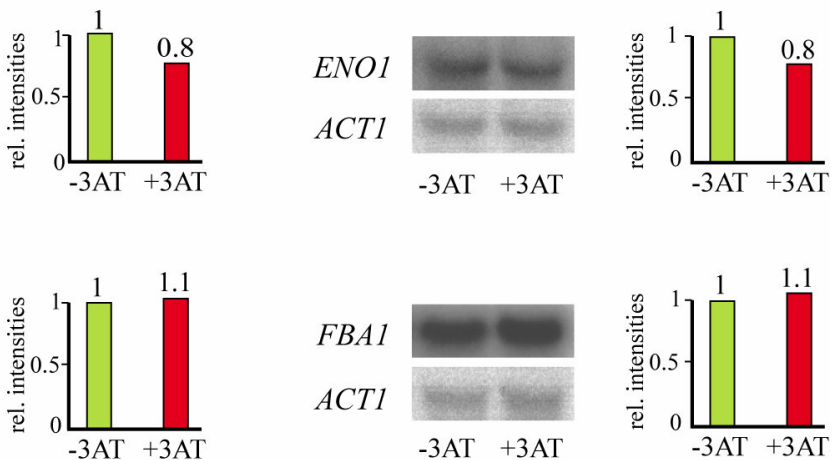

FBA1

$A C T 1$
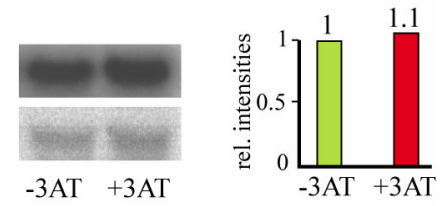

TPII

$A C T 1$
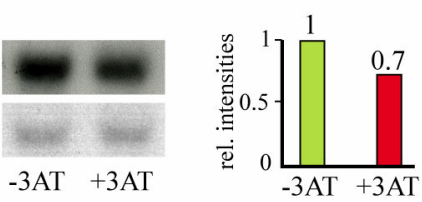

Figure 9. Total protein- and mRNA-amount of candidates, determined under non-starvation (-3AT) and aa-starvation (+3AT) conditions. (A) Western hybridizations. myc ${ }^{3}$-tagged variants of the candidateproteins Enolp and Fbalp were hybridized to anti-myc antibody, whereas Tpilp was detected by specific antibody. For quantification the total intensity of all spots marked by crosshairs under the respective condition was determined. (B) Northern hybridizations. mRNA amounts for ENOI, FBAl and TPII were determined. ACT1 served for quantification and as loading control.

The adjacent graphs illustrate the fold changes relative to the signal strengths under non-starvation conditions, respectively. Cells were grown to exponential phase before further incubation for $90 \mathrm{~min}$ in absence $(-3 \mathrm{AT})$ or presence $(+3 \mathrm{AT})$ of $10 \mathrm{mM} 3 \mathrm{AT}$. 
The determined total protein amounts of myc-tagged Enolp and Fba1p are not significantly increased under aa-starvation conditions. This suggests that the existing changes in their de novo protein biosynthesis are not extensive enough to effectively influence their total protein amount after $90 \mathrm{~min}$ of treatment with $10 \mathrm{mM} 3 \mathrm{AT}$. Another possibility might be that protein degradation for these candidates is more rapid under aastarvation conditions than their increase in de novo biosynthesis. Nevertheless the evidence of a post-transcriptional regulation of Enolp and Fba1p, which was obtained via proteome and testing system, suggests that their total protein amount is subject to enhancement upon a longer induction of aa-starvation conditions. For Tpilp on the other hand a significant increase in total protein could be determined even after only 90min of growth under aa-starvation conditions. This implies a considerable enhancement in the translational rate of the TPII-mRNA upon induction of starvation, quickly enlarging the pool of available Tpilp in the cell. In the proteome analysis of radioactively labeled protein extracts Tpilp was identified with an average up-regulation of 3.76 from non-starvation to aa-starvation conditions. This is similar to the up-regulation of total Tpilp amount in the cell with a factor of 3.3 determined via 2D-western experiment. Furthermore the highest confidence factor among post-transcriptionally regulated candidates could be assigned to Tpilp and the measured effects from non-starvation to aa-starvation conditions in the $\beta$-galactosidase assays were the highest when the TPI1-5'UTR was inserted in the testing vector with a factor of 4.1. Taken together, these findings strongly suggest an aa-dependent translational regulation of Tpilp biosynthesis mediated by elements in its 5'UTR. The resulting effects prove to be significant enough to affect the total Tpilp amount in the cell even after a short period of time.

To illustrate that the mRNA-levels of ENOI, FBAI and TPII are not significantly up-regulated when aa-starvation is induced northern hybridizations were performed (Figure 9B). For all three candidates the obtained fold changes of their mRNA-levels from non-starvation to aa-starvation resemble, and therefore confirm, the microarray data used in this study. 


\section{Regulative 5'UTR sequences are A-rich and weakly folded}

Additionally to the experimental evaluation of the candidate-5'UTRs, they were analyzed bioinformatically. A first comparison of the respective thirteen 5'UTRs with each other revealed no distinct structural features or obvious consensus sequences, suggesting other elements in the 5'UTRs to be responsible for the effects monitored in the performed $\beta$-galactosidase assays. The lengths of the analyzed 5'UTR sequences are slightly shorter than the average length of 89 nucleotides (nt) determined for 5'UTRs in yeast. They rather agree with the majority of yeast-5'UTRs, measuring less than 50nt in length (Lawless et al., 2009) (Table 2).

Table 2. Core information of bioinformatical 5'UTR-analysis. For every analyzed 5'UTR sequence its minimal free energies (MFEs) were determined by RNALFOLD (see Supplementary Table 4) and the respective greatest negative MFE (minMFE) is listed here. Start point and length of the corresponding secondary structure predicted are denoted with position 1 matching the first nucleotide of the respective 5'UTR at its 5'end. The GC- and A-content for each 5'UTR sequence are given in percentage. An increase in A-content of at least $20 \%$ within the last $25 \mathrm{nt}$ of the 5'UTR is indicated by asterisks.

\begin{tabular}{|c|c|c|c|c|c|c|c|}
\hline mRNA & $\begin{array}{c}\text { length of } \\
\text { 5'UTR [nt] }\end{array}$ & $\begin{array}{c}\text { min MFE } \\
{[\mathbf{k c a l / m o l ]}}\end{array}$ & $\begin{array}{c}\text { start of } \\
\text { structure }\end{array}$ & $\begin{array}{c}\text { length of } \\
\text { structure [nt] }\end{array}$ & $\begin{array}{c}\text { GC-content } \\
{[\%]}\end{array}$ & $\begin{array}{c}\text { A-content } \\
{[\%]}\end{array}$ & $\begin{array}{c}\text { A-content } \\
\text { last 25nt } \\
{[\%]}\end{array}$ \\
\hline$A H P 1$ & 49 & - & - & - & 35 & 53 & 52 \\
\hline$A L D 6$ & 65 & -0.63 & 1 & 42 & 26 & 52 & 52 \\
\hline$A S C 1$ & 34 & -1.9 & 11 & 21 & 24 & 53 & 60 \\
\hline$E N O 1$ & 38 & - & - & - & 34 & 50 & $60^{*}$ \\
\hline$F B A 1$ & 56 & - & - & - & 25 & 32 & $52^{*}$ \\
\hline$F P R 1$ & 31 & - & - & - & 19 & 65 & 68 \\
\hline$G R X 1$ & 68 & -6.3 & 4 & 59 & 34 & 44 & $64^{*}$ \\
\hline$I L V 5$ & 91 & -7.9 & 17 & 44 & 26 & 47 & $64^{*}$ \\
\hline$I P P 1$ & 59 & -6.4 & 1 & 39 & 41 & 24 & 24 \\
\hline$P G K 1$ & 82 & -9.7 & 1 & 63 & 23 & 34 & $52^{*}$ \\
\hline$R H R 2$ & 53 & -1.5 & 4 & 24 & 24 & 46 & $56^{*}$ \\
\hline$T P I 1$ & 45 & - & - & - & 22 & 53 & $68^{*}$ \\
\hline$T R P 5$ & 47 & -5.2 & 8 & 35 & 47 & 38 & 40 \\
\hline
\end{tabular}

This rather short length of most candidate-5'UTRs is regarded as indicator for a facilitated translation (Lawless et al., 2009). Correspondingly elevated lacZ-expressions were achieved by all but two of the thirteen 5'UTR sequences evaluated via testing system. To determine the potential and characteristics of secondary structure formation the minimal free energies (MFEs) for each 5'UTR sequence were predicted (Supplementary Table 4). The predicted structures are considered more stable the greater their negative free energies 
are. The greatest negative free energy (minMFE) found within each respective 5'UTR is listed in Table 2 along with the start and length of the corresponding secondary structure. The structures predicted stretch from 21 to $63 \mathrm{nt}$ in length with an average of $41 \mathrm{nt}$. The corresponding average minMFE for the predicted secondary structures lies at $-4.9 \mathrm{kcal} / \mathrm{mol}$. The weakest MFE of $-0.63 \mathrm{kcal} / \mathrm{mol}$ was predicted for the $A L D 6-5$ ' UTR and the greatest for the $P G K 1-5$ 'UTR at $-9.7 \mathrm{kcal} / \mathrm{mol}$. No secondary structures were predicted for the 5'UTR sequences of AHP1, ENO1, FBA1, FPRI and TPI1. Even though the greatest minimal free energy was predicted for one of the longest 5'UTRs, belonging to the mRNA of PGK1 (82nt), there seems to be no obvious correlation between MFE gained from secondary structure formation and 5'UTR-length as far as this can be stated by this rather small group of 5'UTR sequences analyzed. Overall these findings imply a weak secondary structure formation for the candidate-5' UTRs. Additionally, a comparison of the stabilities of the mRNA structures formed by the candidate 5'UTRs in comparison to randomly computed sequences of the same length and dinucleotide composition was performed. The resulting z-score further confirms the lack of significant secondary structure formation in the candidate-5'UTRs (Supplementary Table 4). When evaluating the obtained structural information in combination with the data generated in the $\beta$-galactosidase assays it is striking that for all 5'UTRs, that show an aa-dependent up-regulation of translation in the reporter-assays, namely ENO1-, FBA1- and TPII5'UTR, no secondary structure could be predicted. This was only the case for two other 5'UTRs in the bioinformatical analysis (Table 2). Thus, the share of 5'UTRs without predicted secondary structure is well-above average for the group of 5'UTRs showing an aa-specific effect.

Furthermore the GC-content for each 5'UTR sequence was determined averaging at 29\% (Table 2). Interestingly this is consistent with the average GC-content found for the least stable structures in a genome-wide analysis of 5'UTRs in comparison to $47 \%$ for the most stable structures (Ringnér and Krogh, 2005). Also striking is the high amount of adenine bases contained in the analyzed 5'UTR sequences. It even further increases to over 50\% for all but two 5'UTRs proximal to the AUG translation initiation codon. For seven of the thirteen 5'UTR sequences this increase amounts to at least $20 \%$ including the 5'UTRs of ENO1, FBA1 and TPII (Table 2). 
Taken together our data indicates an up-regulation in the translational rate for the ENO1-, FBA1-, and TPII-mRNAs mediated by their respective 5'UTR. For TPII these effects are significant enough to induce substantial changes to the Tpilp pool within the cell even after a short period of time. The bioinformatical analysis suggests weak, A-rich 5'UTR sequences to be beneficial for translation efficiency. 


\section{Discussion}

Proteins that have so far been identified to be regulated by translational initiation mechanisms in S. cerevisiae belong to the group of low copy number effectors like the transcription factors Gcn4p or Flo8p (Hinnebusch, 1993; Gilbert et al., 2007). Due to our 2D-gel-based proteome approach all candidate-5'UTRs analyzed here belong to mRNAs of proteins of higher abundance. Most of the evaluated 5'UTRs in this study enhanced the lacZ-reporter expression and yielded weak secondary structures in the bioinformatical analysis or had no structure predicted at all like the TPI1-5'UTR. This is in agreement with the finding that 5'UTRs of highly abundant proteins generally possess weaker secondary structures resulting in an elevated translation initiation of their respective mRNAs (Ringnér and Krogh, 2005). In accordance, the rather strong secondary structure predicted for the PGK1-5'UTR might contribute to its repressing effect on the lacZ-reporter expression determined in the $\beta$-galactosidase assays.

Additionally to the mainly weak secondary structures predicted, another striking feature of the analyzed 5'UTRs is the high content of adenine. Adenine bases are especially dominant in proximity to the mRNA-initiation codon reaching up to $68 \%$ for the last $25 \mathrm{nt}$ of the unstructured TPI1-5'UTR, CTTGCTTAAATCTATAACTACAAAAAAACACATA CATAAACTAAAA (Table 2). Such unstructured poly(A) tracts in 5'UTR sequences have previously been shown to function as binding sites for the poly(A) binding protein (Pab1p). This binding is suggested to be able to substitute for cap and eIF4E in recruiting eIF4G for translation initiation, thus displaying an IRES event (Gilbert et al., 2007). Strong eukaryotic IRES have been linked to weak secondary structures, as they are present for most analyzed candidates in this study, and have been described to be predominantly located immediately upstream of the mRNA-initiation codon (Xia and Holcik, 2009). This context indicates a possible regulation via IRES for some of the candidates of this study. With special interest on the TPII-mRNA the respective candidate-5'UTR sequences should be further analyzed according to Pab1p-binding and IRES activity.

Amino acid-starvation conditions generally reduce the rate of translation initiation due to lower levels of the ternary complex (Hinnebusch, 2000). The translation of the distinct uORF-containing 5'UTR sequence of the GCN4-mRNA on the other hand is derepressed under aa-starvation conditions (Hinnebusch, 1993). This regulatory mechanism could be successfully reproduced via testing system in this study. Three of the candidate-5'UTRs, 
corresponding to proteins identified to be post-transcriptionally up-regulated upon aa-starvation, also showed an increased lacZ-expression in the $\beta$-galactosidase assays, namely those of ENOI, FBAI and TPII. It is striking that all of the corresponding proteins are glycolytic enzymes. Proteins engaged in the processes of carbohydrate metabolism have previously been suggested to be translationally up-regulated under aa-starvation conditions (Smirnova et al., 2005). These data support the results we gained from the $\beta$-galactosidase assays with the 5'UTRs of ENO1, FBAI and TPII. In the study of Smirnova and colleagues (2005) polysome and microarray analyses resulted in translation profiles, disclosing proteins with an enhanced translation when cells were starved for amino acids. The obtained data states an over-representation of proteins taking part in carbohydrate metabolism, which is speculated to occur in preparation for an elevated aabiosynthesis.

The testing system as it is described in this study displays a very strict screening tool. It aims to identify proteins regulated via translation solely mediated by their 5'UTR sequence. An interesting continuative approach could be to expand the current testing vector to enable the incorporation of not only the 5'UTR but also the 3'UTR of an mRNA to monitor their combined influence on lacZ-reporter expression. Apart from the known regulative function of 5'UTRs, roles in the regulation of translation initiation have also been described for the 3'UTR as well as for the ring formation of the mRNA. This formation is mediated by the interaction of 5'- and 3'-end via cap-binding protein complex (eIF4F) and Pab1p (Tarun and Sachs, 1995; Wells et al., 1998; Amrani et al., 2008). Thus, a comprehensive picture of the broad range of translational control mechanisms could be obtained by the described expansion of the testing system, since a synergy of 5 ' and 3' UTR has previously been suggested to be important for the establishment of correct translation (Gallie, 1991).

Taken together this study demonstrates a well-suited approach to identify translationally regulative 5'UTR sequences of abundant proteins by a combination of proteomics, transcriptomics as well as bioinformatical and molecular genetic tools. The presented testing system is not only applicable under various growth conditions but also suitable to compare the translational capabilities of different deletion mutants or strain backgrounds and therefore opens up the possibility to gain more insight into a proteins function within the cell. 


\section{Acknowledgement}

We especially thank Verena Pretz for her outstanding technical assistance. We cordially thank Thomas Dever and Alan Hinnebusch for providing the anti-eIF2 antibody and Jürgen Dohmen for providing the anti-Tpilp antibody. This project was supported by the Deutsche Forschungsgemeinschaft. 


\section{References}

Amrani, N., Ghosh, S., Mangus, D. A., and Jacobson, A. (2008) Translation factors promote the formation of two states of the closed-loop mRNP. Nature 453 (7199), 1276-1280.

Blum, H., Eyer, H., and Gross, H. J. (1987) Improved silver staining of plant proteins, RNA and DNA in polyacrylamide gels. Electrophoresis 8, 93-99.

Bradford, M. M. (1976) A rapid and sensitive method for the quantitation of microgram quantities of protein utilizing the principle of protein-dye binding. Anal Biochem $72,248-254$.

Clote, P., Ferre, F., Kranakis, E., and Krizanc, D. (2005) Structural RNA has lower folding energy than random RNA of the same dinucleotide frequency. RNA 11 (5), 578-591.

Cross, F. R., and Tinkelenberg, A. H. (1991) A potential positive feedback loop controlling CLN1 and CLN2 gene expression at the start of the yeast cell cycle. Cell 65 (5), 875-883.

David, L., Huber, W., Granovskaia, M., Toedling, J., Palm, C. J., Bofkin, L., Jones, T., Davis, R. W., and Steinmetz, L. M. (2006) A high-resolution map of transcription in the yeast genome. Proc Natl Acad Sci U S A 103 (14), 5320-5325.

Day, D. A., and Tuite, M. F. (1998) Post-transcriptional gene regulatory mechanisms in eukaryotes: an overview. J Endocrinol 157 (3), 361-371.

Eng, J. K., McCormack, A. L., and Yates III, J. R. (1994) An approach to correlate tandem mass spectral data of peptides with amino acid sequences in a protein database. J. Am. Soc. Mass Spectrom. 5, 976-989.

Gallie, D. R. (1991) The cap and poly(A) tail function synergistically to regulate mRNA translational efficiency. Genes Dev 5 (11), 2108-2116.

Gebauer, F., and Hentze, M. W. (2004) Molecular mechanisms of translational control. Nat Rev Mol Cell Biol 5 (10), 827-835.

Gilbert, W. V., Zhou, K., Butler, T. K., and Doudna, J. A. (2007) Cap-independent translation is required for starvation-induced differentiation in yeast. Science 317 (5842), 1224-1227. 
Harding, H. P., Novoa, I., Zhang, Y., Zeng, H., Wek, R., Schapira, M., and Ron, D. (2000) Regulated translation initiation controls stress-induced gene expression in mammalian cells. Mol Cell 6 (5), 1099-1108.

Hilton, J. L., Kearney, P. C., and Ames, B. N. (1965) Mode of action of the herbicide, 3-amino-1,2,4-triazole(amitrole): inhibition of an enzyme of histidine biosynthesis. Arch Biochem Biophys 112 (3), 544-547.

Hinnebusch, A. G. (1993) Gene-specific translational control of the yeast GCN4 gene by phosphorylation of eukaryotic initiation factor 2. Mol Microbiol 10 (2), 215-223.

Hinnebusch, A. G. (2000) Mechanism and regulation of initiator methionyl tRNA binding to ribosomes. Sonenberg, N., Hershey, J. W. B., and Mathews, M. B. (eds.), Translational Control of Gene Expression. Cold Spring Harbor Laboratory Press, 185-243.

Hinnebusch, A. G. (2005) Translational regulation of GCN4 and the general amino acid control of yeast. Annu Rev Microbiol 59, 407-450.

Hofacker, I. L., Fontana, W.,Stadler, P. F., Bonhoeffer, L. S., Tacker, M., and Schuster, P. (1995) Fast Folding and Comparison of RNA Secondary Structures. Monatshefte f. Chem. (125), 167-188.

Hofacker, I. L., Priwitzer, B., and Stadler, P. F. (2004) Prediction of locally stable RNA secondary structures for genome-wide surveys. Bioinformatics 20 (2), 186-190.

Hoffman, C. S., and Winston, F. (1987) A ten-minute DNA preparation from yeast efficiently releases autonomous plasmids for transformation of Escherichia coli. Gene 57 (2-3), 267-272.

Holcik, M., and Sonenberg, N. (2005) Translational control in stress and apoptosis. Nat Rev Mol Cell Biol 6 (4), 318-327.

Ito, H., Fukuda, Y., Murata, K., and Kimura, A. (1983) Transformation of intact yeast cells treated with alkali cations. J Bacteriol 153 (1), 163-168.

Janke, C., Magiera, M. M., Rathfelder, N., Taxis, C., Reber, S., Maekawa, H., Moreno-Borchart, A., Doenges, G., Schwob, E., Schiebel, E., and Knop, M. (2004) A versatile toolbox for PCR-based tagging of yeast genes: new fluorescent proteins, more markers and promoter substitution cassettes. Yeast 21 (11), 947-962. 
Kleinschmidt, M., Grundmann, O., Blüthgen, N., Mösch, H. U., and Braus, G. H. (2005) Transcriptional profiling of Saccharomyces cerevisiae cells under adhesioninducing conditions. Mol Genet Genomics 273 (5), 382-393.

Lawless, C., Pearson, R. D., Selley, J. N., Smirnova, J. B., Grant, C. M., Ashe, M. P., Pavitt, G. D., and Hubbard, S. J. (2009) Upstream sequence elements direct posttranscriptional regulation of gene expression under stress conditions in yeast. BMC Genomics 10, 7.

Livak, K. J., and Schmittgen, T. D. (2001) Analysis of relative gene expression data using real-time quantitative PCR and the $2^{-\Delta \Delta C}$ T Method. Methods 25 (4), 402-408.

Ringnér, M., and Krogh, M. (2005) Folding free energies of 5'-UTRs impact posttranscriptional regulation on a genomic scale in yeast. PLoS Comput Biol 1 (7), e72.

Rose, M., and Botstein, D. (1983) Construction and use of gene fusions to lacZ ( $\beta$-galactosidase) that are expressed in yeast. Methods Enzymol 101, 167-180.

Shevchenko, A., Wilm, M., Vorm, O., and Mann, M. (1996) Mass spectrometric sequencing of proteins silver-stained polyacrylamide gels. Anal Chem 68 (5), 850858.

Smirnova, J. B., Selley, J. N., Sanchez-Cabo, F., Carroll, K., Eddy, A. A., McCarthy, J. E., Hubbard, S. J., Pavitt, G. D., Grant, C. M., and Ashe, M. P. (2005) Global gene expression profiling reveals widespread yet distinctive translational responses to different eukaryotic translation initiation factor $2 \mathrm{~B}$-targeting stress pathways. Mol Cell Biol 25 (21), 9340-9349.

Tarun, S. Z., Jr., and Sachs, A. B. (1995) A common function for mRNA 5' and 3' ends in translation initiation in yeast. Genes Dev 9 (23), 2997-3007.

Valerius, O., Kleinschmidt, M., Rachfall, N., Schulze, F., López Marín, S., Hoppert, M., Streckfuss-Bömeke, K., Fischer, C., and Braus, G. H. (2007) The Saccharomyces homolog of mammalian RACK1, Cpc2/Asc1p, is required for FLO11-dependent adhesive growth and dimorphism. Mol Cell Proteomics 6 (11), 1968-1979.

Vattem, K. M., and Wek, R. C. (2004) Reinitiation involving upstream ORFs regulates ATF4 mRNA translation in mammalian cells. Proc Natl Acad Sci U S A 101 (31), 11269-11274. 
Wells, S. E., Hillner, P. E., Vale, R. D., and Sachs, A. B. (1998) Circularization of mRNA by eukaryotic translation initiation factors. Mol Cell 2 (1), 135-140.

Wessel, D., and Flügge, U. I. (1984) A method for the quantitative recovery of protein in dilute solution in the presence of detergents and lipids. Anal Biochem 138 (1), 141143.

Xia, X., and Holcik, M. (2009) Strong eukaryotic IRESs have weak secondary structure. PLoS One 4 (1), e4136.

Yaman, I., Fernandez, J., Liu, H., Caprara, M., Komar, A. A., Koromilas, A. E., Zhou, L., Snider, M. D., Scheuner, D., Kaufman, R. J., and Hatzoglou, M. (2003) The zipper model of translational control: a small upstream ORF is the switch that controls structural remodeling of an mRNA leader. Cell 113 (4), 519531. 


\title{
CHAPTER III
}

\section{Asc1p, a ribosomal protein in the abyss of cellular signaling}

\begin{abstract}
Asc1p and its orthologues in other organisms, as e.g. RACK1 in mammalian, have been discussed in several distinct cellular processes, but their function has never been assessed in a comprehensive manner.

This study reveals the major cellular processes affected in a Saccharomyces cerevisiae Aascl mutant background via ${ }^{35}$ S-methionine labeled de novo proteome study and transcriptome analysis, combined with subsequent phenotypical characterizations. The deletion of $A S C l$ reduces iron uptake, and alters energy metabolism, manifesting in a compromised respiration and elevated fermentation. Moreover, processes regulated by MAP kinase signal transduction pathways as invasive/filamentous growth, pheromone response and cell wall integrity are affected in the deletion strain. The observed effects can be linked to changes in protein abundances of Ste12p, Phd1p, Tec1p, Rap1p and Flo8p, some of the transcription factors involved in these processes. Evidence for their possible translational regulation suggests Asc1p to be involved in signal transduction pathways by controlling the biosynthesis of transcriptional regulators.
\end{abstract}




\section{Introduction}

The highly abundant WD40-repeat protein Asc1p of Saccharomyces cerevisiae was originally found as suppressor of the absence of growth phenotype of a heml ${ }^{-}$cypl $^{-}$strain, functionally placing it to the processes of respiration and fermentation (Chantrel et al., 1998). Polysome profiling early on suggested a role of Asc1p in translational control (Chantrel et al., 1998), an assumption that was strengthened later on as it was identified as integral component of the small 40S ribosomal subunit (Gerbasi et al., 2004). Further evidence for its implementation in ribosome function is the co-regulation of its gene expression with the bulk of ribosomal genes through the transcription factors Fhl1p and Ifh1p (Kleinschmidt et al., 2006). Further, the deletion of ASCl restores the growth of a $\Delta g c n 2$ strain on amino acid starvation-inducing medium (Hoffmann et al., 1999), establishing a genetic interaction between $A S C 1$ and the initiation of translation, which is regulated by the phosphorylation of the $\alpha$ subunit of eIF2A via Gcn2p. Additionally, the Gcn2p-dependent eIF2 phosphorylation has been shown to be increased in a $\Delta$ ascl background as well as the phosphorylation of the translation initiation factor eIF4A, an RNA helicase (Valerius et al., 2007). A function of Asc1p as monomeric protein beyond its ribosomal association can not be excluded and is supported by the finding that it functions as $G \beta$ subunit of the glucose-receptor coupled $G \alpha$ protein Gpa2p in the signal transduction pathway of invasive/pseudohyphal growth (Zeller et al., 2007). The analysis of variants of Asc1p reduced in ribosomal-binding revealed that previously described Asc1p-related processes differ in their dependence on Asc1p ribosome-association, suggesting a dual role for Asc1p within the cell as ribosomal and non-ribosomal protein (Coyle et al., 2009). Beyond interacting with a multitude of other proteins Asc1p specifically interacts with the mRNA-binding protein Scp160 (Gavin et al., 2002; Gavin et al., 2006). The interaction of Scp160p with the ribosome is dependent on Asc1p, suggesting a role for Asc1p as adapter protein, bringing specific mRNAs, translation factors and the ribosome in proximity (Baum et al., 2004). An extended Asc1p network (Smy2p, Eap1p, Scp160p and Asc1p, SESA network) has been identified to specifically inhibit the translation initiation of the POM34-mRNA, encoding an integral membrane protein of the nuclear pore complex (Sezen et al., 2009). Furthermore Asc1p has been proposed to support cell wall integrity (Valerius et al., 2007; Melamed et al., 2010). It is 
essential for the expression of the GPI-anchored cell wall flocculin Flo11p and the Flo11pdependent developmental processes of adhesive and filamentous growth (Valerius et al., 2007). Asc1p is highly conserved and its orthologues have been described to be involved in the development of several other organisms. In Schizosaccharomyces pombe $\mathrm{Cpc} 2 \mathrm{p} /$ Asc1p regulates sexual differentiation in a complex with Moc1p/Sds23p and Moc2p/Ded1p (Paul et al., 2009). RACK1, the orthologue of Asc1p in higher eukaryotes, is required for several developmental processes, including seed germination, root formation, leaf production and flowering in Arabidopsis thaliana (Chen et al., 2006; Guo et al., 2009). Studies in Drosophila melanogaster revealed RACK1 to be expressed in many tissues with a specific requirement at multiple steps of development (Kadrmas et al., 2007). RACK1 in mammals is involved in various processes, such as cell proliferation and cell cycle (Hermanto et al., 2002). Furthermore, RACK1 is involved in apoptosis and contributes to tumor growth in vivo (Zhang et al., 2008; Mamidipudi and Cartwright, 2009). It is up-regulated during angiogenesis and in colon carcinoma, non-small cell lung carcinoma (Berns et al., 2000) and melanomas (López-Bergami et al., 2005). Whereas the deletion of $A S C 1$-orthologues in higher eukaryotes as plants and mammals is lethal at early developmental stages (Guillemot et al., 1989) it is not essential in yeast. This makes yeast a valuable model organism to study the effects of an $A S C l$ deletion and to unveil its cellular and molecular function.

This study delivers the first comprehensive proteome and transcriptome analysis of a $\Delta a s c 1$ strain. Together with phenotypical characterizations it delivers functional groups of proteins/mRNAs with an altered expression in response to the deletion of ASC1 and determines cellular processes affected. This work demonstrates that Asc1p controls the abundances of transcription factors involved in the MAPK signaling pathways of invasive/pseudohyphal growth and pheromone response. Furthermore, cell wall integrity, regulated by the Pkc1-MAPK pathway, as well as iron uptake and energy metabolism are misregulated in a $\Delta a s c 1$ mutant. 


\section{Materials and Methods}

Yeast strains and growth conditions - The Saccharomyces cerevisiae strains used in this work are of $\Sigma 1278 \mathrm{~b}$ background and are listed in Table 1. Strain RH3428 was derived from strain RH2816 by deleting the ASC1 gene with a URA3 cassette as described in Gueldener et al. (2002). The strains RH3429 - RH3436 were generated by C-terminally tagging HBN1, YHB1, PHD1 and FLO8 with 3xmyc, respectively, according to Janke and colleagues (2004). Transformations were carried out according to the lithium acetate method (Ito et al., 1983). Cultures were grown at $30^{\circ} \mathrm{C}$ overnight in $10 \mathrm{ml}$ liquid minimal medium (YNB) containing respective supplements, diluted and cultivated in main cultures to midlog phase before isolation of protein extracts. Experiment-specific growth conditions are given in the respective paragraphs.

Table 1. S. cerevisiae strains used in this work.

\begin{tabular}{|c|c|c|}
\hline strain & genotype & reference \\
\hline RH2817 & MAT $\alpha$, ura3-52, trp1::hisG & Valerius et al., 2007 \\
\hline RH3263 & 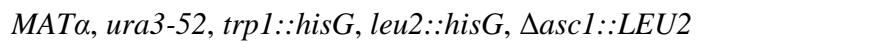 & Valerius et al., 2007 \\
\hline RH2681 & MATa, ura3-52, trp1::hisG, $\Delta$ flo11::kanMX4 & Braus et al., 2003 \\
\hline RH3428 & MATa, ura3-52, trp1::hisG, $\triangle a s c 1:: U R A 3$ & This work \\
\hline RH3429 & MAT $\alpha$, ura3-52, $\operatorname{trp} 1: \because h i s G, P H D 1-\mathrm{myc}^{3}$ & This work \\
\hline RH3430 & 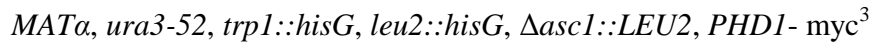 & This work \\
\hline RH3431 & MAT $\alpha$, ura3-52, $\operatorname{trp} 1:: h i s G$, FLO8- myc ${ }^{3}$ & This work \\
\hline RH3432 & 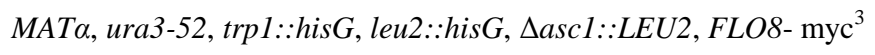 & This work \\
\hline RH3433 & MAT $\alpha$, ura3-52, $\operatorname{trpl}: \because h i s G, H B N 1-\mathrm{myc}^{3}$ & This work \\
\hline RH3434 & 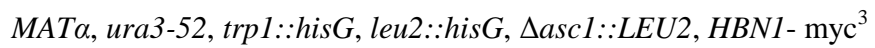 & This work \\
\hline RH3435 & MAT $\alpha$, ura3-52, $\operatorname{trp} 1:: h i s G, Y H B 1-\mathrm{myc}^{3}$ & This work \\
\hline RH3436 & 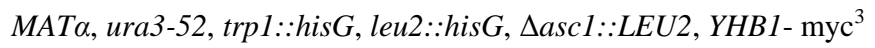 & This work \\
\hline
\end{tabular}

Plasmid construction - All plasmids used in this study are listed in Table 2. The reporter plasmid (pME3680) is a derivative of the cloning vector YEp355. It contains the constitutive PGK1-promotor, followed by a BamHI restriction site and the lacZ-reporter gene (Rachfall et al., under revision). To construct plasmids 'pME3751 - pME3755' the lengths of the 5'UTRs of respective transcription factors were determined (David et al., 
2006, www.ebi.ac.uk/huber-srv/queryGene). The 5'UTR sequences were amplified by PCR inserting $B g l \mathrm{II}$ restriction sites on both ends and ligated with pME3680 (testing vector) utilizing its BamHI restriction site. Plasmids were amplified in the Escherichia coli strain DH5 $\alpha$ in LB medium with $100 \mu \mathrm{g} / \mathrm{ml}$ ampicillin.

Table 2. Plasmids used in this work.

\begin{tabular}{|c|l|c|}
\hline plasmid & \multicolumn{1}{|c|}{ description } & reference \\
\hline Yep355 & 7.94 kb vector, amp $^{R}$ (bla), lacZ, ori, $2 \mu m$, URA3 & $\begin{array}{c}\text { ATCC, The Global } \\
\text { Bioresource Center } \\
\text { (Wesel, Germany) }\end{array}$ \\
\hline pME3680 & $\begin{array}{l}\text { YEp355 containing }{ }^{\text {prom }} \text { PGK1 followed by BamHI restriction site and ATG } \\
\text { start codon (testing vector) }\end{array}$ & $\begin{array}{c}\text { Rachfall } \text { et al., under } \\
\text { revision }\end{array}$ \\
\hline pME3751 & pME3680 with STE12-5'UTR introduced by BamHI restriction & This work \\
\hline pME3752 & pME3680 with RAP1-5'UTR introduced by BamHI restriction & This work \\
\hline pME3753 & pME3680 with TEC1-5'UTR introduced by BamHI restriction & This work \\
\hline pME3754 & pME3680 with FLO8-5'UTR introduced by BamHI restriction & This work \\
\hline pME3755 & pME3680 with PHD1-5'UTR introduced by BamHI restriction & This work \\
\hline
\end{tabular}

De novo proteome and 2D-PAGE analysis - Yeast cultures were grown to midlog phase $\left(\mathrm{OD}_{600}=0.8\right)$ prior to the addition of $450 \mu \mathrm{Ci}$ Met- $\left[{ }^{35} \mathrm{~S}\right]$-label (Hartmann Analytik, Braunschweig, Germany) and further incubated for an additional hour. Cells were harvested and washed in wash buffer $(0.1 \mathrm{M}$ Tris, $\mathrm{pH} 8.0$ with $1 \%$ DMSO and $1 \mathrm{mM}$ PMSF). Protein extracts were obtained by lysing cells with Y-PER ${ }^{\circledR}$ Plus reagent (\#78999, Pierce, Rockford, IL, USA) containing cOmplete Protease Inhibitor Cocktail (Roche Diagnostics $\mathrm{GmbH}$, Mannheim, Germany) and purification by methanol-chloroform extraction (Wessel and Flügge, 1984). Protein concentrations were determined via BCA

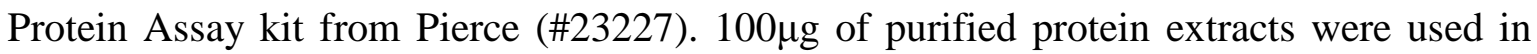
2D-PAGE analyses. Gels were silver-stained according to Blum et al. (1987), vacuum dried and exposed on imaging plates (Fuji, Tokyo, Japan) for two weeks. The protein-spots of the resulting autoradiographies were quantified with the image analysis software PDQuest $^{\text {TM }}$ (Bio-Rad, Munich, Germany). Protein-spots were further analyzed upon a regulation by at least 2 fold. The analysis was performed for seven biologically independent replicates. 
LC-MS/MS protein identification - Excised polyacrylamide gel pieces of stained protein-spots were digested with trypsin according to Shevchenko et al. (1996). Tryptic peptides extracted from each gel piece were injected onto a reverse-phase liquid chromatographic column (Dionex-NAN75-15-03-C18 PM) utilizing the ultimate HPLC system (Dionex, Idstein, Germany) to further reduce sample complexity prior to mass analyses with an LCQ DecaXP mass spectrometer (Thermo Scientific, San Jose, CA, USA), equipped with a nano-electrospray ion source. Cycles of MS spectra with $\mathrm{m} / \mathrm{z}$ ratios of peptides and four data-dependent MS2 spectra were recorded by mass spectrometry. The "peak list" was created with extractms provided with the Xcalibur software package (BioworksBrowser 3.3.1, Thermo Scientific). The MS2 spectra with a total ion current higher than 10,000 were used to search for matches against a yeast genome protein sequence database from the National Center for Biotechnology Information (NCBI) Saccharomyces Genome Database (Stanford, CA, USA, 6882 sequences, March 2005, plus 180 sequences of the most commonly appearing contaminants as e.g. keratins and proteases, provided with the BioworksBrowser package) using the TurboSEQUEST algorithm (Eng et al., 1994) of the Bioworks software. The search parameters based on the TurboSEQUEST software included: (i) precursor ion mass tolerance less than $1.4 \mathrm{amu}$, (ii) fragment ion mass tolerance less than $1.0 \mathrm{amu}$, (iii) up to three missed tryptic cleavages allowed and (iv) fixed cysteine modifications by carboxyamidomethylation (plus $57.05 \mathrm{amu}$ ) and variable modifications by methionine oxidation (plus $15.99 \mathrm{amu}$ ) and phosphorylation of serine, threonine or tyrosine (plus $79.97 \mathrm{amu}$ ). At least two matched peptide sequences of identified proteins must pass the following criteria: (i) the cross-correlation scores (XCorr) of matches must be greater than 2.0, 2.5 and 3.0 for peptide ions of charge state 1,2 and 3, respectively, (ii) $\Delta \mathrm{Cn}$ values of the best peptide matches must be at least 0.4 and (iii) the primary scores (Sp) were at least 600. Each protein included in further analyses had to be identified according to these criteria in at least two independent proteome analyses performed (Supplementary Table 1). Peptides of identified proteins were individually blasted against the Saccharomyces genome database (SGD) (BLASTP at http://seq.yeastgenome.org/cgi-bin/blast-sgd.pl against the dataset Protein Encoding Genes) to ensure their unambiguous assignment to the TurboSEQUESTspecified protein. 
Scintillation counting - Metabolically labeled protein extracts were separated from free Met- $\left[{ }^{35} \mathrm{~S}\right]$-isotope by methanol-chloroform extraction (Wessel and Flügge, 1984) and the sediment was resuspended in $400 \mu \mathrm{l}$ Y-PER ${ }^{\circledR}$ Plus reagent. $200 \mu 1$ of the suspension were mixed with $5 \mathrm{ml}$ of ULTIMA GOLD XR LCS-Cocktail (Perkin Elmer, Boston, MA, USA) and subjected to scintillation counting. The measured counts per minute (cpm) were related to the concentration of protein extracts determined via BCA Protein Assay kit from Pierce. The insoluble fraction was washed in wash buffer and incubated in Y-PER ${ }^{\circledR}$ Plus reagent overnight. After washing in $\mathrm{H}_{2} \mathrm{O}$ the pellet was weighed and resuspended in $1 \mathrm{ml}_{2} \mathrm{O}$. $100 \mu \mathrm{l}$ of this suspension were added to $5 \mathrm{ml}$ of ULTIMA GOLD XR LCS-Cocktail followed by scintillation counting. The relative activities were determined by normalization to respective pellet masses. The data shown results from five independent experiments.

Microarray analysis - The array was constructed by spotting a $15 \mu \mathrm{M}$ solution of 5' amino-C6-modified oligonucleotides in 50mM sodium phosphate $\mathrm{pH} 8.5$ with a length of 70 bases on CodeLink microarray slides (SurModics, Eden Prairie, MN, USA) using a MicroGrid II microarray spotter (Zinsser Analytic, Frankfurt, Germany). Each spot contains around $1.5 \mathrm{fmol}$ of oligonucleotide. Oligonucleotides were covalently coupled to the slide surface and blocked using ethanolamine according to the instructions of the supplier. The array consists of 6388 probes, as provided by the Array-Ready Oligo Set V1.1 for S. cerevisiae (Eurofins, Ebersberg, Germany).

RNA isolation, cDNA labeling and hybridization. Yeast cultures were grown according to western hybridization protocol. Total RNA from yeast was isolated following the protocol described by Cross and Tinkelenberg (1991). For preparation of fluorescently labeled cDNA $25 \mu \mathrm{g}$ of total RNA were treated according to the instructions for the CyScribe First-Strand cDNA Labelling Kit from GE Healthcare (Munich, Germany). Primer annealing was carried out with random nonamers and anchored oligo(dT) and for the extension reaction $\mathrm{Cy} 3$ or Cy5 labeled dCTP (GE Healthcare) was used. RNA was removed from the formed heteroduplexes by the addition of $2 \mu 12.5 \mathrm{M} \mathrm{NaOH}$ and incubation for $15 \mathrm{~min}$ at $37^{\circ} \mathrm{C}$. Hydrolysis was stopped by the addition of $10 \mu 12 \mathrm{M}$ HEPES $\mathrm{pH}$ 7.0. Labeled cDNA was separated from the reaction mixture via CyScribe GFX Purification Kit (GE Healthcare) according to the suppliers' instructions. Before hybridization, samples were denatured by incubation at $98^{\circ} \mathrm{C}$ for $5 \mathrm{~min}$. The hybridization 
was carried out in Tom Freeman hybridization buffer (Fitzpatrick et al., 2005) for $15 \mathrm{~h}$ at $58^{\circ} \mathrm{C}$ with cDNA containing approximately $60 \mathrm{pmol}$ of $\mathrm{Cy} 3$ and $\mathrm{Cy} 5$ in an automatic Lucidea slide processor (GE Healthcare). Slides were washed using a program applying consecutive washes two times with 1x SSC buffer containing 0.2\% SDS and then with $0.1 \mathrm{x}$ SSC. At the end the hybridization chambers were flushed with isopropanol and the slides were dried by evaporation. Scanning was done by a GenePix 4000B microarray scanner (Molecular Devices, Sunnyvale, CA, USA) with the GenePix Pro 6.0 software.

Data analysis. To normalize the data the arithmetic mean of the ratios was set equal to 1 (GenePix Pro 6.0 software). Only features with fluorescence greater than the local background plus one standard deviation were included in the analysis. To correct for features with irregular spot morphology, only those were included differing less than $30 \%$ in the ratio of medians, the ratio of means and a regression ratio. The transcriptional data shown results from three biologically independent experiments. For each biological replicate two technical replications and dye-swaps were analyzed. Genes were considered as significantly up- or down-regulated if the logarithmic (to the basis of two) expression ratio was $\geq 0.59$ or $\leq-0.59$ for a gene in all three biological replicates, corresponding to a transcriptional change of at least 1.5 fold. Additionally, the statistical error could not exceed 5\%. Microarray data were deposited in the NCBI Gene Expression Omnibus (GEO) database (http://www.ncbi.nlm.nih.gov/geo/).

Growth assays - Yeast cell main-cultures were grown to midlog phase, adjusted to $\mathrm{OD}_{600}=0.1$ by dilution and serial 10 fold diluted up to $1: 10,000.20 \mu \mathrm{l}$ of each dilution were spotted onto plates containing $2 \%$ agar and the denoted supplements. Cell wall integrity was scored on yeast extract-peptone dextrose (YEPD) medium containing $10 \mu \mathrm{M}$ caffeine. Aerobic growth was determined on YNB medium containing $2 \%$ glucose or $2 \%$ ethanol $(\mathrm{EtOH})$ as carbon source. YNB plates containing $30 \mu \mathrm{M}$ of the iron (II) chelator Bathophenanthrolinedisulfonic acid (BPS) were used to determine the sensitivity to iron-limitation. The control plates contained $100 \mu \mathrm{M}\left(\mathrm{NH}_{4}\right)_{2} \mathrm{Fe}\left(\mathrm{SO}_{4}\right)_{2}$.

Growth conditions for glucose-dependent colony morphology alterations - Yeast cells were grown to midlog phase and diluted to $2 \times 10^{3}$ cells $/ \mathrm{ml}$. $150 \mu$ l of the cell suspension were plated onto YEPD medium with $0.4 \%$ or $2 \%$ glucose and the plates were incubated at $30^{\circ} \mathrm{C}$ for 3 days before examination of colonies. 
Assay to score for respiratory activity - Yeast cells were grown to midlog phase and diluted to $2 \times 10^{3}$ cells $/ \mathrm{ml}$. $150 \mu$ l of the cell suspension were plated onto minimal medium (YNB) with $0.4 \%$ glucose to establish preferential conditions for respiration. The plates were incubated at $30^{\circ} \mathrm{C}$ for 3 days. To determine respiratory activity $20 \mathrm{ml}$ of Triphenyltetrazolium chloride (TTC) agar (1.2\% agar and 0.5\% TTC) were overlaid and red and white colonies scored after $20 \mathrm{~min}$ of incubation at $30^{\circ} \mathrm{C}$. Red colonies indicate the reduction of TTC, which requires the activity of the respiratory chain, whereas colonies impaired in their respiratory chain remain white (Ogur et al., 1957).

Determination of glucose consumption and ethanol production - Cell main cultures were grown in $\mathrm{YNB}$ medium at $30^{\circ} \mathrm{C}$ to $\mathrm{OD}_{600}=0.5$. Thereafter samples of $500 \mu \mathrm{l}$ were drawn every hour for 8 hours. Additionally, the cell density was determined at the respective time points. Proteins were precipitated with $0.4 \mathrm{ml} 0.33 \mathrm{M}$ perchloric acid and chilled. After neutralization with $0.1 \mathrm{ml} 1.25 \mathrm{M} \mathrm{NaOH}$ the proteins were sedimented by centrifugation at $12,000 \mathrm{rpm}$ for $5 \mathrm{~min}$. The supernatants were diluted 1:10 with $\mathrm{H}_{2} \mathrm{O}$ prior to the determination of ethanol or glucose concentrations.

To determine the ethanol production $100 \mu$ of the diluted supernatant, $100 \mu$ standard $(2 \mathrm{mM} \mathrm{EtOH})$ and $100 \mu \mathrm{l} \mathrm{YNB}$ (blank) were added to $3 \mathrm{ml}$ E-buffer (26.7g pyrophosphate, $6.7 \mathrm{~g}$ semicarbazide, $1.26 \mathrm{~g}$ glycine, $\left.800 \mathrm{ml} \mathrm{H}_{2} \mathrm{O}\right), 100 \mu \mathrm{l} 13 \mathrm{mM} \mathrm{NAD}$ and $100 \mu \mathrm{l}$ $13.84 \mathrm{kU}$ ADH from $S$. cerevisiae, respectively. The solution was incubated at $37^{\circ} \mathrm{C}$ for $25 \mathrm{~min}$ before the optical density was measured at $363 \mathrm{~nm}$. Standard and blank values served for quantification and normalization, respectively.

For the determination of glucose consumption the glucose concentration in the medium was measured. Therefore $50 \mu \mathrm{l}$ of the diluted supernatant, $50 \mu \mathrm{l}$ standard ( $5 \mathrm{mM}$ glucose) and $50 \mu \mathrm{l} \mathrm{H}_{2} \mathrm{O}$ (blank) were added to $1 \mathrm{ml}$ glucose test-solution (Glucose-Hexokinase kit, DiaSys Diagnostic Systems GmbH, Holzheim, Germany). $\mathrm{OD}_{363}$ was measured after $15 \mathrm{~min}$ of incubation at room temperature. Glucose concentrations were determined according to standard and blank values.

Growth inhibition assay/halo assay - Yeast cells were grown to saturation in YEPD medium. $10 \mu \mathrm{l}$ of culture were mixed with $4 \mathrm{ml}$ of $55^{\circ} \mathrm{C}$ warm YEPD medium containing $0.5 \%$ agar and plated on solid YEPD medium. The pheromone response was tested by placing filter papers containing $10 \mu \mathrm{g}$ or $20 \mu \mathrm{g}$ a-factor onto the plate (Hoffman et al., 
2002). Plates were incubated at $30^{\circ} \mathrm{C}$ for $3-5$ days. The zone of no growth around the filter paper represents the halo.

Western hybridization analysis - Cell cultures were grown at $30^{\circ} \mathrm{C}$ to midlog phase $\left(\mathrm{OD}_{600}=0.8\right)$. Harvested cells were washed in ice-cold buffer b $(100 \mathrm{mM}$ Tris- $\mathrm{HCl} \mathrm{pH} 7.5$, $200 \mathrm{mM} \mathrm{NaCl}, 20 \%$ glycerol, 5mM EDTA), lysed with glass beads in $500 \mu \mathrm{l}$ of buffer b+ (1x cOmplete Protease Inhibitor Cocktail, $0.5 \% \beta$-mercaptoethanol) and protein extracts obtained by centrifugation at $13,000 \mathrm{rpm}$ for $15 \mathrm{~min}$. Protein concentrations were determined according to Bradford (1976). Proteins were denatured in SDS loading dye at $65^{\circ} \mathrm{C}$ for $15 \mathrm{~min}$ and subjected to SDS-PAGE followed by blotting onto nitrocellulose membrane.

The membranes were incubated with polyclonal goat anti-Rap1 (yN-18), monoclonal mouse anti-myc (\#sc-40), polyclonal anti-Ste12 (yC-20) (all obtained from Santa Cruz Biotechnology, Heidelberg, Germany), polyclonal rabbit anti-eIF2 $\alpha$ (kindly provided by Thomas Dever, NIH, Bethesda, MD, USA) or polyclonal rabbit anti-Tec1 (gift from Hans-Ulrich Mösch, Philipps-Universität Marburg, Germany) antibodies. Subsequently, the membranes were incubated with peroxidase-coupled donkey anti-goat (\#sc-2020, Santa Cruz Biotechnology), goat anti-rabbit (\#G21234, MoBiTec, Göttingen, Germany) or goat anti-mouse (\#115-035-003, Dianova, Hamburg, Germany) secondary antibodies. Proteins were visualized using ECL technology (Amersham Biosciences, Munich, Germany). The quantification was carried out via Kodak Molecular Imaging Software (v. 4.0.5, raytest GmbH, Straubenhardt, Germany).

$\boldsymbol{\beta}$-galactosidase assay - Assays were performed with extracts grown in liquid minimal medium. $10 \mathrm{ml}$ pre-cultures were grown overnight at $30^{\circ} \mathrm{C}$ and $1 \mathrm{ml}$ was used to inoculate $10 \mathrm{ml}$ main cultures. Cells were harvested after $6 \mathrm{~h}$ of growth at $30^{\circ} \mathrm{C}$. Protein extracts were obtained via lysing with glass beads in breaking buffer $(100 \mathrm{mM}$ Tris $\mathrm{pH} 8.0$, $20 \%$ glycerol). Specific $\beta$-galactosidase activities were normalized to the total protein amount (Bradford, 1976) in each extract and calculated according to Rose and Botstein (1983) $\left(\mathrm{A}_{415} \times \mathrm{0}\right.$ 0.3)/(0.0045 x protein concentration $\mathrm{x}$ extract volume $\mathrm{x}$ time). The values obtained for the inserted 5'UTR sequences were related to the values obtained for the empty testing vector for wild type and $\Delta a s c 1$ strain, respectively. 


\section{Results}

Asc1p is known to be involved in the regulation of various biological processes. As a ribosomal protein it is involved in the process of translation (Gerbasi et al., 2004), e.g. by affecting the phosphorylation state of translation initiation factors (Valerius et al., 2007). Additionally, or as consequence of these translational changes, processes like maintenance of cell wall integrity are influenced by Asc1p (Valerius et al., 2007) and its participation in complex signal transduction pathways was revealed (Chasse et al., 2006; Zeller et al., 2007).

The variety of affected processes and Asc1p localization on the ribosome, suggests that the absence of Asc1p at this central point of gene expression influences respective downstream effectors. These effectors, e.g. in the form of transcription factors (TFs), might be modified in number or state when Asc1p is absent and then in turn exercise their control in diverse cellular processes. The approach presented here aims to find functional groups of proteins and mRNAs that are differentially expressed in a $\Delta a s c 1$ strain. This data in combination with phenotypical investigations should reveal the major processes affected by Asc1p. In a next step the TFs inducing the majority of the observed transcriptional changes are analyzed according to their abundance and their translational regulation mediated by their $5^{\prime}$ ' untranslated regions (5'UTRs) in a $\Delta a s c 1$ strain.

\section{De novo proteome analysis - Misregulation of energy metabolism in $\Delta$ asc1 cells}

Due to its proposed role in translational regulation, the deletion of ASCl can be assumed to induce extensive changes in gene/protein expression within the cell, substantially taking place on different levels of regulation. To assess those changes and globally identify affected proteins/processes, we compared the proteomes of a $\Delta a s c 1$ and an isogenic wild type (wt) strain. This proteome analysis was conducted with cells grown in the presence of Met- $\left[{ }^{35} \mathrm{~S}\right]$-isotope within the last hour of cultivation, which leads to the radioactive labeling of each protein synthesized in that time frame (Figure 1A). The radioactively labeled protein extracts were subjected to 2D-PAGE analysis. The resulting 2D-gels were exposed on imaging plates to produce autoradiographies, which were used for the analysis of the respective de novo proteomes. Thus, it is possible to reveal differences in the 
de novo protein biosynthesis between $\Delta a s c 1$ and wt cells, allowing conclusions regarding the processes influenced by Asc1p.

A

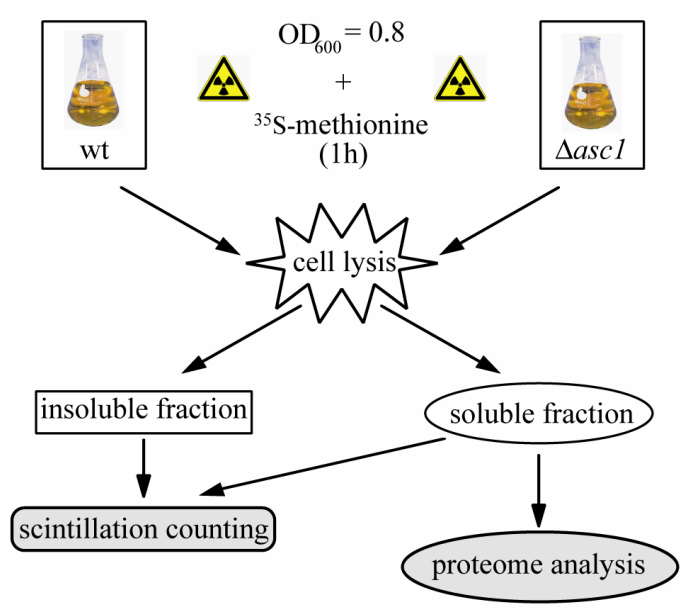

$\mathrm{B}$ soluble fraction insoluble fraction

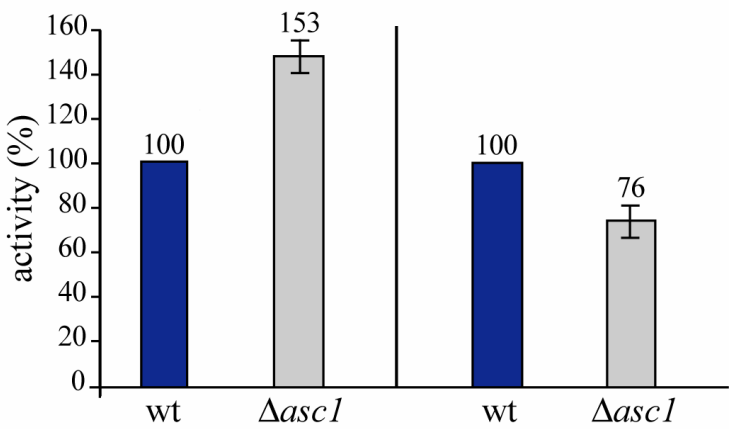

Figure 1. Experimental set-up for the analysis of the de novo protein biosynthesis of soluble and insoluble proteins in wt and $\Delta a s c 1$ cells. (A) Experimental set-up. Wt and $\Delta a s c 1$ cell cultures were grown to an optical density of 0.8 before the addition of ${ }^{35}$ S-labeled methionine. Cells were incubated for an additional hour and thereupon lysed by Y-PER ${ }^{\circledR}$ Plus reagent. The soluble protein extracts and the insoluble remains were subjected to scintillation counting and the protein extracts were further analyzed via 2D-PAGE analysis. (B) Scintillation counting. The relative activities of protein-incorporated radioactive ${ }^{35} \mathrm{~S}$-methionine were determined. The activity for the soluble fraction was normalized against the total protein content of the respective extract as determined by BCA protein assay, whereas the activity of the insoluble fraction was normalized against the mass of the respective pellet.

The cell lysis with Y-PER ${ }^{\circledR}$ Plus reagent results in two separate fractions, the soluble protein extracts of the $\Delta a s c l$ and the wt strain as well as the insoluble remains. In order to determine qualitative differences in protein biosynthesis rates of wt and $\Delta$ ascl mutant, both fractions were analyzed by scintillation counting regarding the respective amounts of incorporated radioactive methionine (Figure 1B). The soluble fraction represents a measure for the de novo biosynthesis of soluble proteins, whereas the insoluble fraction corresponds to newly synthesized insoluble proteins, e.g. cell wall or plasma membrane proteins (Trimpin and Brizzard, 2009). Relative to the wt strain the $\Delta$ ascl mutant shows an elevated de novo biosynthesis for soluble proteins which corresponds to the described role for Asc1p as translation repressor (Gerbasi et al., 2004). The measured activities for the deletion strain are about 50\% higher than for the wt. For the insoluble fraction on the other 
hand activities are reduced by nearly a quarter in the $\Delta a s c l$ strain compared to the wt. This converse effect on the de novo biosynthesis of soluble and insoluble proteins indicates an influence of Asc1p on cell wall and/or membrane biogenesis. This finding is supported by the results of the de novo proteome analysis.

A

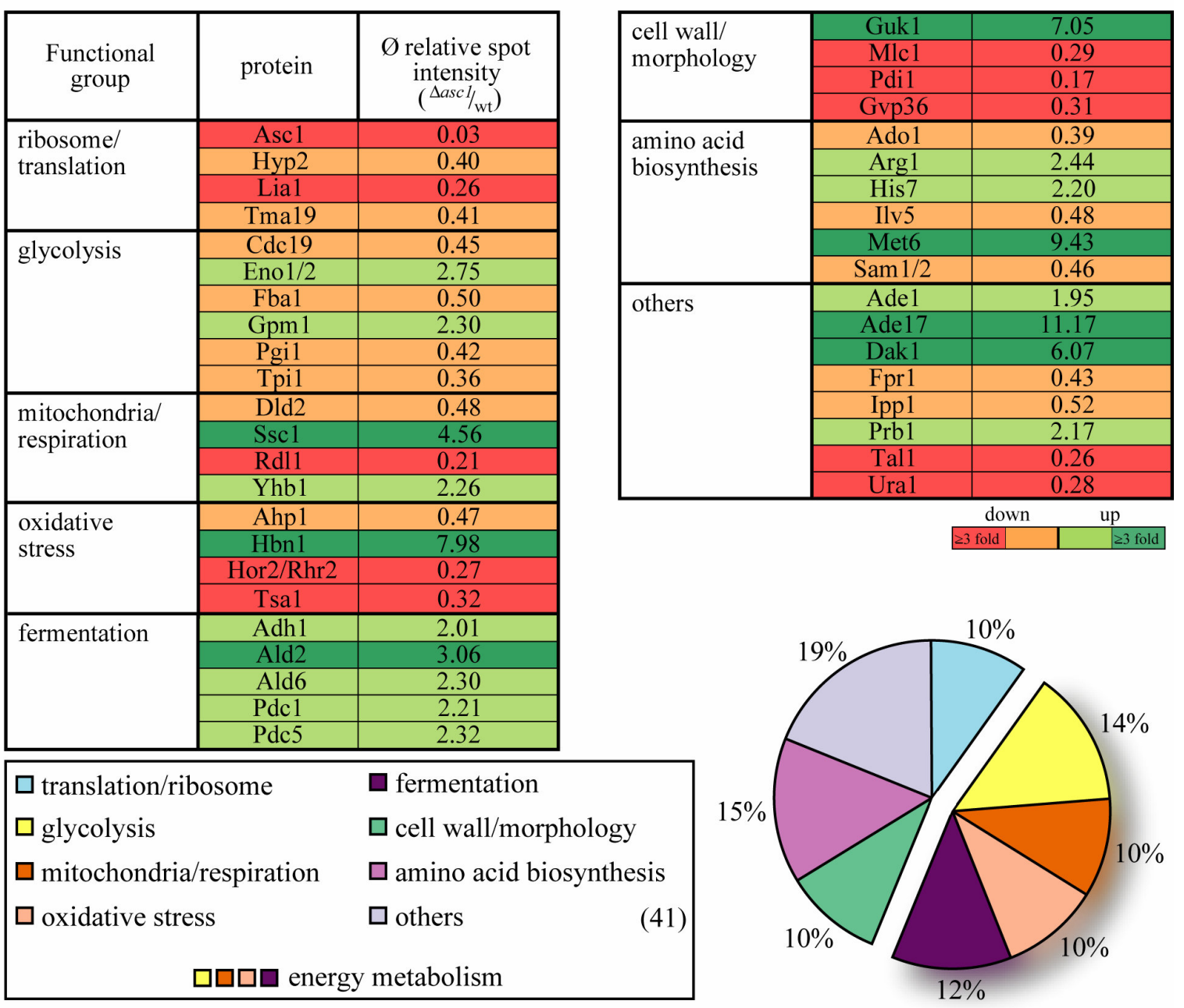

B
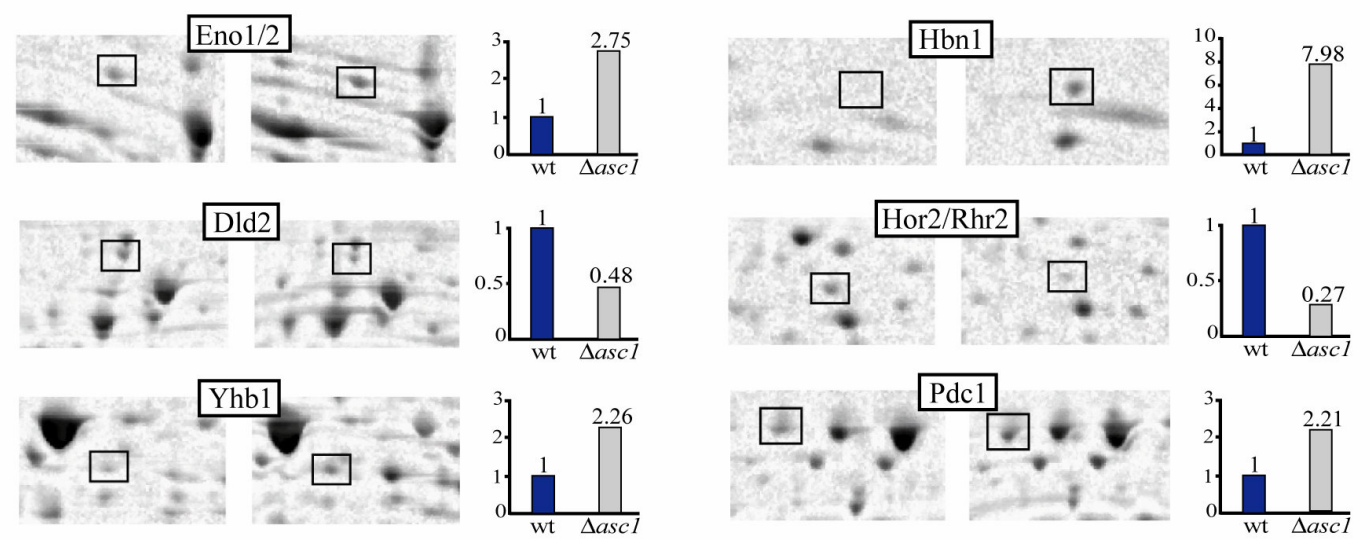
Figure 2. Proteins identified to be regulated in $\Delta$ asc1 cells. (A) Proteome analysis. Regulated proteins were classified according to their cellular function or localization. The regulation for each protein is given as average relative spot intensity $\left({ }^{\text {spot intensity }[\Delta a s c l]} /\right.$ spot intensity $[\mathrm{wt}]$ ). The percental distribution of proteins in the functional groups is illustrated in a pie chart relative to the number of total proteins found to be regulated. The proteins belonging to the composed group of energy metabolism is accentuated. (B) Close-up views of selected protein-spots regulated in Sascl cells. Protein names are given according to LC-MS/MS identification. The corresponding proteins belong to the joined group of energy metabolism making up $46 \%$ of total proteins regulated. For each of the proteins its average regulation is displayed relative to wt $\left(\varnothing\left[{ }^{\Delta a s c l} / \mathrm{wt}\right]\right)$.

Although insoluble cell wall proteins could not be expected to appear in the proteome analysis of the soluble fraction, several proteins involved in cell wall biogenesis and overall cell morphology were found to be down-regulated in $\Delta a s c 1$ cells (Figure 2A). Three of the regulated proteins in this group are essential for viability, namely Pdilp and Mlc1p, showing a significantly reduced protein biosynthesis in the $\Delta$ ascl strain, and Guk1p, being up-regulated 7 fold. Pdi1p is a protein disulfide isomerase required for the formation of disulfide bonds in secretory and cell surface proteins (Farquhar et al., 1991). Mlc1p localizes to the bud neck and plays a role in actin ring formation, promoting targeted membrane deposition at the bud neck during cytokinesis (Luo et al., 2004). The guanylate kinase Guk1p is required for mannose outer chain elongation of cell wall N-linked glycoproteins (Shimma et al., 1997).

Another group of proteins regulated in $\Delta a s c l$ cells is involved in amino acid biosynthesis. Ado1p, Ilv5p and Sam1/2p show a reduced expression in the mutant strain, whereas Arg1p, His7p and Met6p are up-regulated. The strongest effect can be observed for the methionine synthase Met6p, showing an enhanced biosynthesis in $\Delta a s c 1$ cells by over 9 fold. Three ribosome/translation associated proteins, namely Tma19p, Hyp2p and Lia1p, were found in the proteome analysis as down-regulated when deleting ASC1. Tma19p depicts the yeast orthologue of the translationally controlled tumor protein (TCTP). Hyp2p is the anaerobically expressed variant of the essential translation elongation factor eIF5A. Lia1p catalyzes the second step in the essential hypusination modification of eIF5A.

The by far largest group, consisting of almost $50 \%$ of all proteins found to be regulated in $\Delta a s c 1$ cells, is made up by proteins involved in energy metabolism (Figure 2A). This comprehensive group is composed of proteins taking part in 'glycolysis', 'mitochondria/respiration', 'oxidative stress' and 'fermentation'. Representative 
protein-spots out of each group are illustrated in Figure 2B, respectively. The six proteins involved in glycolysis span nearly the entire glycolytic process. Cdc19p, Fba1p, Pgi1p and Tpilp are down-regulated in $\Delta$ ascl cells but Eno1/2p and Gpm1p were found to be up-regulated. Glycolysis is directly connected to the energy restoring/generating processes in the cell by delivering the starting products for respiration in the mitochondria on the one hand or fermentation in the cytosol on the other hand, dependent on glucose- and oxygenavailability. For the four proteins assigned to the group of 'mitochondria/respiration' a differential regulation was found. The D-lactate dehydrogenase Dld2p resides in the mitochondrial matrix. Its biosynthesis is down-regulated in the $\Delta a s c 1$ strain as well as for Rdl1p, a protein of the outer mitochondrial membrane. Ssc1p and Yhb1p show an up-regulation of 4.5 fold and 2.3 fold, respectively. Ssc1p is an essential constituent of the import motor component of the translocase of the inner mitochondrial membrane (TIM23 complex). The yeast flavohemoglobin, Yhb1p, acts as nitric oxide oxidoreductase in nitric oxide (NO) detoxification (Liu et al., 2000). NO is described to lead to the inhibition of mitochondrial respiration and to enhance production of reactive oxygen species (ROS) (Cassanova et al., 2005). ROS are produced as an unavoidable byproduct of cellular respiration, causing oxidative stress in the cell (Turrens, 2003). In this analysis four proteins were assigned to the group of 'oxidative stress'. The nitroreductase-like protein Hbn1p has been described to be important for superoxide dismutase activity (de Oliveira et al., 2010). While the other three proteins involved in oxidative stress response, namely Ahp1p, Hor2p/Rhr2p and Tsa1p, are down-regulated in the analysis, Hbn $1 p$ biosynthesis is 8 fold up-regulated when $A S C 1$ is deleted. In the context of energy metabolism it is especially striking that all five proteins assigned to the group of 'fermentation' are uniformly at least 2 fold up-regulated when Asc1p is absent. This group includes amongst others the alcohol dehydrogenase Adhlp and the pyruvate decarboxylases Pdc1p and Pdc5p which are key enzymes of the alcoholic fermentation in yeast.

Taken together, the major processes found to be affected through the conducted proteome analysis in the $\Delta a s c 1$ strain seem to be cell wall biogenesis and energy metabolism. According to scintillation counting the de novo biosynthesis of insoluble proteins is reduced by $50 \%$ in $\Delta$ ascl cells. Additionally, significant changes in the expression of several proteins involved in the maintenance of cell morphology were revealed when 
Asc1p is absent. Proteins involved in energy metabolism, assigned to the associated groups of 'glycolysis', 'mitochondria/respiration', 'oxidative stress' and 'fermentation', amount to almost half of all regulated proteins. Especially proteins involved in fermentation show a distinct up-regulation in response to the deletion of $A S C 1$, suggesting an elevated fermentation in $\Delta$ ascl cells.

\section{Transcriptome analysis - Asc1p is involved in several cellular signaling pathways}

In order to obtain a comprehensive profile of the processes affected by Asc1p a microarray analysis was conducted in addition to the proteome analysis. The genes transcriptionally regulated in $\Delta a s c 1$ cells were identified and functionally classified (Figure 3). The stringent thresholds and settings applied to the raw microarray data (see Materials and Methods section) yielded 80 genes that are considered differentially expressed in the $\Delta a s c 1$ strain in comparison to the wt.

A significant up-regulation was found for mRNAs assigned to the group of 'transposition'. The group solely consists of retrotransposons of the Ty1 and Ty2 type. Corresponding to their common promoter, they show a uniform regulation in the $\Delta a s c l$ strain. Another group consists of candidates involved in 'ribosome/translation'. The mRNAs in this group show a differential change in expression in response to the deletion of ASC1. KTI11, SIS1 and $Y O L 114 C$ are more strongly transcribed in a $\triangle a s c 1$ strain, whereas the mRNA of TMA10 is less abundant. An association to the ribosomal machinery has been shown for Tma10p as well as for the essential protein Sis1p, required for the initiation of translation (Zhong and Arndt, 1993). For Yol114cp a function in translation termination is speculated. Kti11p is involved in the modification of the translation elongation factor eEF2 and wobble nucleosides in tRNAs.

Furthermore, the expression of many mRNAs involved in energy metabolism is affected in the $\Delta a s c 1$ strain. They are presented here in the groups of, 'mitochondria/respiration', 'oxidative stress' and 'glucose transporters' (Figure 3). The affected mRNAs of the latter group code for the low-affinity transporter Hxt3p and the two almost identical high-affinity transporters Hxt6p and Hxt7p. All three corresponding proteins reside in the plasma membrane and show a significant down-regulation on their mRNA level in the mutant strain. Amongst the mRNAs assigned to the group 'oxidative stress' DDR2 and PEP4 can 
be found as down-regulated in $\Delta a s c 1$ cells. They code for proteins expressed in response to multiple stressors and oxidative damage-induced protein turnover, respectively. Additionally, the HBN1-mRNA level is 3 fold up-regulated in the mutant, coding for a putative nitroreductase.

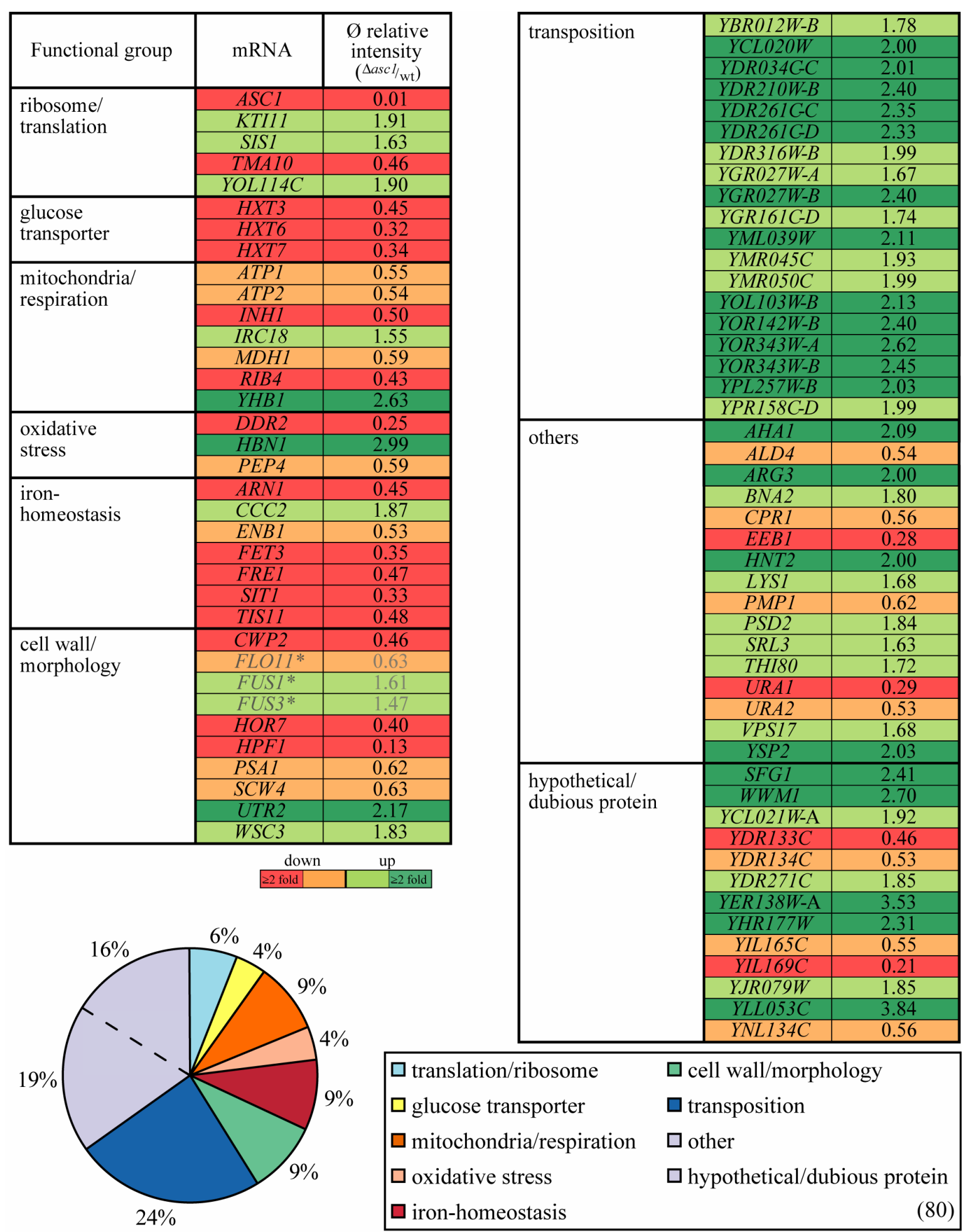


Figure 3. Functional classification of mRNAs regulated in $\Delta a s c 1$ cells. The regulation for each mRNA is given as average relative to the wt ( $\left(^{\text {spot intensity }[\Delta a s c l]} /\right.$ spot intensity $\left.[\mathrm{wt}]\right)$. The groups resulting from the respective function of mRNA-products are expressed as the percentage of the total number of regulated mRNAs. The asterisk marks mRNAs not conform with the criteria for all three biological replicates but of importance for the discussion. The complete data sets are supplied in Supplementary Table 2A and 2B.

The group of 'mitochondria and respiration' consists of seven regulated mRNAs. $M D H 1$, RIB4, ATP1, ATP2 and INH1 are down-regulated in the $\triangle a s c 1$ strain. MDH1 codes for the mitochondrial malate dehydrogenase of the tricarboxylic acid (TCA) cycle. Rib4p is required for riboflavin synthesis, which is a precursor of the flavin coenzymes FAD (flavin adenine dinucleotide) and FMN (flavin mononucleotide). As non-covalently bound part of the NADH:ubiquinone oxidoreductase, Ndi1p, FAD is involved in the electron transfer from the TCA cycle to ubiquinone in the electron transport chain at the inner mitochondrial membrane (Li et al., 2006; Seo et al., 2006). ATP1 and ATP2 code for the $\alpha$ and $\beta$ subunit of the $F_{1}$ sector of the mitochondrial $F_{1} F_{0}$ ATPase synthase, respectively. ATPase synthase activity is required for the hydrolysis of ATP, which is inhibited by Inh1p. Additionally, IRC18 can be found to be up-regulated, an indication for respiratory-deficiency. $Y H B 1$, encoding for nitric oxide oxidoreductase, is more efficiently transcribed in the mutant strain.

Another group of high interest in this context consists of genes involved in 'iron-homeostasis', since iron is directly involved in respiration via heme-biosynthesis and iron-sulfur cluster (Fe-S cluster) formation (Hausmann et al., 2008). All proteins corresponding to the mRNAs in this group have their function in the uptake of iron, except for Tis $11 \mathrm{p}$, which is an mRNA-binding protein, promoting mRNA-degradation under iron-starvation. FRE1 codes for the major cell-surface iron reductase, reducing iron prior to uptake. Ccc $2 p$ is required for the translocation of the Fet3p/Ftr1p complex to the plasma membrane, which mediates high-affinity iron uptake. Enb1p, Sit1p and Arn1p are directly linked to iron uptake as members of the Arn family of siderophore iron-transporters. Except for Ccc2p all corresponding proteins involved in iron uptake reside in the plasma membrane. The negative influence on the transcription of genes coding for membrane proteins involved in iron uptake and glucose transport in $\Delta$ ascl cells further becomes apparent in the group of 'cell wall/morphology'. CWP2 coding for a major constituent of the cell wall as well as $H O R 7, H P F 1$ and SCW4 coding for further cell wall components 
are clearly down-regulated in $\triangle a s c 1$ cells. Additionally, PSA1, coding for an essential protein required for a normal cell wall structure, can be found as down-regulated in the mutant strain. Furthermore the two mRNAs up-regulated in this group, namely WSC3 and $U T R 2$, are described to be induced under cell wall stress. The integral membrane protein Wsc3p is the sensor-transducer of the MAPK cell wall integrity pathway (Verna et al., 1997; Wojda et al., 2003).

According to the presented transcriptome data, transposition seems to be a process up-regulated in the $\Delta a s c 1$ mutant strain. Additionally, Asc1p takes part in the regulation of iron-homeostasis and there specifically in the uptake of iron. The transcriptional changes further indicate a compromised cell wall integrity for $\Delta a s c 1$ cells. Additionally, processes involved in energy metabolism, expressed by the regulated groups of 'glucose transporters', mitochondria/respiration' and oxidative stress, are affected by the deletion of $A S C 1$. Especially the particular regulation of mRNAs involved in respiration, suggests a significance of Asc1p in this process.

These effects strengthen the previously suggested influence of Asc1p on energy metabolism determined via proteome analysis, especially apparent by an up-regulation of proteins involved in fermentation (Figure 2A). Translation and cell wall integrity present two further processes that seem to be influenced by Asc1p on the mRNA- as well as on the protein-level. Alterations concerning the processes of transposition and iron-homeostasis are solely detected on the transcriptional level. An involvement of Asc1p in amino acid biosynthesis is only suggested by the observed proteome changes.

Interestingly only two distinct candidates assigned to the established groups were found to be regulated in the proteome as well as in the transcriptome analysis. HBN1/Hbn1p and $Y H B 1 / Y h b 1 p$ are assigned to the groups 'mitochondria/respiration' and 'oxidative stress', respectively. Both rank amongst the most significantly up-regulated candidates in both data sets. Their determined protein amount emphasizes on their distinctive regulation in $\Delta$ asc1 cells (Figure 4). The total protein amounts of Hbn1p and Yhb1p show an up-regulation in the $\Delta a s c 1$ strain of 8 and 4 fold, respectively. 


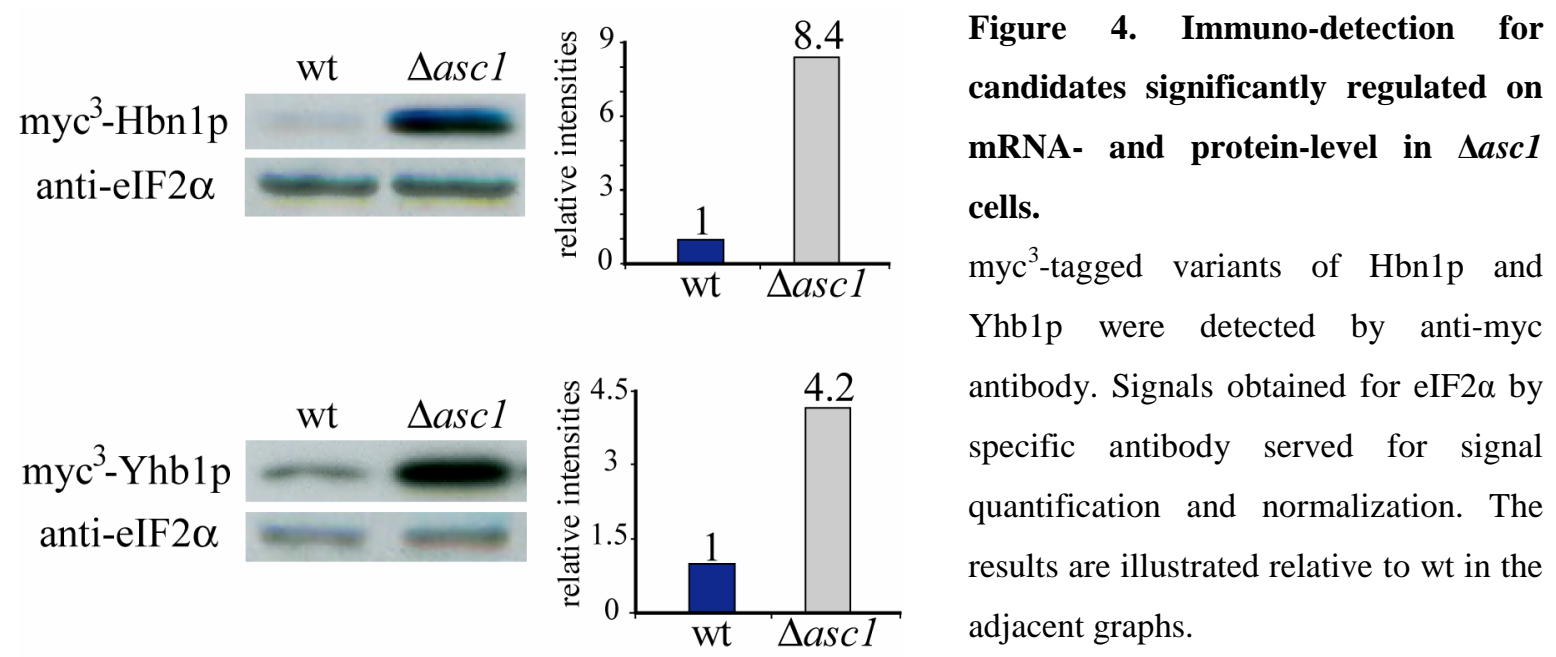

\section{Phenotypic characterization of the $\Delta a s c 1$ strain based on the global expression data}

Global expression data was obtained via proteome and transcriptome analysis of the $\Delta a s c 1$ strain in comparison to wt. This data reveals several diverse biological processes to be affected by Asc1p and suggests its involvement in cell signaling. In a next step the influence of Asc1p on the following processes was investigated phenotypically: maintenance of cell wall integrity, respiration, fermentation, and iron-homeostasis.

\section{Cell wall integrity is compromised in $\Delta a s c 1$ cells}

Several proteins and mRNAs involved in cell wall integrity and maintenance were found as down-regulated in $\Delta a s c 1$ cells. This especially becomes apparent in the drastic reduction of mRNAs coding for cell wall constituents. In agreement the rate of total de novo biosynthesis of insoluble proteins is significantly down-regulated in the $\Delta$ ascl strain determined by scintillation counting. Assuming a misregulation in the cell wall integrity pathway, a growth assay on medium supplemented with caffeine was performed, a chemical compound commonly used to score for defects in cell wall integrity (Martín et al., 1996). The $\Delta a s c l$ strain shows a significantly enhanced sensitivity for caffeine in comparison to the wt (Figure 5A), which confirms maintenance of cell wall integrity to be a process influenced by Asc1p, as has been indicated by the global expression data. 
A

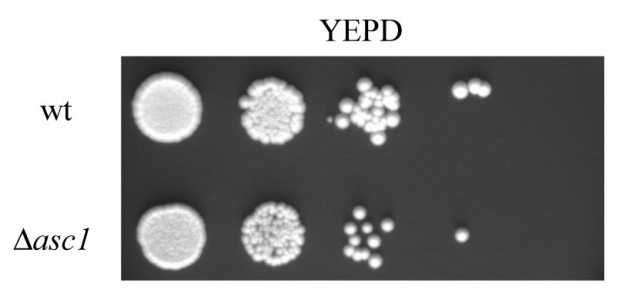

YEPD $+10 \mu \mathrm{M}$ caffeine

wt

$\Delta a s c 1$
B

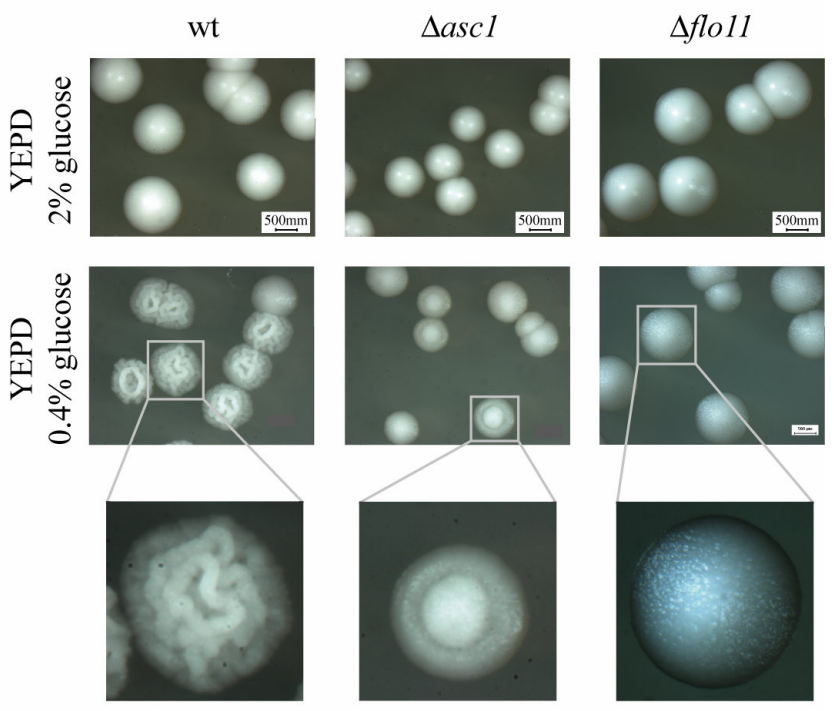

Figure 5. Investigation of cell wall integrity. (A) Caffeine growth assay. Cells were serial 10 fold diluted and spotted on YEPD plates with and without $10 \mu \mathrm{M}$ caffeine. Growth was documented after 3 days of incubation at $30^{\circ} \mathrm{C}$. (B) Colony morphology alterations under glucose-limitation. Wt cells as well as $\Delta$ ascl and $\Delta$ flo11 mutant cells were plated on YEPD medium containing $2 \%$ (no limitation) or $0.4 \%$ glucose (glucose-limitation). Colonies were investigated via binocular after 3 days of incubation at $30^{\circ} \mathrm{C}$.

The role of Asc1p in proper cell wall morphology is further evident when evaluating the colony morphology of the $\Delta a s c l$ mutant in comparison to the wt strain under limiting glucose concentrations (0.4\%) (Figure 5B). Wt colonies form a distinct loopy structure when grown under limiting glucose conditions as has been previously described for yeast mat formation (Reynolds et al., 2008). This effect could be linked to the expression of the cell surface glycoprotein Flo11p and is therefore absent in a $\Delta$ floll strain. $\Delta a s c l$ colonies also lack the structure formation observed for the wt strain but merely show a faint rim formation for some colonies. This effect can be attributed to the significantly reduced expression of FLO11 in a $\triangle a s c 1$ strain (Valerius et al., 2007).

\section{Respiration is restrained in $\Delta a s c 1$ cells}

Gained proteome and transcriptome data suggests that the fermentation in $\Delta$ ascl cells is up-regulated and furthermore that respiration is reduced. Phenotypical investigations were conducted to shed light on the role of Asc1p in these processes of energy metabolism. 
Respiratory activity in the $\Delta a s c 1$ strain in comparison to the wt was scored via Triphenyltetrazolium chloride (TTC) assay (Figure 6A).
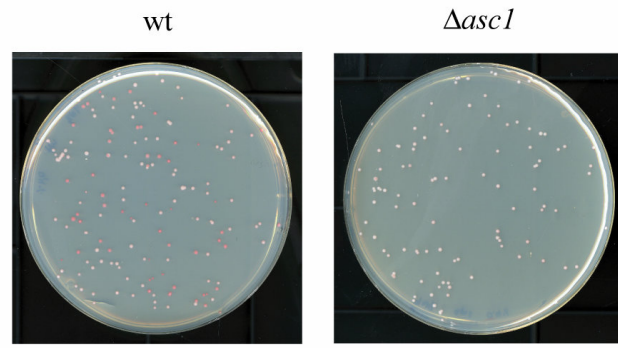

YNB $(0.4 \%$ glc $)+0.5 \%$ TTC overlay
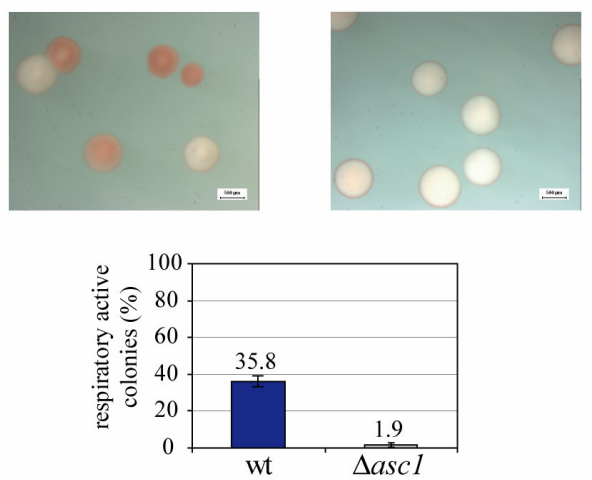

$\mathrm{C}$

YEP $+2 \%$ glucose (fermentable C-source)
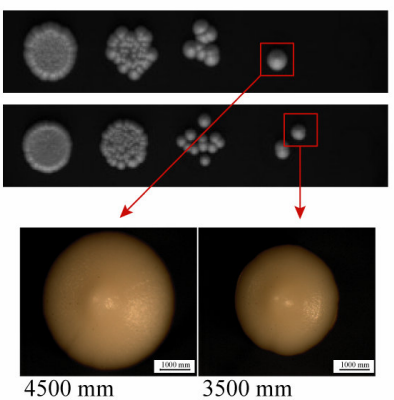

$\mathrm{YEP}+2 \% \mathrm{EtOH}$

(non-fermentable C-source)

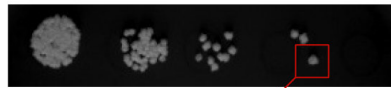

$\Delta a s c 1$
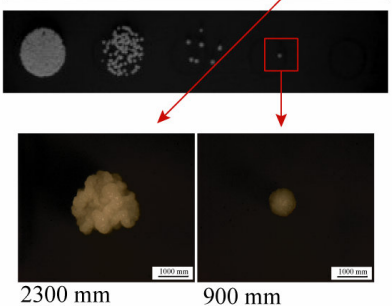

B

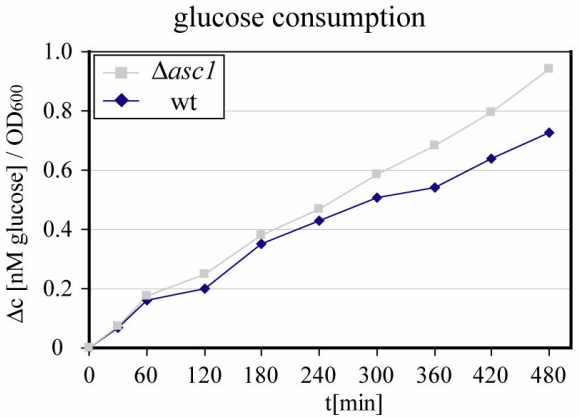

ethanol production

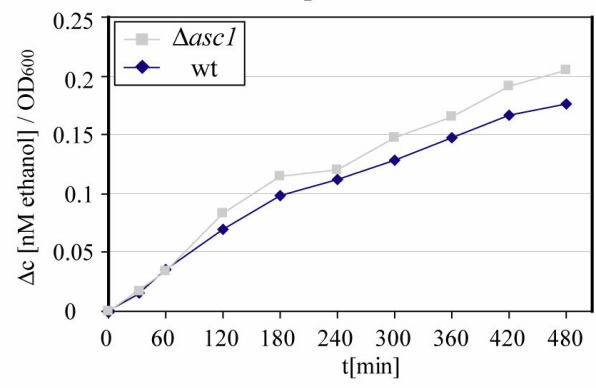

Figure 6. Evaluation of respiratory and fermentative activity in $\Delta$ asc1 cells.

(A) Assay to determine respiratory activity in wt and Aascl cells. Colonies were grown on YNB under limited glucose conditions $(0.4 \%$ glc) for 3 days and subsequently overlaid with $1.2 \%$ agar containing $0.5 \%$ Triphenyltetrazolium chloride (TTC). Red and white colonies were scored after 20min of incubation with TTC at $30^{\circ} \mathrm{C}$. The fraction of red (respiratory active) colonies was determined for wt and $\Delta a s c l$ and is expressed in percentage relative to the respective total colony count. (B) Comparative analysis of glucose consumption and ethanol production in wt and $\Delta$ ascl cells. Wt and $\Delta$ ascl cells were grown to $\mathrm{OD}_{600}=0.5$ before the first sample drawing $(\mathrm{t}=0)$. Over a period of 8 hours samples were drawn at the given time points 
to determine glucose or ethanol concentrations in the medium. Additionally, the cell density was determined. The data was obtained in three biologically independent analyses and the standard deviation did not exceed $10 \%$. Glucose concentration in the medium was measured and the glucose consumption $(\Delta \mathrm{c})$ determined for wt and $\Delta a s c 1$ relative to the cell density $\left(\mathrm{OD}_{600}\right)$ at the given time points $\left(\Delta \mathrm{c}[\mathrm{nM}\right.$ glucose $\left.] / \mathrm{OD}_{600}\right)$. The consumption $(\Delta \mathrm{c})$ is defined as the difference in glucose concentration from the first sample drawing $(\mathrm{t}=0)$ to the concentration at the given time points. Ethanol concentration was determined in wt and $\Delta$ ascl cell cultures at the given time points and related to the respective cell density $\left(\Delta \mathrm{c}[\mathrm{nM}\right.$ ethanol $\left.] / \mathrm{OD}_{600}\right)$. The illustrated graph displays the average ethanol production relative to the cell density at $\mathrm{t}=\mathrm{x}[\mathrm{min}]$. (C) Growth assay to evaluate respiratory colony growth. Cells were spotted in serial 10 fold dilutions on plates containing a fermentable $(2 \%$ glucose $)$ or non-fermentable $(2 \% \mathrm{EtOH})$ carbon source. After incubation at $30^{\circ} \mathrm{C}$ for 3 days colony diameters were determined via binocular. The results are displayed relative to the wt in the adjacent graph.

TTC functions as electron acceptor and is reduced in the course of electron transfer within the respiratory chain, leading to the production of a red pigment when colonies are actively respiring (Ogur et al., 1957). Under the given growth conditions about $40 \%$ of wt colonies are respiratory active, whereas only $2 \%$ of $\Delta a s c 1$ colonies show the red pigmentation. This drastic reduction in respiratory activity of about 20 fold illustrates a significant impairment in the respiratory chain in response to the deletion of ASC1. The absence of Asc1p seems to have the contrary effect on fermentation. Glucose consumption and ethanol production of wt and $\Delta a s c 1$ cultures was monitored over a period of 8 hours (Figure 6B). The data shows that $\Delta a s c l$ cells consume increasingly more glucose than wt cells. This suggests that $\Delta$ ascl cells either require more energy or that more glucose needs to be consumed by $\Delta$ ascl cells to achieve the same level of available energy as present in wt cells. The measured elevated ethanol production for the $\Delta a s c 1$ strain indicates a shift of the energy metabolism in the mutant cells from respiration towards fermentation. This elevated fermentative activity explains the higher glucose consumption of $\Delta a s c l$ cells, since the same amount of glucose delivers less energy when fermented than respired. A growth assay of wt and $\Delta a s c l$ cells on agar plates either containing a fermentable ( $2 \%$ glucose) or non fermentable $(2 \% \mathrm{EtOH})$ carbon source was conducted to further assess the respiratory capability of the mutant strain (Figure 6C). It illustrates that colony growth is rather similar when glucose is readily available as carbon source, which can be used either for respiration or fermentation. But when only the path of respiration is left, induced by growth on ethanol as a non-fermentable carbon source, $\Delta a s c l$ cells show a clearly reduced colony growth. 
The colonies of both strains further demonstrate an altered morphology, whereas $\Delta$ ascl colonies exhibit a significantly stronger phenotype than wt colonies. $\Delta a s c l$ colony size halves upon the growth on ethanol as carbon source and measures only $40 \%$ compared to wt colony size on ethanol. This 'petite' phenotype is an additional indication for an impaired respiration in the $\Delta a s c 1$ strain (Ogur and John, 1956).

Taken together the data supports that Asc1p is required for respiratory chain activity and that respiration is significantly reduced in $\Delta a s c 1$ cells. Furthermore fermentation is up-regulated in $\Delta a s c 1$ cells, possibly as a secondary effect to compensate for the reduced respiratory activity.

\section{$\Delta a s c 1$ cells are more sensitive to iron depletion}

Several mRNAs involved in iron uptake were found to be strongly down-regulated in $\Delta$ ascl cells. The corresponding proteins are involved in high-affinity and low-affinity iron uptake by both, the iron transport system and iron-chelating siderophores. To confirm these indications for a reduction in iron uptake the sensitivity for iron depletion of a $\Delta a s c 1$ mutant was determined. A growth assay with the iron (II) chelator Bathophenanthrolinedisulfonic acid (BPS) was conducted (Figure 7).

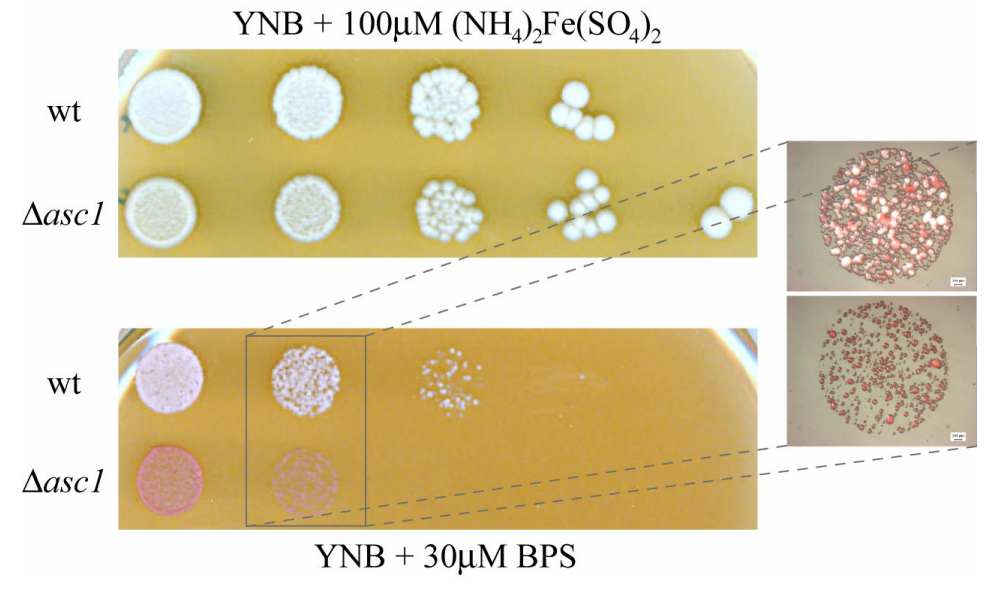

Figure 7. Sensitivity for iron limitation. Serial 10 fold dilutions of wt and $\Delta a s c 1$ cells were plated on YNB medium containing $30 \mu \mathrm{M}$ of the iron (II) chelator Bathophenanthrolinedisulfonic acid (BPS) or $100 \mu \mathrm{M}$ $\left(\mathrm{NH}_{4}\right)_{2} \mathrm{Fe}\left(\mathrm{SO}_{4}\right)_{2}$ as control. Plates were incubated at $30^{\circ} \mathrm{C}$ for 5 days.

Upon binding to ferrous (II) iron BPS forms a red colored complex. The assay reveals a higher sensitivity of the $\Delta a s c l$ strain for the iron chelator in comparison to the wt, suggesting that the absence of Asc1p leads to lower iron concentrations within the cell. 
This can be seen as a consequence of a reduced iron uptake in $\Delta a s c l$ cells as indicated by the transcriptome data. Additionally to a reduced growth, $\Delta$ ascl colonies show an enhanced red pigmentation compared to wt upon incubation with BPS (Figure 7). $\Delta a s c 1$ colonies exhibit a much darker red coloring early on, which is met by wt colonies only after several additional days of incubation (data not shown).

\section{Asc1p post-transcriptionally influences the expression of transcription factors}

In a next step the Asc1p-downstream effectors causing the changes, apparent on the protein- and mRNA-level as well as in the phenotypical observations, were analyzed. Since Asc1p is a constituent of the ribosome it is likely to exhibit its influence on such effectors during the process of translation or through post-translational modifications. Most proteins described to be regulated in such a way are of low abundance, as e.g. transcription factor (TFs). Changes in their availability depict an efficient and rapid way of globally altering gene expression. The transcriptome data generated for the $\Delta a s c l$ strain served as a starting point to determine candidate-TFs possibly regulated in an Asc1p-dependent manner. The number of mRNAs that were found to be regulated in the $\Delta a s c l$ strain was submitted to YEASTRACT (http://www.yeastract.com/, May 2010) to identify TF that have been shown to bind to these mRNAs by direct evidence (Teixeira et al., 2006; Monteiro et al., 2008). The TFs with a described direct binding to the respective genes were collected and are displayed in Table 3. The four TFs, involved in the regulation of most genes, are Ste12p, Phd1p, Tec1p and Rap1p, each binding to over 20\% of the genes, regulated in the $\Delta a s c 1$ strain. They therefore have high potential to be responsible for the majority of transcriptome changes in the mutant.

Table 3. Major transcription factors inducing changes in the $\Delta a s c 1$ transcriptome. The list of regulated genes was subjected to YEASTRACT (http://www.yeastract.com/) (Teixeira et al., 2006; Monteiro et al., 2008) to determine their respective transcription factors (TFs). The search criteria were set to only consider direct evidence for TF-binding. The ten top TFs are ordered according to the number of genes in the list regulated by them. This number is given in percentage relative to the total number of genes in the list. TFs subjected to further analysis are highlighted. The target genes for each TF are separated according to the up- or down-regulation of their respective mRNAs in the $\Delta a s c l$ strain. 


\begin{tabular}{|c|c|c|c|}
\hline TF & $\begin{array}{l}\text { regulated } \\
\text { genes }[\%]\end{array}$ & $\Delta a s c 1$ & genes bound by TF \\
\hline \multirow{2}{*}{ Ste12 } & \multirow{2}{*}{$40.0 \%$} & up & $\begin{array}{l}\text { YCL021W-A, AHA1, YDR316W-B, UTR2, YER138W-A, YHB1, } \\
\text { YHR177W, ARG3, BNA2, YJR079W, SRL3, YMR045C, WSC3, THI80, } \\
\text { SFG1, YOR343W-A, YOR343W-B }\end{array}$ \\
\hline & & down & $\begin{array}{l}\text { ATP1, PMP1, PSA1, HXT7, HXT6, HXT3, SCW4, ARN1, YIL169c, URA2, } \\
\text { CWP2, TMA10, HOR7, DDR2, HPF1 }\end{array}$ \\
\hline \multirow{2}{*}{ Phd1 } & \multirow{2}{*}{$23.8 \%$} & up & SFG1, UTR2 \\
\hline & & down & $\begin{array}{l}\text { PSA1, INH1, YDR134C, CPR1, HXT7, HXT6, HXT3, SIT1, SCW4, ARN1, } \\
\text { YIL169C, CWP2, TIS11, FRE1, TMA10, HOR7, DDR2 }\end{array}$ \\
\hline \multirow{2}{*}{ Tec1 } & \multirow{2}{*}{$22.5 \%$} & up & $\begin{array}{l}\text { YBR012W-B, YCL021W-A, YDR316W-B, UTR2, YER138W-A, YHB1, } \\
\text { SRL3, WSC3, SFG1 }\end{array}$ \\
\hline & & down & ATP1, PSA1, HXT7, HXT6, HXT3, URA2, CWP2, HOR7, DDR2, \\
\hline \multirow{2}{*}{ Rap1 } & \multirow{2}{*}{$22.5 \%$} & up & KTI11, UTR2, YHB1, YHR177W, ARG3, SFG1 \\
\hline & & down & $\begin{array}{l}\text { PMP1, PSA1, CWP2, FRE1, TMA10, ASC1, DDR2, ENB1, ALD4, EEB1, } \\
\text { HXT6, SCW3 }\end{array}$ \\
\hline \multirow{2}{*}{ Sok2 } & \multirow{2}{*}{$20.0 \%$} & up & UTR2, YHR177W, SFG1 \\
\hline & & down & $\begin{array}{l}\text { PMP1, PSA1, YDR134C, HXT7, HXT6, HXT3, SIT1, SCW4, YIL169C, } \\
\text { CWP2, HOR7, DDR2, EEB1 }\end{array}$ \\
\hline \multirow{2}{*}{ Skn7 } & \multirow{2}{*}{$17.5 \%$} & up & BNA2, YJR079W, SFG1, YOR343W-A,YOR343W-B, YPR158C-D \\
\hline & & down & $\begin{array}{l}\text { ATP1, CPR1, SCW4, BNA2, YJR079W, CWP2, FRE1, HOR7, DDR2, } \\
\text { HPF1, }\end{array}$ \\
\hline \multirow[b]{2}{*}{ Flo8 } & \multirow[b]{2}{*}{$15.0 \%$} & up & UTR2, SFG1 \\
\hline & & down & $\begin{array}{l}\text { PSA1, YDR134C, HXT3, SCW4, ARN1, YIL169C, CWP2, FET3, HOR7, } \\
D D R 2\end{array}$ \\
\hline \multirow{2}{*}{ Fhl1 } & \multirow{2}{*}{$15.0 \%$} & up & KTI11, AHA1, BNA2 \\
\hline & & down & PSA1, YDR133C, YDR134C, CPR1, CWP2, TMA10, FET3, ASC1, HOR7 \\
\hline \multirow{2}{*}{ Pho4 } & \multirow{2}{*}{$13.8 \%$} & up & $W W M 1, Y H B 1$ \\
\hline & & down & INH1, CPR1, HXT7, HXT6, YIL169C, MDH1, TIS11, HOR7, HPF1 \\
\hline \multirow{2}{*}{ Swi4 } & \multirow{2}{*}{$13.8 \%$} & up & UTR2, YHB1, YOL114C, SFG1, YPR158C-D \\
\hline & & down & $P S A 1, Y D R 134 c, H X T 3, S C W 4, C W P 2, H P F 1$ \\
\hline
\end{tabular}

Furthermore all of these TFs bind to the promoter of FLO11, whose expression has been described to be drastically down-regulated in the $\Delta a s c 1$ strain (Valerius et al., 2007). The next step was to determine whether the protein levels for these TFs are affected by the deletion of ASC1. Comparative western hybridizations for the candidate-TFs were performed in the $\Delta a s c 1$ and the wt strain (Figure 8). Additionally, the protein abundance of Flo8p, found at position seven on the ranking list, was analyzed since this transcription factor is also known to be crucial for FLO11-expression (Rupp et al., 1999). All five TFs show a significant abundance change in response to the deletion of ASC1. Rap1p is strongly down-regulated by 10 fold in the $\Delta a s c 1$ strain. Protein levels of Tec1p, Phd1p and Flo8p are as well significantly reduced to $20 \%-30 \%$ of wt levels when Asc1p is absent. 
Ste12p on the other hand shows an opposing behaviour and is 9 fold up-regulated in the $\Delta a s c 1$ strain.
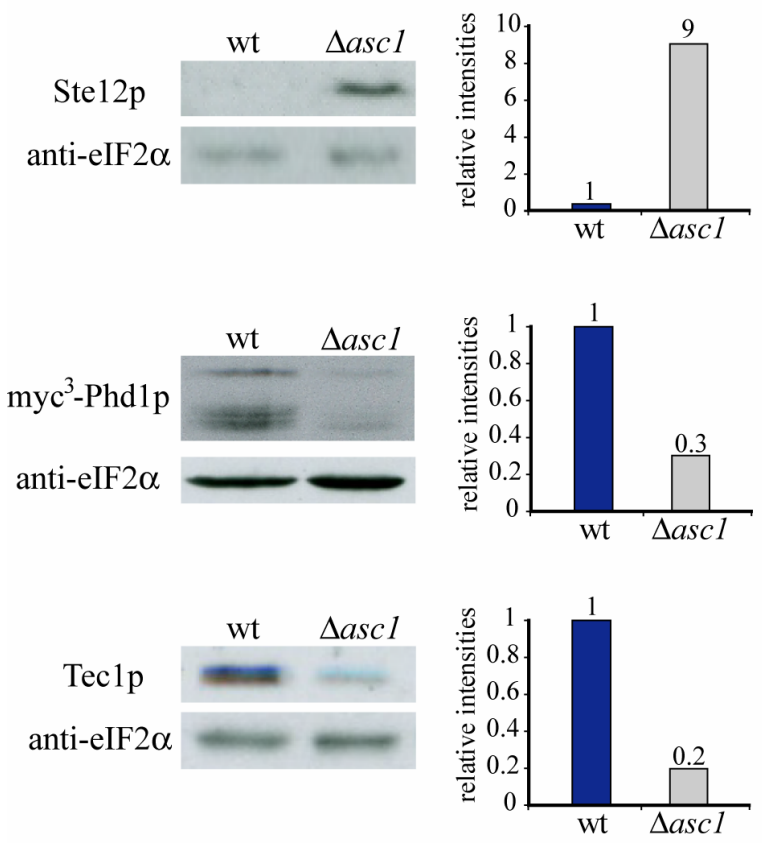
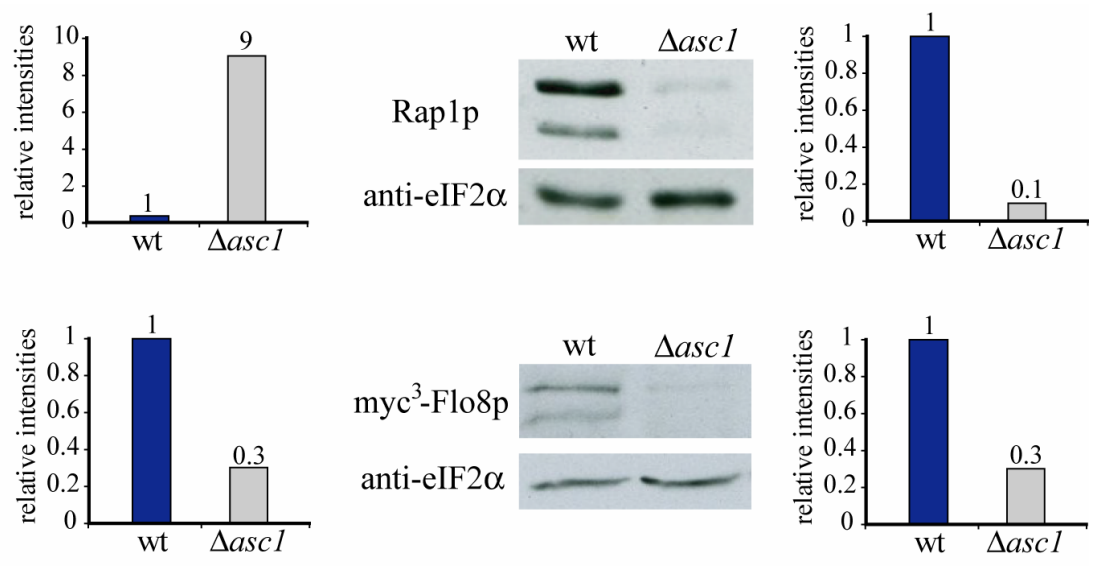

Figure 8. Western hybridization for transcription factors in the wt and $\Delta$ asc1 background. Ste12p, Tec1p and Rap1p were detected by specific antibodies. The myc ${ }^{3}$-tagged variants of Phd1p and Flo8p were detected with anti-myc antibody. Signals were quantified and normalized against eIF2 $\alpha$ levels detected by anti-eIF2 $\alpha$ antibody. The adjacent graphs illustrate the fold changes relative to wt signal intensities.

The significance of the difference in the protein levels suggests that these TFs are indeed involved in the induction of the majority of proteome and transcriptome changes in the Aascl strain as well as its described phenotypical characteristics. Thus, these global changes can be considered as a consequence of the function of Asc1p in altering the abundance of TFs. Interestingly our transcriptome data does not show an alteration in the mRNA levels of Ste12p, Tec1p, Rap1p, Phd1p or Flo8p from the wt to the $\Delta$ asc1 mutant. This implies that Asc1p does not alter the abundance of TFs through their mRNA-levels but influences their protein levels post-transcriptionally. 


\section{The MAPK pathway of mating is hyperactive in the $\Delta a s c 1$ strain}

The observed increase in protein abundance for Ste12p and the decrease of Tec1p resembles the changes taking place in response to pheromone signaling and corresponding activation of the MAPK pathway of mating. When activated the MAP kinase of this pathway, Fus $3 p$, phosphorylates the TFs Tec1p, Ste12p and the cyclin-dependent kinase inhibitor Far1p (Elion et al., 1993). This leads to the degradation of Tec1p (Brückner et al., 2004) and in addition, to the activation of Ste12p and Far1p, inducing mating-specific genes and G1-cell cycle arrest, respectively (Elion et al., 1993, Peter et al., 1993). Indeed, an elevated activity of Far1p and therefore the mating pathway is indicated in the $\Delta a s c l$ strain via growth inhibition/halo assay (Figure 9).

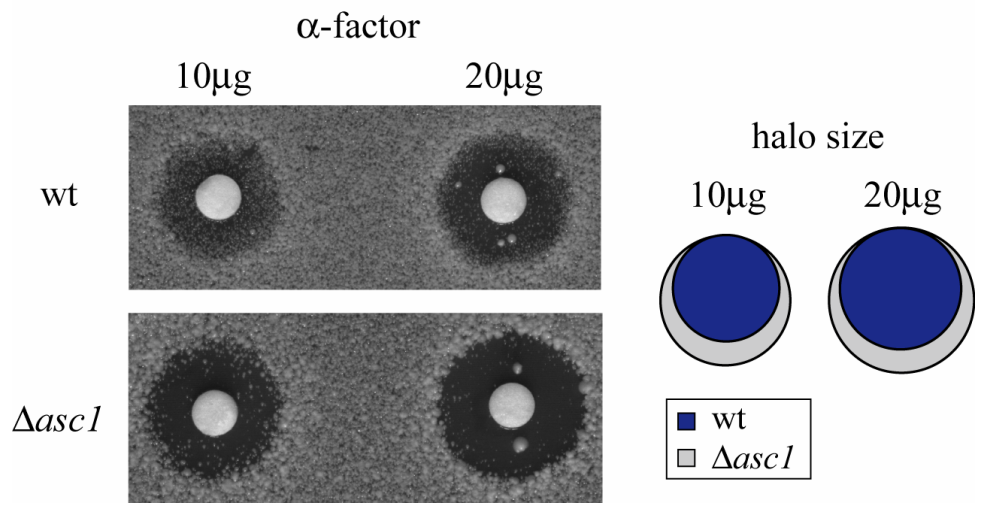

Figure 9. Growth inhibition/halo assay. Wt and $\triangle a s c 1$ cells of saturated cultures were plated on YEPD plates and filter papers containing $10 \mu \mathrm{g}$ or $20 \mu \mathrm{g} \alpha$-factor pheromone were applied to the agar surface. The halo sizes for the wt and $\Delta a s c l$ strain serve to determine their sensitivity for $\alpha$-factor and activity of the pheromone response pathway.

The mutant strain shows an enhanced sensitivity for $\alpha$-factor pheromone, which is visualized by a larger area of no growth (halo) around the pheromone-containing filter paper. In comparison to the wt strain the $\Delta a s c 1$ strain shows a 1.5 fold increase in halo size, as previously observed by Chasse and colleagues (2006) in the BY4741 strain background. This data suggests that the mating pathway is abnormally active in the $\Delta a s c l$ mutant strain. 


\section{Asc1p influences the translational regulation of Ste12p, Phd1p and Tec1p by their respective mRNA-5'UTR}

As demonstrated, Asc1p influences the protein abundances of Ste12p, Phd1p, Tec1p, Rap1p and Flo8p post-transcriptionally. The regulation of protein abundance could be influenced by Asc1p at different post-transcriptional stages in the cell, including mRNA-translation, co-/post-translational modifications and protein degradation.

Due to the ribosomal localization of Asc1p we followed up on a possible translational regulation of Ste12p, Phd1p, Tec1p, Rap1p and Flo8p via their respective mRNAs. Therefore we utilized a lacZ-reporter assay, specifically determining the influence on translation initiation mediated by the 5 ' untranslated regions (5'UTRs) of mRNAs of interest (Rachfall et al., under revision) (Figure 10A, see also Chapter II).

A
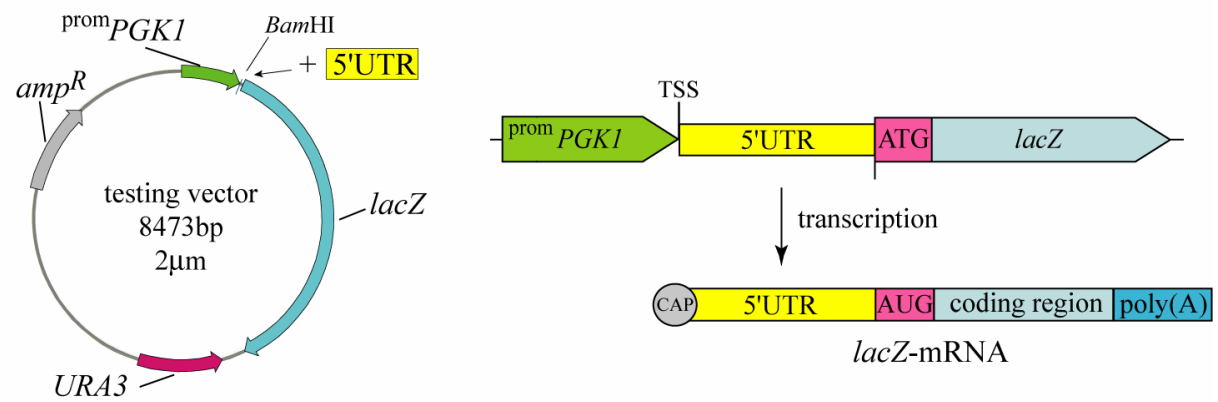

B

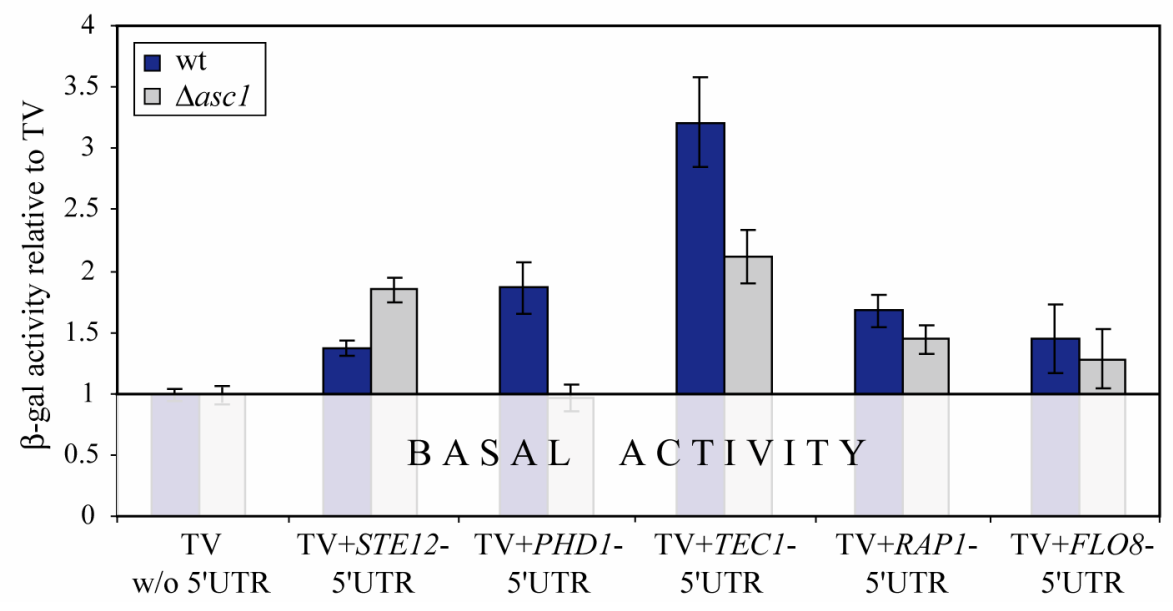

Figure 10. Testing system to evaluate the 5'UTR-mediated translational regulation of transcription factors by Asc1p. (A) Illustration of testing system (Rachfall et al., under revision). The testing vector (TV) contains a lacZ-reporter gene under the control of the constitutive PGKl-promoter with a defined 
transcription start site (TSS). An interjacent BamHI restriction site enables the insertion of arbitrary 5'UTR sequences. Transcription results in a lacZ-mRNA including the inserted 5'UTR as its own. (B) $\beta$-galactosidase assay. Wt and $\Delta a s c l$ strain were transformed with the testing vector (TV) with or w/o respective 5'UTRs. The changes in $\beta$-galactosidase activity upon the introduction of the respective 5'UTRs are illustrated relative to the basal $\beta$-galactosidase activity measured for the empty TV w/o 5'UTR in the wt and $\Delta a s c 1$ mutant.

The respective 5'UTR is inserted in the reporter-testing vector (TV) to be transcribed along with the lacZ-reporter gene. This results in a lacZ-mRNA carrying the respective 5'UTR of interest as its own. In case the integration of the 5'UTR causes changes in the translational rate of the lacZ-mRNA, this can be detected via $\beta$-galactosidase assay. To test the translationally regulative potential of the 5'UTRs of the STE12-, PHD1-, TEC1-, RAP1and FLO8-mRNAs, their respective sequences were introduced in the reporter-testing vector (TV) (Supplementary Table 3). The basal lacZ-expression for the wt and $\Delta a s c 1$ strain is expressed by the $\beta$-galactosidase activity measured for the empty TV without any 5'UTR-insertion (Figure 10B). Upon the introduction of the STE12-5'UTR, the induction of $\beta$-galactosidase activity is twice as high in the $\Delta a s c 1$ mutant strain than for the wt. A reduced induction in the $\Delta a s c l$ strain can be observed when the 5'UTRs of the PHD1-, TEC1-, RAP1- and FLO8-mRNAs are introduced in the TV, being rather mild effects for the RAPI- and FLO8-5'UTR. A significant reduction in lacZ-expression can be observed upon the introduction of the PHD1- and TEC1-5'UTRs. For the PHD1-5'UTR the $\beta$-galactosidase activity stays at basal levels in the mutant strain whereas it nearly doubles for the wt. The insertion of the TEC1-5'UTR leads to the highest induction of activities in both strains, which is halved in the $\Delta$ ascl strain compared to the wt. At least for the mRNAs of STE12, PHDI and TEC1 this suggests their regulation at the level of translation initiation by their respective 5'UTR sequence with the involvement of Asc1p. Further the changes in $\beta$-galactosidase activity from the wt to the $\Delta$ ascl strain correlate with the observed changes in protein abundance for these candidates, supporting that Ste12p, Phd1p and Tec1p are at least partially regulated translationally via Asc1p.

This study provides evidence for the involvement of Asc1p in a diversity of cellular processes including translation, transposition, iron-homeostasis, energy metabolism (glycolysis, respiration, fermentation, oxidative stress), cell wall maintenance and mating. 
The transcription factors causing the majority of the transcriptional changes in the $\Delta$ ascl strain are drastically regulated in their abundance upon the deletion of ASCl. The changes observed for Ste12p, Tec1p and Phd1p can, at least partially, be linked to an altered translation of their mRNAs in the $\Delta a s c 1$ strain mediated by their respective 5'UTR.

Taken together, the data suggests that Asc1p is involved in the regulation of the MAPK pathways of invasive/pseudohyphal growth, cell wall integrity and mating, possibly by alterations of targeted TFs. 


\section{Discussion}

A comprehensive analysis of gene and protein expression was performed to unravel the cellular function of the highly conserved Asc1/RACK1 protein. The obtained data is supported by growth assays specifically addressing the impact of the deletion of ASCl on the respective physiological processes found to be affected.

Iron-homeostasis seems to be highly imbalanced in the $\Delta a s c l$ strain especially caused by the reduced expression of siderophore transporters and the high-affinity iron uptake complex Fet3p/Ftr1p (Figure 11).

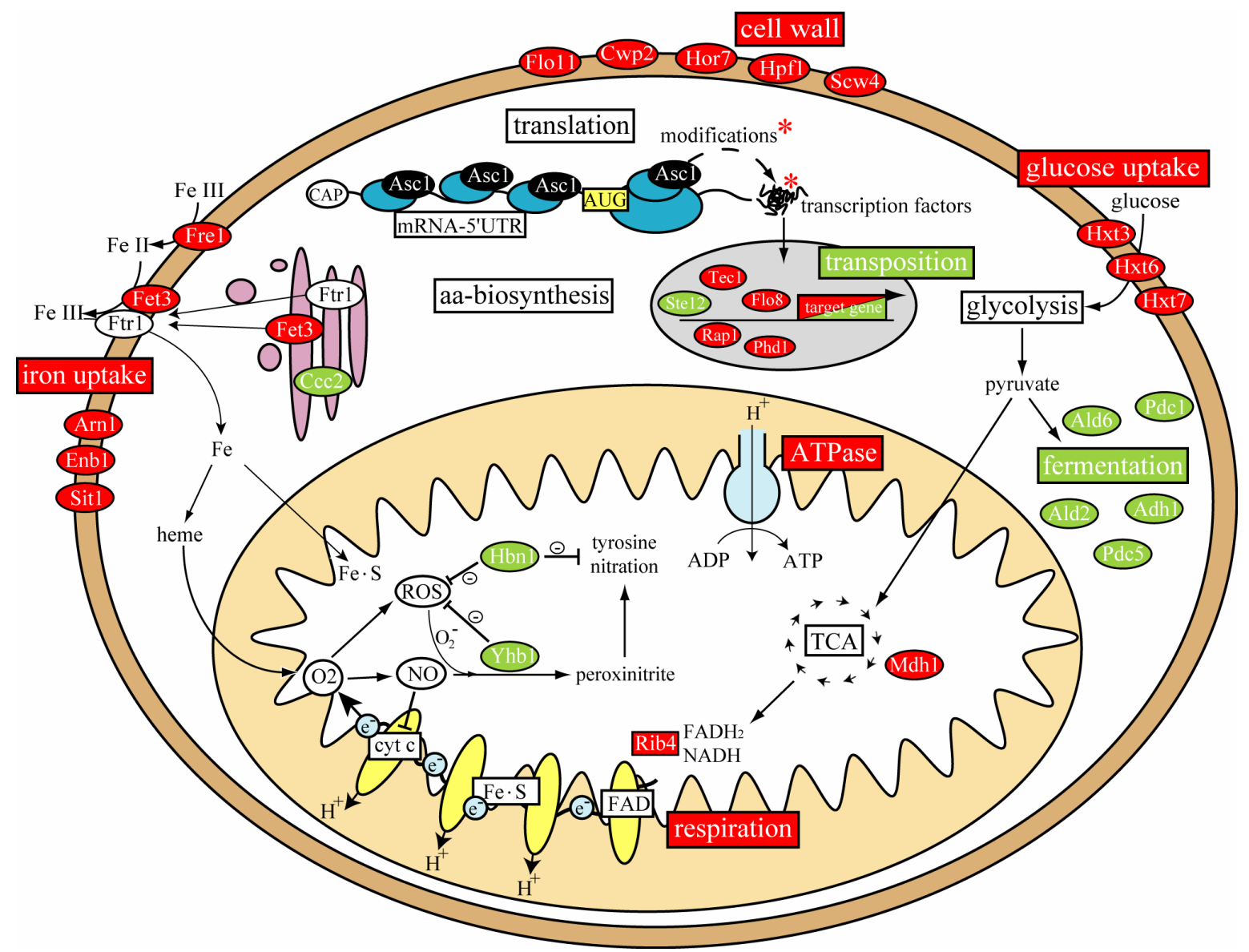

Figure 11. Scheme illustrating the cellular context of processes affected by Asc1p. Expression data and phenotypical observations are incorporated according to the cellular localization of the corresponding protein or process, respectively. Regulations supported by direct evidence are illustrated in red for a down-regulation in the $\Delta a s c 1$ strain and green for an up-regulation. 
Reduced cellular iron levels in the deletion strain consequently imply negative implications for the two major iron-consuming processes in the cell, the biosynthesis of iron-sulfur cluster (Fe-S) containing proteins and heme (Hausmann et al., 2008). Fe-S proteins are directly involved in the electron transport chain at the inner mitochondrial membrane. Heme is required for oxygen binding and transport, e.g. into the mitochondria to serve as final electron acceptor in the respiratory chain (Figure 11). A reduced amount of cellular heme results in hypoxic (low-oxygen) conditions within the cell. RACK1, the human orthologue of Asc1p, has been shown to promote the degradation of the hypoxia-induced transcription factor HIF-1 (Liu et al., 2007), the master regulator of hypoxic genes. It also controls the gene expression of key players in angiogenesis, erythropoiesis and glucose/energy metabolism (Baek et al., 2007). Yeast cells grown under oxygen-limited conditions have previously been shown to down-regulate Asc1p (Bruckmann et al., 2009). This indicates that Asc1p is specifically required for aerobic respiration, as shown in this work via TTC-assay and the impaired growth of the $\Delta a s c 1$ strain on ethanol as non-fermentable carbon source. Underlining the importance of Asc1p for respiratory activity, IRC18 is up-regulated in the mutant strain, an indicator for respiratory deficiency (Epstein et al., 2001).

The down-regulation of $M D H 1$, coding for the tricarboxylic acid (TCA) cycle malate dehydrogenase, and RIB4, required for riboflavin synthesis, further implies a reduced respiratory activity in $\Delta a s c 1$ cells (Figure 11). As a result of a prevailing compromised respiration in $\Delta$ ascl cells the coupled electron transfer across the inner mitochondrial membrane can be assumed to be reduced. In agreement ATP1 and ATP2, coding for components of the $\mathrm{F}_{1} \mathrm{~F}_{2}$-ATPase, are down-regulated in the mutant strain, suggesting a reduced ATP production (Senior et al., 2002).

In the course of the respiratory chain, electrons, transferred along the inner mitochondrial membrane to the final electron acceptor, may leak along the way, leading to the production of reactive oxygen species (ROS) (Turrens, 2003). Exposure to hypoxic conditions and the inhibition of the respiratory chain increases the production of ROS, as e.g. superoxide anions (Dirmeier et al., 2002) by an enhanced leakage of electrons. This is indicated by the strong up-regulation of Hbn1p and Yhb1p in the mutant strain on the mRNA level as well as the protein level. Hbn1p levels have previously been reported to be up-regulated upon iron-deficiency (Seo et al., 2008) and its function in the activation of superoxide dismutase 
(SOD) has been described (de Oliveira et al., 2010). The expression levels of Yhb1p are low in respiring yeast but strongly increase under hypoxic conditions, when the electron transfer chain is compromised and oxidative as well as nitrosative stress enhances (Waterland et al., 1991; Zhao et al., 1996; Castello et al., 2006). Accordingly the function of Yhb1p in oxidative stress response is indirect as nitric oxide reductase (Liu et al., 2000) (Figure 11). It consumes nitric oxide (NO), diminishing its inhibitory effect on mitochondrial respiration through cytochrome c oxidase (Brown and Borutaite, 2001; Groot et al., 2007) and the consequently enhanced ROS production (Cassanova et al., 2005) (Figure 11). Despite the lack of an NO synthase, yeast cells are capable of NO-production, carried out by the cytochrome c oxidase, as a result of $\mathrm{NO}_{2}{ }^{-}$functioning as alternative final electron acceptor, when cellular oxygen-levels are reduced (Castello et al., 2006). Mediated by Yhb1p, NO and the superoxide anion $\left(\mathrm{O}_{2}^{-}\right)$combine to produce peroxynitrite $\left(\mathrm{ONOO}_{2}\right)$, which can in turn mediate protein tyrosine nitration (Radi, 2004; Castello et al., 2006) (Figure 11). This modification specifically activates mammalian protein kinase $\mathrm{C}(\mathrm{PKC} \varepsilon)$ through its increased interaction with RACK2 (Balafanova et al., 2002). Increased protein tyrosine nitration has been reported as a consequence of hypoxic growth conditions (Castello et al., 2006) and might represent a very effective mechanism to influence protein activities upon ROS and NO inducing conditions, especially in the mitochondria. A proteome study for tyrosine nitrated proteins in rat revealed nitration targets especially within the functional groups of oxidative stress, energy production and fatty acid metabolism but also for the Asc1p homologue RACK1 (Aulak et al., 2001). Probably closely associated to cellular nitration is the function of Hbnlp through its $\mathrm{NAD}(\mathrm{P}) \mathrm{H}$-dependent activity as putative nitroreductase and its involvement in SOD-activation (de Oliveira et al., 2007; de Oliveira et al., 2010).

Although nitration of yeast Pkc1p or Asc1p has not yet been shown, the Pkc1-dependent maintenance of cell wall integrity is clearly compromised in the $\Delta a s c 1$ strain. This has been shown through an increased sensitivity for the cell wall disturbing agents calcofluor white, zymolyase (Valerius et al., 2007) and caffeine, a characteristic phenotype in mutants affected in the Pkc1 pathway (Martín et al., 1996). Furthermore, the misregulation of multiple mRNAs and proteins involved in cell wall biogenesis and morphology as well as the reduced biosynthesis of radioactively labeled proteins of the insoluble fraction in the $\Delta$ ascl strain confirms this observation (Figure 11). Despite these unambiguous 
phenotypes, several findings indicate that the corresponding signaling pathway of cell wall integrity is however, activated. The mRNA for WSC3, coding for the sensor-transducer of the pathway, is up-regulated in the mutant strain. Additionally, the MAP kinase of the cell wall integrity pathway, Slt2p, physically interacts with Asc1p (Breitkreutz et al., 2010) and, more importantly, shows an elevated phosphorylation when ASC1 is deleted (Figure 12) (Chasse et al., 2006).

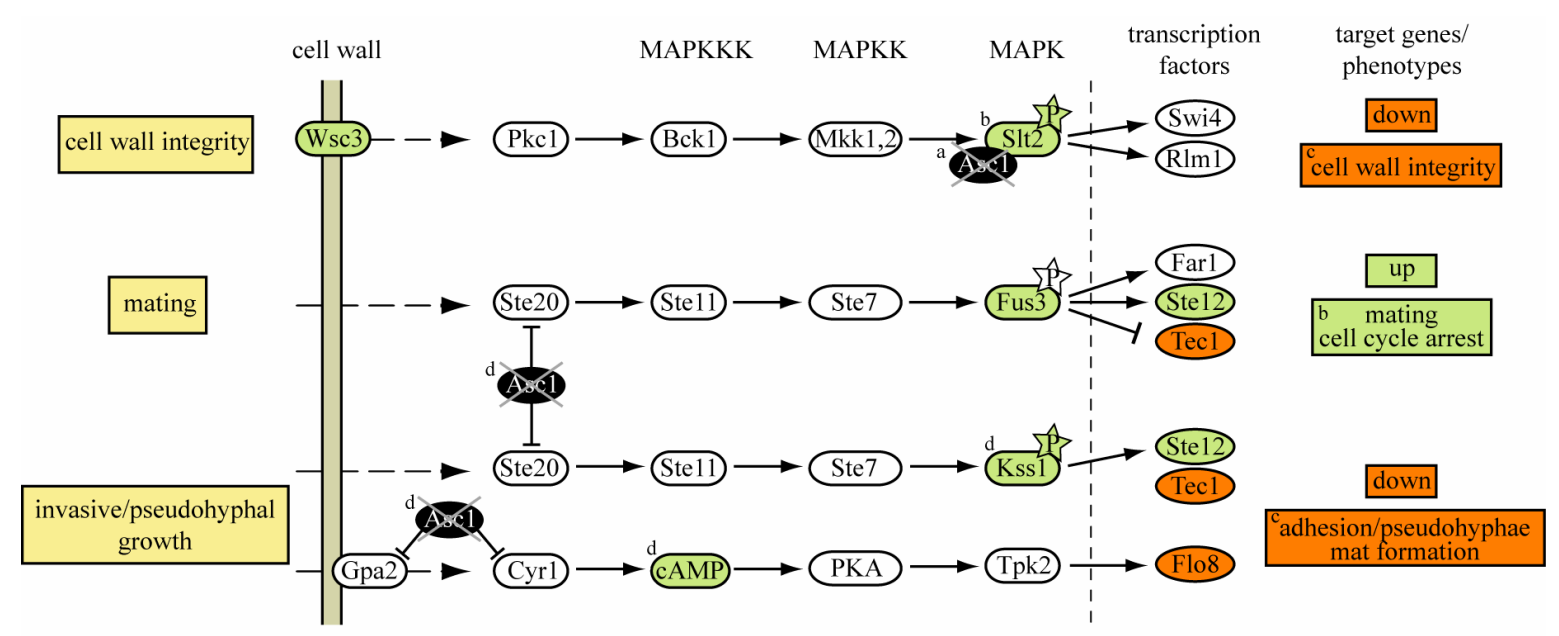

Figure 12. Implications of ASC1-deletion on the MAPK-pathways of cell wall integrity, mating and invasive/pseudohyphal growth. The components of the MAPK pathways are illustrated according to their relevance in context with observed changes in a $\Delta a s c 1$ mutant. Changes in abundance, phosphorylation state or phenotype in response to the deletion of $A S C 1$ are illustrated in green (up-regulation) or red (downregulation) ( ${ }^{\mathrm{a}}$ Breitkreutz et al., 2010; ${ }^{\mathrm{b}}$ Chasse et al., 2006; ${ }^{\mathrm{c}}$ Valerius et al., 2007; ${ }^{\mathrm{d}}$ Zeller et al., 2007).

This discrepancy between pathway-activation and the absence of the corresponding read-out illustrates that the MAPK pathway of cell wall integrity is rigorously influenced downstream of its MAP kinase Slt2p in the $\Delta a s c 1$ mutant and consequently implies that Asc1p is required for the activation of the Slt2p-downstream transcriptional activators Rlm1p and Swi4p. This is confirmed by the fact, that the bulk of target genes of the cell wall integrity pathway are not up-regulated but even show a down-regulation in the $\Delta$ ascl strain (Table 3, Figure 12).

A similar discrepancy is observed in the $\Delta a s c l$ strain for the signaling cascade of adhesive and pseudohyphal growth, divided in the cAMP-dependent PKA pathway and the MAPK pathway (Figure 12). Both pathways were shown to be constitutively activated when ASC1 
is deleted via elevated cAMP-levels as well as the enhanced phosphorylation of the MAP kinase Kss1p (Zeller et al., 2007). Generally the activation of the PKA pathway leads to the phosphorylation of the TF Flo8p, thereby enabled to induce its target genes, such as FLO11 (Rupp et al., 1999). Additionally, activated Kss1p mediates the transcriptional activity of the TFs Ste12p and Tec1p on the FLO11-promotor. In the course of activation it phosphorylates Ste12p and its inhibitors Dig1p/Dig2p, leading to the release and activation of Ste12p (Elion et al., 1993; Tedford et al., 1997). In spite of the activated FLO11-inducing pathways, FLO11-expression is clearly down-regulated in $\triangle a s c 1$ cells and Flo11p-dependent adhesive/pseudohyphal growth and mat formation can not be induced (Figure 12) (Valerius et al., 2007; Reynolds et al., 2008) (Figure 3, Supplementary Table 2B). This again suggests a misregulation at the level of TFs in the $\Delta$ ascl strain. Indeed, the abundances of Ste12p, Tec1p and Flo8p and the PKA and MAPK pathwayindependent FLO11-promoter-binding TFs Phd1p and Rap1p are drastically altered in the $\Delta$ asc1 strain. Whereas the protein-levels of Tec1p, Flo8p, Phd1p and Rap1p are severely reduced, Ste $12 \mathrm{p}$ is more abundant in $\Delta$ ascl cells. Accordingly, the transcriptome data reveals a down-regulation for the majority of target genes regulated by Tec1p, Flo8p, Phd1p and Rap1p and an up-regulation for most Ste12p target genes in the mutant strain (Table 3).

Additionally to the signaling pathways of cell wall integrity and adhesive/pseudohyphal growth, the mating MAPK pathway is influenced by Asc1p. The Map kinase of this pathway, Fus3p, enables the cross-talk between the MAPK-pathways of mating and invasive/pseudohyphal growth (Figure 12). Like Kss1p, Fus3p phosphorylates Ste12p and Dig1p/Dig2p, leading to Ste12p activation in both pathways (Elion et al., 1993; Tedford et al., 1997). Furthermore it phosphorylates Tec1p, resulting in Tec1p degradation and inhibition of the pathway of invasive/pseudohyphal growth (Brückner et al., 2004). In contrast to the previously discussed pathways, the suggested enhanced activity of the MAP kinase Fus3p in the $\Delta a s c 1$ strain is carried on to efficiently express FUS1, a direct target gene of Ste12p in the mating pathway (Supplementary Table 2B). A further indication for an elevated mating pathway activity is the enhanced pheromone-sensitivity of the $\Delta a s c l$ strain, linked to Far1-phosphorylation by Fus3p (Elion et al., 1993), assessed via halo assay (Figure 9; Chasse et al., 2006). An additional influence for Fus3p has been described in inhibiting Ty1-transposition (Conte and Curcio, 2000). Curiously, despite the elevated 
expression of FUS3 in the $\Delta a s c 1$ strain (Supplementary Table 2B) and its proposed enhanced activity, an up-regulation in Ty1-mRNA (Figure 3) as well as in Ty1-transposition can be observed when deleting ASC1 (Nyswaner et al., 2008). This discrepancy might be explained by the drastic reduction in Tec1p when ASCl is deleted since the inhibitory effect of Fus3p on transposition is dependent on both TFs, Ste12p and Tec1p (Conte and Curcio, 2000).

The 5'UTR reporter system used in this work strongly suggests that the changes in Tec1p as well as Phd1p and Ste12p abundances are linked to a translational regulation mediated by Asc1p. Despite these findings several alternative mechanisms by which Asc1p might influence protein abundances are conceivable, including mRNA-stability control, co- and post-translational modifications and resultant changes in protein stability. For example, Asc1p has been shown to greatly influence phosphorylations of proteins, including the phosphorylation state of the translation initiation factors eIF2 and eIF4A, which can influence protein abundances substantially (Valerius et al., 2007).

In conclusion this study provides evidence that Asc1p is involved in the regulation of diverse cellular processes, ranging from iron homeostasis and energy metabolism to intracellular signaling through MAPK cascades and the cAMP-dependent PKA pathway. On the basis of the discrepancies between the activation of signaling pathways and the TF-mediated phenotypical read-out, it can be hypothesized that the interactions of the ribosomal protein Asc1p with upstream signal transduction proteins specifically alters ribosomal settings (e.g. post-translational modifications of translation factors or ribosomal proteins). This in turn could determine the translational rates of specific downstream transcription factor mRNAs or confer ribosome specificity for distinct groups of mRNAs. 


\section{Acknowledgements}

We especially thank Verena Pretz for her outstanding technical assistance and Stefan Irniger for the contribution of ideas and helpful discussions. We cordially thank Thomas Dever and Hans-Ulrich Mösch for providing respective antibodies. This project was supported by the Deutsche Forschungsgemeinschaft. 


\section{References}

Aulak, K. S., Miyagi, M., Yan, L., West, K. A., Massillon, D., Crabb, J. W., and Stuehr, D. J. (2001) Proteomic method identifies proteins nitrated in vivo during inflammatory challenge. Proc Natl Acad Sci U S A 98 (21), 12056-12061.

Baek, J. H., Liu, Y. V., McDonald, K. R., Wesley, J. B., Zhang, H., and Semenza, G. L. (2007) Spermidine/spermine $N^{1}$-acetyltransferase-1 binds to hypoxiainducible factor-1 $\alpha$ (HIF-1 $\alpha$ ) and RACK1 and promotes ubiquitination and degradation of HIF-1 $\alpha$. J Biol Chem 282 (46), 33358-33366.

Balafanova, Z., Bolli, R., Zhang, J., Zheng, Y., Pass, J. M., Bhatnagar, A., Tang, X. L., Wang, O., Cardwell, E., and Ping, P. (2002) Nitric oxide (NO) induces nitration of protein kinase $\mathrm{C} \varepsilon(\mathrm{PKC} \varepsilon)$, facilitating $\mathrm{PKC} \varepsilon$ translocation via enhanced PKC $\varepsilon$-RACK2 interactions: a novel mechanism of NO-triggered activation of PKCع. J Biol Chem 277 (17), 15021-15027.

Baum, S., Bittins, M., Frey, S., and Seedorf, M. (2004) Asc1p, a WD40-domain containing adaptor protein, is required for the interaction of the RNA-binding protein Scp160p with polysomes. Biochem J (380), 823-830.

Berns, H., Humar, R., Hengerer, B., Kiefer, F. N., and Battegay, E. J. (2000) RACK1 is up-regulated in angiogenesis and human carcinomas. FASEB $J 14$ (15), 2549-2558.

Blum, H., Eyer, H., and Gross, H. J. (1987) Improved silver staining of plant proteins, RNA and DNA in polyacrylamide gels. Electrophoresis 8, 93-99.

Bradford, M. M. (1976) A rapid and sensitive method for the quantitation of microgram quantities of protein utilizing the principle of protein-dye binding. Anal Biochem 72, 248-254.

Braus, G. H., Grundmann, O., Brückner, S., and Mösch, H. U. (2003) Amino acid starvation and Gcn $4 p$ regulate adhesive growth and FLO11 gene expression in Saccharomyces cerevisiae. Mol Biol Cell 14 (10), 4272-4284.

Breitkreutz, A., Choi, H., Sharom, J. R., Boucher, L., Neduva, V., Larsen, B., Lin, Z. Y., Breitkreutz, B. J., Stark, C., Liu, G., Ahn, J., Dewar-Darch, D., Reguly, T., Tang, X., Almeida, R., Qin, Z. S., Pawson, T., Gingras, A. C., Nesvizhskii, 
A. I., and Tyers, M. (2010) A global protein kinase and phosphatase interaction network in yeast. Science 328 (5981), 1043-1046.

Brown, G. C., and Borutaite, V. (2001) Nitric oxide, mitochondria, and cell death. IUBMB Life 52 (3-5), 189-195.

Bruckmann, A., Hensbergen, P. J., Balog, C. I., Deelder, A. M., Brandt, R., Snoek, I. S., Steensma, H. Y., and van Heusden, G. P. (2009) Proteome analysis of aerobically and anaerobically grown Saccharomyces cerevisiae cells. J Proteomics $71(6), 662-669$.

Brückner, S., Köhler, T., Braus, G. H., Heise, B., Bolte, M., and Mösch, H. U. (2004) Differential regulation of Tec1 by Fus3 and Kss 1 confers signaling specificity in yeast development. Curr Genet 46 (6), 331-342.

Cassanova, N., O'Brien, K. M., Stahl, B. T., McClure, T., and Poyton, R. O. (2005) Yeast flavohemoglobin, a nitric oxide oxidoreductase, is located in both the cytosol and the mitochondrial matrix: effects of respiration, anoxia, and the mitochondrial genome on its intracellular level and distribution. J Biol Chem 280 (9), 7645-7653.

Castello, P. R., David, P. S., McClure, T., Crook, Z., and Poyton, R. O. (2006) Mitochondrial cytochrome oxidase produces nitric oxide under hypoxic conditions: implications for oxygen sensing and hypoxic signaling in eukaryotes. Cell Metab 3 (4), 277-287.

Chantrel, Y., Gaisne, M., Lions, C., and Verdière, J. (1998) The transcriptional regulator Hap1p (Cyp1p) is essential for anaerobic or heme-deficient growth of Saccharomyces cerevisiae: Genetic and molecular characterization of an extragenic suppressor that encodes a WD repeat protein. Genetics 148 (2), 559-569.

Chasse, S. A., Flanary, P., Parnell, S. C., Hao, N., Cha, J. Y., Siderovski, D. P., and Dohlman, H. G. (2006) Genome-scale analysis reveals Sst2 as the principal regulator of mating pheromone signaling in the yeast Saccharomyces cerevisiae. Eukaryot Cell 5 (2), 330-346.

Chen, J. G., Ullah, H., Temple, B., Liang, J., Guo, J., Alonso, J. M., Ecker, J. R., and Jones, A. M. (2006) RACK1 mediates multiple hormone responsiveness and developmental processes in Arabidopsis. J Exp Bot 57 (11), 2697-2708.

Conte, D., Jr., and Curcio, M. J. (2000) Fus3 controls Ty1 transpositional dormancy through the invasive growth MAPK pathway. Mol Microbiol 35 (2), 415-427. 
Coyle, S. M., Gilbert, W. V., and Doudna, J. A. (2009) Direct link between RACK1 function and localization at the ribosome in vivo. Mol Cell Biol 29 (6), 1626-1634.

Cross, F. R., and Tinkelenberg, A. H. (1991) A potential positive feedback loop controlling $C L N 1$ and $C L N 2$ gene expression at the start of the yeast cell cycle. Cell 65 (5), 875-883.

David, L., Huber, W., Granovskaia, M., Toedling, J., Palm, C. J., Bofkin, L., Jones, T., Davis, R. W., and Steinmetz, L. M. (2006) A high-resolution map of transcription in the yeast genome. Proc Natl Acad Sci U S A 103 (14), 5320-5325.

de Oliveira, I. M., Henriques, J. A., and Bonatto, D. (2007) In silico identification of a new group of specific bacterial and fungal nitroreductases-like proteins. Biochem Biophys Res Commun 355 (4), 919-925.

de Oliveira, I. M., Zanotto-Filho, A., Moreira, J. C., Bonatto, D., and Henriques, J. A. (2010) The role of two putative nitroreductases, Frm2p and Hbn1p, in the oxidative stress response in Saccharomyces cerevisiae. Yeast 27 (2), 89-102.

Dirmeier, R., O'Brien, K. M., Engle, M., Dodd, A., Spears, E., and Poyton, R. O. (2002) Exposure of yeast cells to anoxia induces transient oxidative stress. Implications for the induction of hypoxic genes. J Biol Chem 277 (38), 34773-34784.

Elion, E. A., Satterberg, B., and Kranz, J. E. (1993) Fus3 phosphorylates multiple components of the mating signal transduction cascade: evidence for Ste12 and Far1. Mol Biol Cell 4 (5), 495-510.

Eng, J. K., McCormack, A. L., and Yates III, J. R. (1994) An approach to correlate tandem mass spectral data of peptides with amino acid sequences in a protein database. J. Am. Soc. Mass Spectrom. 5, 976-989.

Epstein, C. B., Waddle, J. A., Hale, W. t., Dave, V., Thornton, J., Macatee, T. L., Garner, H. R., and Butow, R. A. (2001) Genome-wide responses to mitochondrial dysfunction. Mol Biol Cell 12 (2), 297-308.

Farquhar, R., Honey, N., Murant, S. J., Bossier, P., Schultz, L., Montgomery, D., Ellis, R. W., Freedman, R. B., and Tuite, M. F. (1991) Protein disulfide isomerase is essential for viability in Saccharomyces cerevisiae. Gene 108 (1), 81-89. 
Fitzpatrick, J. M., Johnston, D. A., Williams, G. W., Williams, D. J., Freeman, T. C., Dunne, D. W., and Hoffmann, K. F. (2005) An oligonucleotide microarray for transcriptome analysis of Schistosoma mansoni and its application/use to investigate gender-associated gene expression. Mol Biochem Parasitol 141 (1), $1-13$.

Gavin, A. C., Aloy, P., Grandi, P., Krause, R., Bösche, M., Marzioch, M., Rau, C., Jensen, L. J., Bastuck, S., Dümpelfeld, B., Edelmann, A., Heurtier, M. A., Hoffman, V., Hoefert, C., Klein, K., Hudak, M., Michon, A. M., Schelder, M., Schirle, M., Remor, M., Rudi, T., Hooper, S., Bauer, A., Bouwmeester, T., Casari, G., Drewes, G., Neubauer, G., Rick, J. M., Kuster, B., Bork, P., Russell, R. B., and Superti-Furga, G. (2006) Proteome survey reveals modularity of the yeast cell machinery. Nature 440 (7084), 631-636.

Gavin, A. C., Bösche, M., Krause, R., Grandi, P., Marzioch, M., Bauer, A., Schultz, J., Rick, J. M., Michon, A. M., Cruciat, C. M., Remor, M., Höfert, C., Schelder, M., Brajenovic, M., Ruffner, H., Merino, A., Klein, K., Hudak, M., Dickson, D., Rudi, T., Gnau, V., Bauch, A., Bastuck, S., Huhse, B., Leutwein, C., Heurtier, M. A., Copley, R. R., Edelmann, A., Querfurth, E., Rybin, V., Drewes, G., Raida, M., Bouwmeester, T., Bork, P., Seraphin, B., Kuster, B., Neubauer, G., and Superti-Furga, G. (2002) Functional organization of the yeast proteome by systematic analysis of protein complexes. Nature 415 (6868), 141-147.

Gerbasi, V. R., Weaver, C. M., Hill, S., Friedman, D. B., and Link, A. J. (2004) Yeast Asc1p and mammalian RACK1 are functionally orthologous core 40S ribosomal proteins that repress gene expression. Mol Cell Biol 24 (18), 8276-8287.

Groot, M. T., Merkx, M., and Koper, M. T. (2007) Reorganization of immobilized horse and yeast cytochrome c induced by $\mathrm{pH}$ changes or nitric oxide binding. Langmuir 23 (7), 3832-3839.

Gueldener, U., Heinisch, J., Koehler, G. J., Voss, D., and Hegemann, J. H. (2002) A second set of loxP marker cassettes for Cre-mediated multiple gene knockouts in budding yeast. Nucleic Acids Res 30 (6), e23. 
Guillemot, F., Billault, A., and Auffray, C. (1989) Physical linkage of a guanine nucleotide-binding protein-related gene to the chicken major histocompatibility complex. Proc Natl Acad Sci U S A 86 (12), 4594-4598.

Guo, J., Wang, J., Xi, L., Huang, W. D., Liang, J., and Chen, J. G. (2009) RACK1 is a negative regulator of ABA responses in Arabidopsis. J Exp Bot 60 (13), 3819-3833.

Hausmann, A., Samans, B., Lill, R., and Mühlenhoff, U. (2008) Cellular and mitochondrial remodeling upon defects in iron-sulfur protein biogenesis. J Biol Chem 283 (13), 8318-8330.

Hermanto, U., Zong, C. S., Li, W., and Wang, L. H. (2002) RACK1, an insulin-like growth factor I (IGF-I) receptor-interacting protein, modulates IGF-I-dependent integrin signaling and promotes cell spreading and contact with extracellular matrix. Mol Cell Biol 22 (7), 2345-2365.

Hoffman, G. A., Garrison, T. R., and Dohlman, H. G. (2002) Analysis of RGS proteins in Saccharomyces cerevisiae. Methods Enzymol 344, 617-631.

Hoffmann, B., Mösch, H. U., Sattlegger, E., Barthelmess, I. B., Hinnebusch, A., and Braus, G. H. (1999) The WD protein Cpc2p is required for repression of Gcn4 protein activity in yeast in the absence of amino-acid starvation. Mol Microbiol $31(3), 807-822$.

Ito, H., Fukuda, Y., Murata, K., and Kimura, A. (1983) Transformation of intact yeast cells treated with alkali cations. J Bacteriol 153 (1), 163-168.

Janke, C., Magiera, M. M., Rathfelder, N., Taxis, C., Reber, S., Maekawa, H., Moreno-Borchart, A., Doenges, G., Schwob, E., Schiebel, E., and Knop, M. (2004) A versatile toolbox for PCR-based tagging of yeast genes: new fluorescent proteins, more markers and promoter substitution cassettes. Yeast 21 (11), 947-962.

Kadrmas, J. L., Smith, M. A., Pronovost, S. M., and Beckerle, M. C. (2007) Characterization of RACK1 function in Drosophila development. Dev Dyn 236 (8), 2207-2215.

Kleinschmidt, M., Schulz, R., and Braus, G. H. (2006) The yeast $C P C 2 / A S C 1$ gene is regulated by the transcription factors Fhl1p and Ifh1p. Curr Genet 49 (4), 218-228.

Li, W., Sun, L., Liang, Q., Wang, J., Mo, W., and Zhou, B. (2006) Yeast AMID homologue Ndi1p displays respiration-restricted apoptotic activity and is involved in chronological aging. Mol Biol Cell 17 (4), 1802-1811. 
Liu, L., Zeng, M., Hausladen, A., Heitman, J., and Stamler, J. S. (2000) Protection from nitrosative stress by yeast flavohemoglobin. Proc Natl Acad Sci U S A 97 (9), 4672-4676.

Liu, Y. V., Baek, J. H., Zhang, H., Diez, R., Cole, R. N., and Semenza, G. L. (2007) RACK1 competes with HSP90 for binding to HIF-1 $\alpha$ and is required for $\mathrm{O}_{2}$-independent and HSP90 inhibitor-induced degradation of HIF-1 $\alpha$. Mol Cell 25 (2), 207-217.

López-Bergami, P., Habelhah, H., Bhoumik, A., Zhang, W., Wang, L. H., and Ronai, Z. (2005) RACK1 mediates activation of JNK by protein kinase C [corrected]. Mol Cell 19 (3), 309-320.

Luo, J., Vallen, E. A., Dravis, C., Tcheperegine, S. E., Drees, B., and Bi, E. (2004) Identification and functional analysis of the essential and regulatory light chains of the only type II myosin Myo1p in Saccharomyces cerevisiae. J Cell Biol 165 (6), 843-855.

Mamidipudi, V., and Cartwright, C. A. (2009) A novel pro-apoptotic function of RACK1: suppression of Src activity in the intrinsic and Akt pathways. Oncogene 28 (50), 4421-4433.

Martín, H., Castellanos, M. C., Cenamor, R., Sánchez, M., Molina, M., and Nombela, C. (1996) Molecular and functional characterization of a mutant allele of the mitogen-activated protein-kinase gene SLT2 (MPK1) rescued from yeast autolytic mutants. Curr Genet 29 (6), 516-522.

Melamed, D., Bar-Ziv, L., Truzman, Y., and Arava, Y. (2010) Asc1 supports cell-wall integrity near bud sites by a Pkc1 independent mechanism. PLoS One 5 (6), e11389.

Monteiro, P. T., Mendes, N. D., Teixeira, M. C., d'Orey, S., Tenreiro, S., Mira, N. P., Pais, H., Francisco, A. P., Carvalho, A. M., Lourenco, A. B., Sá-Correia, I., Oliveira, A. L., and Freitas, A. T. (2008) YEASTRACT-DISCOVERER: new tools to improve the analysis of transcriptional regulatory associations in Saccharomyces cerevisiae. Nucleic Acids Res 36 (Database issue), D132-136.

Nyswaner, K. M., Checkley, M. A., Yi, M., Stephens, R. M., and Garfinkel, D. J. (2008) Chromatin-associated genes protect the yeast genome from Ty1 insertional mutagenesis. Genetics 178 (1), 197-214. 
Ogur, M., and St John, R. (1956) A differential and diagnostic plating method for population studies of respiration deficiency in yeast. J Bacteriol 72 (4), 500-504.

Ogur, M., St. John, R., and Nagai, S. (1957) Tetrazolium overlay technique for population studies of respiration deficiency in yeast. Science 125 (3254), 928-929.

Paul, S. K., Oowatari, Y., and Kawamukai, M. (2009) A large complex mediated by Moc1, Moc2 and Cpc2 regulates sexual differentiation in fission yeast. FEBS J 276 (18), 5076-5093.

Peter, M., Gartner, A., Horecka, J., Ammerer, G., and Herskowitz, I. (1993) Far1 links the signal transduction pathway to the cell cycle machinery in yeast. Cell 73 (4), 747-760.

Rachfall, N., Heinemeyer, I., Morgenstern, B., Valerius, O., and Braus, G. H. (2010) 5'TRU: Identification and analysis of translationally regulative 5'untranslated regions in amino acid starved yeast cells. Mol Cell Proteomics (under revision).

Radi, R. (2004) Nitric oxide, oxidants, and protein tyrosine nitration. Proc Natl Acad Sci U S A 101 (12), 4003-4008.

Reynolds, T. B., Jansen, A., Peng, X., and Fink, G. R. (2008) Mat formation in Saccharomyces cerevisiae requires nutrient and pH gradients. Eukaryot Cell 7 (1), 122-130.

Rose, M., and Botstein, D. (1983) Construction and use of gene fusions to lacZ ( $\beta$-galactosidase) that are expressed in yeast. Methods Enzymol 101, 167-180.

Rupp, S., Summers, E., Lo, H. J., Madhani, H., and Fink, G. (1999) MAP kinase and cAMP filamentation signaling pathways converge on the unusually large promoter of the yeast FLO11 gene. EMBO J 18 (5), 1257-1269.

Senior, A. E., Nadanaciva, S., and Weber, J. (2002) The molecular mechanism of ATP synthesis by $\mathrm{F}_{1} \mathrm{~F}_{0}$-ATP synthase. Biochim Biophys Acta 1553 (3), 188-211.

Seo, B. B., Marella, M., Yagi, T., and Matsuno-Yagi, A. (2006) The single subunit $\mathrm{NADH}$ dehydrogenase reduces generation of reactive oxygen species from complex I. FEBS Lett 580 (26), 6105-6108.

Seo, H. Y., Chang, Y. J., Chung, Y. J., and Kim, K. S. (2008) Proteomic analysis of recombinant Saccharomyces cerevisiae upon iron deficiency induced via human H-ferritin production. J Microbiol Biotechnol 18 (8), 1368-1376. 
Sezen, B., Seedorf, M., and Schiebel, E. (2009) The SESA network links duplication of the yeast centrosome with the protein translation machinery. Genes Dev 23 (13), 1559-1570.

Shevchenko, A., Wilm, M., Vorm, O., and Mann, M. (1996) Mass spectrometric sequencing of proteins silver-stained polyacrylamide gels. Anal Chem 68 (5), 850-858.

Shimma, Y., Nishikawa, A., bin Kassim, B., Eto, A., and Jigami, Y. (1997) A defect in GTP synthesis affects mannose outer chain elongation in Saccharomyces cerevisiae. Mol Gen Genet 256 (5), 469-480.

Tedford, K., Kim, S., Sa, D., Stevens, K., and Tyers, M. (1997) Regulation of the mating pheromone and invasive growth responses in yeast by two MAP kinase substrates. Curr Biol 7 (4), 228-238.

Teixeira, M. C., Monteiro, P., Jain, P., Tenreiro, S., Fernandes, A. R., Mira, N. P., Alenquer, M., Freitas, A. T., Oliveira, A. L., and Sá-Correia, I. (2006) The YEASTRACT database: a tool for the analysis of transcription regulatory associations in Saccharomyces cerevisiae. Nucleic Acids Res 34 (Database issue), D446-451.

Trimpin, S., and Brizzard, B. (2009) Analysis of insoluble proteins. Biotechniques 46 (6), 409-419.

Turrens, J. F. (2003) Mitochondrial formation of reactive oxygen species. J Physiol (552), 335-344.

Valerius, O., Kleinschmidt, M., Rachfall, N., Schulze, F., López Marín, S., Hoppert, M., Streckfuss-Bömeke, K., Fischer, C., and Braus, G. H. (2007) The Saccharomyces homolog of mammalian RACK1, Cpc2/Asc1p, is required for FLO11-dependent adhesive growth and dimorphism. Mol Cell Proteomics 6 (11), 1968-1979.

Verna, J., Lodder, A., Lee, K., Vagts, A., and Ballester, R. (1997) A family of genes required for maintenance of cell wall integrity and for the stress response in Saccharomyces cerevisiae. Proc Natl Acad Sci U S A 94 (25), 13804-13809.

Waterland, R. A., Basu, A., Chance, B., and Poyton, R. O. (1991) The isoforms of yeast cytochrome $\mathrm{c}$ oxidase subunit $\mathrm{V}$ alter the in vivo kinetic properties of the holoenzyme. J Biol Chem 266 (7), 4180-4186. 
Wessel, D., and Flügge, U. I. (1984) A method for the quantitative recovery of protein in dilute solution in the presence of detergents and lipids. Anal Biochem 138 (1), 141-143.

Wojda, I., Alonso-Monge, R., Bebelman, J. P., Mager, W. H., and Siderius, M. (2003) Response to high osmotic conditions and elevated temperature in Saccharomyces cerevisiae is controlled by intracellular glycerol and involves coordinate activity of MAP kinase pathways. Microbiology (149), 1193-1204.

Zeller, C. E., Parnell, S. C., and Dohlman, H. G. (2007) The RACK1 ortholog Asc1 functions as a G-protein $\beta$ subunit coupled to glucose responsiveness in yeast. J Biol Chem 282 (34), 25168-25176.

Zhang, W., Cheng, G. Z., Gong, J., Hermanto, U., Zong, C. S., Chan, J., Cheng, J. Q., and Wang, L. H. (2008) RACK1 and CIS mediate the degradation of BimEL in cancer cells. J Biol Chem 283 (24), 16416-16426.

Zhao, X. J., Raitt, D., P, V. B., Clewell, A. S., Kwast, K. E., and Poyton, R. O. (1996) Function and expression of flavohemoglobin in Saccharomyces cerevisiae. Evidence for a role in the oxidative stress response. J Biol Chem 271 (41), 25131-25138.

Zhong, T., and Arndt, K. T. (1993) The yeast SIS1 protein, a DnaJ homolog, is required for the initiation of translation. Cell 73 (6), 1175-1186. 



\title{
Chapter IV
}

\section{Asc1p mediates the regulation of translation elongation and balances eIF5A and eEF2 expression}

\begin{abstract}
Asc1p, the orthologue of mammalian RACK1, is localized at the 40S ribosomal subunit and has previously been shown to influence translation and specifically translation initiation. This work provides first evidence for the additional requirement of Asc1p in translation elongation. Asc1p mediates abundance changes of the translation factors eIF5A and eEF2, both participating in translation elongation, and affects the essential hypusination modification of eIF5A. Accordingly, a $\Delta a s c 1$ strain shows an enhanced sensitivity for the spermidine analog N1-guanyl-1,7-diaminoheptane (GC7) and the translation elongation inhibitors anisomycin and sordarin. Additionally, the expression of Oazlp is up-regulated in $\Delta a s c l$ cells, a process strictly dependent on polyamine-induced programmed ribosomal +1 frameshifting during the elongation process.

The expression levels of eIF5A and eEF2 are synergistically regulated by ASC1 and $G C N 2$, coding for the kinase of translation initiation factor eIF2, implying a function of Asc1p in the coordination of translation initiation and elongation.
\end{abstract}




\section{Introduction}

The Saccharomyces cerevisiae protein Asc1p, or RACK1 in mammalian, is a highly conserved ribosomal protein in the eukaryotic kingdom. It is located at the head of the 40S ribosomal subunit in close proximity to the mRNA exit tunnel (Coyle et al., 2009) and has previously been described to be involved in the regulation of translation (Chantrel et al., 1998; Gerbasi et al., 2004). Asc1p genetically interacts with GCN2 (Hoffmann et al., 1999), coding for the kinase mediating eIF2-phophorylation in response to various stressors (Hinnebusch, 1993). An enhanced phosphorylation of the translation initiation factors eIF2 and eIF4A in a $\Delta a s c 1$ strain as well as an inhibitory effect of Asc1p on translation initiation of the POM34-mRNA depict its specific influence on translation initiation (Valerius et al., 2007; Sezen et al., 2009). Even though this generally results in a reduced rate of translation initiation, some mRNAs are still sufficiently or even more efficiently translated, as e.g. the mRNA of $G C N 4$, coding for a transcriptional activator (Hinnebusch, 1993).

The following step in protein biosynthesis is translational elongation, primarily mediated by the translation elongation factors eEF1A and eEF2, which are involved in the binding reaction of aminoacyl-tRNAs to the ribosome and the translocation step during elongation, respectively. Additionally, the translation initiation factor eIF5A has been linked to the process of translation elongation by a functional interaction with eEF2 (Saini et al., 2009). eIF5A is the only cellular protein containing the rare polyamine-derived amino acid, hypusine (Park, 2006). Its essential modification is conferred in two enzymatic reactions mediated by Dys1p and Lia1p (Schnier et al., 1991). Dys1p mediates the cleavage of the polyamine spermidine and transfers its 4-aminobutyl moiety to lysine residue 51 of the eIF5A precursor. In a second step Lia1p hydroxylates the resultant deoxyhypusine to the mature, active hypusine-containing eIF5A (Thompson et al., 2003; Park, 2006). Recently a function for eIF5A in translation elongation has been proposed due to a down-regulated +1 frameshifting in a ts-eIF5A variant (Saini et al., 2009) +1 frameshifting describes the event of the slippage in the translational reading frame towards the 5' direction of the mRNA by one nucleotide (Taliaferro and Farabaugh, 2007). The process of frameshifting is tightly linked to the polyamine pool in the cell. It is part of a distinct feedback inhibition loop, by which polyamines regulate their own biosynthesis through the ornithine 
decarboxylase (ODC), the rate-limiting enzyme in polyamine biosynthesis (Wallace et al., 2003). Upon excess, polyamines induce frameshifting, thereby enhancing the expression of the +1 frameshifting-dependent ODC antizyme (Oaz1p) (Palanimurugan et al., 2004), resulting in ODC-degradation (Coffino, 2001). In contrast to Oazlp, which requires +1 programmed frameshifting for its expression, increased frameshifting rates can cause errors in translational elongation, e.g. leading to premature translation termination or the misreading of termination codons (nonsense read-through) (Raman et al., 2006).

This study demonstrates that Asc1p reduces the expression of +1 frameshifting-dependent Oaz1p and provides evidence for the influence of Asc1p on the regulation of translation elongation by eIF5A and eEF2. Furthermore it shows that these translation factors are additionally regulated through the synergistic genetic interaction of ASC1 with GCN2. 


\section{Materials and Methods}

Yeast strains and growth conditions - The Saccharomyces cerevisiae strains used in this work are of $\Sigma 1278$ b background and are listed in Table 1. The strains RH3437 - RH3440 were generated by C-terminally tagging $O A Z 1$ and DYS1 with 3xmyc, respectively, according to Janke and colleagues (2004). Transformations were carried out according to the lithium acetate method (Ito et al., 1983). Cultures were grown at $30^{\circ} \mathrm{C}$ overnight in $10 \mathrm{ml}$ liquid minimal medium (YNB) containing respective supplements, diluted and cultivated in main cultures to midlog phase before isolation of protein extracts. Experiment-specific growth conditions are given in the respective paragraphs.

Table 1. S. cerevisiae strains used in this work.

\begin{tabular}{|c|c|c|}
\hline strain & genotype & reference \\
\hline RH2817 & MAT $\alpha$, ura3-52, $\operatorname{trpl}:: h i s G$ & Valerius et al., 2007 \\
\hline RH3263 & 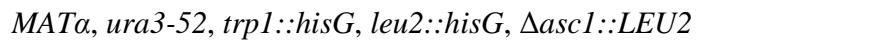 & Valerius et al., 2007 \\
\hline RH2649 & MATa, ura3-52, leu2::hisG, $\triangle g c n 2: \because L E U 2$ & Braus et al., 2003 \\
\hline RH3329 & 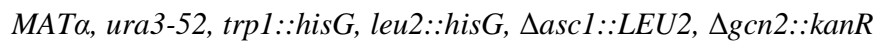 & Valerius et al., 2007 \\
\hline RH3437 & MAT $\alpha$, ura3-52, $\operatorname{trp} 1:: h i s G, O A Z 1-\mathrm{myc}^{3}$ & This work \\
\hline RH3438 & 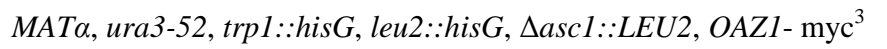 & This work \\
\hline RH3439 & 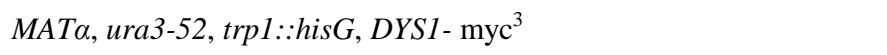 & This work \\
\hline RH3440 & 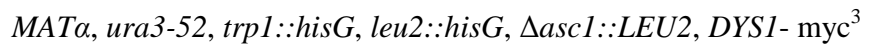 & This work \\
\hline
\end{tabular}

De novo proteome data - The proteome data described in this work results from a previous proteome study described in detail in Chapter III (Supplementary Table 1, Chapter III) (Rachfall et al., to be submitted). In summary, wt and $\Delta a s c 1$ cells were grown to midlog phase prior to the addition of ${ }^{35} \mathrm{~S}$-labeled methionine and further incubated for an additional hour. $100 \mu \mathrm{g}$ of purified, radioactive protein extracts were subjected to 2D-PAGE. The gels were exposed to imaging plates and the protein-spots of the resulting autoradiographies were quantified with the image analysis software PDQuest ${ }^{\mathrm{TM}}$ (Bio-Rad, Munich, Germany). Protein-spots regulated at least 2 fold were excised from the polyacrylamide gel and digested with trypsin according to Shevchenko et al. (1996) and subjected to analysis by mass spectrometry. Peptides of identified proteins were individually blasted against the Saccharomyces genome database (SGD; 
http://www.yeastgenome.org) to ensure their unambiguous assignment to the TurboSEQUEST-specified protein. The analysis was performed for seven biologically independent replicates.

Growth assays - Yeast cell main-cultures were grown to midlog phase in liquid minimal medium (YNB), adjusted to $\mathrm{OD}_{600}=0.1$ by dilution and serial 10 fold diluted up to 1:10,000. Growth was scored by spotting $20 \mu \mathrm{l}$ of each dilution onto YNB plates containing $2 \%$ agar. $1.8 \mathrm{mM}$ of the spermidine analog N1-guanyl-1,7-diaminoheptane (GC7) were added to inhibit the hypusination of eIF5A. To score for fidelity of translation elongation the plates contained the translation elongation inhibitors anisomycin $(30 \mu \mathrm{g} / \mathrm{ml})$ or sordarin $(1 \mu \mathrm{g} / \mathrm{ml})$. The plates were incubated at $30^{\circ} \mathrm{C}$ for 3-6 days.

Western hybridization analysis - Cell cultures were grown at $30^{\circ} \mathrm{C}$ to midlog phase $\left(\mathrm{OD}_{600}=0.8\right)$. Harvested cells were washed in ice-cold buffer b $(100 \mathrm{mM}$ Tris- $\mathrm{HCl} \mathrm{pH} 7.5$, $200 \mathrm{mM} \mathrm{NaCl}, 20 \%$ glycerol, 5mM EDTA), lysed with glass beads in $500 \mu \mathrm{l}$ of buffer $\mathrm{b}+(1 \mathrm{x}$ cOmplete Protease Inhibitor Cocktail, $0.5 \% \quad \beta$-mercaptoethanol) and protein extracts were obtained by centrifugation at $13,000 \mathrm{rpm}$ for $15 \mathrm{~min}$. Protein concentrations were determined according to Bradford (1976). Proteins were denatured in SDS loading dye at $65^{\circ} \mathrm{C}$ for $15 \mathrm{~min}$ and subjected to SDS-PAGE followed by blotting onto nitrocellulose membrane.

The membranes were incubated with polyclonal goat anti-Rap1 (yN-18), monoclonal mouse anti-myc (\#sc-40) (both from Santa Cruz Biotechnology, Heidelberg, Germany), polyclonal anti-eIF5A (gift from Sandro R. Valentini, School of Pharmaceutical Sciences, São Paulo State University, São Paulo, Brazil), polyclonal rabbit anti-Tec1 (provided by Hans-Ulrich Mösch, Philipps-Universität Marburg, Germany), anti-eEF2 (gift from Terri Kinzy, University of Medicine and Dentistry, Piscataway, New Jersey, USA) or polyclonal rabbit anti-eIF2 $\alpha$ (kindly provided by Thomas Dever, NIH, Bethesda, MD, USA) antibodies. Subsequently the membranes were incubated with peroxidase-coupled goat anti-rabbit (\#G21234, MoBiTec, Göttingen, Germany), donkey anti-goat (\#sc-2020, Santa Cruz Biotechnology) or goat anti-mouse (\#115-035-003, Dianova, Hamburg, Germany) secondary antibodies. Proteins were visualized using ECL technology (Amersham Biosciences, Munich, Germany). The quantification was carried out via Kodak Molecular Imaging Software (v. 4.0.5, raytest GmbH, Straubenhardt, Germany). 


\section{Results}

\section{The deletion of $A S C 1$ affects the expression of eIF5A and its hypusinating enzymes}

An ambiguous factor in translational regulation, namely eIF5A, is encoded by the HYP2 gene. eIF5A is involved in both, translation initiation and elongation (Park et al., 1991; Saini et al., 2009) and is required to undergo a hypusination modification at lysine residue 51, essential for its activity (Figure1).

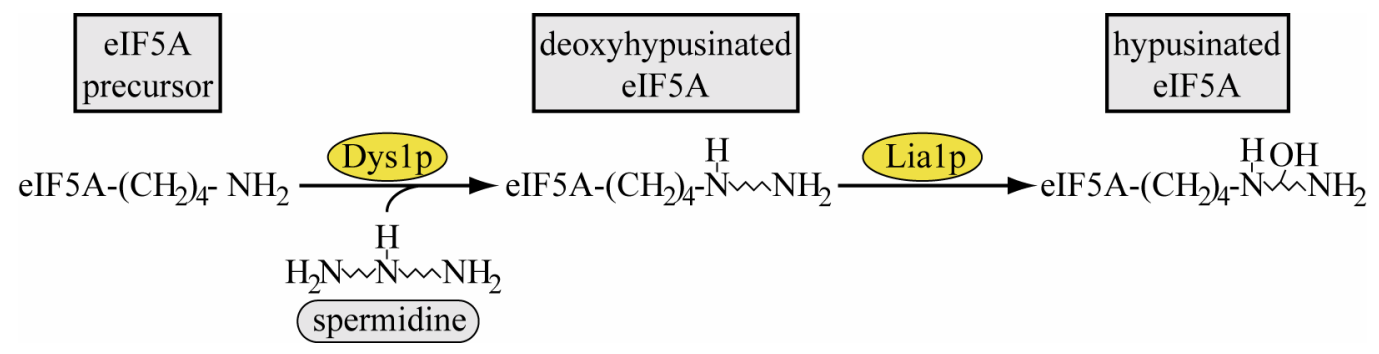

Figure 1. Hypusination modification of eIF5A. The intermediate forms of eIF5A are displayed as well as the enzymes Dys1p and Lia1p mediating the reaction steps to mature, active hypusine-containing eIF5A.

Interestingly eIF5A was identified as Asc1p-regulated protein in the previously described proteome study, assessing the changes in the de novo protein biosynthesis of a $\Delta a s c l$ mutant strain in comparison to wild type (wt) (Supplementary Table 1, Chapter III) (Rachfall et al., to be submitted). Hyp2p as well as the protein-spots corresponding to its hypusinating enzymes Dys1p and Lia1p were identified to be down-regulated in the mutant strain to $20 \%$ - $40 \%$ compared to wt (Figure 2A), indicating the requirement of ASC1 for their de novo biosynthesis. Dys1p and Lialp mediate the hypusinationmodification of eIF5A, required for its active function in the cell (Schnier et al., 1991; Abid et al., 1997; Thompson et al., 2003).

The protein amount of eIF5A was determined in this study by western hybridization experiments to confirm the reduction observed in the 2D-proteome analyses (Figure 2B). The deletion of $A S C 1$ leads to a significant reduction in the total amount of the active form of eIF5A. 
A

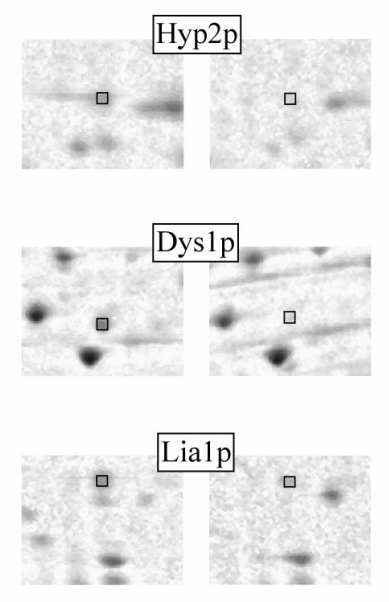

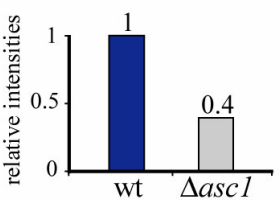
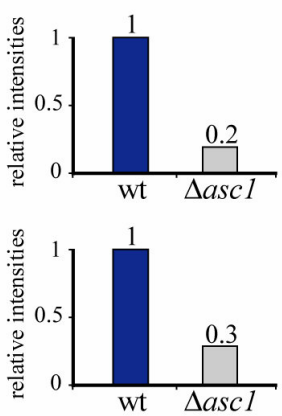

$\mathrm{B}$
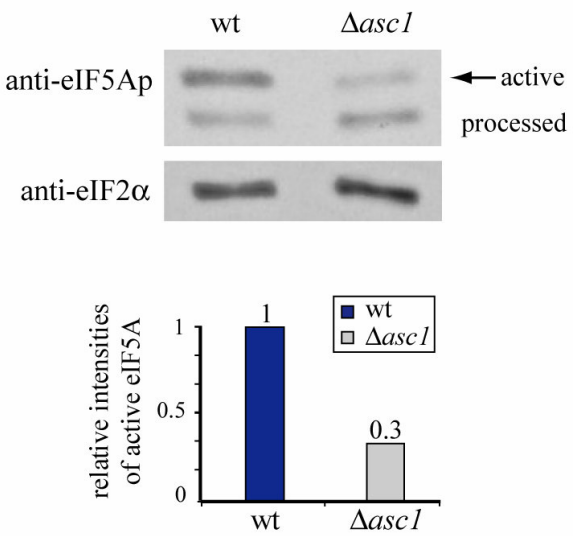

$\mathrm{D}$

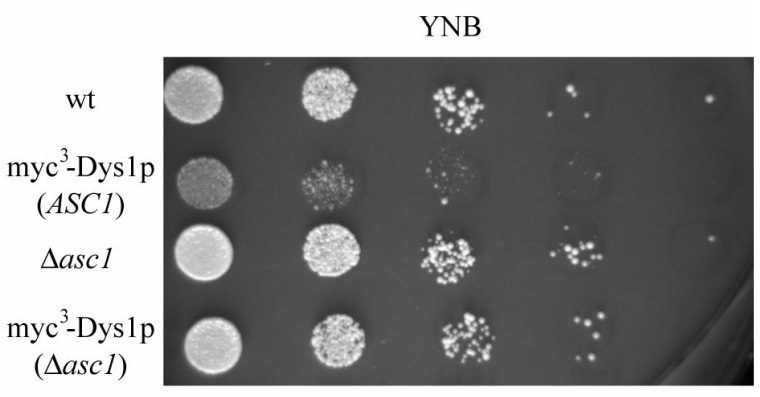

Figure 2. Availability of functional eIF5A in wt and $\Delta$ asc1 cells. (A) Close-up views of radioactivelylabeled protein-spots of Hyp2p, Dyslp and Lialp. ${ }^{35} \mathrm{~S}$-methionine labeled protein extracts of wt and $\Delta a s c 1$ cells were subjected to 2D-PAGE. Protein-spot intensities were determined by analysis of the autoradiographies, resulting from exposure of the 2D-gels on imaging plates. The protein-spots for Hyp2p, Dys1p and Lia1p are marked in the zoomed in autoradiographies and their respective average changes in intensity are illustrated in the adjacent graphs relative to wt. (B) Western hybridization against eIF5A. Total eIF5A was detected by specific antibody. The upper band illustrates the amount of mature eIF5A in the cell, whereas the bottom band represents a processed form of the protein (Wöhl et al., 1993). The signal intensities for active eIF5A are expressed in the adjacent graph relative to wt. Anti-eIF2 $\alpha$ antibody served as loading control and for normalization. $(C)$ Sensitivity for inhibition of deoxyhypusine synthase. Suspensions of wt and $\Delta a s c 1$ cells were 10 fold diluted and spotted on YNB medium (control) and YNB medium containing $1.8 \mathrm{mM}$ of the spermidine analogue N1-guanyl-1,7-diaminoheptane (GC7). Growth is shown after 3 days of incubation at $30^{\circ} \mathrm{C}$. (D) Growth assay. The growth of the wt and $\Delta a s c 1$ strain with myc ${ }^{3}$-tagged Dys1 $\mathrm{p}$ was monitored on YNB-medium. The untagged strains serve as control. 
A misregulation concerning eIF5A in the $\Delta a s c 1$ strain is further illustrated by the colony growth of the wt and $\Delta a s c 1$ strain on agar containing the spermidine analog N1-guanyl1,7-diaminoheptane (GC7), which inhibits the essential hypusination of eIF5A (Jakus et al., 1993). The $\Delta a s c 1$ strain shows a clearly enhanced sensitivity for GC7 (Figure 2C). These findings demonstrate that less functional hypusinated eIF5A is present in $\triangle a s c 1$ cells and indicates that eIF5A as well as its hypusination modification is influenced by Asc1p.

This is further supported by the observed differences in colony growth for myc ${ }^{3}$-tagged variants of Dys1p in the wt and the $\Delta a s c 1$ strain (Figure 2D). A reduced growth for the wt strain containing the tagged Dys1p-variant can be observed, which is suppressed in the $\triangle a s c 1$ strain, suggesting a genetic interaction of $A S C 1$ and DYS1, coding for the essential enzyme mediating the first spermidine-dependent modification step of eIF5A (Figure 1).

\section{The polyamine metabolism is compromised in the $\Delta a s c 1$ strain}

A further line of evidence for the regulative effect of Asc1p on eIF5A is Asc1p's impact on enzymes, taking part in the metabolism of polyamines, such as spermidine, required for the hypusination modification of eIF5A (Figure 1). Polyamines derive from the precursor amino acids L-methionine and via ornithine from L-glutamate and L-arginine, whereas arginine is converted to ornithine by the arginase Carlp, when optimal nitrogen sources are unavailable (Figure 3B) (Middelhoven, 1964). In the proteome analysis several proteins involved in the biosynthesis of these amino acids and ornithine were identified from regulated protein-spots in the $\Delta a s c 1$ strain (Figure 3A). Whereas Ado1p, Arg7p and Sam1/2p were down-regulated by about 2.5 fold in comparison to the wt, Arg1p and Met6p showed an up-regulation of 2.5 and 9.5 fold, respectively. Additionally, the mRNAs of Cpa1p and Arg3p, required for arginine biosynthesis, are up-regulated when ASC1 is deleted (Supplementary Table 2A, Chapter III) (Rachfall et al., to be submitted). The up-regulation of Cpa1p, Arg3p and Arg1p indicates the enhanced biosynthesis of arginine and a corresponding diversion of available ornithine from polyamine biosynthesis, in the form of putrescine, towards citrulline (Figure 3B). 
A
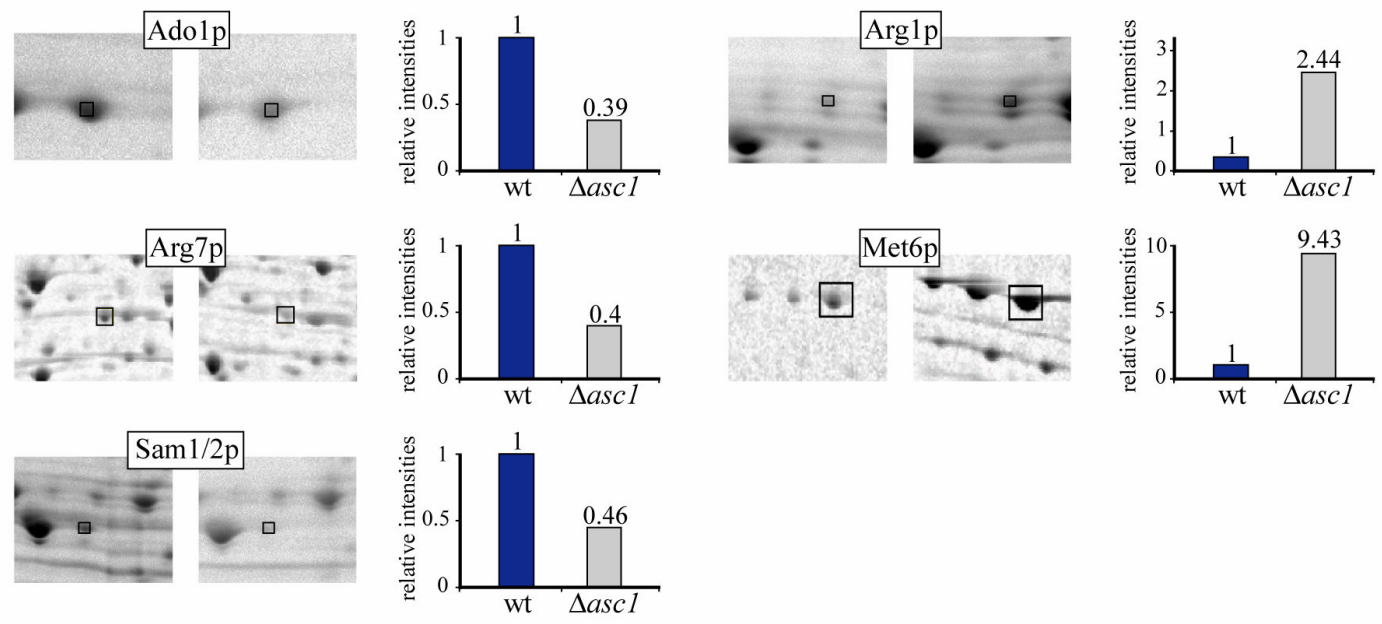

$\mathrm{B}$

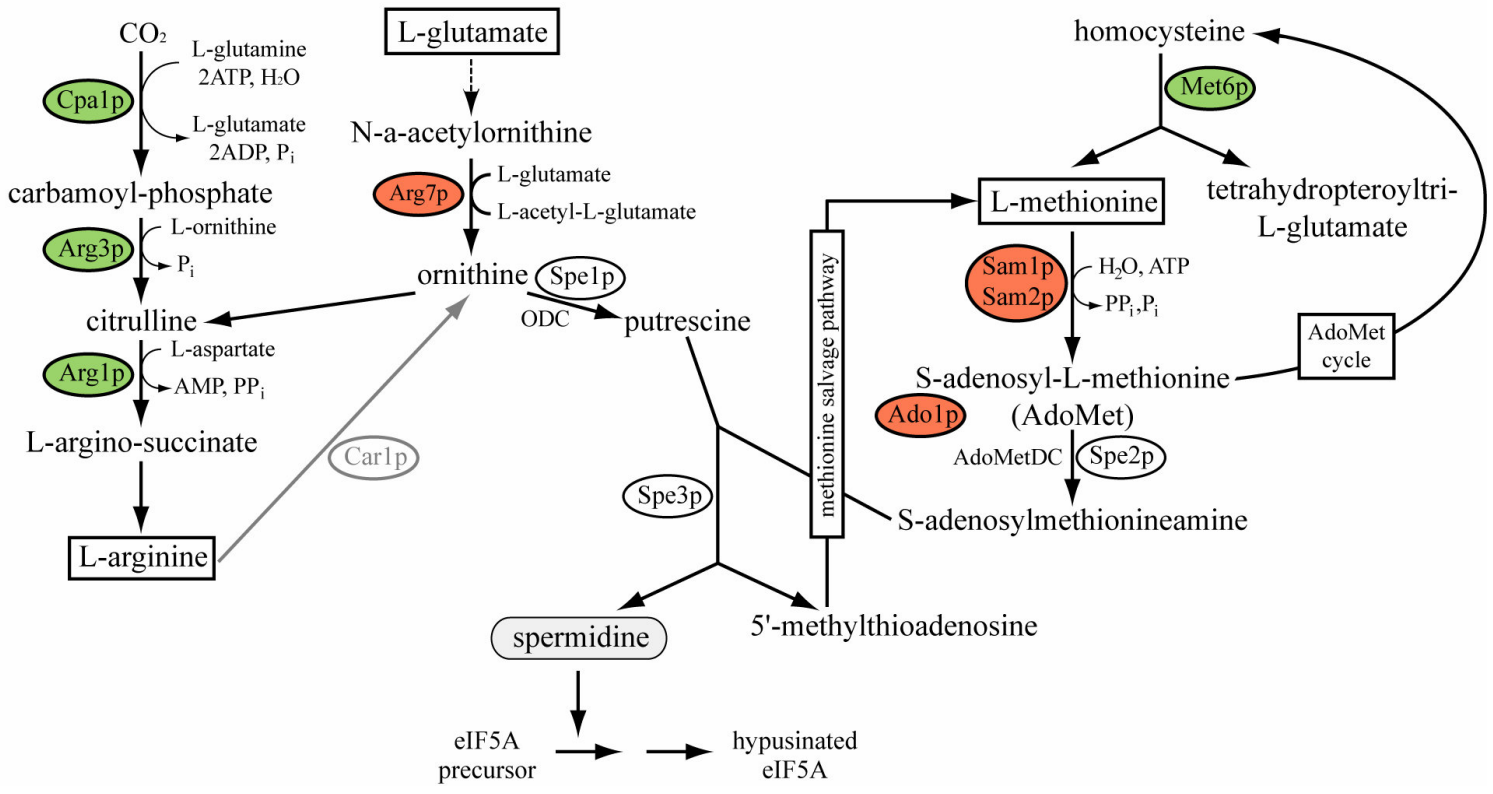

Figure 3. Asc1p-mediated influences on polyamine metabolism. (A) Close-up views of autoradiographies for proteins involved in polyamine metabolism. The depicted protein-spots result from autoradiographies, obtained by $2 \mathrm{D}$-PAGE of ${ }^{35} \mathrm{~S}$-methionine labeled wt and $\Delta a s c 1$ protein extracts (Supplementary Table 1, Chapter III) (Rachfall et al., to be submitted). Their relative average spot-intensities are illustrated relative to wt in the adjacent graphs. (B) Scheme of polyamine biosynthesis. S. cerevisiae cells can autonomously synthesize polyamines (e.g. putrescine and spermidine) from the precursor amino acids glutamate, methionine and arginine. The colored enzymes, participating in this process, were found as up- (green) or down-regulated (red) in the $\Delta a s c l$ strain in a comprehensive gene/protein expression analysis (Supplementary Table 1 and 2A, Chapter III) (Rachfall et al., to be submitted). 
Additionally, the down-regulation of Arg7p in the $\triangle a s c 1$ strain indicates a reduced synthesis of ornithine. Both effects reduce the amount of cellular ornithine available for the conversion to the first polyamine putrescine via the ornithine decarboxylase (ODC) Spe1p. The biosynthesis of all other polyamines, including spermidine, requires S-adenosylmethionineamine, derived from L-methionine via AdoMet. This process is influenced by the Asc1p-regulated proteins Met6p, Sam1/2p and Ado1p. The up-regulation of Met6p suggests the enhanced biosynthesis of methionine and tetrahydropteroyltri-Lglutamate from homocysteine. Sam1p and Sam2p convert L-methionine to S-adenosylmethionine (AdoMet), whose utilization is Ado1p-dependent. Their down-regulation entails a limited availability of AdoMet in $\Delta a s c l$ cells for the synthesis of S-adenosylmethionineamine by the AdoMet decarboxylase (AdoMetDC) Spe2p.

In conclusion, the generated expression data illustrates that Asc1p influences eIF5A in abundance as well as its essential spermidine-dependent hypusination modification. This is supported by the regulative influence of Asc1p on enzymes involved in polyaminemetabolism.

\section{Asc1p is involved in the regulation of translation elongation}

Additionally to polyamine abundances being influenced by the biosynthesis of their precursors, more importantly, polyamine-levels are tightly regulated through an intricate feedback regulation. In this regulation polyamines induce ribosomal +1 frameshifting during the process of translation elongation, which is absolutely required for the synthesis of Oaz1p from the OAZ1-mRNA. OAZ1 codes for the ornithine decarboxylase (ODC) antizyme, which mediates the degradation of ODC, the rate-limiting enzyme in polyamine biosynthesis. Furthermore polyamines inhibit the degradation of Oaz1p by the proteasome (Palanimurugan et al., 2004). Both events result in higher levels of Oazlp when polyamines are abundant and analogously to the reduction of Oaz1p when polyamines are scarce.

Surprisingly, despite everything hinting towards reduced polyamine-levels in the $\Delta a s c 1$ strain, the total protein amount of Oaz1p is almost twice as high in the mutant as in the wt strain (Figure 4), indicating a misregulation of the polyamine feedback-inhibition in the $\Delta a s c 1$ strain. 

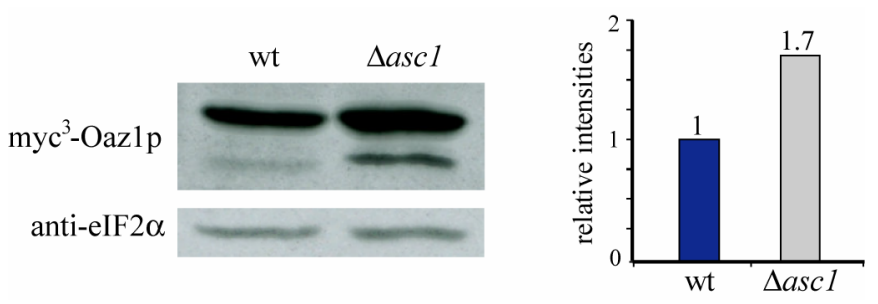

Figure 4. Western hybridization for Oaz1p. The myc ${ }^{3}$-tagged version of Oaz1p was detected by anti-myc antibody. Signals obtained for eIF2 $\alpha$ by specific antibody served for quantification and normalization. The results are illustrated relative to wt in the adjacent graph.

On this basis and the dependence of Oaz1p synthesis on programmed +1 frameshifting during the translation elongation process, the $\Delta a s c 1$ strain was analyzed in regard to its properties in translational elongation.

Growth of the wt and the mutant strain was scored on medium containing the translation elongation inhibitors anisomycin and sordarin. Anisomycin specifically targets the peptidyl transferase activity, thereby inhibiting the transfer of the nascent polypeptide chain to the next amino acid (Carrasco and Vazquez, 1973). The following translocation step of the ribosome is inhibited by sordarin, which binds to the translation elongation factor eEF2 and prevents its release during translocation (Botet et al., 2008). Indeed, the $\Delta$ ascl strain shows an increased sensitivity for both elongation inhibiting drugs, demonstrating the involvement of Asc1p in the regulation of translation elongation (Figure 5A). Additional evidence is given by the up-regulation of the translation elongation factor eEF2 by 1.5 fold in the $\Delta a s c 1$ strain (Figure 5B).

The alterations of eEF2 abundances in the $\triangle a s c 1$ strain as well as its increased sensitivity for the translation elongation inhibitors anisomycin and sordarin suggest that Asc1p is in close relation with the process of translational elongation. The impact of Asc1p on this process might be expressed in the increased amount of Oaz1p observed in the $\Delta a s c 1$ strain.

\section{$A S C 1$ genetically interacts with $G C N 2$ in altering eIF5A and eEF2 expression}

In a previous study of our group the genetic interaction of ASC1 and GCN2 was observed. The deletion of $A S C 1$ in a $\Delta g c n 2$ strain led to the suppression of its absence of growth phenotype under amino acid starvation conditions (Hoffmann et al., 1999). Additionally, 
we showed that the Gcn2p-dependent phosphorylation of the translation initiation factor eIF2 is enhanced in the $\Delta a s c 1$ strain (Valerius et al., 2007).

Based on these findings, we also analyzed the expression of the translation factors eIF5A and $\mathrm{eEF} 2$ in a $\Delta g c n 2$ strain and a $\Delta a s c 1 \Delta g c n 2$ double mutant (Figure 5B).

A
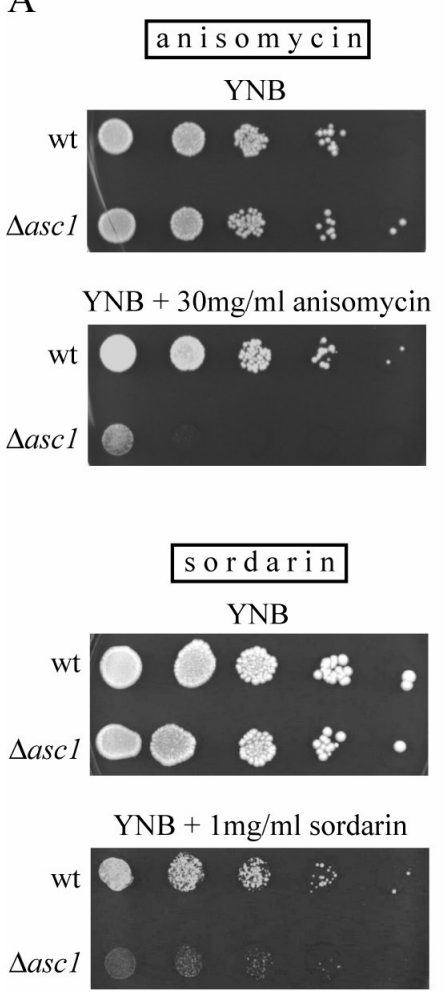

B
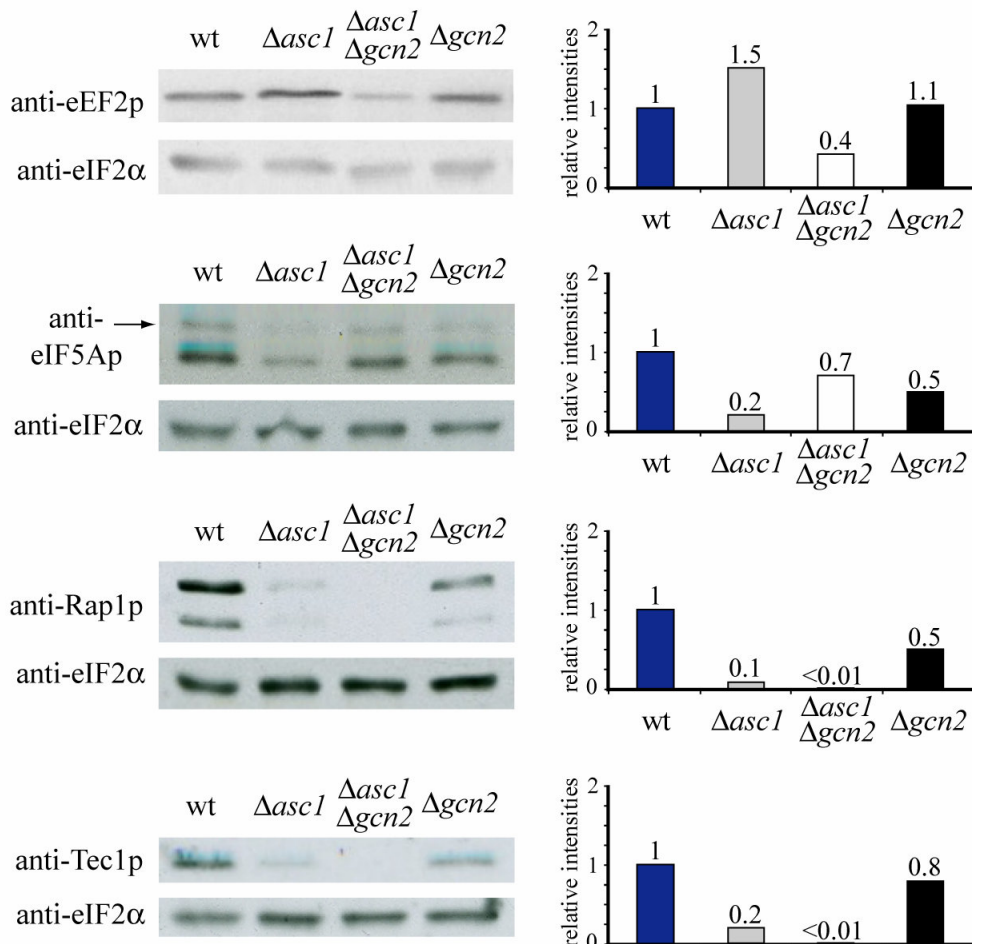

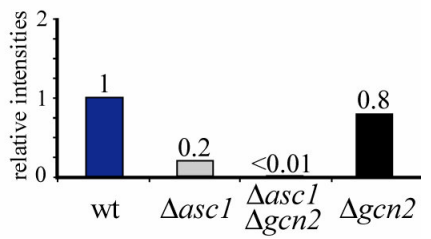

Figure 5. Investigation of the influence of Asc1p on translational regulation. (A) Growth assays with anisomycin and sordarin. Wt and $\Delta a s c 1$ cells were serial 10 fold diluted and plated on YNB medium containing the translation elongation inhibitors anisomycin $(20 \mu \mathrm{g} / \mathrm{ml})$ or sordarin $(1 \mu \mathrm{g} / \mathrm{ml})$. Plates were incubated at $30^{\circ} \mathrm{C}$ for 5 or 6 days, respectively. (B) Western hybridizations for the translation factors eIF5A and eEF2 and the transcription factors Raplp and Teclp. Proteins were detected from wt and $\triangle a s c 1$ whole protein extracts by specific antibodies. eIF $2 \alpha$ served as loading control for the normalization of signal intensities. The adjacent graphs illustrate the changes in protein abundance relative to wt.

Whereas the single deletions of ASC1 and GCN2 show increased or unchanged eEF2 expression levels, respectively, the $\Delta a s c 1 \Delta g c n 2$ strain displays a significant reduction in eEF2 abundance to $40 \%$ of wt-levels. This indicates a synergistic genetic interaction of $A S C 1$ and GCN2 in regulating eEF2. A likewise genetic interaction of $A S C 1$ and GCN2 is observed for eIF5A expression. The single deletions of ASC1 and GCN2 induce a 
reduction in eIF5A by 5 and 2 fold, respectively. Interestingly, this repression is partially suppressed when both genes are deleted, resulting in eIF5A abundances of $70 \%$ compared to the wt strain.

From previous work it was known that Asc1p influences the expression of specific transcription factors, as e.g. Rap1p and Tec1p (Figure 8, Chapter III) (Rachfall et al., to be submitted). The western hybridizations illustrate that ASC1 and GCN2 also genetically interact in the regulation of these factors. Rap1p as well as Tec1p are virtually absent in the $\Delta$ asc $1 \Delta g c n 2$ double mutant (Figure 5B). This represents a more severe phenotype than each single mutation on its own, describing an additive effect on protein expression mediated by ASC1 and GCN2.

Taken together, our data indicates that Asc1p is required for translation elongation by altering the expression levels of eIF5A and eEF2, which are both directly involved in this process. Additionally, the genetic interaction of $A S C 1$ and GCN2 in the regulation of these translation factors suggests a tight control and linkage between the regulation of translation initiation and elongation, in which Asc1p takes part. 


\section{Discussion}

Previous studies concerning the ribosomal function of Asc1p in translational regulation have placed it towards the initiation process of translation (Gerbasi et al., 2004; Sezen et al., 2009). The study presented here provides first evidence for an extended influence of Asc1p, spanning not only translation initiation but also the elongation step of protein biosynthesis. A strict assignment of Asc1p to either process is infeasible due to its combined influence on factors involved in the initiation of translation, as eIF2 and eIF4A (Valerius et al., 2007), and factors affecting the elongation step, as illustrated in this study by eIF5A and eEF2.

The synergistic genetic interaction of $A S C 1$ and $G C N 2$, coding for the kinase phosphorylating the translation initiation factor eIF2, in regulating eIF5A and eEF2 abundances further suggests the regulatory connection of translation initiation and elongation through Asc1p. Indeed, the $\Delta a s c 1 \Delta g c n 2$ double mutant displays an additive effect on the expression levels of the transcription factors Rap1p and Tec1p. Additionally to the expression data indicating an influence of Asc1p in translation elongation, the $\Delta a s c 1$ strain shows an enhanced sensitivity for the elongation inhibitors anisomycin and sordarin. These growth phenotypes might be linked to the reduced amount of eIF5A in the $\Delta a s c 1$ strain, as a ts-eIF5A mutant strain correspondingly displays an impaired growth on sordarin (Saini et al., 2009). Since sordarin specifically compromises the eEF2-mediated translocation step during elongation, the documented sensitivities imply an impairment in the translocation step for the $\Delta a s c 1$ strain as well as for the ts-eIF5A mutant (Botet et al., 2008). The integrity of translocation has been described to be required for programmed +1 frameshifting as well as the transposition of Ty1-elements in yeast (Harger et al., 2001). Accordingly, a reduced +1 frameshifting was monitored for the ts-eIF5A mutant strain (Saini et al., 2009). Interestingly, despite a misregulated translocation and reduced eIF5A-levels in the $\Delta a s c 1$ strain, Ty1 mobility increases 27.5 fold compared to wt when ASCl is deleted (Nyswaner et al., 2008), presenting an opposing effect on translocation and transposition/+1 frameshifting events in response to the deletion of ASC1.

+1 frameshifting as well as eIF5A expression has been linked to the cellular pool of polyamines. When polyamines are scarce, +1 frameshifting is repressed, which in turn reduces the +1 frameshifting-dependent expression of Oazlp as part of the polyamine 
feedback loop. Additionally, low polyamine levels were shown to reduce eIF5A abundance and promote eIF2 $\alpha$-phosphorylation in mammalian cells (Landau et al., 2010). A limited availability of polyamines is also indicated for the $\Delta a s c l$ strain in this study due to the respective regulation of enzymes involved in polyamine metabolism. Accordingly, a reduction in eIF5A as well as an enhanced eIF2 $\alpha$-phosphoralytion was observed upon the deletion of ASC1 (Figure 2B) (Valerius et al., 2007). Surprisingly though, the amount of Oazlp is enhanced in the $\Delta a s c l$ strain, a protein that strictly requires +1 frameshifting events for its expression. In addition to the enhanced transposition rate in a $\Delta$ ascl mutant, this implies a misregulation at the level of translation elongation, or more specifically +1 frameshifting, when Asc1p is absent. Furthermore it suggests that the deletion of ASC1 overrules the effect of eIF5A on +1 ribosomal frameshifting and supports a function for Asc1p in translational accuracy. 


\section{Acknowledgement}

We especially thank Verena Pretz for her outstanding technical assistance. We cordially thank Thomas Dever, Terri Kinzy, Sandro Valentini and Hans-Ulrich Mösch for providing antibodies. This project was supported by the Deutsche Forschungsgemeinschaft. 


\section{References}

Abid, R., Ueda, K., and Miyazaki, M. (1997) Novel features of the functional site and expression of the yeast deoxyhypusine synthase. Biol Signals 6 (3), 157-165.

Botet, J., Rodríguez-Mateos, M., Ballesta, J. P., Revuelta, J. L., and Remacha, M. (2008) A chemical genomic screen in Saccharomyces cerevisiae reveals a role for diphthamidation of translation elongation factor 2 in inhibition of protein synthesis by sordarin. Antimicrob Agents Chemother 52 (5), 1623-1629.

Bradford, M. M. (1976) A rapid and sensitive method for the quantitation of microgram quantities of protein utilizing the principle of protein-dye binding. Anal Biochem $72,248-254$.

Braus, G. H., Grundmann, O., Brückner, S., and Mösch, H. U. (2003) Amino acid starvation and Gcn $4 p$ regulate adhesive growth and FLO11 gene expression in Saccharomyces cerevisiae. Mol Biol Cell 14 (10), 4272-4284.

Carrasco, L., and Vazquez, D. (1973) Differences in eukaryotic ribosomes detected by the selective action of an antibiotic. Biochim Biophys Acta 319 (2), 209-215.

Chantrel, Y., Gaisne, M., Lions, C., and Verdière, J. (1998) The transcriptional regulator Hap1p (Cyp1p) is essential for anaerobic or heme-deficient growth of Saccharomyces cerevisiae: Genetic and molecular characterization of an extragenic suppressor that encodes a WD repeat protein. Genetics 148 (2), 559-569.

Coffino, P. (2001) Antizyme, a mediator of ubiquitin-independent proteasomal degradation. Biochimie 83 (3-4), 319-323.

Coyle, S. M., Gilbert, W. V., and Doudna, J. A. (2009) Direct link between RACK1 function and localization at the ribosome in vivo. Mol Cell Biol 29 (6), 1626-1634.

Gerbasi, V. R., Weaver, C. M., Hill, S., Friedman, D. B., and Link, A. J. (2004) Yeast Asc1p and mammalian RACK1 are functionally orthologous core 40S ribosomal proteins that repress gene expression. Mol Cell Biol 24 (18), 8276-8287.

Harger, J. W., Meskauskas, A., Nielsen, J., Justice, M. C., and Dinman, J. D. (2001) Ty1 retrotransposition and programmed +1 ribosomal frameshifting require the integrity of the protein synthetic translocation step. Virology 286 (1), 216-224.

Hinnebusch, A. G. (1993) Gene-specific translational control of the yeast GCN4 gene by phosphorylation of eukaryotic initiation factor 2. Mol Microbiol 10 (2), 215-223. 
Hoffmann, B., Mösch, H. U., Sattlegger, E., Barthelmess, I. B., Hinnebusch, A., and Braus, G. H. (1999) The WD protein Cpc2p is required for repression of Gcn4 protein activity in yeast in the absence of amino-acid starvation. Mol Microbiol 31 (3), 807-822.

Ito, H., Fukuda, Y., Murata, K., and Kimura, A. (1983) Transformation of intact yeast cells treated with alkali cations. J Bacteriol 153 (1), 163-168.

Jakus, J., Wolff, E. C., Park, M. H., and Folk, J. E. (1993) Features of the spermidinebinding site of deoxyhypusine synthase as derived from inhibition studies. Effective inhibition by bis- and mono-guanylated diamines and polyamines. J Biol Chem 268 (18), 13151-13159.

Janke, C., Magiera, M. M., Rathfelder, N., Taxis, C., Reber, S., Maekawa, H., Moreno-Borchart, A., Doenges, G., Schwob, E., Schiebel, E., and Knop, M. (2004) A versatile toolbox for PCR-based tagging of yeast genes: new fluorescent proteins, more markers and promoter substitution cassettes. Yeast 21 (11), 947-962.

Landau, G., Bercovich, Z., Park, M. H., and Kahana, C. (2010) The role of polyamines in supporting growth of mammalian cells is mediated through their requirement for translation initiation and elongation. J Biol Chem 285 (17), 12474-12481.

Middelhoven, W. J. (1964) The Pathway of Arginine Breakdown in Saccharomyces cerevisiae. Biochim Biophys Acta 93, 650-652.

Nyswaner, K. M., Checkley, M. A., Yi, M., Stephens, R. M., and Garfinkel, D. J. (2008) Chromatin-associated genes protect the yeast genome from Ty1 insertional mutagenesis. Genetics 178 (1), 197-214.

Palanimurugan, R., Scheel, H., Hofmann, K., and Dohmen, R. J. (2004) Polyamines regulate their synthesis by inducing expression and blocking degradation of ODC antizyme. EMBO J 23 (24), 4857-4867.

Park, M. H. (2006) The post-translational synthesis of a polyamine-derived amino acid, hypusine, in the eukaryotic translation initiation factor 5A (eIF5A). J Biochem 139 (2), 161-169.

Park, M. H., Wolff, E. C., Smit-McBride, Z., Hershey, J. W., and Folk, J. E. (1991) Comparison of the activities of variant forms of eIF-4D. The requirement for hypusine or deoxyhypusine. J Biol Chem 266 (13), 7988-7994. 
Rachfall, N., Bandau, S., Dielschneider, I., Braus, G. H., and Valerius, O. (2010) Asc1p, a ribosomal protein in the abyss of cellular signaling. (to be submitted).

Raman, A., Guarraia, C., Taliaferro, D., Stahl, G., and Farabaugh, P. J. (2006) An mRNA sequence derived from a programmed frameshifting signal decreases codon discrimination during translation initiation. RNA 12 (7), 1154-1160.

Saini, P., Eyler, D. E., Green, R., and Dever, T. E. (2009) Hypusine-containing protein eIF5A promotes translation elongation. Nature 459 (7243), 118-121.

Schnier, J., Schwelberger, H. G., Smit-McBride, Z., Kang, H. A., and Hershey, J. W. (1991) Translation initiation factor 5A and its hypusine modification are essential for cell viability in the yeast Saccharomyces cerevisiae. Mol Cell Biol 11 (6), 3105-3114.

Sezen, B., Seedorf, M., and Schiebel, E. (2009) The SESA network links duplication of the yeast centrosome with the protein translation machinery. Genes Dev 23 (13), 1559-1570.

Shevchenko, A., Wilm, M., Vorm, O., and Mann, M. (1996) Mass spectrometric sequencing of proteins silver-stained polyacrylamide gels. Anal Chem 68 (5), 850-858.

Taliaferro, D., and Farabaugh, P. J. (2007) An mRNA sequence derived from the yeast EST3 gene stimulates programmed +1 translational frameshifting. RNA 13 (4), 606-613.

Thompson, G. M., Cano, V. S., and Valentini, S. R. (2003) Mapping eIF5A binding sites for Dys1 and Lia1: in vivo evidence for regulation of eIF5A hypusination. FEBS Lett 555 (3), 464-468.

Valerius, O., Kleinschmidt, M., Rachfall, N., Schulze, F., López Marín, S., Hoppert, M., Streckfuss-Bömeke, K., Fischer, C., and Braus, G. H. (2007) The Saccharomyces homolog of mammalian RACK1, Cpc2/Asc1p, is required for FLO11-dependent adhesive growth and dimorphism. Mol Cell Proteomics 6 (11), 1968-1979.

Wallace, H. M., Fraser, A. V., and Hughes, A. (2003) A perspective of polyamine metabolism. Biochem J (376), 1-14.

Wöhl, T., Klier, H., Ammer, H., Lottspeich, F., and Magdolen, V. (1993) The HYP2 gene of Saccharomyces cerevisiae is essential for aerobic growth: characterization 
of different isoforms of the hypusine-containing protein Hyp2p and analysis of gene disruption mutants. Mol Gen Genet 241 (3-4), 305-311. 


\section{Chapter V}

\section{Does Asc1p/RACK1 talk the signal into the ribosome? - A conclusive model}

This work proposes the ribosomal protein Asc1p to be involved in the regulation of several cellular signaling pathways, including invasive/pseudohyphal growth, mating and cell wall integrity and furthermore that the impact of Asc1p on these pathways is mediated through its influence on translation factors that determine the translation rates of the transcription factors targeted by the pathways. Based on literature and the consolidated findings introduced in this work, a model for the cellular function for Asc1p is developed in this chapter.

It has been shown that the MAPK SIt2p of the cell wall integrity pathway as well as the signal transducing MAPKKKK Ste20p of the pathways of invasive/pseudohyphal growth and mating are binding partners of Asc1p under non-inducing conditions (Zeller et al., 2007; Breitkreutz et al., 2010). This interaction of Asc1p with cell signaling components brings the respective pathways and the ribosome in immediate proximity. Additionally, cellular signaling and the translational machinery are interconnected within the cytoplasm via the elaborately organized actin cytoskeleton. It exhibits a highly dynamic organization, enabling its adaptation to changing environmental conditions and its involvement in the activation and subcellular localization of signaling proteins and their targets as well as mRNAs (Care et al., 2004; Motizuki et al., 2008; Kim and Coulombe, 2010). The cytoskeleton actively translocates mRNAs, which facilitates localized translation at sites within the cell, where protein function is needed (Zarnack and Feldbrügge, 2007). A wellstudied example is the translocation of the ASHI-mRNA to the bud site, mediated by the mRNA binding protein She $2 p$, the adapter protein She $3 p$ and the myosin motor protein Myo4p (Munchow et al., 1999; Böhl et al., 2000; Long et al., 2000; Takizawa and Vale, 2000). Also it was shown that the translation elongation factor eEF1A affects translation initiation through the actin cytoskeleton (Gross and Kinzy, 2007). A binding to Actlp, a critical cytoskeletal element, has previously been stated for the MAPK pathway components Ste20p and Slt2p as well as for Asc1p (Shortle et al., 1982; Mazzoni et al., 
1993; Haarer et al., 2007; Costanzo et al., 2010). Additionally, several other ribosomal proteins, including the translation initiation factors eIF2, eIF3 and eIF4A, associate with the cytoskeleton (Zumbé et al., 1982; Howe and Hershey, 1984; Heuijerjans et al., 1989). Two of these factors, namely eIF2 and eIF4A, have been demonstrated to show an enhanced phosphorylation upon the deletion of ASC1 (Valerius et al., 2007).

Interaction of the signaling components Slt2p and Ste20p with Asc1p might mediate a controlling effect on the translation rate of specific mRNAs, coding for target-transcription factors of the corresponding pathways. When the pathways are not turned on by their specific inducing signals, Slt2p and Ste20p bind to Asc1p on the small ribosomal subunit and inhibit translation for the mRNAs of RLM1 and TEC1, respectively (Figure 1A). This effect might be conferred by sterically inhibiting other interaction partners from binding to the scaffold protein Asclp, or by an altered internal ribosomal organization through conformational changes or modifications mediated by Slt $2 p$ and Ste20p, as e.g. the phosphorylation of translation factors.

Upon the appropriate signals the pathways of cell wall integrity and invasive/pseudohyphal growth are turned on, resulting in the activation of the phosphorylation cascades from Pkc1p to Slt2p and from Ste20p to Kss1p, respectively. The model proposes that the phosphorylation of Slt2p and Ste20p triggers their dissociation from Asc1p, releasing the ribosome to induce translation for the mRNAs of $R L M 1$ and $T E C 1$, respectively (Figure 1B). This is supported by the described translocation of Slt $2 p$ into the nucleus upon induction of the cell wall integrity pathway (Baetz et al., 2001), mediated by the karyopherine Kap95, also required for the nuclear import of the Slt2p target-transcription factor Rlm1p (Martínez-Bono et al., 2010). The phosphorylation and subsequent dissociation of the MAPK pathway-associated kinases from Asc1p could in turn induce modifications or conformational changes concerning regulatory components of the ribosome, as e.g. translation factors. This assumption is strengthened by the illustrated influences of Asc1p on the phosphorylation state of eIF2 and eIF4A (Valerius et al., 2007) as well as the abundance changes of eIF5A and eEF2 (Chapter IV), involved in translation initiation and elongation, respectively. 
Signal transduction-coupled translation
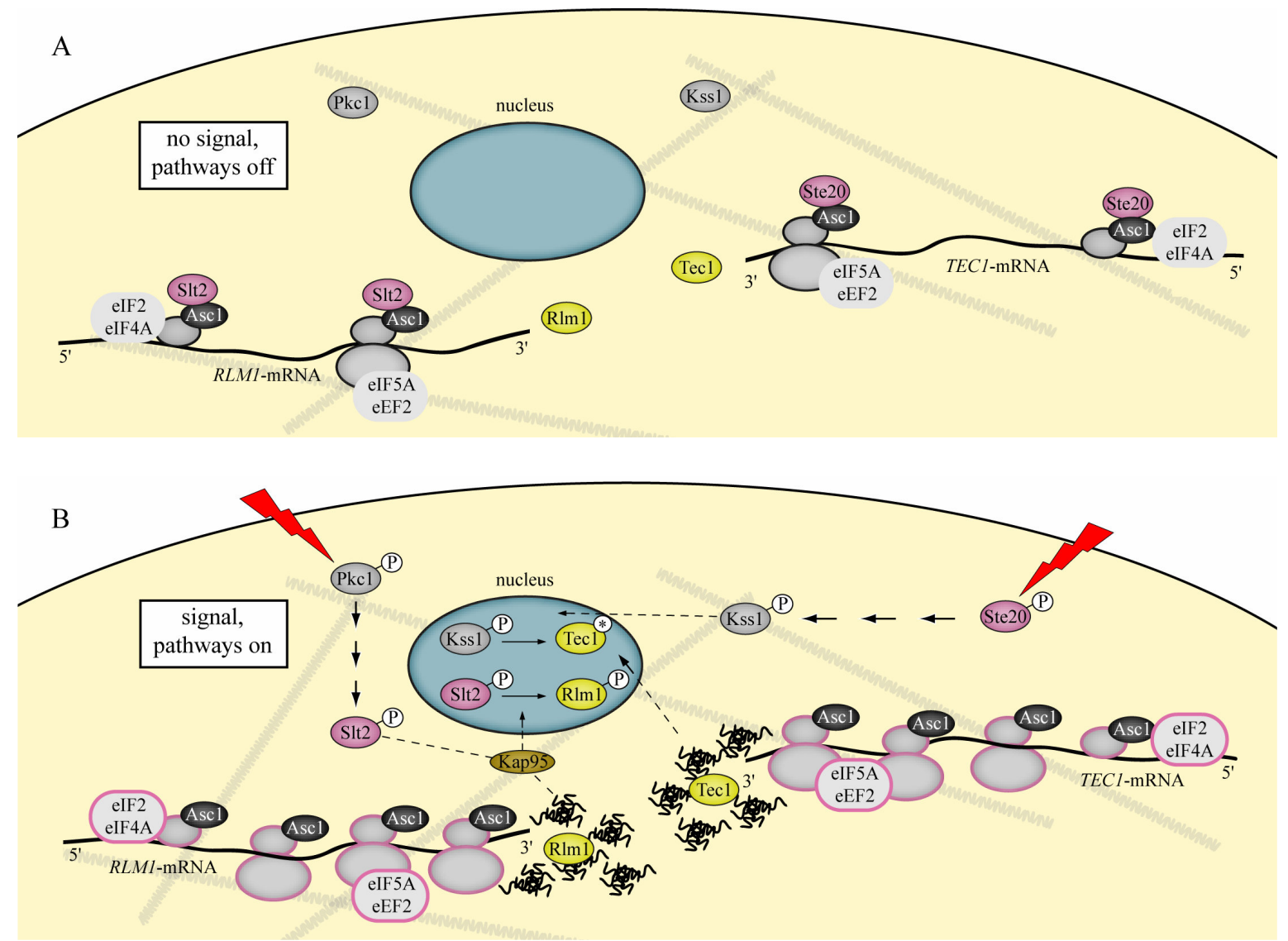

Signal transduction-decoupled translation

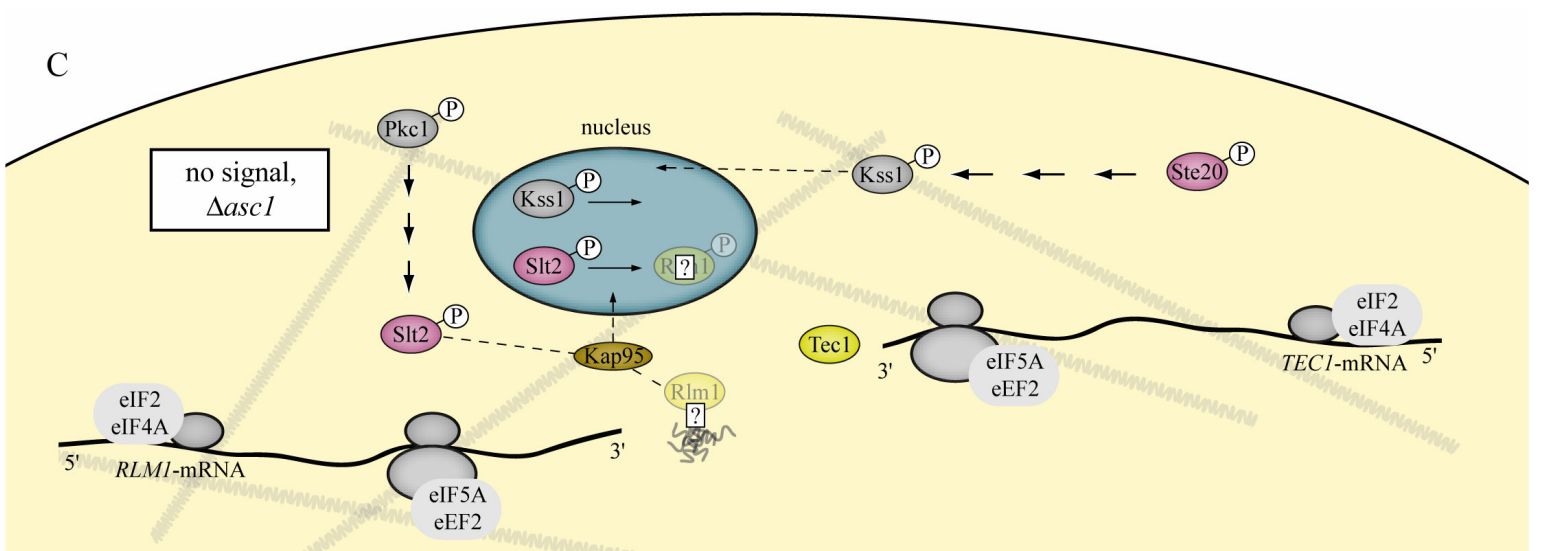

Figure 1. Model of the coupled control of cell signaling and translation by the ribosomal protein Asc1p.

(A) Cellular organization under non-inducing conditions with respect to the pathways of cell wall integrity and invasive/pseudohyphal growth in wt yeast cells. (B) Cellular response to signal-induction is illustrated in wt cells. Pink borders depict components that are subject to changes upon pathway activation. (C) Illustration of the decoupled regulation of signal transduction and translation upon the deletion of $A S C l$. 
The proposed coupling of signal transduction pathways and the translational machinery through Asc1p presented by this model would result in i) the activation of the MAPK pathway by an incoming signal to promote specific transcription factor activation/deactivation and at the same time lead to ii) the enhanced production of the required target-transcription factors by a reorganized translation.

In a $\Delta a s c 1$ strain the pathways of cell wall integrity and invasive/pseudohyphal growth are constitutively turned on even under non-inducing conditions as shown via elevated phosphorylation of the MAP kinases SIt2p and Kss1p when ASC1 is deleted (Chasse et al., 2006; Zeller et al., 2007). Furthermore, it was shown in this work that the target transcription factor Tec1p of the MAPK of invasive/pseudohyphal growth is significantly misregulated in a $\Delta a s c 1$ strain, leading to reduced Tec1p amounts in the cell. Additionally, the target genes of the cell wall integrity pathway are not induced in spite of enhances Slt2p phosphorylation (Chapter III).

According to the presented hypothetical model these changes in protein expression result from the decoupling of the signaling pathways and the translational machinery by the absence of the connector Asc1p (Figure 1C). The unfeasible Ste20p-Asc1p interaction on the ribosome upon the deletion of $A S C l$ is proposed to result in a non-derepressable state for the translation of the TEC1-mRNA and possibly also for the mRNA of RLM1. The control of Asc1p on the translational machinery is absent as well as the possible ribosomal changes mediated through the interaction and dissociation of binding partners as Slt $2 p$ and Ste20p.

The interaction of Asc1p with components of MAPK pathways and the suggested coupling of these pathways to the translational regulation of specific mRNAs proposes Asc1p to function as ribosomal specificity factor, controlling translational settings upon changing environmental conditions. Such a control mechanism might especially be of importance in multicellular organisms in regard to cell differentiation. This is supported by the essential function for the Asc1p orthologue RACK1 in higher eukaryotes for viability during cell differentiation (Hermanto et al., 2002; Kadrmas et al., 2007; Guo et al., 2009). Further the transfection with RACK1 has been shown to contribute to carcinoma proliferation and invasion/metastasis and its knock-down by siRNA, conversely, inhibited proliferation underlining the regulatory effect of RACK1 on cellular fate (Cao et al., 2010). 


\section{References}

Baetz, K., Moffat, J., Haynes, J., Chang, M., and Andrews, B. (2001) Transcriptional coregulation by the cell integrity mitogen-activated protein kinase Slt 2 and the cell cycle regulator Swi4. Mol Cell Biol 21 (19), 6515-6528.

Böhl, F., Kruse, C., Frank, A., Ferring, D., and Jansen, R. P. (2000) She2p, a novel RNA-binding protein tethers ASH1 mRNA to the Myo4p myosin motor via She3p. EMBO J 19 (20), 5514-5524.

Breitkreutz, A., Choi, H., Sharom, J. R., Boucher, L., Neduva, V., Larsen, B., Lin, Z. Y., Breitkreutz, B. J., Stark, C., Liu, G., Ahn, J., Dewar-Darch, D., Reguly, T., Tang, X., Almeida, R., Qin, Z. S., Pawson, T., Gingras, A. C., Nesvizhskii, A. I., and Tyers, M. (2010) A global protein kinase and phosphatase interaction network in yeast. Science 328 (5981), 1043-1046.

Cao, X. X., Xu, J. D., Xu, J. W., Liu, X. L., Cheng, Y. Y., Li, Q. Q., Xu, Z. D., and Liu, X. P. (2010) RACK1 promotes breast carcinoma migration/metastasis via activation of the RhoA/Rho kinase pathway. Breast Cancer Res Treat, Epub.

Care, A., Vousden, K. A., Binley, K. M., Radcliffe, P., Trevethick, J., Mannazzu, I., and Sudbery, P. E. (2004) A synthetic lethal screen identifies a role for the cortical actin patch/endocytosis complex in the response to nutrient deprivation in Saccharomyces cerevisiae. Genetics 166 (2), 707-719.

Chasse, S. A., Flanary, P., Parnell, S. C., Hao, N., Cha, J. Y., Siderovski, D. P., and Dohlman, H. G. (2006) Genome-scale analysis reveals Sst2 as the principal regulator of mating pheromone signaling in the yeast Saccharomyces cerevisiae. Eukaryot Cell 5 (2), 330-346.

Costanzo, M., Baryshnikova, A., Bellay, J., Kim, Y., Spear, E. D., Sevier, C. S., Ding, H., Koh, J. L., Toufighi, K., Mostafavi, S., Prinz, J., St Onge, R. P., VanderSluis, B., Makhnevych, T., Vizeacoumar, F. J., Alizadeh, S., Bahr, S., Brost, R. L., Chen, Y., Cokol, M., Deshpande, R., Li, Z., Lin, Z. Y., Liang, W., Marback, M., Paw, J., San Luis, B. J., Shuteriqi, E., Tong, A. H., van Dyk, N., Wallace, I. M., Whitney, J. A., Weirauch, M. T., Zhong, G., Zhu, H., Houry, W. A., Brudno, M., Ragibizadeh, S., Papp, B., Pál, C., Roth, F. P., Giaever, G., Nislow, C., Troyanskaya, O. G., Bussey, H., Bader, G. D., Gingras, A. C., 
Morris, Q. D., Kim, P. M., Kaiser, C. A., Myers, C. L., Andrews, B. J., and Boone, C. (2010) The genetic landscape of a cell. Science 327 (5964), 425-431.

Gross, S. R., and Kinzy, T. G. (2007) Improper organization of the actin cytoskeleton affects protein synthesis at initiation. Mol Cell Biol 27 (5), 1974-1989.

Guo, J., Wang, J., Xi, L., Huang, W. D., Liang, J., and Chen, J. G. (2009) RACK1 is a negative regulator of ABA responses in Arabidopsis. J Exp Bot 60 (13), 3819-3833.

Haarer, B., Viggiano, S., Hibbs, M. A., Troyanskaya, O. G., and Amberg, D. C. (2007) Modeling complex genetic interactions in a simple eukaryotic genome: actin displays a rich spectrum of complex haploinsufficiencies. Genes Dev 21 (2), 148-159.

Hermanto, U., Zong, C. S., Li, W., and Wang, L. H. (2002) RACK1, an insulin-like growth factor I (IGF-I) receptor-interacting protein, modulates IGF-I-dependent integrin signaling and promotes cell spreading and contact with extracellular matrix. Mol Cell Biol 22 (7), 2345-2365.

Heuijerjans, J. H., Pieper, F. R., Ramaekers, F. C., Timmermans, L. J., Kuijpers, H., Bloemendal, H., and Van Venrooij, W. J. (1989) Association of mRNA and eIF-2 $\alpha$ with the cytoskeleton in cells lacking vimentin. Exp Cell Res 181 (2), 317-330.

Howe, J. G., and Hershey, J. W. (1984) Translational initiation factor and ribosome association with the cytoskeletal framework fraction from HeLa cells. Cell 37 (1), 85-93.

Kadrmas, J. L., Smith, M. A., Pronovost, S. M., and Beckerle, M. C. (2007) Characterization of RACK1 function in Drosophila development. Dev Dyn 236 (8), 2207-2215.

Kim, S., and Coulombe, P. A. (2010) Emerging role for the cytoskeleton as an organizer and regulator of translation. Nat Rev Mol Cell Biol 11 (1), 75-81.

Long, R. M., Gu, W., Lorimer, E., Singer, R. H., and Chartrand, P. (2000) She2p is a novel RNA-binding protein that recruits the Myo4p-She3p complex to ASH1 mRNA. EMBO J 19 (23), 6592-6601.

Martínez-Bono, B., Quilis, I., Zalve, E., and Igual, J. C. (2010) Yeast karyopherins Kap123 and Kap95 are related to the function of the cell integrity pathway. FEMS Yeast Res 10 (1), 28-37. 
Mazzoni, C., Zarov, P., Rambourg, A., and Mann, C. (1993) The Slt2 (MPK1) MAP kinase homolog is involved in polarized cell growth in Saccharomyces cerevisiae. J Cell Biol (123), 1821-1833.

Motizuki, M., Yokota, S., and Tsurugi, K. (2008) Effect of low pH on organization of the actin cytoskeleton in Saccharomyces cerevisiae. Biochim Biophys Acta 1780 (2), 179-184.

Munchow, S., Sauter, C., and Jansen, R. P. (1999) Association of the class V myosin Myo4p with a localised messenger RNA in budding yeast depends on She proteins. J Cell Sci (112) 1511-1518.

Shortle, D., Haber, J. E., and Botstein, D. (1982) Lethal disruption of the yeast actin gene by integrative DNA transformation. Science 217 (4557), 371-373.

Takizawa, P. A., and Vale, R. D. (2000) The myosin motor, Myo4p, binds Ash1 mRNA via the adapter protein, She3p. Proc Natl Acad Sci U S A 97 (10), 5273-5278.

Valerius, O., Kleinschmidt, M., Rachfall, N., Schulze, F., López Marín, S., Hoppert, M., Streckfuss-Bömeke, K., Fischer, C., and Braus, G. H. (2007) The Saccharomyces homolog of mammalian RACK1, Cpc2/Asc1p, is required for FLO11-dependent adhesive growth and dimorphism. Mol Cell Proteomics 6 (11), 1968-1979.

Zarnack, K., and Feldbrügge, M. (2007) mRNA trafficking in fungi. Mol Genet Genomics 278 (4), 347-359.

Zeller, C. E., Parnell, S. C., and Dohlman, H. G. (2007) The RACK1 ortholog Asc1 functions as a G-protein $\beta$ subunit coupled to glucose responsiveness in yeast. J Biol Chem 282 (34), 25168-25176.

Zumbé, A., Stähli, C., and Trachsel, H. (1982) Association of a Mr 50,000 cap-binding protein with the cytoskeleton in baby hamster kidney cells. Proc Natl Acad Sci U S A 79 (9), 2927-2931. 



\section{Chapter VI}

\section{Supplementary Material}

\section{Supplementary Material - Chapter II}
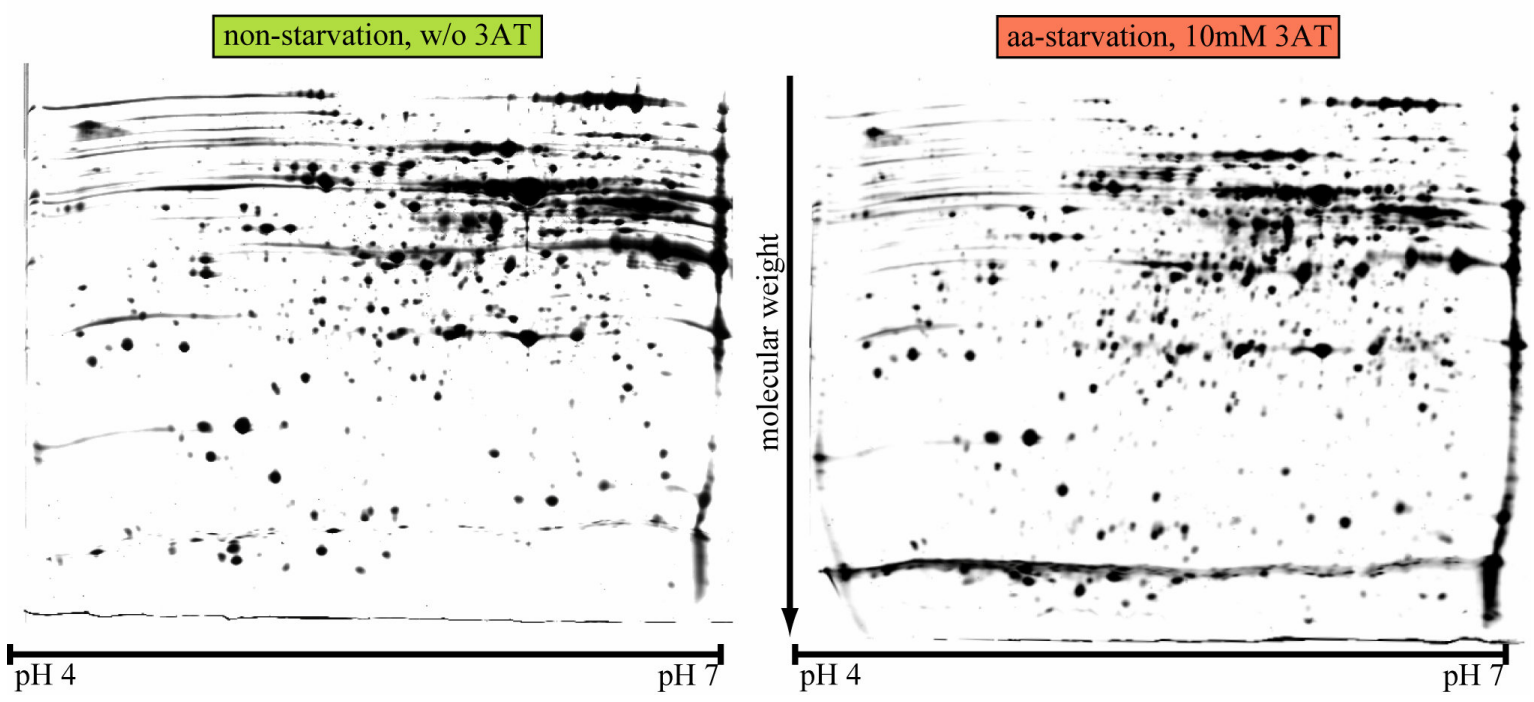

Supplementary Figure 1. Silver-stained 2D-gels corresponding to autoradiographies in Figure 3.

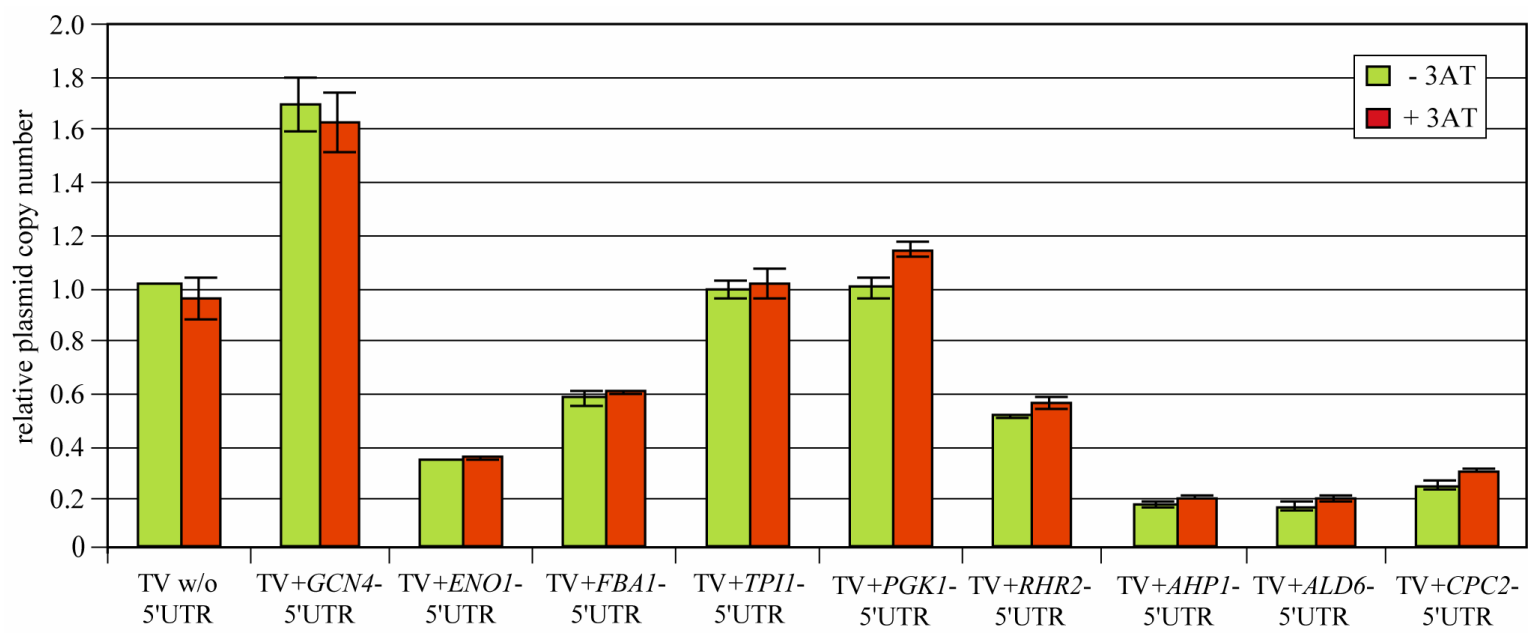

Supplementary Figure 2. Determination of plasmid copy number. Copy numbers are displayed relative to the copy number determined for the empty TV (w/o 5'UTR) under non-starvation conditions (-3AT). 
Supplementary Table 1. 5'UTR sequences confirmed by sequencing.

\begin{tabular}{|c|c|}
\hline 5'UTR & Sequence \\
\hline$A H P 1$ & 5'-UUU CAA CAA ACC AGA ACA ACA CAA GUA CUA CCA AUA ACC ACA ACA AAA C-3' \\
\hline ALD6 & $\begin{array}{l}\text { 5'-GUU UAU AGA AGA AAA AAC AUC AAG AAA CAU CUU UAA CAU ACA CAA ACA CAU } \\
\text { ACU AUC AGA AUA CA-3' }\end{array}$ \\
\hline$A S C 1$ & 5'-UCC UUA UAA CAC ACU AAA GUA AAU AAA GUG AAA A-3' \\
\hline ENO1 & 5'-CAA GCA ACU GCU UAU CAA CAC ACA AAC ACU AAA UCA AA-3' \\
\hline FBA1 & $\begin{array}{l}\text { 5'-CUG UUC UUC UUU UUC UUU UGU CAU AUA UAA CCA UAA CCA AGU AAU ACA UAU } \\
\text { UCA AA-3' }\end{array}$ \\
\hline FPRI & 5'- AUA AGC AAA AAA UCA AUC AAA ACA AGU AAU A-3' \\
\hline GRX1 & $\begin{array}{l}\text { 5'-CUU CGU GCA GUA CUU AUA CGA GCA UUC GCA UAA UUA UAC AAA UAG ACA AAA } \\
\text { CCU CAG AAG GAA AAA AA-3' }\end{array}$ \\
\hline ILV5 & $\begin{array}{l}\text { 5'-AAU UAU AGA AGC AAG ACA AAA ACA UAU AGA CAA CCU AUU CCU AGG AGU UAU } \\
\text { AUU UUU UUA CCC UAC CAG CAA UAU AAG UAA AAA AUA AAA C-3' }\end{array}$ \\
\hline$I P P 1$ & $\begin{array}{l}\text { 5'-AUU UUG AUU UGU UGU CCC UUA GGU CUA UAG AAC AGG AUA UCC CGC CGC GCA } \\
\text { AUU UAC UA-3' }\end{array}$ \\
\hline$P G K 1$ & $\begin{array}{l}\text { 5'-AAG UUC UUA GAU GCU UUC UUU UUC UCU UUU UUA CAG AUC AUC AAG GAA GUA } \\
\text { AUU AUC UAC UUU UUA CAA CAA AUA UAA AAC A-3' }\end{array}$ \\
\hline RHR2 & $\begin{array}{l}\text { 5'-UCA AUG UUU UAA AAU AUA UCA GAA CAA CAA AAG CAA AUA UAC AAA CCA UCG CA- } \\
\text { 3' }\end{array}$ \\
\hline TPII & 5'-CUU GCU UAA AUC UAU AAC UAC AAA AAA CAC AUA CAU AAA CUA AAA-3' \\
\hline TRP5 & 5'-UGU AAA CAU CGA UUG CUC CAA AAA GGG ACA UAG CAC ACC GAC AGA CC-3' \\
\hline
\end{tabular}

Supplementary Table 2. Protein names/functions of candidates presented in Figure 4. Information was taken from the Saccharomyces genome database (SGD; http://www.yeastgenome.org).

\begin{tabular}{|l|l|l|}
\hline \multicolumn{1}{|c|}{ candidate } & \multicolumn{1}{|c|}{ protein name } & \multicolumn{1}{c|}{ protein funtion } \\
\hline Tpi1 & triose phosphate isomerase & glycolysis \\
\hline Cpc2/Asc1 & $\begin{array}{l}\text { G-protein } \beta \text {-subunit and guanine nucleotide } \\
\text { dissociation inhibitor for Gpa2p; ortholog of } \\
\text { RACK1 that inhibits translation }\end{array}$ & Translation, signal transduction \\
\hline Fba1 & fructose 1,6-bisphosphate aldolase & glycolysis \\
\hline Ipp1 & ccytoplasmic inorganic pyrophosphatase & phosphate metabolic process \\
\hline Ald6 & cytosolic aldehyde dehydrogenase & acetate biosynthesis \\
\hline Rhr2 & isoform of DL-glycerol-3 phosphatase & glycerol biosynthesis \\
\hline
\end{tabular}


Supplementary Table 2. Continued.

\begin{tabular}{|c|c|c|}
\hline Ilv5 & acetohydroxyacid reductoisomerase & branched chain family amino acid biosynthetic process \\
\hline Pgk1 & 3-phosphoglycerate kinase & glycolysis \\
\hline Fpr1 & peptidyl-prolyl cis-trans isomerase & $\begin{array}{l}\text { chromatin organization, homoserine metabolic process, } \\
\text { protein folding }\end{array}$ \\
\hline Trp5 & tryptophan synthase & tryptophan biosynthesis \\
\hline Ahp1 & thiol-specific peroxiredoxin & cell redox homeostasis \\
\hline Eno1 & enolase I & glycolysis \\
\hline Grx1 & disulfide oxidoreductase & cell redox homeostasis \\
\hline Tdh3 & glyceraldehyde-3-phosphate dehydrogenase & apoptosis, glycolysis \\
\hline Rib5 & riboflavin synthase & riboflavin biosynthesis \\
\hline $\operatorname{Arg} 1$ & arginosuccinate synthetase & arginine biosynthesis \\
\hline Aro8 & aromatic aminotransferase I & aromatic amino acid family metabolic process \\
\hline Bnal & 3-hydroxyanthranilic acid dioxygenase & de novo NAD biosynthetic process from tryptophan \\
\hline Yhr029c & protein of unknown function & \\
\hline His7 & imidazole glycerol phosphate synthase & histidine biosynthesis \\
\hline Ecm40 & mitochondrial ornithine acetyltransferase & $\begin{array}{l}\text { arginine biosynthesis, fungal-type cell wall } \\
\text { organization, ornithine biosynthesis }\end{array}$ \\
\hline Thr1 & homoserine kinase & $\begin{array}{l}\text { homoserine, isoleucine, methionine and threonine } \\
\text { metabolic process }\end{array}$ \\
\hline Hor2 & isoform of DL-glycerol-3-phosphatase & glycerol biosynthesis \\
\hline Ccp1 & mitochondrial cytochrome-c peroxidase & cytochrome-c peroxidase activity \\
\hline Ubc13 & ubiquitin-conjugating enzyme & $\begin{array}{l}\text { free ubiquitin chain polymerization, postreplication } \\
\text { repair, protein mono- and polyubiquitination }\end{array}$ \\
\hline Sod2 & mitochondrial superoxide dismutase & oxygen and reactive oxygen species metabolic process \\
\hline $\mathrm{Bmh} 2$ & $14-3-3$ protein & DNA replication origin binding \\
\hline Pdc1 & pyruvate decarboxylase & $\begin{array}{l}\text { glucose catabolic process to ethanol, pyruvate } \\
\text { metabolic process }\end{array}$ \\
\hline His 1 & ATP phosphoribosyltransferase & histidine biosynthesis \\
\hline Ade1 & $\begin{array}{l}\text { N-succinyl-5-aminoimidazole-4- } \\
\text { carboxamide ribotide (SAICAR) synthetase }\end{array}$ & purine nucleotide biosynthesis \\
\hline Gev3 & $\begin{array}{l}\text { H subunit of the mitochondrial glycine } \\
\text { decarboxylase complex }\end{array}$ & glycine catabolic process \\
\hline
\end{tabular}


Supplementary Table 3. Protein sequence information corresponding to successfully identified proteins listed in Figure 4.

\begin{tabular}{|c|c|c|c|c|}
\hline Protein name & $\begin{array}{c}\text { NCBI } \\
\text { Accession } \\
\text { number }\end{array}$ & $\begin{array}{c}\text { MW } \\
\text { (kDa) }\end{array}$ & IP & p-value \\
\hline Tpi1p & $\underline{6320255}$ & 26.8 & 5.9 & $1.3 \mathrm{E}-12$ \\
\hline Peptide (charge state) & Xcorr & $\Delta \mathbf{C n}$ & Sp & Ions \\
\hline K.ADVDGFLVGGASLKPEFVDIINSR.N (3) & 5.65 & 0.64 & 2951.8 & $43 / 92$ \\
\hline K.KPQVTVGAQNAYLK.A (2) & 4.93 & 0.45 & 2064.9 & $23 / 26$ \\
\hline R.ILYGGSANGSNAVTFK.D (2) & 4.91 & 0.67 & 1713.7 & $13 / 15$ \\
\hline K.KPQVTVGAQNAYLK.A (3) & 4.50 & 0.37 & 1722.3 & $15 / 26$ \\
\hline K.ADVDGFLVGGASLKPEFVDIINSR.N (2) & 4.49 & 0.54 & 1190.2 & $25 / 46$ \\
\hline R.ILYGGSANGSNAVTFK.D (2) & 4.46 & 0.65 & 1694.9 & $7 / 10$ \\
\hline K.ASGAFTGENSVDQIK.D (2) & 4.30 & 0.57 & 1037.1 & $5 / 7$ \\
\hline K.ASGAFTGENSVDQIK.D (2) & 4.22 & 0.56 & 1037.2 & $5 / 7$ \\
\hline K.DKADVDGFLVGGASLKPEFVDIINSR.N (3) & 4.22 & 0.37 & 751.6 & $3 / 10$ \\
\hline K.KPQVTVGAQNAYLK.A (2) & 4.12 & 0.45 & 1040.3 & $17 / 26$ \\
\hline R.SYFHEDDKFIADK.T (3) & 4.08 & 0.55 & 1645.2 & $29 / 48$ \\
\hline R.ILYGGSANGSNAVTFK.D (2) & 3.91 & 0.67 & 776.6 & $3 / 5$ \\
\hline K.ADVDGFLVGGASLKPEFVDIINSR.N (3) & 3.86 & 0.50 & 1053.1 & $17 / 46$ \\
\hline K.DKADVDGFLVGGASLKPEFVDIINSR.N (3) & 3.86 & 0.47 & 1277.5 & $9 / 25$ \\
\hline K.ASGAFTGENSVDQIKDVGAK.W (2) & 3.74 & 0.56 & 1322.7 & $10 / 19$ \\
\hline K.ASGAFTGENSVDQIK.D (2) & 3.60 & 0.41 & 1018.9 & $19 / 28$ \\
\hline K.ASGAFTGENSVDQIKDVGAK.W (3) & 3.58 & 0.50 & 658.2 & $25 / 76$ \\
\hline R.ILYGGSANGSNAVTFK.D (2) & 3.46 & 0.64 & 944.4 & $17 / 30$ \\
\hline R.SYFHEDDKFIADK.T (2) & 3.38 & 0.54 & 1849.8 & $5 / 6$ \\
\hline K.ASGAFTGENSVDQIK.D (2) & 3.33 & 0.50 & 1116.1 & $9 / 14$ \\
\hline K.WVILGHSER.R (2) & 3.30 & 0.39 & 1073.5 & $7 / 8$ \\
\hline K.FALGQGVGVILCIGETLEEK.K (2) & 2.41 & 0.55 & 974.5 & $10 / 19$ \\
\hline K.WVILGHSER.R (2) & 2.19 & 0.26 & 747.7 & $3 / 4$ \\
\hline \multicolumn{5}{|l|}{ Total number of peptides: 9} \\
\hline Sequence coverage: $\mathbf{4 7 . 5 8 \%}$ & & & & \\
\hline
\end{tabular}

\begin{tabular}{|c|c|c|c|c|}
\hline Protein name & $\begin{array}{c}\text { NCBI } \\
\text { Accession } \\
\text { number }\end{array}$ & $\begin{array}{c}\text { MW } \\
\mathbf{( k D a})\end{array}$ & IP & p-value \\
\hline Cpc2p/Asc1p & $\underline{6323763}$ & 34.8 & 6.2 & $6.12 \mathrm{E}-9$ \\
\hline Peptide (charge state) & & & & \\
\hline Xcorr & $\mathbf{u C n}$ & $\mathbf{S p}$ & Ions \\
\hline R.GTLEGHNGWVTSLATSAGQPNLLLSASR.D (3) & 5.09 & 0.54 & 862.0 & $19 / 54$ \\
\hline K.ADDDSVTISAGNDK.M (2) & 4.92 & 0.57 & 1956.8 & $6 / 7$ \\
\hline R.GTLEGHNGWTSLATSAGQPNLLLSASR.D (3) & 4.61 & 0.62 & 1155.1 & $1 / 3$ \\
\hline K.ADDDSVTISAGNDK.M (2) & 4.35 & 0.55 & 2118.8 & $6 / 7$ \\
\hline R.LWDVATGETYQR.F (2) & 4.11 & 0.65 & 1902.1 & $19 / 22$ \\
\hline R.LWDVATGETYQR.F (2) & 3.95 & 0.61 & 1853.5 & $19 / 22$ \\
\hline R.LWDVATGETYQR.F (2) & 3.95 & 0.62 & 1953.2 & $10 / 11$ \\
\hline R.LWDVATGETYQR.F (2) & 3.88 & 0.67 & 2047.5 & $10 / 11$ \\
\hline K.DGEIMLWNLAAK.K (2) & 3.88 & 0.52 & 1279.6 & $17 / 22$ \\
\hline K.DGEIMLWNLAAK.K (2) & 3.83 & 0.47 & 1215.4 & $17 / 22$ \\
\hline R.VVPNEKADDDSVTIISAGNDK.M (3) & 3.77 & 0.43 & 836.8 & $7 / 20$ \\
\hline K.DGEIMLWNLAAK.K (2) & 3.56 & 0.52 & 1278.2 & $17 / 22$ \\
\hline R.LWDVATGETYQR.F (2) & 3.54 & 0.64 & 1876.0 & $19 / 22$ \\
\hline R.YWLAAATATGIK.V (2) & 3.50 & 0.56 & 1634.3 & $10 / 11$ \\
\hline R.YWLAAATATGIK.V (2) & 3.36 & 0.42 & 1539.8 & $19 / 22$ \\
\hline R.YWLAAATATGIK.V (2) & 3.25 & 0.53 & 1709.9 & $10 / 11$ \\
\hline K.GQCLATLLGHNDWVSQVR.V (3) & 3.23 & 0.53 & 547.2 & $6 / 17$ \\
\hline K.ADDDSVTIISAGNDK.M (2) & 3.13 & 0.46 & 1471.2 & $5 / 7$ \\
\hline
\end{tabular}


Supplementary Table 3. Continued.

\begin{tabular}{|c|c|c|c|c|}
\hline R.YWLAAATATGIK.V (2) & 3.12 & 0.52 & 1442.8 & $19 / 22$ \\
\hline R.YWLAAATATGIK.V (2) & 3.08 & 0.38 & 1724.3 & $19 / 22$ \\
\hline K.SDVMSVDIDK.K (2) & 2.98 & 0.48 & 966.6 & $8 / 9$ \\
\hline K.GQCLATLLGHNDWVSQVR.V (2) & 2.90 & 0.51 & 594.8 & $1 / 2$ \\
\hline K.DGEIM*LWNLAAK.K (2) & 2.89 & 0.36 & 658.8 & $7 / 11$ \\
\hline K.SDVMSVDIDKK.A (2) & 2.84 & 0.35 & 690.6 & $3 / 4$ \\
\hline R.YWLAAATATGIK.V (2) & 2.83 & 0.36 & 1494.8 & $19 / 22$ \\
\hline K.SDVM*SVDIDK.K (2) & 2.73 & 0.35 & 667.6 & $7 / 9$ \\
\hline K.ASMIISGSR.D (2) & 2.73 & 0.49 & 984.8 & $7 / 8$ \\
\hline R.VWQVMTAN.- (2) & 2.69 & 0.56 & 646.5 & $6 / 7$ \\
\hline R.YWLAAATATGIK.V (1) & 2.63 & 0.32 & 804.7 & $8 / 11$ \\
\hline K.SDVMSVDIDKK.A (2) & 2.63 & 0.38 & 763.1 & $3 / 4$ \\
\hline R.YWLAAATATGIK.V (1) & 2.58 & 0.40 & 935.6 & $8 / 11$ \\
\hline K.SDVMSVDIDKK.A (2) & 2.55 & 0.41 & 788.2 & $3 / 4$ \\
\hline K.SDVMSVDIDKK.A (2) & 2.46 & 0.41 & 883.3 & $4 / 5$ \\
\hline K.AMYSAQDEVFSLAFSPNR.Y (2) & 2.29 & 0.50 & 1081.8 & $1 / 2$ \\
\hline R.YWLAAATATGIK.V (1) & 2.14 & 0.42 & 590.3 & $7 / 11$ \\
\hline R.YWLAAATATGIK.V (1) & 2.13 & 0.24 & 675.8 & $15 / 22$ \\
\hline R.YWLAAATATGIK.V (1) & 2.09 & 0.29 & 831.7 & $17 / 22$ \\
\hline K.DGEIMLWNLAAK.K (1) & 1.82 & 0.10 & 983.6 & $8 / 11$ \\
\hline K.ADDDSVTISAGNDK.M (2) & 1.79 & 0.13 & 647.1 & $7 / 11$ \\
\hline K.GQCLATLLGHNDWVSQVR.V (3) & 1.79 & 0.40 & 557.8 & $9 / 14$ \\
\hline R.DKTLISWK.L (2) & 1.50 & 0.20 & 593.2 & $11 / 34$ \\
\hline K.ASM*IISGSRDKTIK.V (2) & 1.27 & 0.05 & 324.6 & $5 / 7$ \\
\hline K.FGVPVR.S (1) & 1.22 & 0.08 & 195.6 & $9 / 26$ \\
\hline Sequence coverage: 53.29\% & 1.04 & 0.06 & 190.3 & $7 / 10$ \\
\hline & & & & \\
\hline & & & & \\
\hline
\end{tabular}

\begin{tabular}{|c|c|c|c|c|}
\hline Protein name & $\begin{array}{c}\text { NCBI } \\
\text { Accession } \\
\text { number }\end{array}$ & MW (kDa) & IP & p-value \\
\hline Fba1p & $\underline{6322790}$ & 39.6 & 5.7 & $3.90 \mathrm{E}-11$ \\
\hline Peptide (charge state) & & & & \\
\hline K.SPIILQTSNGGAAYFAGK.G (2) & Xcorr & $\mathbf{\Delta C n}$ & Sp & Ions \\
\hline K.VNLDTDCQYAYLTGIR.D (2) & 5.47 & 0.64 & 1912.5 & $12 / 17$ \\
\hline K.GAIAAAHYIR.S (2) & 4.76 & 0.57 & 1580.9 & $2 / 3$ \\
\hline K.GISNEGQNASIK.G (2) & 2.60 & 0.44 & 1310.8 & $5 / 6$ \\
\hline Total number of peptides: 4 & 2.47 & 0.45 & 668.7 & $15 / 22$ \\
\hline Sequence coverage: 15.60\% & & & & \\
\hline
\end{tabular}

\begin{tabular}{|c|c|c|c|c|}
\hline Protein name & $\begin{array}{c}\text { NCBI } \\
\text { Accession } \\
\text { number }\end{array}$ & $\begin{array}{c}\text { MW } \\
(\mathbf{k D a})\end{array}$ & IP & p-value \\
\hline Ipp1p & $\underline{6319483}$ & 32.3 & 5.3 & $\begin{array}{c}3,33 \mathrm{E}- \\
12\end{array}$ \\
\hline Peptide (charge state) & & & & \\
\hline K.ALGIMALLDEGETDWK.V (2) & $\mathbf{X c o r r}$ & $\mathbf{\Delta C n}$ & $\mathbf{S p}$ & Ions \\
\hline K.AVGDNPIDVLEIGETIAYTGQVK.Q (2) & 6.03 & 0.65 & 2030.8 & $4 / 5$ \\
\hline K.LEITKEETLNPIIQDTK.K (2) & 5.29 & 0.58 & 1472.0 & $27 / 46$ \\
\hline K.VIAIDINDPLAPK.L (2) & 5.17 & 0.61 & 2201.3 & $25 / 32$ \\
\hline K.LEITKEETLNPIIQDTK.K (3) & 4.41 & 0.63 & 1406.5 & $19 / 24$ \\
\hline K.IPDGKPENQFAFSGEAK.N (3) & 4.39 & 0.46 & 1477.1 & $33 / 64$ \\
\hline K.IPDGKPENQFAFSGEAK.N (2) & 3.54 & 0.44 & 967.8 & $27 / 64$ \\
\hline
\end{tabular}


Supplementary Table 3. Continued.

\begin{tabular}{|c|c|c|c|c|}
\hline K.WFFISGSV.- (1) & 1.25 & 0.18 & 517.4 & $9 / 14$ \\
\hline Total number of peptides: 6 & & & & \\
\hline Sequence coverage: 33.10\% & & & & \\
\hline
\end{tabular}

\begin{tabular}{|c|c|c|c|c|}
\hline Protein name & $\begin{array}{c}\text { NCBI } \\
\text { Accession } \\
\text { number }\end{array}$ & $\begin{array}{c}\text { MW } \\
(\mathbf{k D a})\end{array}$ & IP & p-value \\
\hline Ald6p & $\underline{6325196}$ & 54.4 & 5.2 & $1.57 \mathrm{E}-07$ \\
\hline Peptide (charge state) & & & & \\
\hline K.SAHLVFDDANIKK.T (3) & $\mathbf{X c o r r}$ & $\mathbf{\Delta C n}$ & $\mathbf{S p}$ & Ions \\
\hline K.VGIPAGVVNIVPGPGR.T (2) & 4.19 & 0.54 & 1980.3 & $7 / 12$ \\
\hline K.ANFQGAITNR.Q (2) & 3.55 & 0.61 & 960.6 & $19 / 30$ \\
\hline R.TVGAALTNDPR.I (2) & 3.08 & 0.46 & 976.1 & $8 / 9$ \\
\hline R.KLAFTGSTEVGK.S (2) & 2.97 & 0.50 & 1090.3 & $17 / 20$ \\
\hline R.IVKEEIFGPVVTVAK.F (3) & 2.88 & 0.44 & 598.5 & $7 / 11$ \\
\hline R.IVKEEIFGPVVTVAK.F (2) & 2.68 & 0.26 & 828.8 & $3 / 7$ \\
\hline K.LAFTGSTEVGK.S (2) & 2.02 & 0.35 & 618.4 & $15 / 28$ \\
\hline Total number of peptides: 7 & 2.01 & 0.44 & 1312.9 & $17 / 20$ \\
\hline Sequence coverage: 15.40\% & & & & \\
\hline
\end{tabular}

\begin{tabular}{|c|c|c|c|c|}
\hline Protein name & $\begin{array}{c}\text { NCBI } \\
\text { Accession } \\
\text { number }\end{array}$ & $\begin{array}{c}\text { MW } \\
(\mathbf{k D a})\end{array}$ & IP & p-value \\
\hline Rhr2p & $\underline{8655907}$ & 27.9 & 5.3 & $7.50 \mathrm{E}-11$ \\
\hline Peptide (charge state) & & & & \\
\hline K.GRNGLGFPINEQDPSK.S (2) & $\mathbf{X c o r r}$ & $\mathbf{\Delta C n}$ & $\mathbf{S p}$ & Ions \\
\hline K.FAPDFDEEYVNKLEGEIPEK.Y (2) & 4.75 & 0.61 & 1415.3 & $23 / 30$ \\
\hline K.RPEYFITANDVK.Q (2) & 4.27 & 0.68 & 1110.4 & $1 / 2$ \\
\hline K.RPEYFITANDVK.Q (2) & 4.25 & 0.57 & 1106.1 & $10 / 11$ \\
\hline K.IKRPEYFITANDVK.Q (3) & 4.13 & 0.03 & 938.0 & $19 / 22$ \\
\hline K.IVGIATTFDLDFLK.E (2) & 3.92 & 0.39 & 1079.3 & $1 / 2$ \\
\hline K.IKRPEYFITANDVK.Q (2) & 3.89 & 0.57 & 1244.5 & $21 / 26$ \\
\hline K.YGEHSIEVPGAVK.L (2) & 3.79 & 0.56 & 783.7 & $17 / 26$ \\
\hline K.IKRPEYFITANDVK.Q (2) & 3.62 & 0.46 & 1106.2 & $3 / 4$ \\
\hline K.YGEHSIEVPGAVK.L (2) & 3.56 & 0.45 & 854.8 & $9 / 13$ \\
\hline K.FAPDFADEEYVNKLEGEIPEK.Y (3) & 3.48 & 0.45 & 1610.6 & $5 / 6$ \\
\hline K.WAVATSGTRDMAK.K (2) & 3.35 & 0.54 & 518.0 & $17 / 40$ \\
\hline K.RPEYFITANDVK.Q (3) & 3.29 & 0.49 & 894.2 & $2 / 3$ \\
\hline R.NGLGFPINEQDPSK.S (2) & 3.26 & 0.34 & 1484.7 & $29 / 44$ \\
\hline K.IVGIATTFDLDFLKEK.G (2) & 3.19 & 0.48 & 536.5 & $9 / 13$ \\
\hline K.GRNGLGFPINEQDPSK.S (3) & 3.15 & 0.46 & 701.3 & $8 / 15$ \\
\hline R.NGLGFPINEQDPSK.S (2) & 3.14 & 0.43 & 1014.9 & $9 / 20$ \\
\hline K.RPEYFITANDVK.Q (2) & 3.09 & 0.53 & 622.5 & $9 / 13$ \\
\hline K.FAPDFADEEYVNK.L (2) & 3.02 & 0.11 & 957.3 & $19 / 22$ \\
\hline K.DKPYFDAEHVIHISHGWR.T (3) & 2.99 & 0.55 & 711.9 & $19 / 24$ \\
\hline R.NGLGFPINEQDPSK.S (2) & 2.94 & 0.64 & 624.3 & $33 / 68$ \\
\hline K.KWFDILK.I (1) & 2.61 & 0.46 & 680.3 & $19 / 26$ \\
\hline Sequence coverage: 43.54\% & 1.48 & 0.02 & 499.0 & $3 / 4$ \\
\hline & & & & \\
\hline
\end{tabular}


Supplementary Table 3. Continued.

\begin{tabular}{|c|c|c|c|c|}
\hline Protein name & $\begin{array}{c}\text { NCBI } \\
\text { Accession } \\
\text { number }\end{array}$ & $\begin{array}{c}\text { MW } \\
(\mathbf{k D a})\end{array}$ & IP & p-value \\
\hline Ilv5p & $\underline{6323387}$ & 44.4 & 9.8 & $7.85 \mathrm{E}-14$ \\
\hline Peptide (charge state) & & & & \\
\hline K.AQALAVAIGSGYVYQTTFER.E (2) & $\mathbf{X c o r r}$ & $\mathbf{\Delta C n}$ & $\mathbf{S p}$ & Ions \\
\hline K.YGMDYMYDACSTTAR.R (2) & 6.29 & 0.67 & 2189.9 & $13 / 19$ \\
\hline R.SLEFNSQPDYR.E (2) & 3.32 & 0.56 & 1136.1 & $19 / 28$ \\
\hline R.EVNSDLYGER.G (2) & 3.09 & 0.49 & 655.5 & $3 / 4$ \\
\hline R.NMEIWK.V (2) & 2.76 & 0.55 & 998.6 & $8 / 9$ \\
\hline K.YGM*DYMYDACSTTAR.R (2) & 1.51 & 0.22 & 521.2 & $9 / 10$ \\
\hline R.GINSSYAVWNDVTGK.A (2) & 1.47 & 0.05 & 323.6 & $11 / 28$ \\
\hline Total number of peptides: 7 & 1.34 & 0.14 & 719.0 & $15 / 28$ \\
\hline Sequence coverage: 19.49\% & & & & \\
\hline
\end{tabular}

\begin{tabular}{|c|c|c|c|c|}
\hline Protein name & $\begin{array}{c}\text { NCBI } \\
\text { Accession } \\
\text { number }\end{array}$ & $\begin{array}{c}\text { MW } \\
\text { (kDa) }\end{array}$ & IP & p-value \\
\hline Pgk1p & 10383781 & 44.7 & 7.8 & 2.67E-14 \\
\hline Peptide (charge state) & Xcorr & $\Delta \mathbf{C n}$ & Sp & Ions \\
\hline R.HELSSLADVYINDAFGTAHR.A (3) & 5.62 & 0.65 & 2545.2 & $37 / 76$ \\
\hline K.GVEVVLPVDFIIADAFSADANTK.T (2) & 5.56 & 0.62 & 1080.9 & $13 / 22$ \\
\hline K.ISHVSTGGGASLELLEGK.E (2) & 4.96 & 0.62 & 1905.7 & $27 / 34$ \\
\hline K.DVTFLNDCVGPEVEAAVK.A (2) & 4.76 & 0.60 & 718.0 & $10 / 17$ \\
\hline K.VLENTEIGDSIFDK.A (2) & 4.61 & 0.64 & 1466.1 & $11 / 13$ \\
\hline K.TIVWNGPPGVFEFEK.F (2) & 4.60 & 0.57 & 1122.7 & $5 / 7$ \\
\hline K.FRHELSSLADVYINDAFGTAHR.A (3) & 4.53 & 0.53 & 2965.0 & $37 / 84$ \\
\hline K.TIVWNGPPGVFEFEK.F (2) & 4.36 & 0.62 & 1096.8 & $5 / 7$ \\
\hline K.KVLENTEIGDSIFDK.A (2) & 4.31 & 0.46 & 1918.5 & $5 / 7$ \\
\hline K.SSAAGNTVIIGGGDTATVAK.K (2) & 4.15 & 0.60 & 1201.0 & $12 / 19$ \\
\hline K.TVTDKEGIPAGWQGLDNGPESR.K (3) & 4.15 & 0.62 & 1224.8 & $17 / 42$ \\
\hline K.ALENPTRPFLAILGGAK.V (3) & 4.11 & 0.63 & 928.7 & $29 / 64$ \\
\hline K.SSAAGNTVIIGGGDTATVAK.K (2) & 4.04 & 0.62 & 1442.3 & $13 / 19$ \\
\hline K.ALENPTRPFLAILGGAK.V (2) & 3.99 & 0.40 & 1202.8 & $5 / 8$ \\
\hline R.AHSSMVGFDLPQR.A (2) & 3.89 & 0.60 & 1888.7 & $5 / 6$ \\
\hline R.AHSSMVGFDLPQR.A (2) & 3.82 & 0.64 & 1928.2 & $5 / 6$ \\
\hline K.ISHVSTGGGASLELLEGK.E (3) & 3.73 & 0.43 & 924.3 & $25 / 68$ \\
\hline R.AHSSMVGFDLPQR.A (2) & 3.68 & 0.65 & 1704.0 & $19 / 24$ \\
\hline R.AHSSMVGFDLPQR.A (2) & 3.62 & 0.60 & 1596.7 & $3 / 4$ \\
\hline R.AHSSM*VGFDLPQR.A (3) & 3.58 & 0.25 & 1980.0 & $7 / 12$ \\
\hline K.TVTDKEGIPAGWQGLDNGPESR.K (2) & 3.47 & 0.43 & 682.6 & $1 / 2$ \\
\hline R.AHSSMVGFDLPQR.A (3) & 3.44 & 0.30 & 983.4 & $1 / 2$ \\
\hline K.SSAAGNTVIIGGGDTATVAK.K (2) & 3.34 & 0.56 & 1448.8 & $27 / 38$ \\
\hline K.ASAPGSVILLENLR.Y (2) & 2.94 & 0.30 & 759.5 & $9 / 13$ \\
\hline R.AAGFLLEK.E (2) & 2.75 & 0.45 & 852.6 & $13 / 14$ \\
\hline R.AHSSM*VGFDLPQR.A (2) & 2.63 & 0.50 & 967.8 & $2 / 3$ \\
\hline K.ALENPTRPFLAILGGAK.V (2) & 2.46 & 0.34 & 500.6 & $7 / 16$ \\
\hline K.DVTFLNDCVGPEVEAAVK.A (2) & 2.26 & 0.32 & 562.2 & $1 / 2$ \\
\hline K.KVLENTEIGDSIFDK.A (2) & 2.10 & 0.43 & 840.8 & $15 / 28$ \\
\hline K.ELPGVAFLSEK.K (2) & 2.06 & 0.45 & 536.1 & $3 / 4$ \\
\hline K.ALLDEVVK.S (2) & 1.64 & 0.07 & 301.2 & $11 / 14$ \\
\hline K.ALLDEVVK.S (1) & 1.58 & 0.19 & 534.7 & $5 / 7$ \\
\hline K.ELPGVAFLSEK.K (1) & 1.44 & 0.07 & 236.8 & $11 / 20$ \\
\hline K.ELQSLLGK.D (1) & 1.38 & 0.03 & 236.2 & $5 / 7$ \\
\hline K.TIVWNGPPGVFEFEK.F (2) & 1.38 & 0.05 & 431.6 & $13 / 28$ \\
\hline
\end{tabular}


Supplementary Table 3. Continued.

\begin{tabular}{|c|l|l|l|l|}
\hline Total number of peptides: 17 & & & & \\
\hline Sequence coverage: $55.77 \%$ & & & & \\
\hline
\end{tabular}

\begin{tabular}{|c|c|c|c|c|}
\hline Protein name & $\begin{array}{c}\text { NCBI } \\
\text { Accession } \\
\text { number }\end{array}$ & $\begin{array}{c}\text { MW } \\
(\mathbf{k D a})\end{array}$ & IP & p-value \\
\hline Fpr1p & $\underline{6324194}$ & 12.1 & 5.9 & $5.74 \mathrm{E}-11$ \\
\hline Peptide (charge state) & & & & \\
\hline K.TGDLVTIHYTGTLENGQK.F (2) & $\mathbf{X c o r r}$ & $\mathbf{\Delta C n}$ & $\mathbf{S p}$ & Ions \\
\hline K.TGDLVTIHYTGTLENGQK.F (3) & 4.98 & 0.58 & 1178.4 & $11 / 17$ \\
\hline K.TGDLVTIHYTGTLENGQK.F (2) & 4.14 & 0.65 & 1068.3 & $7 / 17$ \\
\hline R.GSPFQCNIGVGQVIK.G (2) & 4.14 & 0.56 & 831.8 & $21 / 34$ \\
\hline R.GFPGLIPPNSTLVFDVELLKVN.- (2) & 3.67 & 0.50 & 850.6 & $5 / 7$ \\
\hline K.GWDVGIPK.L (2) & 2.96 & 0.39 & 530.4 & $10 / 21$ \\
\hline Total number of peptides: 4 & 1.99 & 0.34 & 851.4 & $6 / 7$ \\
\hline Sequence coverage: 55.26\% & & & & \\
\hline
\end{tabular}

\begin{tabular}{|c|c|c|c|c|}
\hline Protein name & $\begin{array}{c}\text { NCBI } \\
\text { Accession } \\
\text { number }\end{array}$ & $\begin{array}{c}\text { MW } \\
\text { (kDa) }\end{array}$ & IP & p-value \\
\hline Trp5p & $\underline{6321412}$ & 76.6 & 6.5 & 7.55E-14 \\
\hline Peptide (charge state) & Xcorr & $\Delta \mathbf{C n}$ & Sp & Ions \\
\hline R.NEGVTVPIILMGYYNPILNYGEER.F (3) & 4.49 & 0.68 & 1230.0 & $33 / 92$ \\
\hline R.LELLSHIADSFVYVVSR.M (2) & 4.03 & 0.62 & 1089.1 & $11 / 16$ \\
\hline K.AGANGFIIVDLPPEEALK.V (2) & 3.98 & 0.55 & 992.9 & $21 / 34$ \\
\hline R.LELLSHIADSFVYVVSR.M (2) & 3.98 & 0.66 & 1094.9 & $11 / 16$ \\
\hline R.M*GTTGVQSSVASDLDELISR.V (2) & 3.94 & 0.60 & 660.0 & $1 / 2$ \\
\hline R.MGTTGVQSSVASDLDELISR.V (2) & 3.83 & 0.54 & 644.4 & $9 / 19$ \\
\hline K.DTPLAVGFGVSTR.E (2) & 3.63 & 0.64 & 1729.2 & $19 / 24$ \\
\hline R.EHFQSVGSVADGVVIGSK.I (3) & 3.61 & 0.59 & 1221.5 & $15 / 34$ \\
\hline K.IVTLCGDAPEGK.R (2) & 3.32 & 0.56 & 1540.8 & $19 / 22$ \\
\hline K.IVTLCGDAPEGK.R (2) & 3.26 & 0.55 & 1194.2 & $9 / 11$ \\
\hline R.EHFQSVGSVADGVVIGSK.I (2) & 2.77 & 0.41 & 623.4 & $1 / 2$ \\
\hline R.NALVTFMTAGYPTVK.D (2) & 1.67 & 0.35 & 711.9 & $4 / 7$ \\
\hline Total number of peptides: 9 & & & & \\
\hline Sequence coverage: $19.38 \%$ & & & & \\
\hline
\end{tabular}

\begin{tabular}{|c|c|c|c|c|}
\hline Protein name & $\begin{array}{c}\text { NCBI } \\
\text { Accession } \\
\text { number }\end{array}$ & $\begin{array}{c}\text { MW } \\
(\mathbf{k D a})\end{array}$ & IP & p-value \\
\hline Ahp1p & $\underline{6323138}$ & 19.1 & 4.9 & $1.34 \mathrm{E}-6$ \\
\hline & & & & \\
\hline Peptide (charge state) & $\mathbf{X c o r r}$ & $\mathbf{\Delta C n}$ & $\mathbf{S p}$ & Ions \\
\hline K.FQYIAISQSDADSESCK.M (2) & 5.58 & 0.53 & 1339.7 & $3 / 4$ \\
\hline K.FASDPGCAFTK.S (2) & 3.12 & 0.45 & 917.6 & $17 / 20$ \\
\hline K.M*PQTVEWSK.L (2) & 1.76 & 0.12 & 552.5 & $11 / 16$ \\
\hline Total number of peptides: 3 & & & & \\
\hline Sequence coverage: 21.02\% & & & & \\
\hline
\end{tabular}


Supplementary Table 3. Continued.

\begin{tabular}{|c|c|c|c|c|}
\hline Protein name & $\begin{array}{c}\text { NCBI } \\
\text { Accession } \\
\text { number }\end{array}$ & $\begin{array}{c}\text { MW } \\
\text { (kDa) }\end{array}$ & IP & p-value \\
\hline Eno1p & 6321693 & 46.8 & 6.6 & $2.24 \mathrm{E}-8$ \\
\hline Peptide (charge state) & Xcorr & $\Delta \mathbf{C n}$ & Sp & Ions \\
\hline K.TAGIQIVADDLTVTNPK.R (2) & 4.97 & 0.58 & 1542.6 & $23 / 32$ \\
\hline K.AVDDFLISLDGTANK.S (2) & 4.70 & 0.48 & 1328.9 & $23 / 28$ \\
\hline K.AVDDFLISLDGTANK.S (2) & 3.64 & 0.42 & 1082.6 & $3 / 4$ \\
\hline K.VNQIGTLSESIK.A (2) & 3.23 & 0.50 & 659.9 & $17 / 22$ \\
\hline K.IGLDCASSEFFK.D (2) & 3.16 & 0.41 & 911.4 & $15 / 22$ \\
\hline K.VNQIGTLSESIK.A (2) & 3.15 & 0.52 & 725.2 & $17 / 22$ \\
\hline K.VNQIGTLSESIK.A (2) & 3.09 & 0.42 & 726.3 & $17 / 22$ \\
\hline R.GNPTVEVELTTEK.G (2) & 3.01 & 0.49 & 601.2 & $2 / 3$ \\
\hline K.VNQIGTLSESIK.A (2) & 3.01 & 0.46 & 662.9 & $8 / 11$ \\
\hline R.GNPTVEVELTTEK.G (2) & 2.97 & 0.57 & 812.1 & $17 / 24$ \\
\hline K.IGLDCASSEFFK.D (2) & 2.89 & 0.40 & 937.3 & $15 / 22$ \\
\hline K.NVNDVIAPAFVK.A (2) & 2.80 & 0.22 & 722.7 & $15 / 22$ \\
\hline K.NVNDVIAPAFVK.A (2) & 2.75 & 0.31 & 642.6 & $15 / 22$ \\
\hline K.NVNDVIAPAFVK.A (2) & 2.73 & 0.36 & 750.5 & $8 / 11$ \\
\hline K.TAGIQIVADDLTVTNPK.R (2) & 2.72 & 0.51 & 657.8 & $1 / 2$ \\
\hline K.NVNDVIAPAFVK.A (2) & 2.71 & 0.07 & 745.4 & $8 / 11$ \\
\hline R.GNPTVEVELTTEK.G (2) & 2.67 & 0.52 & 715.0 & $2 / 3$ \\
\hline K.IGLDCASSEFFK.D (2) & 2.66 & 0.35 & 990.1 & $8 / 11$ \\
\hline K.IGLDCASSEFFK.D (2) & 2.60 & 0.34 & 1135.4 & $17 / 22$ \\
\hline K.IGLDCASSEFFK.D (2) & 2.44 & 0.40 & 1118.5 & $8 / 11$ \\
\hline K.IGLDCASSEFFK.D (2) & 2.43 & 0.33 & 742.9 & $13 / 22$ \\
\hline K.IGLDCASSEFFK.D (2) & 2.42 & 0.48 & 825.0 & $15 / 22$ \\
\hline K.AADALLLK.V (2) & 1.72 & 0.14 & 577.5 & $11 / 14$ \\
\hline K.TAGIQIVADDLTVTNPK.R (2) & 1.67 & 0.41 & 513.6 & $13 / 32$ \\
\hline R.IGSEVYHNLK.S (2) & 1.56 & 0.04 & 455.3 & $5 / 9$ \\
\hline \multicolumn{5}{|l|}{ Total number of peptides: 8} \\
\hline Sequence coverage: $22.65 \%$ & & & & \\
\hline
\end{tabular}

\begin{tabular}{|c|c|c|c|c|}
\hline Protein name & $\begin{array}{c}\text { NCBI } \\
\text { Accession } \\
\text { number }\end{array}$ & $\begin{array}{c}\text { MW } \\
(\mathbf{k D a})\end{array}$ & IP & p-value \\
\hline Grx1p & $\underline{6319814}$ & 12.4 & 4.8 & $1.45 \mathrm{E}-8$ \\
\hline & & & & \\
\hline Peptide (charge state) & $\mathbf{X c o r r}$ & $\mathbf{\Delta C n}$ & $\mathbf{S p}$ & $\mathbf{I}$ Ions \\
\hline K.DLIAENEIFVASK.T (2) & 4.77 & 0.64 & 1706.0 & $7 / 8$ \\
\hline K.VLVLQLNDMK.E (2) & 3.93 & 0.37 & 1139.0 & $8 / 9$ \\
\hline K.HIGGNDDLQELR.E (2) & 3.01 & 0.55 & 835.3 & $10 / 11$ \\
\hline K.EGADIQAALYEINGQR.T (2) & 2.66 & 0.53 & 628.3 & $17 / 30$ \\
\hline K.VLVLQLNDM*K.E (2) & 2.65 & 0.49 & 1151.6 & $5 / 6$ \\
\hline K.HIGGNDDLQELR.E (2) & 2.32 & 0.49 & 591.0 & $17 / 22$ \\
\hline K.VLVLQLNDMK.E (1) & 2.09 & 0.32 & 805.1 & $13 / 18$ \\
\hline R.TVPNIYINGK.H (2) & 1.36 & 0.01 & 175.4 & $4 / 9$ \\
\hline Total number of peptides: 6 & & & & \\
\hline Sequence coverage: 55.45\% & & & & \\
\hline
\end{tabular}


Supplementary Table 3. Continued.

\begin{tabular}{|c|c|c|c|c|}
\hline Protein name & $\begin{array}{c}\text { NCBI } \\
\text { Accession } \\
\text { number }\end{array}$ & $\begin{array}{c}\text { MW } \\
\mathbf{( k D a})\end{array}$ & IP & p-value \\
\hline Tdh3p & $\underline{6321631}$ & 35.7 & 7.0 & $4.52 \mathrm{E}-12$ \\
\hline Peptide (charge state) & & & & \\
\hline K.IVSNASCTTNCLAPLAK.V (2) & $\mathbf{X c o r r}$ & $\mathbf{\Delta C n}$ & $\mathbf{S p}$ & Ions \\
\hline R.DPANLPWGSSNVDIAIDSTGVFK.E (2) & 5.01 & 0.69 & 1109.0 & $5 / 8$ \\
\hline K.IVSNASCTTNCLAPLAK.V (2) & 4.96 & 0.59 & 1231.6 & $13 / 22$ \\
\hline K.LNKETTYDEIKK.V (3) & 4.92 & 0.61 & 1267.4 & $19 / 32$ \\
\hline K.LNKETTYDEIKK.V (3) & 4.59 & 0.40 & 1193.1 & $6 / 11$ \\
\hline K.IVSNASCTTNCLAPLAK.V (2) & 4.29 & 0.47 & 1085.6 & $6 / 11$ \\
\hline R.YAGEVSHDDKHIIVDGK.K (3) & 4.18 & 0.66 & 1282.6 & $5 / 8$ \\
\hline R.VPTVDVSVVDLTVK.L (2) & 4.05 & 0.50 & 793.4 & $27 / 64$ \\
\hline K.IVSNASCTTNCLAPLAK.V (2) & 3.88 & 0.68 & 1117.2 & $19 / 26$ \\
\hline K.LVSWYDNEYGYSTR.V (2) & 3.86 & 0.53 & 808.8 & $9 / 16$ \\
\hline K.VINDAFGIEEGLMTTVHSLTATQK.T (3) & 3.54 & 0.59 & 1041.2 & $9 / 13$ \\
\hline K.LNKETTYDEIK.K (2) & 3.53 & 0.53 & 885.6 & $8 / 23$ \\
\hline R.VVDLVEHVAK.A (2) & 3.37 & 0.31 & 818.0 & $3 / 4$ \\
\hline K.LVSWYDNEYGYSTR.V (2) & 3.23 & 0.48 & 1147.5 & $8 / 9$ \\
\hline R.VPTVDVSVVDLTVK.L (2) & 3.10 & 0.30 & 569.3 & $7 / 23$ \\
\hline K.VLPELQGK.L (1) & 2.75 & 0.61 & 597.2 & $7 / 13$ \\
\hline Sotal number of peptides: 10 & 2.66 & 0.40 & 696.6 & $7 / 13$ \\
\hline & 1.15 & 0.04 & 174.7 & $4 / 7$ \\
\hline
\end{tabular}

\begin{tabular}{|c|c|c|c|c|}
\hline Protein name & $\begin{array}{c}\text { NCBI } \\
\text { Accession } \\
\text { number }\end{array}$ & $\begin{array}{c}\text { MW } \\
\text { (kDa) }\end{array}$ & IP & p-value \\
\hline Rib5p & $\underline{6319733}$ & 26.2 & 4.9 & $2.58 \mathrm{E}-13$ \\
\hline Peptide (charge state) & Xcorr & $\Delta \mathbf{C n}$ & Sp & Ions \\
\hline R.SNVASWIQGTQVNLER.A (2) & 5.55 & 0.50 & 2148.5 & $4 / 5$ \\
\hline K.VDPLSQGGAFYISM*IK.H (2) & 5.08 & 0.60 & 1548.6 & $4 / 5$ \\
\hline K.VDPLSQGGAFYISMIK.H (2) & 5.01 & 0.65 & 1426.1 & $23 / 30$ \\
\hline R.SNVASWIQGTQVNLER.A (2) & 5.01 & 0.42 & 1909.3 & $23 / 30$ \\
\hline K.DSTLNTM*ISNIIEEK.V (2) & 4.80 & 0.57 & 1782.5 & $11 / 14$ \\
\hline R.FGGHYVQGHVDTVANIVSR.R (3) & 4.70 & 0.62 & 2531.3 & $1 / 2$ \\
\hline R.SNVASWIQGTQVNLER.A (3) & 4.50 & 0.46 & 2799.3 & $17 / 30$ \\
\hline K.DSTLNTMISNIIEEK.V (2) & 4.48 & 0.44 & 1550.8 & $3 / 4$ \\
\hline R.FGGHYVQGHVDTVANIVSR.R (3) & 4.42 & 0.61 & 2297.6 & $35 / 72$ \\
\hline R.FGGHYVQGHVDTVANIVSR.R (2) & 4.31 & 0.61 & 1623.8 & $23 / 36$ \\
\hline K.IGDEVNIEVDLTGK.I (2) & 4.29 & 0.55 & 1472.0 & $21 / 26$ \\
\hline K.IGDEVNIEVDLTGK.I (2) & 4.08 & 0.62 & 1425.0 & $21 / 26$ \\
\hline K.QILLTLENQISK.K (2) & 3.82 & 0.56 & 1213.0 & $19 / 22$ \\
\hline K.GFICIDGTSLTIIK.V (2) & 3.70 & 0.52 & 1606.6 & $21 / 26$ \\
\hline K.HTQDNVIMPLKK.I (3) & 3.66 & 0.46 & 1371.7 & $27 / 44$ \\
\hline R.FGGHYVQGHVDTVANIVSR.R (3) & 3.44 & 0.50 & 2104.1 & $1 / 2$ \\
\hline K.GFICIDGTSLTIIK.V (2) & 3.31 & 0.51 & 777.7 & $8 / 13$ \\
\hline K.QILLTLENQISKK.D (2) & 3.18 & 0.31 & 539.8 & $13 / 24$ \\
\hline K.HTQDNVIMPLK.K (2) & 3.10 & 0.55 & 885.1 & $4 / 5$ \\
\hline R.FGGHYVQGHVDTVANIVSR.R (3) & 2.69 & 0.46 & 1117.9 & $5 / 12$ \\
\hline K.VGISPETIKR.S (2) & 2.59 & 0.46 & 725.2 & $8 / 9$ \\
\hline R.SNVASWIQGTQVNLER.A (2) & 1.74 & 0.30 & 723.1 & $1 / 2$ \\
\hline \multicolumn{5}{|l|}{ Total number of peptides: 13} \\
\hline Sequence coverage: $54.20 \%$ & & & & \\
\hline
\end{tabular}


Supplementary Table 3. Continued.

\begin{tabular}{|c|c|c|c|c|}
\hline Protein name & $\begin{array}{c}\text { NCBI } \\
\text { Accession } \\
\text { number }\end{array}$ & $\begin{array}{c}\text { MW } \\
(\mathbf{k D a})\end{array}$ & IP & p-value \\
\hline $\operatorname{Arg1p}$ & $\underline{6324514}$ & 46.9 & 5.5 & $1.68 \mathrm{E}-13$ \\
\hline Peptide (charge state) & Xcorr & $\Delta \mathbf{C n}$ & Sp & Ions \\
\hline K.AKPWSTDENQAHISYEAGILEDPDTTPPK.D (3) & 5.43 & 0.57 & 1559.5 & $37 / 112$ \\
\hline K.AQIDVAKQEGCFAVSHGCTGK.G (3) & 5.16 & 0.71 & 1272.6 & $3 / 8$ \\
\hline R.SM*IQPSQNSVNGTVR.V (2) & 4.63 & 0.56 & 984.8 & $23 / 28$ \\
\hline R.KAHVDLEGLTLDK.E (2) & 4.36 & 0.55 & 1518.6 & $5 / 6$ \\
\hline K.LIVDPMDAPDQPQDLTIDFER.G (2) & 4.34 & 0.66 & 1030.6 & $5 / 8$ \\
\hline R.KAHVDLEGLTLDK.E (2) & 4.29 & 0.60 & 1272.2 & $19 / 24$ \\
\hline R.KAHVDLEGLTLDK.E (3) & 4.27 & 0.43 & 1345.1 & $7 / 12$ \\
\hline R.SMIQPSQNSVNGTVR.V (2) & 4.21 & 0.52 & 624.2 & $5 / 7$ \\
\hline K.LIVDPM*DAPDQPQDLTIDFER.G (2) & 4.07 & 0.68 & 1026.1 & $5 / 8$ \\
\hline R.GCYEQAPLTVLR.K (2) & 4.04 & 0.65 & 1333.2 & $19 / 22$ \\
\hline R.SM*IQPSQNSVNGTVR.V (2) & 3.97 & 0.55 & 825.8 & $11 / 14$ \\
\hline K.AHVDLEGLTLDK.E (2) & 3.76 & 0.70 & 1127.4 & $9 / 11$ \\
\hline R.SMIQPSQNSVNGTVR.V (2) & 3.72 & 0.45 & 566.0 & $19 / 28$ \\
\hline K.EVSVTKPLDVFLAASNLAR.A (3) & 3.33 & 0.35 & 735.0 & $1 / 3$ \\
\hline R.SMIQPSQNSVNGTVR.V (2) & 3.25 & 0.32 & 510.7 & $19 / 28$ \\
\hline R.KDLLDYAAQK.G (2) & 2.94 & 0.39 & 934.7 & $5 / 6$ \\
\hline K.DLLDYAAQK.G (2) & 2.70 & 0.49 & 958.5 & $7 / 8$ \\
\hline R.DSFVTPNYSR.L (2) & 2.62 & 0.42 & 616.9 & $7 / 9$ \\
\hline K.GNVIILGR.S (2) & 2.57 & 0.35 & 870.0 & $11 / 14$ \\
\hline R.IDIVEDR.Y (2) & 2.21 & 0.41 & 803.5 & $11 / 12$ \\
\hline R.MPEFFER.F (2) & 2.10 & 0.39 & 657.7 & $11 / 12$ \\
\hline R.M*PEFFER.F (2) & 1.81 & 0.31 & 522.5 & $5 / 6$ \\
\hline K.AHVDLEGLTLDKEVR.Q (2) & 1.15 & 0.01 & 92.3 & $11 / 28$ \\
\hline \multicolumn{5}{|l|}{ Total number of peptides: 17} \\
\hline Sequence coverage: $41.67 \%$ & & & & \\
\hline
\end{tabular}

\begin{tabular}{|c|c|c|c|c|}
\hline Protein name & $\begin{array}{c}\text { NCBI } \\
\text { Accession } \\
\text { number }\end{array}$ & $\begin{array}{c}\text { MW } \\
(\mathbf{k D a})\end{array}$ & IP & p-value \\
\hline Aro8p & $\underline{6321236}$ & 56.2 & 5.9 & $1.05 \mathrm{E}-8$ \\
\hline Peptide (charge state) & & & & Ions \\
\hline K.YNSDPYQLEQSLYHK.V (2) & $\mathbf{X c o r r}$ & $\mathbf{\Delta C n}$ & $\mathbf{S p}$ & $17 / 28$ \\
\hline K.SLANTFLSLDTEGR.V (2) & 4.38 & 0.52 & 723.2 & $21 / 26$ \\
\hline K.DFSYLFSDETNAR.K (2) & 4.32 & 0.65 & 1294.5 & $7 / 8$ \\
\hline R.LGDTLYEEFGISK.- (2) & 4.26 & 0.48 & 1504.2 & $19 / 24$ \\
\hline R.LGDTLYEEFGISK.- (2) & 4.20 & 0.62 & 842.9 & $5 / 6$ \\
\hline K.YNSDPYQLEQSLYHK.V (2) & 4.17 & 0.59 & 975.2 & $3 / 4$ \\
\hline K.SEGETEPPQPAESK.E (2) & 3.77 & 0.59 & 1076.6 & $19 / 26$ \\
\hline K.SEGETEPPQPAESK.E (2) & 3.72 & 0.45 & 600.4 & $8 / 9$ \\
\hline R.GTYAAVSPEK.L (2) & 3.49 & 0.45 & 538.3 & $19 / 26$ \\
\hline K.SEGETEPPQPAESK.E (2) & 3.45 & 0.42 & 1291.0 & $9 / 13$ \\
\hline R.GTYAAVSPEK.L (2) & 3.30 & 0.41 & 515.4 & $8 / 9$ \\
\hline K.SLANTFLSLDTEGR.V (2) & 3.28 & 0.47 & 1381.2 & $17 / 26$ \\
\hline K.SEGETEPPQPAESK.E (2) & 3.25 & 0.59 & 807.5 & $9 / 13$ \\
\hline K.EVSNPNIIFFR.G (2) & 3.23 & 0.46 & 500.1 & $4 / 5$ \\
\hline R.GTYAAVSPEK.L (2) & 3.18 & 0.57 & 956.6 & $8 / 9$ \\
\hline K.SANPSNDIPLSR.A (2) & 3.06 & 0.44 & 1407.3 & $7 / 11$ \\
\hline K.VMENWTPGAPKPK.L (2) & 3.04 & 0.57 & 553.7 & $17 / 24$ \\
\hline K.SANPSNDIPLSR.A (2) & 3.02 & 0.52 & 730.2 & $8 / 11$ \\
\hline K.SANPSNDIPLSR.A (2) & 3.00 & 0.48 & 678.0 & $15 / 22$ \\
\hline
\end{tabular}


Supplementary Table 3. Continued.

\begin{tabular}{|c|c|c|c|c|}
\hline R.GTYAAVSPEK.L (2) & 2.95 & 0.43 & 1393.1 & $8 / 9$ \\
\hline K.SANPSNDIPLSR.A (2) & 2.94 & 0.49 & 548.2 & $7 / 11$ \\
\hline R.GTYAAVSPEK.L (2) & 2.93 & 0.48 & 1372.4 & $8 / 9$ \\
\hline K.SANPSNDIPLSR.A (2) & 2.88 & 0.58 & 681.9 & $15 / 22$ \\
\hline R.GTYAAVSPEK.L (2) & 2.87 & 0.41 & 1004.9 & $7 / 9$ \\
\hline K.SANPSNDIPLSR.A (2) & 2.80 & 0.53 & 527.3 & $7 / 11$ \\
\hline K.SANPSNDIPLSR.A (2) & 2.72 & 0.43 & 546.8 & $7 / 11$ \\
\hline R.GTYAAVSPEK.L (2) & 2.72 & 0.40 & 1325.8 & $8 / 9$ \\
\hline K.SANPSNDIPLSR.A (2) & 2.71 & 0.52 & 584.4 & $15 / 22$ \\
\hline R.GTYAAVSPEK.L (2) & 2.68 & 0.38 & 1213.2 & $8 / 9$ \\
\hline R.GTYAAVSPEK.L (2) & 2.61 & 0.45 & 1035.6 & $7 / 9$ \\
\hline K.SEGETEPPQPAESK.E (2) & 2.59 & 0.36 & 635.1 & $10 / 13$ \\
\hline R.GTYAAVSPEK.L (2) & 2.58 & 0.43 & 1313.4 & $8 / 9$ \\
\hline K.SANPSNDIPLSR.A (2) & 2.53 & 0.59 & 614.5 & $15 / 22$ \\
\hline R.GVLVVPGSWFK.S (2) & 2.47 & 0.45 & 518.0 & $7 / 10$ \\
\hline R.DCAIDALYK.Y (2) & 2.45 & 0.28 & 693.6 & $13 / 16$ \\
\hline K.DWDVLATAGNTNAWESTLR.V (2) & 2.37 & 0.54 & 674.9 & $17 / 36$ \\
\hline K.SANPSNDIPLSR.A (2) & 2.25 & 0.27 & 527.8 & $13 / 22$ \\
\hline R.DCAIDALYK.Y (2) & 2.19 & 0.06 & 540.6 & $11 / 16$ \\
\hline R.DCAIDALYK.Y (2) & 2.11 & 0.07 & 459.0 & $11 / 16$ \\
\hline R.LGWITGSSK.I (2) & 2.01 & 0.46 & 792.0 & $7 / 8$ \\
\hline R.DCAIDALYK.Y (2) & 1.99 & 0.09 & 609.4 & $3 / 4$ \\
\hline R.DCAIDALYK.Y (2) & 1.97 & 0.10 & 634.6 & $3 / 4$ \\
\hline R.DCAIDALYK.Y (2) & 1.94 & 0.27 & 618.9 & $3 / 4$ \\
\hline R.LGWITGSSK.I (2) & 1.88 & 0.44 & 801.3 & $7 / 8$ \\
\hline R.GTYAAVSPEK.L (2) & 1.55 & 0.39 & 881.3 & $13 / 18$ \\
\hline R.DCAIDALYK.Y (2) & 1.54 & 0.04 & 448.2 & $11 / 16$ \\
\hline K.QDHDEFLK.S (2) & 1.52 & 0.01 & 189.1 & $5 / 7$ \\
\hline K.YNSDPYQLEQSLYHK.V (2) & 1.46 & 0.08 & 294.4 & $9 / 28$ \\
\hline R.GTYAAVSPEK.L (1) & 1.45 & 0.16 & 602.8 & $2 / 3$ \\
\hline R.LGWITGSSK.I (1) & 1.34 & 0.03 & 356.5 & $5 / 8$ \\
\hline R.DCAIDALYK.Y (1) & 1.26 & 0.27 & 610.9 & $11 / 16$ \\
\hline R.DCAIDALYK.Y (1) & 1.17 & 0.03 & 177.2 & $9 / 16$ \\
\hline R.DCAIDALYK.Y (1) & 1.16 & 0.02 & 472.0 & $5 / 8$ \\
\hline R.LGWITGSSK.I (1) & 1.14 & 0.00 & 214.1 & $1 / 2$ \\
\hline \multicolumn{5}{|l|}{ Total number of peptides: 15} \\
\hline Sequence coverage: $34,20 \%$ & & & & \\
\hline
\end{tabular}

\begin{tabular}{|c|c|c|c|c|}
\hline Protein name & $\begin{array}{c}\text { NCBI } \\
\text { Accession } \\
\text { number }\end{array}$ & $\begin{array}{c}\text { MW } \\
(\mathbf{k D a})\end{array}$ & IP & p-value \\
\hline Bna1p & $\underline{6322485}$ & 20.2 & 5.7 & $1.02 \mathrm{E}-11$ \\
\hline Peptide (charge state) & & & & \\
\hline R.QVVHESELQMLDLGTQVK.E (3) & $\mathbf{X c o r r}$ & $\mathbf{\Delta C n}$ & $\mathbf{S p}$ & Ions \\
\hline R.FADTVGIVVEQDRPGGENDK.I (2) & 4.49 & 0.31 & 1308.8 & $13 / 34$ \\
\hline R.QVVHESELQMLDLGTQVK.E (3) & 4.14 & 0.61 & 947.3 & $10 / 19$ \\
\hline R.QVVHESELQMLDLGTQVK.E (2) & 4.12 & 0.33 & 1143.0 & $25 / 68$ \\
\hline R.FADTVGIVVEQDRPGGENDK.I (2) & 4.01 & 0.54 & 994.2 & $19 / 34$ \\
\hline R.FADTVGIVVEQDRPGGENDK.I (2) & 3.79 & 0.60 & 572.3 & $8 / 19$ \\
\hline R.QVVHESELQMLDLGTQVK.E (3) & 3.78 & 0.58 & 638.4 & $17 / 38$ \\
\hline -.M*FNTTPINIDK.W (2) & 3.72 & 0.38 & 1401.8 & $27 / 68$ \\
\hline K.GGFTVMIVGGPNER.T (2) & 3.65 & 0.46 & 800.2 & $4 / 5$ \\
\hline R.FADTVGIVVEQDRPGGENDK.I (2) & 3.61 & 0.55 & 1217.1 & $19 / 26$ \\
\hline R.QVVHESELQMLDLGTQVK.E (3) & 3.59 & 0.53 & 673.1 & $17 / 38$ \\
\hline R.QVVHESELQMLDLGTQVK.E (3) & 3.57 & 0.32 & 907.1 & $6 / 17$ \\
\hline K.EAILDFENDVEK.R (2) & 3.50 & 0.29 & 853.6 & $23 / 68$ \\
\hline -.MFNTTPINIDK.W (2) & 3.49 & 0.49 & 1153.1 & $10 / 11$ \\
\hline
\end{tabular}


Supplementary Table 3. Continued.

\begin{tabular}{|c|c|c|c|c|}
\hline K.EAILDFENDVEKR.T (2) & 3.47 & 0.42 & 1496.5 & $5 / 6$ \\
\hline K.EAILDFENDVEKR.T (2) & 3.44 & 0.43 & 1113.5 & $17 / 24$ \\
\hline R.FADTVGIVVEQDRPGGENDK.I (3) & 3.40 & 0.55 & 601.3 & $29 / 76$ \\
\hline K.GGFTVMIVGGPNER.T (2) & 3.40 & 0.45 & 968.6 & $17 / 26$ \\
\hline K.ENEGLLKPPVNNYCLHK.G (3) & 3.39 & 0.42 & 758.0 & $3 / 8$ \\
\hline K.TLNYARPQSN.- (2) & 3.38 & 0.56 & 1099.9 & $5 / 6$ \\
\hline R.FADTVGIVVEQDRPGGENDK.I (3) & 3.35 & 0.53 & 639.3 & $7 / 19$ \\
\hline K.GGFTVMIVGGPNER.T (2) & 3.26 & 0.52 & 1263.0 & $19 / 26$ \\
\hline R.QVVHESELQMLDLGTQVK.E (2) & 3.18 & 0.54 & 751.4 & $15 / 34$ \\
\hline K.ENEGLLKPPVNNYCLHK.G (3) & 3.15 & 0.48 & 607.9 & $21 / 64$ \\
\hline K.ENEGLLKPPVNNYCLHK.G (3) & 3.14 & 0.38 & 520.2 & $21 / 64$ \\
\hline -.MFNTTPINIDK.W (2) & 3.13 & 0.53 & 560.6 & $7 / 10$ \\
\hline K.EAILDFENDVEKR.T (2) & 3.09 & 0.46 & 928.5 & $17 / 24$ \\
\hline K.EAILDFENDVEKR.T (2) & 3.07 & 0.40 & 780.6 & $5 / 8$ \\
\hline K.ENEGLLKPPVNNYCLHK.G (3) & 3.05 & 0.47 & 671.7 & $11 / 32$ \\
\hline K.TLNYARPQSN.- (2) & 2.78 & 0.48 & 1125.7 & $7 / 9$ \\
\hline K.GGFTVMIVGGPNER.T (2) & 2.78 & 0.37 & 927.4 & $17 / 26$ \\
\hline K.TLNYARPQSN.- (2) & 2.74 & 0.45 & 1237.5 & $5 / 6$ \\
\hline K.EAILDFENDVEK.R (2) & 2.62 & 0.41 & 900.6 & $8 / 11$ \\
\hline K.GGFTVM*IVGGPNER.T (2) & 2.39 & 0.46 & 551.7 & $1 / 3$ \\
\hline K.GGFTVM*IVGGPNER.T (2) & 2.35 & 0.03 & 381.5 & $1 / 2$ \\
\hline K.ENEGLLKPPVNNYCLHK.G (3) & 2.34 & 0.35 & 590.8 & $8 / 13$ \\
\hline K.GGFTVMIVGGPNER.T (2) & 2.08 & 0.07 & 480.8 & $11 / 32$ \\
\hline Total number of peptides: 11 & 1.69 & 0.33 & 582.4 & $6 / 13$ \\
\hline Sequence coverage: 59.32\% & & & & \\
\hline
\end{tabular}

\begin{tabular}{|c|c|c|c|c|}
\hline Protein name & $\begin{array}{c}\text { NCBI } \\
\text { Accession } \\
\text { number }\end{array}$ & $\begin{array}{c}\text { MW } \\
(\mathbf{k D a})\end{array}$ & IP & p-value \\
\hline Yhr029cp & $\underline{6321818}$ & 32.6 & 5.5 & $6.34 \mathrm{E}-13$ \\
\hline Peptide (charge state) & & & & \\
\hline K.NTTATSLVQECK.I (2) & Xcorr & $\mathbf{\Delta C n}$ & Sp & Ions \\
\hline K.EADNSTSYYIAGHATTVIDGK.I (3) & 3.29 & 0.52 & 1294.4 & $8 / 11$ \\
\hline K.IGAVPITINEGLISFK.A (2) & 3.20 & 0.48 & 1018.6 & $7 / 20$ \\
\hline K.TTDITISEGGR.L (2) & 2.92 & 0.43 & 525.4 & $19 / 30$ \\
\hline Total number of peptides: 4 & 2.41 & 0.42 & 819.3 & $3 / 4$ \\
\hline Sequence coverage: 20.41\% & & & & \\
\hline
\end{tabular}

\begin{tabular}{|c|c|c|c|c|}
\hline Protein name & $\begin{array}{c}\text { NCBI } \\
\text { Accession } \\
\text { number }\end{array}$ & $\begin{array}{c}\text { MW } \\
(\mathbf{k D a})\end{array}$ & IP & p-value \\
\hline His7p & $\underline{6319725}$ & 61.1 & 5.2 & $2.47 \mathrm{E}-10$ \\
\hline Peptide (charge state) & & & & \\
\hline K.IPVIASSGAGVPEHFEEAFLK.T (3) & Xcorr & $\mathbf{\Delta C n}$ & $\mathbf{S p}$ & Ions \\
\hline K.IPVIASSGAGVPEHFEEAFLK.T (3) & 5.10 & 0.65 & 971.9 & $17 / 40$ \\
\hline K.AYGAQAVVISVDPK.R (2) & 4.55 & 0.63 & 800.6 & $3 / 8$ \\
\hline K.YGSEEFIAAVNK.N (2) & 4.27 & 0.58 & 2421.5 & $11 / 13$ \\
\hline K.AYGAQAVVISVDPK.R (2) & 4.17 & 0.55 & 1792.3 & $19 / 22$ \\
\hline K.YGSEEFIAAVNK.N (2) & 4.00 & 0.51 & 1989.9 & $21 / 26$ \\
\hline K.VFETEYPGPNGEK.Y (2) & 3.99 & 0.62 & 1593.1 & $19 / 22$ \\
\hline R.TNDQGDLVVTK.G (2) & 3.82 & 0.42 & 848.8 & $19 / 24$ \\
\hline K.IPVIASSGAGVPEHFEEAFLK.T (3) & 3.79 & 0.54 & 1245.4 & $17 / 20$ \\
\hline K.YGSEEFIAAVNK.N (2) & 3.70 & 0.57 & 670.4 & $7 / 20$ \\
\hline & 3.62 & 0.45 & 1386.7 & $17 / 22$ \\
\hline
\end{tabular}


Supplementary Table 3. Continued.

\begin{tabular}{|c|c|c|c|c|}
\hline K.VFETEYPGPNGEK.Y (2) & 3.28 & 0.45 & 774.8 & $2 / 3$ \\
\hline K.IPALEVASLYFR.S (2) & 3.21 & 0.52 & 1161.4 & $17 / 22$ \\
\hline K.VSIGTDAVYAAEK.Y (2) & 2.82 & 0.56 & 681.7 & $2 / 3$ \\
\hline R.GDGTSPIETISK.A (2) & 2.61 & 0.48 & 616.8 & $17 / 22$ \\
\hline K.VSIGTDAVYAAEK.Y (2) & 2.52 & 0.44 & 596.9 & $13 / 24$ \\
\hline K.AGLNVIENFLK.Q (2) & 2.48 & 0.36 & 510.2 & $13 / 20$ \\
\hline K.DFNISGTSR.L (2) & 2.46 & 0.23 & 974.3 & $15 / 16$ \\
\hline K.VSIGTDAVYAAEK.Y (2) & 2.27 & 0.46 & 624.5 & $5 / 8$ \\
\hline K.YGSEEFIAAVNK.N (2) & 2.24 & 0.33 & 671.2 & $8 / 11$ \\
\hline K.VFETEYPGPNGEK.Y (2) & 1.91 & 0.48 & 501.6 & $7 / 12$ \\
\hline K.AYGAQAVVISVDPK.R (2) & 1.73 & 0.06 & 632.5 & $7 / 13$ \\
\hline K.VSIGTDAVYAAEK.Y (2) & 1.45 & 0.29 & 510.8 & $1 / 2$ \\
\hline K.DFNISGTSR.L (2) & 1.34 & 0.04 & 686.5 & $13 / 16$ \\
\hline Total number of peptides: 10 & & & & \\
\hline Sequence coverage: 23.19\% & & & & \\
\hline
\end{tabular}

\begin{tabular}{|c|c|c|c|c|}
\hline Protein name & $\begin{array}{c}\text { NCBI } \\
\text { Accession } \\
\text { number }\end{array}$ & $\begin{array}{c}\text { MW } \\
\mathbf{( k D a})\end{array}$ & IP & p-value \\
\hline Ecm40p & 6323707 & 47.8 & 7.1 & $1.68 \mathrm{E}-10$ \\
\hline Peptide (charge state) & & & & \\
\hline K.INVSFIATDNSEPR.E (2) & $\mathbf{X c o r r}$ & $\mathbf{\Delta C n}$ & $\mathbf{S p}$ & Ions \\
\hline K.IIAESISNSMLVK.T (2) & 4.98 & 0.63 & 1465.8 & $21 / 26$ \\
\hline K.EINEDSKDFEQVK.L (2) & 4.53 & 0.62 & 1509.0 & $7 / 8$ \\
\hline K.EINEDSKDFEQVK.L (2) & 4.23 & 0.45 & 1303.0 & $17 / 24$ \\
\hline K.IIAESISNSM*LVK.T (2) & 3.70 & 0.39 & 1045.8 & $2 / 3$ \\
\hline K.LVANGVPQLEIDETR.A (2) & 3.63 & 0.53 & 883.9 & $3 / 4$ \\
\hline K.LQVTEFAQR.L (2) & 3.30 & 0.59 & 602.5 & $3 / 4$ \\
\hline K.TALYGQDANWGR.I (2) & 3.18 & 0.47 & 761.7 & $13 / 16$ \\
\hline R.ILCAIGYAK.L (2) & 3.08 & 0.44 & 1058.6 & $9 / 11$ \\
\hline R.LAQLVVR.D (2) & 2.75 & 0.27 & 828.2 & $15 / 16$ \\
\hline R.LAQLVVR.D (2) & 2.37 & 0.39 & 876.1 & $11 / 12$ \\
\hline K.EINEDSKDFEQVK.L (3) & 2.32 & 0.44 & 885.2 & $11 / 12$ \\
\hline K.MLTFATTR.S (2) & 2.14 & 0.38 & 734.8 & $19 / 48$ \\
\hline R.ILCAIGYAK.L (1) & 2.13 & 0.51 & 525.1 & $11 / 14$ \\
\hline R.ILCAIGYAK.L (1) & 1.45 & 0.12 & 760.8 & $11 / 16$ \\
\hline R.LAQLVVR.D (1) & 1.21 & 0.10 & 560.9 & $5 / 8$ \\
\hline Total number of peptides: 10 & 1.20 & 0.04 & 143.0 & $1 / 2$ \\
\hline Sequence coverage: 22.68\% & & & & \\
\hline
\end{tabular}

\begin{tabular}{|c|c|c|c|c|}
\hline Protein name & $\begin{array}{c}\text { NCBI } \\
\text { Accession } \\
\text { number }\end{array}$ & $\begin{array}{c}\text { MW } \\
(\mathbf{k D a})\end{array}$ & IP & p-value \\
\hline Thr1p & $\underline{6321814}$ & 38.7 & 5.2 & $6.42 \mathrm{E}-11$ \\
\hline Peptide (charge state) & & & & \\
\hline R.GLGSSGAAVVAGVILGNEVAQLGFSK.Q (2) & $\mathbf{X c o r r}$ & $\mathbf{\Delta C n}$ & $\mathbf{S p}$ & $\mathbf{I o n s}$ \\
\hline K.LLEPAYDGASVEQQ.- (2) & 4.54 & 0.69 & 1757.7 & $14 / 25$ \\
\hline R.GLGSSGAAVVAGVILGNEVAQLGFSK.Q (3) & 4.45 & 0.42 & 1658.9 & $10 / 13$ \\
\hline K.AYPTQDLVFNLQR.L (2) & 4.23 & 0.61 & 822.8 & $33 / 100$ \\
\hline K.CIAIIPQFELSTADSR.G (2) & 3.75 & 0.51 & 574.2 & $7 / 10$ \\
\hline R.MLDYCLMIER.H (2) & 3.25 & 0.47 & 1263.4 & $8 / 9$ \\
\hline K.ESEGYSTVPLR.S (2) & 2.15 & 0.55 & 691.4 & $3 / 4$ \\
\hline R.TALYVLR.C (2) & 1.94 & 0.34 & 1045.2 & $11 / 12$ \\
\hline R.DLTPQEVER.R (2) & 1.64 & 0.15 & 517.6 & $3 / 4$ \\
\hline
\end{tabular}


Supplementary Table 3. Continued.

\begin{tabular}{|c|c|c|c|c|}
\hline Protein name & $\begin{array}{c}\text { NCBI } \\
\text { Accession } \\
\text { number }\end{array}$ & $\begin{array}{c}\text { MW } \\
(\mathbf{k D a})\end{array}$ & IP & p-value \\
\hline Ubc13p & $\underline{6320297}$ & 17.5 & 5.2 & $1.26 \mathrm{E}-12$ \\
\hline Peptide (charge state) & & & & \\
\hline K.LVSDPVPGITAEPHDDNLR.Y (2) & $\mathbf{X c o r r}$ & $\mathbf{\Delta C n}$ & $\mathbf{S p}$ & Ions \\
\hline K.LVSDPVPGITAEPHDDNLR.Y (3) & 4.36 & 0.68 & 833.3 & $23 / 36$ \\
\hline K.LVSDPVPGITAEPHDDNLR.Y (3) & 4.15 & 0.72 & 695.0 & $31 / 72$ \\
\hline K.LVSDPVPGITAEPHDDNLR.Y (2) & 3.79 & 0.69 & 709.4 & $5 / 12$ \\
\hline K.LVSDPVPGITAEPHDDNLR.Y (3) & 3.78 & 0.62 & 786.8 & $11 / 18$ \\
\hline K.LVSDPVPGITAEPHDDNLR.Y (3) & 3.59 & 0.61 & 755.3 & $31 / 72$ \\
\hline K.TNWSPALQIR.T (2) & 3.52 & 0.50 & 892.3 & $11 / 24$ \\
\hline K.LVSDPVPGITAEPHDDNLR.Y (2) & 3.05 & 0.33 & 599.0 & $7 / 9$ \\
\hline K.TNWSPALQIR.T (2) & 2.86 & 0.61 & 739.9 & $7 / 12$ \\
\hline K.TNWSPALQIR.T (2) & 2.74 & 0.31 & 722.8 & $5 / 6$ \\
\hline R.ICLDVLK.T (2) & 2.52 & 0.40 & 755.7 & $5 / 6$ \\
\hline K.LVSDPVGITAEPHDDNLR.Y (2) & 2.30 & 0.04 & 558.1 & $11 / 12$ \\
\hline R.ICLDVLK.T (2) & 2.23 & 0.57 & 638.0 & $19 / 36$ \\
\hline R.ICLDVLK.T (2) & 2.22 & 0.05 & 566.8 & $11 / 12$ \\
\hline R.ICLDVLK.T (2) & 2.13 & 0.21 & 617.8 & $11 / 12$ \\
\hline Total number of peptides: 3 & 1.98 & 0.08 & 617.6 & $11 / 12$ \\
\hline
\end{tabular}

\begin{tabular}{|c|c|c|c|c|}
\hline Protein name & $\begin{array}{c}\text { NCBI } \\
\text { Accession } \\
\text { number }\end{array}$ & $\begin{array}{c}\text { MW } \\
\mathbf{( k D a})\end{array}$ & IP & p-value \\
\hline Sod2p & $\underline{6321796}$ & 25.8 & 9.0 & $2.43 \mathrm{E}-8$ \\
\hline Peptide (charge state) & & & & \\
\hline K.HHQTYVNGFNTAVDQFQELSDLLAK.E (3) & $\mathbf{X c o r r}$ & $\mathbf{\Delta C n}$ & $\mathbf{S p}$ & Ions \\
\hline K.LAGVQGSGWAFIVK.N (2) & 4.52 & 0.67 & 1209.1 & $29 / 96$ \\
\hline K.AIDEQFGSLDELIK.L (2) & 3.94 & 0.43 & 1280.7 & $21 / 26$ \\
\hline R.KMIAIQQNIK.F (2) & 2.98 & 0.30 & 1557.6 & $8 / 9$ \\
\hline K.MIAIQQNIK.F (2) & 2.65 & 0.39 & 713.3 & $7 / 8$ \\
\hline K.AIWNVVNWK.E (2) & 2.63 & 0.49 & 707.7 & $3 / 4$ \\
\hline K.AIWNVVNWK.E (2) & 2.61 & 0.40 & 906.2 & $13 / 16$ \\
\hline K.M*IAIQQNIK.F (2) & 2.43 & 0.25 & 848.1 & $13 / 16$ \\
\hline K.AIWNVVNWK.E (1) & 1.85 & 0.13 & 561.4 & $11 / 16$ \\
\hline Total number of peptides: 7 & & & & \\
\hline
\end{tabular}

\begin{tabular}{|c|c|c|c|c|}
\hline Protein name & $\begin{array}{c}\text { NCBI } \\
\text { Accession } \\
\text { number }\end{array}$ & $\begin{array}{c}\text { MW } \\
(\mathbf{k D a})\end{array}$ & IP & p-value \\
\hline Bmh2p & $\underline{6320304}$ & 31.1 & 4.7 & $1.78 \mathrm{E}-10$ \\
\hline Peptide (charge state) & & & & \\
\hline K.LAEQAERYEEMVENMK.A (3) & $\mathbf{X c o r r}$ & $\mathbf{\Delta C n}$ & $\mathbf{S p}$ & Ions \\
\hline K.LAEQAERYEEMVENMK.A (3) & 5.56 & 0.57 & 1488.4 & $1 / 2$ \\
\hline K.TASEIATTELPPTHPIR.L (3) & 5.02 & 0.57 & 1585.2 & $29 / 60$ \\
\hline K.LAEQAERYEEMVENMK.A (2) & 4.53 & 0.54 & 1280.8 & $33 / 64$ \\
\hline K.TASEIATTELPPTHPIR.L (3) & 3.90 & 0.29 & 1149.3 & $19 / 30$ \\
\hline K.AVASSGQELSVEER.N (2) & 3.81 & 0.48 & 1184.2 & $29 / 64$ \\
\hline K.AVASSGQELSVEER.N (2) & 3.73 & 0.61 & 1306.8 & $19 / 26$ \\
\hline
\end{tabular}


Supplementary Table 3. Continued.

\begin{tabular}{|c|c|c|c|c|}
\hline R.IVSSIEQKEESK.E (2) & 3.64 & 0.45 & 938.2 & $17 / 22$ \\
\hline K.AVASSGQELSVEER.N (2) & 3.58 & 0.55 & 1471.2 & $10 / 13$ \\
\hline R.EKATNSSLEAYK.T (2) & 3.55 & 0.55 & 982.9 & $17 / 22$ \\
\hline R.YLAEFSSGDAR.E (2) & 3.46 & 0.51 & 1125.6 & $17 / 20$ \\
\hline K.TASEIATTELPPTHPIR.L (3) & 3.44 & 0.54 & 1310.6 & $15 / 32$ \\
\hline R.EKATNSSLEAYK.T (2) & 3.30 & 0.53 & 1039.5 & $8 / 11$ \\
\hline K.ATNSSLEAYK.T (2) & 3.22 & 0.50 & 796.9 & $7 / 9$ \\
\hline K.SEHQVELIR.S (2) & 3.19 & 0.38 & 898.4 & $15 / 16$ \\
\hline K.AVASSGQELSVEER.N (2) & 3.16 & 0.55 & 1325.3 & $9 / 13$ \\
\hline K.ATNSSLEAYK.T (2) & 3.15 & 0.43 & 687.8 & $7 / 9$ \\
\hline R.EKATNSSLEAYK.T (2) & 3.07 & 0.60 & 780.2 & $15 / 22$ \\
\hline R.IVSSIEQKEESK.E (2) & 3.07 & 0.47 & 723.7 & $8 / 11$ \\
\hline R.YEEMVENMK.A (2) & 3.07 & 0.46 & 701.3 & $13 / 16$ \\
\hline R.YEEMVENMK.A (2) & 2.83 & 0.42 & 857.6 & $7 / 8$ \\
\hline K.DSTLIMQLLR.D (2) & 2.78 & 0.31 & 1044.3 & $7 / 9$ \\
\hline K.ATNSSLEAYK.T (2) & 2.74 & 0.61 & 863.8 & $5 / 6$ \\
\hline K.SEHQVELIR.S (2) & 2.71 & 0.38 & 1009.1 & $7 / 8$ \\
\hline K.DSTLIMQLLR.D (2) & 1.85 & 0.14 & 1000.0 & $7 / 9$ \\
\hline R.EDSVYLAK.L (2) & 1.55 & 0.06 & 447.0 & $6 / 7$ \\
\hline R.NLLSVAYK.N1) & 1.07 & 0.06 & 185.4 & $4 / 7$ \\
\hline Total number of peptides: 12 & & & & \\
\hline Sequence coverage: 42.86\% & & & & \\
\hline
\end{tabular}

\begin{tabular}{|c|c|c|c|c|}
\hline Protein name & $\begin{array}{c}\text { NCBI } \\
\text { Accession } \\
\text { number }\end{array}$ & $\begin{array}{c}\text { MW } \\
(\mathbf{k D a})\end{array}$ & IP & p-value \\
\hline Pdc1p & $\underline{6323073}$ & 61.5 & 6.1 & $6.76 \mathrm{E}-12$ \\
\hline Peptide (charge state) & & & & \\
\hline X.Morr & $\mathbf{\Delta C n}$ & $\mathbf{S p}$ & Ions \\
\hline K.LIDLTQFPAFVTPMGK.G (2) & 5.00 & 0.69 & 1173.6 & $11 / 23$ \\
\hline K.NPVILADACCSR.H (2) & 4.04 & 0.62 & 846.1 & $2 / 3$ \\
\hline R.YGGVYVGTLSKPEVK.E (2) & 3.98 & 0.49 & 1717.3 & $19 / 22$ \\
\hline R.YGGVYVGTLSKPEVK.E (3) & 3.75 & 0.39 & 625.3 & $17 / 28$ \\
\hline K.NIVEFHSDHMK.I (2) & 3.52 & 0.41 & 903.9 & $13 / 28$ \\
\hline K.IYEVEGMR.W (2) & 2.57 & 0.46 & 915.1 & $7 / 10$ \\
\hline Total number of peptides: 6 & 2.53 & 0.03 & 607.6 & $6 / 7$ \\
\hline Sequence coverage: 15.28\% & & & & \\
\hline
\end{tabular}

\begin{tabular}{|c|c|c|c|c|}
\hline Protein name & $\begin{array}{c}\text { NCBI } \\
\text { Accession } \\
\text { number }\end{array}$ & $\begin{array}{c}\text { MW } \\
(\mathbf{k D a})\end{array}$ & IP & p-value \\
\hline His1p & $\underline{6320896}$ & 32.3 & 6.0 & $1.64 \mathrm{E}-9$ \\
\hline Peptide (charge state) & & & & \\
\hline K.YFADLEGTTVEK.M (2) & $\mathbf{X c o r r}$ & $\mathbf{\Delta C n}$ & $\mathbf{S p}$ & Ions \\
\hline R.FVSCIYNAPEDK.L (2) & 4.52 & 0.62 & 1408.8 & $10 / 11$ \\
\hline K.LQVQVPVNGEYK.K (2) & 4.40 & 0.41 & 1279.0 & $19 / 22$ \\
\hline K.SVSILNGADITFHR.S (2) & 4.17 & 0.43 & 739.4 & $17 / 22$ \\
\hline K.SRIEGVMTAQR.F (2) & 4.05 & 0.52 & 940.1 & $10 / 13$ \\
\hline K.CDLGITGVDQVR.E (2) & 3.69 & 0.33 & 1316.3 & $17 / 20$ \\
\hline K.GVVLDELKR.L (2) & 3.41 & 0.39 & 1111.5 & $19 / 22$ \\
\hline K.TKGVVLDELKR.L (3) & 3.22 & 0.30 & 803.9 & $7 / 8$ \\
\hline R.IEGVMTAQR.E (2) & 2.87 & 0.37 & 1060.9 & $13 / 20$ \\
\hline K.TKGVVLDELKR.L (3) & 2.78 & 0.40 & 1048.2 & $15 / 16$ \\
\hline K.TKGVVLDELKR.L (2) & 2.58 & 0.34 & 893.2 & $5 / 8$ \\
\hline
\end{tabular}


Supplementary Table 3. Continued.

\begin{tabular}{|c|c|c|c|c|}
\hline K.SRIEGVMTAQR.F (3) & 2.18 & 0.29 & 587.9 & $2 / 5$ \\
\hline K.TIVTSFVK.L (1) & 1.63 & 0.39 & 527.6 & $5 / 7$ \\
\hline Total number of peptides: 10 & & & & \\
\hline Sequence coverage: 30.98\% & & & & \\
\hline
\end{tabular}

\begin{tabular}{|c|c|c|c|c|}
\hline Protein name & $\begin{array}{c}\text { NCBI } \\
\text { Accession } \\
\text { number }\end{array}$ & $\begin{array}{c}\text { MW } \\
(\mathbf{k D a})\end{array}$ & IP & p-value \\
\hline Ade1p & $\underline{6319326}$ & 34.6 & 5.8 & $5.70 \mathrm{E}-12$ \\
\hline Peptide (charge state) & & & & \\
\hline K.TELDGILPLVAR.G (2) & $\mathbf{X c o r r}$ & $\mathbf{\Delta C n}$ & $\mathbf{S p}$ & Ions \\
\hline K.TNEIILVDEVLTPDSSR.F (2) & 4.04 & 0.53 & 1082.9 & $31 / 96$ \\
\hline K.TELDGILPLVAR.G (2) & 3.84 & 0.39 & 1753.4 & $10 / 11$ \\
\hline K.YIEAYETLTGSK.W (2) & 3.70 & 0.56 & 838.9 & $5 / 8$ \\
\hline K.TNEIILVDEVLTPDSSR.F (2) & 3.29 & 0.44 & 1494.7 & $19 / 22$ \\
\hline R.ISAYDVIMENSIPEK.G (2) & 3.23 & 0.59 & 1382.9 & $10 / 11$ \\
\hline K.TIFDYLPAK.L (2) & 3.20 & 0.59 & 802.3 & $17 / 32$ \\
\hline K.MPQDIVDR.T (2) & 2.82 & 0.32 & 1031.4 & $9 / 14$ \\
\hline K.TIFDYLPAK.L (1) & 2.50 & 0.51 & 728.8 & $7 / 8$ \\
\hline R.DWLTANK.L (1) & 2.37 & 0.27 & 881.6 & $13 / 14$ \\
\hline K.TIFDYLPAK.L (1) & 1.79 & 0.16 & 543.1 & $11 / 16$ \\
\hline K.FEFGIDEK.T (1) & 1.70 & 0.30 & 542.3 & $5 / 6$ \\
\hline R.ISAYDVIMENSIPEK.G (2) & 1.68 & 0.28 & 619.5 & $11 / 16$ \\
\hline R.GYITGSAWK.E (1) & 1.56 & 0.19 & 680.5 & $6 / 7$ \\
\hline Total number of peptides: 10 & 1.53 & 0.06 & 376.6 & $11 / 28$ \\
\hline Sequence coverage: 39.87\% & 1.47 & 0.11 & 508.3 & $5 / 8$ \\
\hline
\end{tabular}

\begin{tabular}{|c|c|c|c|c|}
\hline Protein name & $\begin{array}{c}\text { NCBI } \\
\text { Accession } \\
\text { number }\end{array}$ & $\begin{array}{c}\text { MW } \\
(\mathbf{k D a})\end{array}$ & IP & p-value \\
\hline Gcv3p & $\underline{37362609}$ & 18.8 & 4.5 & $2.46 \mathrm{E}-8$ \\
\hline Peptide (charge state) & & & & \\
\hline K.LPFLYSSQGPQAVR.Y (2) & Xcorr & $\boldsymbol{\Delta C n}$ & $\mathbf{S p}$ & Ions \\
\hline K.LPFLYSSQGPQAVR.Y (2) & 4.38 & 0.57 & 2339.3 & $17 / 38$ \\
\hline Total number of peptides: 2 & 3.47 & 0.51 & 2016.9 & $13 / 19$ \\
\hline Sequence coverage: 19.77\% & 3.31 & 0.56 & 1578.0 & $29 / 76$ \\
\hline
\end{tabular}


Supplementary Table 4. Additional bioinformatical information. Minimal free energies (MFEs) with start points and lengths of each predicted secondary structure in the 5'UTRs listed. The mean MFE of randomly computed sequences of the same length and dinucleotide composition are given along with their respective standard deviation for each predicted 5'UTR secondary structure. The z-score results from the comparison of candidate and random secondary structure stabilities $(z=(m-\mu): \sigma)$.

\begin{tabular}{|c|c|c|c|c|c|c|}
\hline 5'UTR & $\begin{array}{c}\text { start of } \\
\text { structure }\end{array}$ & $\begin{array}{l}\text { length of } \\
\text { structure }\end{array}$ & $\begin{array}{c}\text { MFE (m) } \\
{[\mathrm{kcal} / \mathrm{mol}]}\end{array}$ & $\begin{array}{c}\text { mean MFE }(\mu) \\
{[\mathrm{kcal} / \mathrm{mol}]}\end{array}$ & $\begin{array}{l}\text { standard } \\
\text { deviation }\end{array}$ & z-score \\
\hline$A H P 1$ & - & - & - & - & - & - \\
\hline ALD6 & 1 & 42 & -0.63 & -1.23 & 1.42 & 0.6 \\
\hline ALD6 & 7 & 29 & -0.43 & -0.64 & 0.91 & 0.23 \\
\hline$A S C 1$ & 11 & 21 & -1.9 & -0.47 & 0.83 & -1.73 \\
\hline ENO1 & - & - & - & - & - & - \\
\hline$F B A 1$ & - & - & - & - & - & - \\
\hline FPRI & - & - & - & - & - & - \\
\hline$G R X 1$ & 4 & 59 & -6.3 & -5.48 & 2.41 & -0.34 \\
\hline GRX1 & 9 & 54 & -4.4 & -3.29 & 1.81 & -0.61 \\
\hline$G R X 1$ & 13 & 50 & -3.1 & -2.57 & 1.72 & -0.31 \\
\hline$G R X 1$ & 21 & 42 & -2.8 & -1.86 & 1.67 & -0.56 \\
\hline ILV5 & 2 & 77 & -7.9 & -4.81 & 1.87 & -1.65 \\
\hline ILV5 & 17 & 44 & -6.6 & -2.92 & 1.75 & -2.11 \\
\hline ILV5 & 23 & 64 & -6.09 & -4.58 & 1.8 & -0.84 \\
\hline ILV5 & 33 & 54 & -5.29 & -4.28 & 1.87 & -0.54 \\
\hline ILV5 & 36 & 51 & -3.79 & -3.72 & 1.73 & -0.04 \\
\hline ILV5 & 41 & 26 & -2.7 & -2.15 & 1.38 & -0.4 \\
\hline ILV5 & 53 & 34 & -2.29 & -0.44 & 0.84 & -2.2 \\
\hline$I P P 1$ & 1 & 39 & -6.4 & -5.71 & 1.89 & -0.37 \\
\hline$I P P 1$ & 10 & 45 & -4.1 & -7.38 & 2.26 & 1.45 \\
\hline$I P P 1$ & 21 & 24 & -2 & -3.09 & 1.96 & 0.56 \\
\hline$P G K 1$ & 1 & 63 & -9.7 & -6.89 & 1.88 & -1.49 \\
\hline$P G K 1$ & 7 & 54 & -8.2 & -5.28 & 1.98 & -1.48 \\
\hline$P G K 1$ & 11 & 42 & -7.3 & -3.66 & 1.76 & -2.07 \\
\hline$P G K 1$ & 43 & 24 & -4.5 & -1.34 & 1.37 & -2.31 \\
\hline RHR2 & 4 & 24 & -1.5 & -0.61 & 0.87 & -1.02 \\
\hline TPII & - & - & - & - & - & - \\
\hline TRP5 & 8 & 35 & -5.2 & -3.11 & 1.79 & -1.17 \\
\hline TRP5 & 13 & 24 & -3.3 & -1.96 & 1.79 & -0.75 \\
\hline
\end{tabular}




\section{Supplementary Material - Chapter III}

Supplementary Table 1. Protein sequence information corresponding to proteins from Figure 2.

\begin{tabular}{|c|c|c|c|c|c|}
\hline \multirow{2}{*}{ Peptide } & \multirow{2}{*}{$\mathbf{z}$} & \multirow{2}{*}{$\begin{array}{l}\mathbf{P} \text { (pro) } \\
\mathbf{P}(\text { pep })\end{array}$} & \multirow{2}{*}{$\begin{array}{c}\text { Score } \\
\mathrm{XC} \\
\end{array}$} & \multirow{2}{*}{$\Delta \mathbf{C n}$} & \multirow{2}{*}{$\frac{\text { MW }}{\text { Sp }}$} \\
\hline & & & & & \\
\hline gi|6323209| Sam1p/Sam2p & & 2.71E-16 & 152.32 & & 41792.2 \\
\hline K.IIVDAYGGASSVGGGAFSGK.D & 2 & $2.71 \mathrm{E}-16$ & 5.58 & 0.74 & 2326.6 \\
\hline R.KIIVDAYGGASSVGGGAFSGK.D & 2 & $1.08 \mathrm{E}-14$ & 6.06 & 0.75 & 2868.7 \\
\hline R.IDTVVISAQHADEISTADLR.T & 3 & $3.05 \mathrm{E}-12$ & 5.34 & 0.61 & 2497.3 \\
\hline K.TFLFTSESVGEGHPDK.I & 2 & 2.83E-09 & 4.28 & 0.65 & 1086.3 \\
\hline R.FVIGGPQGDAGLTGR.K & 2 & $1.70 \mathrm{E}-08$ & 4.65 & 0.57 & 1590.7 \\
\hline K.SDDEIIEIIKK.N & 2 & $2.40 \mathrm{E}-06$ & 3.71 & 0.42 & 1149.0 \\
\hline K.TQVTVEYEDDNGR.W & 2 & $9.79 \mathrm{E}-06$ & 4.28 & 0.61 & 1813.4 \\
\hline R.DGSLPWLRPDTK.T & 2 & $9.87 \mathrm{E}-06$ & 3.11 & 0.40 & 548.9 \\
\hline K.NFDLRPGVLVK.E & 2 & $6.09 \mathrm{E}-05$ & 3.59 & 0.48 & 1336.8 \\
\hline K.SDDEIIEIIK.K & 2 & $6.64 \mathrm{E}-05$ & 4.14 & 0.37 & 1340.6 \\
\hline K.TGMIMVFGEITTK.A & 2 & 7.32E-05 & 4.45 & 0.56 & 1572.1 \\
\hline K.TGMIM*VFGEITTK.A & 2 & $9.38 \mathrm{E}-05$ & 4.12 & 0.18 & 1710.0 \\
\hline K.LNMAMADAR.R & 2 & $1.27 \mathrm{E}-04$ & 3.31 & 0.45 & 1730.0 \\
\hline R.LDYQQIVR.D & 2 & $2.36 \mathrm{E}-04$ & 2.82 & 0.41 & 1057.8 \\
\hline K.SLVAAGLCK.R & 2 & $9.06 \mathrm{E}-04$ & 3.04 & 0.57 & 938.2 \\
\hline R.TQLQKDIVEK.V & 3 & $1.31 \mathrm{E}-03$ & 2.91 & 0.22 & 814.3 \\
\hline K.YFIQPSGR.F & 2 & $1.85 \mathrm{E}-03$ & 2.10 & 0.07 & 669.2 \\
\hline K.YFIQPSGR.F & 2 & $1.88 \mathrm{E}-03$ & 2.10 & 0.07 & 669.2 \\
\hline K.LNMAM*ADAR.R & 2 & $5.12 \mathrm{E}-03$ & 3.14 & 0.32 & 1676.9 \\
\hline K.TGM*IMVFGEITTK.A & 2 & $9.11 \mathrm{E}-03$ & 3.38 & 0.49 & 1051.3 \\
\hline K.RIDTVVISAQHADEISTADLR.T & 3 & $9.54 \mathrm{E}-03$ & 3.95 & 0.53 & 1022.4 \\
\hline K.TGM*IM*VFGEITTK.A & 2 & $1.33 \mathrm{E}-02$ & 2.58 & 0.55 & 443.5 \\
\hline K.VIPRDMLDENTK.Y & 2 & $2.11 \mathrm{E}-02$ & 2.15 & 0.40 & 139.6 \\
\hline K.LNM*AMADAR.R & 2 & 7.91E-01 & 2.13 & 0.50 & 763.2 \\
\hline gi|6322790| Fba1p & & 3.33E-15 & 160.32 & & 39595.8 \\
\hline K.FAIPAINVTSSSTAVAALEAAR.D & 2 & $3.33 \mathrm{E}-15$ & 5.48 & 0.62 & 2069.3 \\
\hline K.SPIILQTSNGGAAYFAGK.G & 2 & $2.34 \mathrm{E}-13$ & 6.37 & 0.65 & 3459.5 \\
\hline K.VNLDTDCQYAYLTGIR.D & 2 & $5.78 \mathrm{E}-12$ & 5.60 & 0.63 & 2119.1 \\
\hline K.TGVIVGEDVHNLFTYAK.E & 2 & $2.15 \mathrm{E}-11$ & 4.96 & 0.65 & 1841.1 \\
\hline K.EDLYTKPEQVYNVYK.A & 2 & $4.38 \mathrm{E}-11$ & 3.98 & 0.39 & 594.5 \\
\hline R.KTGVIVGEDVHNLFTYAK.E & 2 & $1.06 \mathrm{E}-10$ & 4.60 & 0.57 & 1331.6 \\
\hline K.DYIMSPVGNPEGPEKPNK.K & 2 & $1.83 \mathrm{E}-10$ & 4.93 & 0.66 & 1295.7 \\
\hline K.DYIMSPVGNPEGPEKPNKK.F & 2 & $6.86 \mathrm{E}-10$ & 3.74 & 0.54 & 895.1 \\
\hline K.EEKPLFLVFHGGSGSTVQEFHTGIDNGVVK.V & 3 & $1.02 \mathrm{E}-09$ & 4.43 & 0.23 & 1578.6 \\
\hline K.DYIM*SPVGNPEGPEKPNKK.F & 2 & $9.55 \mathrm{E}-09$ & 4.11 & 0.58 & 563.4 \\
\hline R.SIAPAYGIPVVLHSDHCAK.K & 2 & 2.94E-08 & 3.51 & 0.41 & 495.3 \\
\hline K.GISNEGQNASIK.G & 2 & $1.34 \mathrm{E}-06$ & 3.01 & 0.56 & 1105.7 \\
\hline
\end{tabular}


Supplementary Table 1. Continued.

\begin{tabular}{|c|c|c|c|c|c|}
\hline \multirow{2}{*}{ Peptide } & \multirow{2}{*}{$\mathbf{z}$} & \multirow{2}{*}{$\frac{P \text { (pro) }}{P \text { (pep) }}$} & \multirow{2}{*}{$\frac{\text { Score }}{\mathrm{XC}}$} & \multirow{2}{*}{$\Delta \mathbf{C n}$} & \multirow{2}{*}{$\frac{\text { MW }}{\text { Sp }}$} \\
\hline & & & & & \\
\hline K.GAIAAAHYIR.S & 2 & $3.82 \mathrm{E}-05$ & 3.01 & 0.34 & 1366.3 \\
\hline K.DYIM*SPVGNPEGPEKPNK.K & 3 & $1.44 \mathrm{E}-03$ & 2.81 & 0.39 & 549.7 \\
\hline R.DYVLNK.K & 1 & $2.10 \mathrm{E}-02$ & 2.05 & 0.34 & 631.8 \\
\hline R.DYVLNKK.D & 2 & $1.11 \mathrm{E}-01$ & 1.79 & 0.11 & 562.7 \\
\hline gi|6323768| Ade17p & & $6.95 \mathrm{E}-14$ & 62.30 & & 65222.9 \\
\hline K.HVSPAGAAVGIPLSDVEK.Q & 2 & $6.95 \mathrm{E}-14$ & 5.38 & 0.68 & 3443.0 \\
\hline K.NGMVVGLGAGQQSR.I & 2 & $1.03 \mathrm{E}-06$ & 3.11 & 0.39 & 2075.2 \\
\hline K.ADNWWFR.Q & 2 & $1.14 \mathrm{E}-02$ & 2.43 & 0.28 & 739.4 \\
\hline R.QVYGVTLEQK.R & 2 & $2.22 \mathrm{E}-02$ & 2.55 & 0.40 & 369.1 \\
\hline K.TGLLDLAR.G & 2 & $6.21 \mathrm{E}-02$ & 3.08 & 0.20 & 711.3 \\
\hline gi|6323138| Ahp1p & & $1.91 \mathrm{E}-13$ & 130.30 & & 19102.6 \\
\hline K.FQYIAISQSDADSESCK.M & 2 & $1.91 \mathrm{E}-13$ & 5.17 & 0.55 & 1687.6 \\
\hline R.WAM*VVENGIVTYAAK.E & 2 & $1.63 \mathrm{E}-10$ & 2.88 & 0.47 & 924.4 \\
\hline R.WAMVVENGIVTYAAK.E & 2 & 4.54E-10 & 4.29 & 0.54 & 1642.4 \\
\hline K.ETNPGTDVTVSSVESVLAHL.- & 2 & 2.14E-09 & 4.40 & 0.63 & 757.4 \\
\hline K.EVDQVIVVTVDNPFANQAWAK.S & 2 & 3.43E-09 & 5.98 & 0.62 & 1465.0 \\
\hline K.SIGFELAVGDGVYWSGR.W & 2 & $2.20 \mathrm{E}-08$ & 4.33 & 0.66 & 1101.2 \\
\hline K.EKEVDQVIVVTVDNPFANQAWAK.S & 3 & $5.68 \mathrm{E}-08$ & 3.99 & 0.53 & 991.8 \\
\hline K.FASDPGCAFTK.S & 2 & $1.52 \mathrm{E}-07$ & 2.97 & 0.56 & 886.2 \\
\hline K.M*PQTVEWSK.L & 2 & 7.53E-04 & 2.70 & 0.49 & 815.0 \\
\hline K.MPQTVEWSK.L & 2 & $1.44 \mathrm{E}-03$ & 2.50 & 0.42 & 785.6 \\
\hline K.KFPAGDYK.F & 2 & $7.70 \mathrm{E}-03$ & 2.11 & 0.29 & 529.2 \\
\hline K.SLGVKDTTHIK.F & 2 & $7.80 \mathrm{E}-03$ & 2.70 & 0.34 & 617.2 \\
\hline K.FPAGDYK.F & 1 & $5.74 \mathrm{E}-02$ & 1.92 & 0.20 & 435.6 \\
\hline gi|6322565| Ado1p & & 3.46E-13 & 180.32 & & 36349.5 \\
\hline K.IVDTNGAGDAFAGGFM*AGLTK.G & 2 & $3.46 \mathrm{E}-13$ & 5.46 & 0.69 & 1290.9 \\
\hline K.TVIFTHGVEPTVVVSSK.G & 2 & $8.03 \mathrm{E}-13$ & 4.41 & 0.59 & 907.2 \\
\hline R.GAAYVLGAGQVVYFGSVGK.D & 2 & $2.45 \mathrm{E}-11$ & 5.90 & 0.69 & 2553.3 \\
\hline K.IVDTNGAGDAFAGGFMAGLTK.G & 2 & $1.37 \mathrm{E}-10$ & 4.60 & 0.65 & 2054.4 \\
\hline K.YSLKENDAILVDAK.S & 2 & 2.15E-09 & 4.41 & 0.62 & 1454.7 \\
\hline R.SLVTDLGAANFFTPDHLDK.H & 2 & $6.25 \mathrm{E}-09$ & 5.31 & 0.65 & 1805.4 \\
\hline K.SMYQVQNDIGTGK.C & 2 & $5.78 \mathrm{E}-08$ & 4.62 & 0.62 & 1948.0 \\
\hline K.LVAGGAAQNTAR.G & 2 & $1.17 \mathrm{E}-07$ & 3.70 & 0.51 & 1685.8 \\
\hline K.SM*YQVQNDIGTGK.C & 2 & $8.46 \mathrm{E}-07$ & 4.32 & 0.64 & 1551.2 \\
\hline K.HWDLVEAAK.L & 2 & $1.47 \mathrm{E}-06$ & 2.86 & 0.52 & 996.7 \\
\hline K.M*AIFDELLQM*PETK.L & 2 & $6.95 \mathrm{E}-06$ & 4.33 & 0.63 & 2100.3 \\
\hline K.CAALITGHNR.S & 2 & $1.05 \mathrm{E}-05$ & 4.00 & 0.43 & 1311.4 \\
\hline K.ENDAILVDAK.S & 1 & $2.78 \mathrm{E}-05$ & 2.67 & 0.36 & 344.2 \\
\hline K.MAIFDELLQMPETK.L & 2 & $2.00 \mathrm{E}-04$ & 3.66 & 0.52 & 1104.2 \\
\hline K.GTSTYPVKPLDSSK.I & 3 & 4.66E-04 & 1.81 & 0.38 & 223.3 \\
\hline R.IVKDSPVEK.T & 2 & $1.23 \mathrm{E}-03$ & 2.49 & 0.28 & 630.7 \\
\hline K.MAIFDELLQM*PETK.L & 2 & $8.18 \mathrm{E}-03$ & 3.68 & 0.45 & 1266.2 \\
\hline R.LLNENEKAGVK.S & 2 & $7.10 \mathrm{E}-02$ & 2.41 & 0.05 & 1419.0 \\
\hline
\end{tabular}


Supplementary Table 1. Continued.

\begin{tabular}{|c|c|c|c|c|c|}
\hline \multirow{2}{*}{ Peptide } & \multirow{2}{*}{$\mathbf{z}$} & \multirow{2}{*}{$\begin{array}{l}\mathbf{P}(\text { pro) } \\
\mathbf{P}(\text { pep) }\end{array}$} & \multirow{2}{*}{$\frac{\text { Score }}{\text { XC }}$} & \multirow{2}{*}{$\Delta \mathrm{Cn}$} & \multirow{2}{*}{$\frac{\text { MW }}{\text { Sp }}$} \\
\hline & & & & & \\
\hline gi|6322505| Ssc1p & & $2.56 \mathrm{E}-12$ & 172.26 & 30.43 & 70584.9 \\
\hline R.GQTYSPAQIGGFVLNK.M & 2 & $3.61 \mathrm{E}-08$ & 5.02 & 0.62 & 1772.5 \\
\hline K.NAVVTVPAYFNDSQR.Q & 2 & 8.95E-07 & 3.14 & 0.16 & 548.3 \\
\hline R.QAVVNPENTLFATK.R & 2 & $3.56 \mathrm{E}-06$ & 3.25 & 0.60 & 698.0 \\
\hline K.DAGLSTSDISEVLLVGGM*SR.M & 2 & $6.71 \mathrm{E}-05$ & 3.68 & 0.59 & 748.8 \\
\hline R.TTPSVVAFTK.D & 2 & $1.88 \mathrm{E}-03$ & 1.86 & 0.44 & 249.6 \\
\hline gi|6321673| Yhb1p & & 3.04E-11 & 100.28 & & 44618.1 \\
\hline K.HVDELLAECANVDK.I & 2 & $3.04 \mathrm{E}-11$ & 4.99 & 0.68 & 2614.0 \\
\hline K.LSAPAGDFAINK.E & 2 & $2.36 \mathrm{E}-07$ & 3.25 & 0.35 & 895.4 \\
\hline K.ATVPVLEQQGTVITR.T & 2 & $5.26 \mathrm{E}-07$ & 3.95 & 0.55 & 864.3 \\
\hline K.VGAQPNALATTVLAAAK.N & 2 & $5.72 \mathrm{E}-06$ & 3.88 & 0.59 & 538.7 \\
\hline R.HYSLCSASTK.N & 2 & $7.80 \mathrm{E}-06$ & 2.70 & 0.29 & 783.9 \\
\hline K.NIDDLSVLM*DHVK.Q & 2 & $5.25 \mathrm{E}-05$ & 2.85 & 0.50 & 734.7 \\
\hline R.QENQYDALR.H & 2 & $1.77 \mathrm{E}-04$ & 2.45 & 0.35 & 250.8 \\
\hline R.DDM*IHYEPFGPK.M & 2 & $1.39 \mathrm{E}-02$ & 2.03 & 0.17 & 564.2 \\
\hline K.NIDDLSVLMDHVK.Q & 2 & $3.46 \mathrm{E}-02$ & 2.43 & 0.44 & 365.4 \\
\hline gi|6323570| Dak1p & & 2.04E-10 & 102.28 & & 62168.0 \\
\hline K.TSAPSVNDDLLHNEVTAK.A & 2 & $2.04 \mathrm{E}-10$ & 4.43 & 0.68 & 745.3 \\
\hline R.LVNENASGVLLIVK.N & 2 & $2.84 \mathrm{E}-08$ & 5.61 & 0.36 & 2430.4 \\
\hline R.VAVIGDDVAVGR.E & 2 & $3.40 \mathrm{E}-07$ & 4.27 & 0.62 & 1628.2 \\
\hline K.VLDPIPSTEDLISK.Y & 2 & 7.19E-07 & 3.08 & 0.49 & 688.0 \\
\hline K.IVGAFAEEYSSK.Y & 2 & $8.50 \mathrm{E}-07$ & 3.65 & 0.62 & 1207.2 \\
\hline R.ALAGTVLVHK.I & 2 & $3.35 \mathrm{E}-06$ & 3.11 & 0.41 & 1188.6 \\
\hline K.ALQSDFEEIK.S & 2 & $5.71 \mathrm{E}-05$ & 3.26 & 0.51 & 1236.7 \\
\hline K.QILNAIR.L & 2 & $2.94 \mathrm{E}-04$ & 2.02 & 0.26 & 145.3 \\
\hline R.KFESELNEK.Q & 2 & $3.13 \mathrm{E}-03$ & 2.52 & 0.15 & 782.9 \\
\hline K.LLDPNDKDR.A & 2 & $4.52 \mathrm{E}-03$ & 2.65 & 0.34 & 691.7 \\
\hline gi|6323613| Tsa1p & & $2.49 \mathrm{E}-10$ & 70.27 & & 21576.3 \\
\hline R.DYGVLIEEEGVALR.G & 2 & $2.49 \mathrm{E}-10$ & 5.30 & 0.53 & 2792.5 \\
\hline K.TAVVDGVFDEVSLDK.Y & 2 & $7.11 \mathrm{E}-10$ & 4.42 & 0.63 & 2088.9 \\
\hline R.LVEAFQWTDK.N & 2 & 4.39E-08 & 3.71 & 0.55 & 1025.7 \\
\hline R.HITINDLPVGR.N & 2 & $1.06 \mathrm{E}-06$ & 3.30 & 0.60 & 781.3 \\
\hline R.NVDEALR.L & 1 & $2.27 \mathrm{E}-03$ & 1.60 & 0.31 & 142.5 \\
\hline K.EYFEAANK.- & 2 & $6.82 \mathrm{E}-03$ & 1.96 & 0.36 & 508.1 \\
\hline R.GLFIIDPK.G & 1 & $1.02 \mathrm{E}-02$ & 2.05 & 0.21 & 590.7 \\
\hline gi|6324514 Arg1p & & $2.59 \mathrm{E}-10$ & 160.23 & & 46910.1 \\
\hline R.SMIQPSQNSVNGTVR.V & 2 & $2.59 \mathrm{E}-10$ & 4.08 & 0.56 & 823.9 \\
\hline K.AHVDLEGLTLDK.E & 2 & 5.84E-09 & 3.97 & 0.58 & 1273.9 \\
\hline K.EVSVTKPLDVFLAASNLAR.A & 2 & 7.02E-09 & 3.78 & 0.64 & 531.0 \\
\hline R.GCYEQAPLTVLR.K & 2 & 3.07E-08 & 4.13 & 0.55 & 1565.8 \\
\hline K.AHVDLEGLTLDKEVR.Q & 3 & $4.26 \mathrm{E}-08$ & 4.27 & 0.55 & 1035.8 \\
\hline R.KAHVDLEGLTLDK.E & 2 & $6.52 \mathrm{E}-07$ & 4.38 & 0.60 & 1726.7 \\
\hline K.QEGCFAVSHGCTGK.G & 2 & $2.51 \mathrm{E}-06$ & 2.61 & 0.36 & 493.4 \\
\hline R.KDLLDYAAQK.G & 2 & $9.95 \mathrm{E}-06$ & 3.34 & 0.41 & 1069.4 \\
\hline
\end{tabular}


Supplementary Table 1. Continued.

\begin{tabular}{|c|c|c|c|c|c|}
\hline \multirow{2}{*}{ Peptide } & \multirow{2}{*}{$\mathbf{z}$} & \multirow{2}{*}{$\frac{\mathbf{P}(\text { pro })}{\mathbf{P}(\text { pep })}$} & \multirow{2}{*}{$\begin{array}{c}\text { Score } \\
\mathrm{XC} \\
\end{array}$} & \multirow{2}{*}{$\Delta \mathbf{C n}$} & \multirow{2}{*}{$\frac{\text { MW }}{\text { Sp }}$} \\
\hline & & & & & \\
\hline R.SM*IQPSQNSVNGTVR.V & 2 & $1.60 \mathrm{E}-05$ & 3.93 & 0.55 & 758.3 \\
\hline K.DLLDYAAQK.G & 1 & 7.32E-05 & 2.39 & 0.42 & 635.3 \\
\hline R.MPEFFER.F & 2 & $5.98 \mathrm{E}-04$ & 1.95 & 0.23 & 549.8 \\
\hline R.IDIVEDR.Y & 2 & $1.53 \mathrm{E}-03$ & 2.40 & 0.37 & 809.1 \\
\hline K.GNVIILGR.S & 2 & $1.01 \mathrm{E}-02$ & 3.13 & 0.39 & 1104.6 \\
\hline R.DSFVTPNYSR.L & 2 & $1.03 \mathrm{E}-02$ & 2.77 & 0.47 & 758.4 \\
\hline R.M*PEFFER.F & 2 & $2.66 \mathrm{E}-02$ & 2.33 & 0.29 & 728.1 \\
\hline K.FVCVDCR.E & 1 & $5.02 \mathrm{E}-02$ & 1.67 & 0.41 & 250.8 \\
\hline gi|6320936| Met6p & & 3.42E-10 & 264.27 & & 85806.8 \\
\hline R.APEQFDEVVAAIGNK.Q & 2 & $3.42 \mathrm{E}-10$ & 4.68 & 0.52 & 2365.0 \\
\hline K.LNGQKPVDEFLEAK.E & 2 & $1.15 \mathrm{E}-08$ & 2.57 & 0.47 & 543.8 \\
\hline K.NVSGQDVAAALEANAK.S & 2 & $1.35 \mathrm{E}-08$ & 5.30 & 0.62 & 2659.2 \\
\hline K.VIQVDEPALR.E & 2 & $3.14 \mathrm{E}-07$ & 3.42 & 0.45 & 1307.7 \\
\hline R.LSLTHMVEAAK.Y & 2 & $3.87 \mathrm{E}-07$ & 3.59 & 0.55 & 1356.2 \\
\hline K.AYTYFGEQSNLPK.I & 2 & $3.88 \mathrm{E}-07$ & 3.98 & 0.66 & 1181.8 \\
\hline K.ALDADVVSIEFSK.K & 1 & $1.49 \mathrm{E}-06$ & 2.25 & 0.45 & 529.3 \\
\hline K.ESVYAQSITSKPVK.G & 2 & 2.37E-06 & 2.91 & 0.50 & 877.0 \\
\hline K.AVDVTALEMVK.W & 2 & 3.37E-06 & 4.11 & 0.53 & 1543.2 \\
\hline R.YVRPPIIVGDLSR.P & 2 & $5.50 \mathrm{E}-06$ & 3.68 & 0.53 & 871.5 \\
\hline K.GTISAEEYEK.F & 2 & $6.09 \mathrm{E}-06$ & 2.82 & 0.49 & 931.6 \\
\hline K.DDANYIAEFK.N & 2 & 7.64E-06 & 3.97 & 0.51 & 1475.3 \\
\hline K.FWVNPDCGLK.T & 1 & $9.94 \mathrm{E}-06$ & 2.10 & 0.41 & 608.1 \\
\hline R.IPSKDEFIAK.I & 2 & $1.60 \mathrm{E}-05$ & 3.59 & 0.44 & 1135.8 \\
\hline K.KDDANYIAEFK.N & 2 & $4.35 \mathrm{E}-05$ & 3.97 & 0.52 & 1476.6 \\
\hline K.LDEVVVITK.N & 2 & $5.07 \mathrm{E}-05$ & 3.42 & 0.53 & 1373.8 \\
\hline K.QTLSVGIVDGR.N & 2 & 7.98E-05 & 2.74 & 0.55 & 544.0 \\
\hline K.GFFSFATQK.L & 2 & $1.32 \mathrm{E}-04$ & 2.81 & 0.57 & 1136.2 \\
\hline K.ITVDELFK.V & 2 & $1.46 \mathrm{E}-04$ & 2.58 & 0.44 & 363.9 \\
\hline K.AVDVTALEM*VK.W & 2 & $1.75 \mathrm{E}-04$ & 4.14 & 0.58 & 1622.5 \\
\hline K.GM*LTGPITCLR.W & 2 & $3.17 \mathrm{E}-04$ & 3.47 & 0.45 & 1066.2 \\
\hline K.ALDADVVSIEFSKK.D & 2 & $3.36 \mathrm{E}-04$ & 2.50 & 0.14 & 708.4 \\
\hline K.GLPVAALHVDFVR.A & 3 & $9.82 \mathrm{E}-04$ & 1.21 & 0.22 & 219.2 \\
\hline K.FIHDAAVK.A & 1 & $5.29 \mathrm{E}-03$ & 1.68 & 0.20 & 406.3 \\
\hline K.GMLTGPITCLR.W & 1 & $5.72 \mathrm{E}-03$ & 2.27 & 0.44 & 238.6 \\
\hline R.WSFPR.D & 2 & $3.12 \mathrm{E}-02$ & 1.23 & 0.11 & 299.4 \\
\hline gi|6323073| Pdc1p & & 2.13E-09 & 144.22 & & 61456.8 \\
\hline R.VATTGEWDKLTQDK.S & 2 & 2.13E-09 & 3.21 & 0.42 & 847.0 \\
\hline K.NPVILADACCSR.H & 2 & 4.64E-07 & 4.49 & 0.51 & 2024.5 \\
\hline R.YGGVYVGTLSKPEVK.E & 2 & 4.92E-07 & 3.77 & 0.40 & 847.5 \\
\hline R.TPANAAVPASTPLK.Q & 2 & $5.30 \mathrm{E}-07$ & 3.92 & 0.67 & 863.3 \\
\hline K.LLTTIADAAK.G & 2 & $5.01 \mathrm{E}-06$ & 3.07 & 0.42 & 650.9 \\
\hline K.NIVEFHSDHMK.I & 2 & 7.04E-06 & 3.99 & 0.52 & 1488.6 \\
\hline K.NIVEFHSDHM*K.I & 2 & 5.12E-05 & 3.43 & 0.48 & 688.0 \\
\hline K.IYEVEGMR.W & 1 & $1.52 \mathrm{E}-04$ & 2.26 & 0.41 & 385.3 \\
\hline R.NATFPGVQMK.F & 1 & 8.39E-04 & 2.20 & 0.38 & 288.5 \\
\hline R.VATTGEWDK.L & 2 & 8.51E-03 & 2.08 & 0.43 & 263.8 \\
\hline
\end{tabular}


Supplementary Table 1. Continued.

\begin{tabular}{|c|c|c|c|c|c|}
\hline \multirow{2}{*}{ Peptide } & \multirow{2}{*}{$\mathbf{z}$} & \multirow{2}{*}{$\begin{array}{l}\mathbf{P} \text { (pro) } \\
\mathbf{P}(\text { pep) }\end{array}$} & \multirow{2}{*}{$\frac{\text { Score }}{\text { XC }}$} & \multirow{2}{*}{$\Delta \mathbf{C n}$} & \multirow{2}{*}{$\frac{\text { MW }}{\text { Sp }}$} \\
\hline & & & & & \\
\hline K.IYEVEGM*R.W & 2 & $1.68 \mathrm{E}-02$ & 2.71 & 0.26 & 494.7 \\
\hline K.GYKPVAVPAR.T & 3 & 2.07E-02 & 2.45 & 0.18 & 399.5 \\
\hline K.YLFER.L & 1 & 8.53E-01 & 1.50 & 0.11 & 130.6 \\
\hline gi|6323763| Asc1p & & 2.22E-09 & 70.22 & & 34783.6 \\
\hline R.LWDVATGETYQR.F & 2 & $2.22 \mathrm{E}-09$ & 4.35 & 0.66 & 2068.2 \\
\hline K.ADDDSVTIISAGNDK.M & 2 & 2.47E-09 & 3.58 & 0.48 & 1494.6 \\
\hline R.YWLAAATATGIK.V & 2 & $1.22 \mathrm{E}-08$ & 4.26 & 0.55 & 1829.7 \\
\hline K.ASMIISGSR.D & 2 & $1.28 \mathrm{E}-05$ & 3.10 & 0.37 & 1169.0 \\
\hline K.SDVM*SVDIDKK.A & 2 & $4.01 \mathrm{E}-05$ & 2.79 & 0.39 & 931.2 \\
\hline R.VWQVMTAN.- & 1 & $3.47 \mathrm{E}-04$ & 1.51 & 0.56 & 234.7 \\
\hline K.SDVMSVDIDKK.A & 2 & $9.08 \mathrm{E}-03$ & 2.91 & 0.43 & 820.1 \\
\hline gi|6322697| Gpm1p & & 2.89E-09 & 102.21 & & 27591.6 \\
\hline K.TVMIAAHGNSLR.G & 2 & $2.89 \mathrm{E}-09$ & 3.45 & 0.54 & 1104.0 \\
\hline K.HLEGISDADIAK.L & 1 & $5.82 \mathrm{E}-08$ & 3.27 & 0.55 & 803.9 \\
\hline K.KVYPDVLYTSK.L & 2 & $3.14 \mathrm{E}-06$ & 3.54 & 0.41 & 1037.4 \\
\hline R.AIQTANIALEK.A & 2 & $1.33 \mathrm{E}-05$ & 3.73 & 0.35 & 1483.1 \\
\hline K.TVM*IAAHGNSLR.G & 2 & $5.30 \mathrm{E}-05$ & 3.05 & 0.52 & 960.5 \\
\hline K.VYPDVLYTSK.L & 1 & $3.10 \mathrm{E}-04$ & 2.46 & 0.35 & 458.8 \\
\hline R.LWIPVNR.S & 1 & $2.62 \mathrm{E}-02$ & 1.30 & 0.29 & 128.8 \\
\hline -.MPKLVLVR.H & 2 & 7.39E-02 & 1.47 & 0.45 & 411.9 \\
\hline K.NLFTGWVDVK.L & 1 & $1.37 \mathrm{E}-01$ & 2.31 & 0.30 & 339.9 \\
\hline K.DLLSGK.T & 1 & $1.46 \mathrm{E}-01$ & 1.89 & 0.14 & 436.5 \\
\hline R.LLPYWQDVIAK.D & 1 & $2.30 \mathrm{E}-01$ & 2.36 & 0.29 & 701.5 \\
\hline gi|6320662| Guk1p & & 4.11E-09 & 58.21 & & 20624.6 \\
\hline R.LSAAQAELAYAETGAHDK.V & 3 & $4.11 \mathrm{E}-09$ & 3.56 & 0.43 & 887.0 \\
\hline K.TCILDIDMQGVK.S & 2 & $3.20 \mathrm{E}-06$ & 3.91 & 0.29 & 1779.8 \\
\hline K.VIVNDDLDKAYK.E & 2 & $2.29 \mathrm{E}-04$ & 3.15 & 0.27 & 1302.2 \\
\hline K.TCILDIDM*QGVK.S & 2 & $2.94 \mathrm{E}-04$ & 3.75 & 0.44 & 1038.8 \\
\hline R.PIVISGPSGTGK.S & 2 & $3.44 \mathrm{E}-01$ & 2.49 & 0.50 & 729.1 \\
\hline gi|6322531| Lia1p & & 9.17E-09 & 118.23 & & 36142.3 \\
\hline K.HEVAYVLGQTK.N & 2 & $9.17 \mathrm{E}-09$ & 3.70 & 0.70 & 1380.4 \\
\hline K.TVAEEFATKPEEAK.K & 2 & $1.32 \mathrm{E}-08$ & 4.39 & 0.54 & 1989.4 \\
\hline R.HEAAEALGALGDK.D & 2 & 7.54E-07 & 4.58 & 0.71 & 1571.8 \\
\hline K.TVAEEFATKPEEAKK.A & 2 & 8.64E-07 & 4.27 & 0.59 & 1320.9 \\
\hline K.SYLNDEVDVVR.E & 2 & $1.13 \mathrm{E}-06$ & 4.10 & 0.52 & 1775.8 \\
\hline R.HVM*LDQNQEPMVR.H & 2 & $9.47 \mathrm{E}-04$ & 3.32 & 0.05 & 757.9 \\
\hline R.ETCELAINR.I & 2 & $1.76 \mathrm{E}-02$ & 2.49 & 0.34 & 541.2 \\
\hline R.INWTHGGAK.D & 2 & $2.01 \mathrm{E}-02$ & 2.69 & 0.40 & 483.8 \\
\hline K.EDPHVAVR.E & 2 & $2.22 \mathrm{E}-02$ & 1.41 & 0.20 & 560.8 \\
\hline K.QPLFQR.Y & 2 & 2.97E-02 & 1.39 & 0.16 & 191.1 \\
\hline R.HVMLDQNQEPM*VR.H & 2 & $5.40 \mathrm{E}-02$ & 3.17 & 0.50 & 635.6 \\
\hline K.AAKEDPHVAVR.E & 2 & $8.74 \mathrm{E}-01$ & 2.32 & 0.24 & 839.9 \\
\hline
\end{tabular}


Supplementary Table 1. Continued.

\begin{tabular}{|c|c|c|c|c|c|}
\hline \multirow{2}{*}{ Peptide } & \multirow{2}{*}{$\mathbf{z}$} & \multirow{2}{*}{$\begin{array}{l}\mathbf{P} \text { (pro) } \\
\mathbf{P}(\text { pep) } \\
\end{array}$} & \multirow{2}{*}{$\begin{array}{c}\text { Score } \\
\mathrm{XC} \\
\end{array}$} & \multirow{2}{*}{$\Delta \mathbf{C n}$} & \multirow{2}{*}{$\frac{\text { MW }}{\text { Sp }}$} \\
\hline & & & & & \\
\hline gi|6322148| Gvp36p & & $9.54 \mathrm{E}-09$ & 32.22 & & 36647.4 \\
\hline K.YINESVNEFSR.S & 2 & $9.54 \mathrm{E}-09$ & 3.82 & 0.51 & 988.9 \\
\hline R.LGQVTDISQLPR.E & 2 & $3.37 \mathrm{E}-05$ & 4.31 & 0.50 & 1629.4 \\
\hline R.IQQDTLIQTK.F & 2 & $1.05 \mathrm{E}-02$ & 3.65 & 0.36 & 974.8 \\
\hline gi|6319725| His7p & & $1.61 \mathrm{E}-08$ & 98.27 & 22.28 & 61030.0 \\
\hline K.YGSEEFIAAVNK.N & 2 & $1.61 \mathrm{E}-08$ & 4.67 & 0.50 & 2168.3 \\
\hline K.AYGAQAVVISVDPK.R & 2 & $2.58 \mathrm{E}-08$ & 5.43 & 0.60 & 2832.8 \\
\hline K.VSIGTDAVYAAEK.Y & 2 & $1.76 \mathrm{E}-07$ & 3.69 & 0.61 & 1047.7 \\
\hline R.TNDQGDLVVTK.G & 2 & $1.14 \mathrm{E}-05$ & 3.39 & 0.47 & 1093.6 \\
\hline K.STGLNYIDFK.L & 2 & $1.57 \mathrm{E}-05$ & 3.12 & 0.53 & 1062.1 \\
\hline R.GDGTSPIETISK.A & 2 & $5.00 \mathrm{E}-04$ & 2.80 & 0.50 & 1006.2 \\
\hline R.IIACLDVR.T & 2 & $1.28 \mathrm{E}-03$ & 2.79 & 0.38 & 572.3 \\
\hline K.VFETEYPGPNGEK.Y & 2 & $1.42 \mathrm{E}-03$ & 2.74 & 0.27 & 1262.3 \\
\hline R.DLGVWELTR.A & 2 & $1.84 \mathrm{E}-01$ & 1.90 & 0.14 & 254.9 \\
\hline gi|6319725| Eno1p/Eno2p & & 2.09E-08 & 70.19 & & 46773.3 \\
\hline -.NVPLYKHLADLSK.- & 2 & $2.09 \mathrm{E}-08$ & 3.56 & 0.03 & 777.2 \\
\hline R.GNPTVEVELTTEK.G & 2 & $2.75 \mathrm{E}-08$ & 3.87 & 0.38 & 1139.3 \\
\hline K.NVPLYQHLADLSK.S & 2 & $6.96 \mathrm{E}-07$ & 3.56 & 0.00 & 777.2 \\
\hline K.VNQIGTLSESIK.A & 2 & $9.40 \mathrm{E}-07$ & 3.76 & 0.11 & 733.8 \\
\hline R.IGSEVYHNLK.S & 2 & 3.93E-05 & 3.64 & 0.20 & 1161.2 \\
\hline -.IGSEVYHNLK.- & 2 & $1.02 \mathrm{E}-04$ & 3.61 & 0.24 & 1164.2 \\
\hline -.DGKYDLDFK.- & 2 & $1.41 \mathrm{E}-04$ & 2.55 & 0.15 & 714.4 \\
\hline -.IEEELGDK.- & 1 & $2.38 \mathrm{E}-02$ & 2.43 & 0.03 & 718.6 \\
\hline -.IATAIEK.- & 1 & $1.16 \mathrm{E}-01$ & 2.08 & 0.00 & 618.3 \\
\hline -.AADALLLK.- & 1 & $2.28 \mathrm{E}-01$ & 1.74 & 0.11 & 658.7 \\
\hline gi|6320023| Dld2p & & 2.94E-08 & 94.25 & & 59231.3 \\
\hline K.GSCHVGGVVATNAGGLR.L & 2 & $2.94 \mathrm{E}-08$ & 4.91 & 0.58 & 1087.2 \\
\hline K.DLYSLVEATNAR.L & 2 & 2.95E-07 & 4.47 & 0.57 & 1925.6 \\
\hline K.VSLILNYCNDEK.I & 2 & $1.58 \mathrm{E}-06$ & 3.89 & 0.43 & 914.4 \\
\hline K.IRDFDPVSGILK.C & 2 & 3.03E-06 & 3.77 & 0.47 & 951.9 \\
\hline K.SILSEQEILR.A & 2 & $6.10 \mathrm{E}-05$ & 3.06 & 0.39 & 1379.8 \\
\hline K.LTSDDLNYFK.S & 2 & $7.00 \mathrm{E}-04$ & 2.54 & 0.38 & 699.9 \\
\hline R.EM*IPEASQANGGVYK.Y & 2 & $2.60 \mathrm{E}-03$ & 2.31 & 0.15 & 670.2 \\
\hline K.YDVSLPLK.D & 2 & $7.61 \mathrm{E}-03$ & 2.36 & 0.43 & 340.7 \\
\hline R.DFDPVSGILK.C & 2 & $7.29 \mathrm{E}-02$ & 2.36 & 0.30 & 828.4 \\
\hline gi|6319673| Pgi1p & & 3.09E-08 & 50.21 & & 61261.2 \\
\hline K.TFTTAETITNANTAK.N & 2 & $3.09 \mathrm{E}-08$ & 4.29 & 0.58 & 1101.6 \\
\hline K.HFAALSTNETEVAK.F & 2 & $3.79 \mathrm{E}-06$ & 3.94 & 0.64 & 1515.3 \\
\hline K.EANVTGLR.D & 2 & $2.69 \mathrm{E}-04$ & 2.25 & 0.44 & 417.6 \\
\hline K.AEGATGGLVPHK.V & 2 & $1.19 \mathrm{E}-03$ & 3.58 & 0.53 & 1202.7 \\
\hline K.VVDPETTLFLIASK.T & 2 & $8.78 \mathrm{E}-02$ & 1.78 & 0.22 & 191.3 \\
\hline
\end{tabular}


Supplementary Table 1. Continued.

\begin{tabular}{|c|c|c|c|c|c|}
\hline \multirow{2}{*}{ Peptide } & \multirow{2}{*}{$\mathbf{z}$} & \multirow{2}{*}{$\frac{P(\text { pro) }}{P(\text { pep) }}$} & \multirow{2}{*}{$\frac{\text { Score }}{\text { XC }}$} & \multirow{2}{*}{$\Delta \mathbf{C n}$} & \multirow{2}{*}{$\frac{\text { MW }}{\text { Sp }}$} \\
\hline & & & & & \\
\hline gi|6320775| Prb1p & & 5.10E-08 & 90.23 & & 69578.8 \\
\hline K.AITVGASTLSDDR.A & 2 & $5.10 \mathrm{E}-08$ & 3.88 & 0.72 & 1444.1 \\
\hline R.GVTSYVIDTGVNINHK.D & 2 & 7.06E-08 & 4.51 & 0.58 & 1120.9 \\
\hline R.SNGSGTMSDVVK.G & 2 & $4.10 \mathrm{E}-06$ & 2.48 & 0.43 & 838.9 \\
\hline R.LNLGSFNK.Y & 2 & $1.28 \mathrm{E}-03$ & 2.48 & 0.26 & 712.3 \\
\hline K.GSTANMSLGGGK.S & 2 & $1.95 \mathrm{E}-03$ & 2.82 & 0.59 & 1378.6 \\
\hline K.YLYDDDAGR.G & 1 & 3.37E-02 & 2.09 & 0.45 & 487.0 \\
\hline K.DDDEEPSDSEDK.E & 2 & $2.36 \mathrm{E}-01$ & 1.68 & 0.19 & 267.8 \\
\hline gi|6324194| Fpr1p & & $6.86 \mathrm{E}-08$ & 40.21 & & 12150.3 \\
\hline R.GSPFQCNIGVGQVIK.G & 2 & $6.86 \mathrm{E}-08$ & 4.14 & 0.49 & 749.3 \\
\hline R.ISPGDGATFPK.T & 2 & $1.20 \mathrm{E}-05$ & 1.87 & 0.42 & 403.6 \\
\hline R.LTIPGPYAYGPR.G & 2 & $4.63 \mathrm{E}-04$ & 1.80 & 0.32 & 581.0 \\
\hline K.GWDVGIPK.L & 1 & $8.48 \mathrm{E}-02$ & 1.77 & 0.31 & 449.1 \\
\hline gi|6320801| Нyp2p & & 7.02E-08 & 40.19 & & 17103.3 \\
\hline K.VHLVAIDIFTGK.K & 2 & 7.02E-08 & 3.85 & 0.61 & 1497.6 \\
\hline K.KLEDLSPSTHNMEVPVVK.R & 3 & $1.09 \mathrm{E}-03$ & 3.77 & 0.40 & 873.4 \\
\hline K.NGFVVIK.S & 2 & $1.65 \mathrm{E}-02$ & 1.90 & 0.06 & 754.6 \\
\hline K.IVDMSTSK.T & 2 & $1.44 \mathrm{E}-01$ & 1.40 & 0.30 & 319.7 \\
\hline gi|6319806| Pdi1p & & 1.22E-07 & 140.23 & 19.54 & 58190.6 \\
\hline K.KADIADADVFEK.W & 2 & $1.22 \mathrm{E}-07$ & 4.17 & 0.66 & 1533.2 \\
\hline K.KSESVVYQGSR.S & 2 & $5.89 \mathrm{E}-07$ & 3.69 & 0.53 & 1037.1 \\
\hline K.DFLKGDASPIVK.S & 2 & 8.57E-07 & 3.54 & 0.56 & 920.1 \\
\hline K.ADIADADVFEK.W & 2 & $9.39 \mathrm{E}-07$ & 3.95 & 0.55 & 1317.1 \\
\hline K.NHDEIVNDPK.K & 2 & $1.90 \mathrm{E}-06$ & 3.60 & 0.52 & 819.9 \\
\hline R.TAEAIVQFM*IK.Q & 2 & $2.01 \mathrm{E}-06$ & 3.76 & 0.43 & 1214.4 \\
\hline R.GLMNFVSIDAR.K & 2 & $2.73 \mathrm{E}-06$ & 3.62 & 0.49 & 1673.8 \\
\hline K.ENGHFDVDGK.A & 2 & $3.83 \mathrm{E}-05$ & 2.09 & 0.40 & 450.7 \\
\hline R.GLM*NFVSIDAR.K & 2 & $5.56 \mathrm{E}-05$ & 4.09 & 0.54 & 987.7 \\
\hline K.SESVVYQGSR.S & 2 & $8.08 \mathrm{E}-05$ & 3.61 & 0.51 & 1189.6 \\
\hline K.ALYEEAQEK.A & 2 & $8.20 \mathrm{E}-05$ & 2.67 & 0.31 & 835.2 \\
\hline K.NHDEIVNDPKK.D & 2 & $1.14 \mathrm{E}-03$ & 3.01 & 0.42 & 1230.7 \\
\hline K.NMAPEYVK.A & 1 & $1.90 \mathrm{E}-03$ & 1.50 & 0.19 & 304.1 \\
\hline K.AIESLVK.D & 1 & $5.89 \mathrm{E}-02$ & 1.58 & 0.19 & 357.8 \\
\hline gi|6322136| Hor2p/Rhr2p & & 1.89E-07 & 64.20 & & 30419.8 \\
\hline K.VVVFEDAPAGIAAGK.A & 2 & $1.89 \mathrm{E}-07$ & 4.05 & 0.56 & 1706.3 \\
\hline K.LCNALNALPK.E & 2 & $5.74 \mathrm{E}-06$ & 3.53 & 0.38 & 924.7 \\
\hline K.RPEYFITANDVK.Q & 2 & $6.97 \mathrm{E}-05$ & 3.40 & 0.46 & 960.8 \\
\hline K.GCDIIVK.N & 2 & $3.71 \mathrm{E}-03$ & 2.63 & 0.24 & 639.1 \\
\hline R.NGLGFPINEQDPSK.S & 2 & $6.14 \mathrm{E}-03$ & 2.94 & 0.59 & 539.3 \\
\hline K.YGEHSIEVPGAVK.L & 2 & $1.13 \mathrm{E}-02$ & 3.28 & 0.32 & 824.3 \\
\hline gi|6319483| Ipp1p & & 2.58E-07 & 44.21 & & 32279.5 \\
\hline K.EETLNPIIQDTK.K & 2 & $2.58 \mathrm{E}-07$ & 3.80 & 0.56 & 872.0 \\
\hline K.VIAIDINDPLAPK.L & 2 & $9.27 \mathrm{E}-07$ & 4.23 & 0.55 & 1230.4 \\
\hline
\end{tabular}


Supplementary Table 1. Continued.

\begin{tabular}{|c|c|c|c|c|c|}
\hline \multirow{2}{*}{ Peptide } & \multirow{2}{*}{$\mathbf{z}$} & \multirow{2}{*}{$\begin{array}{l}\mathbf{P}(\text { pro) } \\
\mathbf{P}(\text { pep })\end{array}$} & \multirow{2}{*}{$\begin{array}{c}\text { Score } \\
\mathrm{XC}\end{array}$} & \multirow{2}{*}{$\Delta \mathbf{C n}$} & \multirow{2}{*}{$\frac{\text { MW }}{\text { Sp }}$} \\
\hline & & & & & \\
\hline K.LNDIEDVEK.Y & $\overline{1}$ & $6.48 \mathrm{E}-03$ & 3.09 & 0.44 & 877.1 \\
\hline K.YALDIIK.E & 1 & $1.42 \mathrm{E}-01$ & 1.92 & 0.20 & 680.4 \\
\hline gi|6324486| Adh1p & & 7.77E-07 & 120.22 & 33.62 & 36825.7 \\
\hline K.EKDIVGAVLK.A & 2 & $3.53 \mathrm{E}-04$ & 2.04 & 0.32 & 667.7 \\
\hline K.ANELLINVK.Y & 2 & $4.75 \mathrm{E}-04$ & 3.47 & 0.33 & 1427.7 \\
\hline K.GVIFYESHGK.L & 1 & $7.50 \mathrm{E}-03$ & 2.26 & 0.52 & 410.9 \\
\hline R.ANGTTVLVGM*PAGAK.C & 2 & $1.17 \mathrm{E}-02$ & 2.99 & 0.48 & 1074.4 \\
\hline K.IGDYAGIK.W & 2 & $1.27 \mathrm{E}-02$ & 2.08 & 0.26 & 402.7 \\
\hline K.DIVGAVLK.A & 1 & $5.16 \mathrm{E}-02$ & 2.05 & 0.20 & 689.0 \\
\hline gi|6325196| Ald6p & & 9.83E-07 & 130.20 & & 54379.9 \\
\hline K.SVAVDSSESNLK.K & 2 & $9.83 \mathrm{E}-07$ & 3.49 & 0.52 & 1309.8 \\
\hline K.SVAVDSSESNLKK.I & 2 & $2.37 \mathrm{E}-05$ & 2.63 & 0.44 & 754.4 \\
\hline R.TVGAALTNDPR.I & 2 & 2.65E-05 & 3.20 & 0.42 & 888.1 \\
\hline K.LAFTGSTEVGK.S & 2 & $1.12 \mathrm{E}-04$ & 2.97 & 0.44 & 1377.1 \\
\hline R.GDVTIAINCLR.D & 2 & $1.45 \mathrm{E}-04$ & 3.92 & 0.44 & 1188.3 \\
\hline K.AYLETEIK.V & 2 & 7.91E-04 & 2.49 & 0.25 & 519.2 \\
\hline K.ANFQGAITNR.Q & 2 & 8.01E-04 & 2.98 & 0.35 & 1330.8 \\
\hline K.VGNPFDK.A & 2 & $1.32 \mathrm{E}-03$ & 2.22 & 0.16 & 831.0 \\
\hline K.EEIFGPVVTVAK.F & 2 & $7.30 \mathrm{E}-03$ & 2.33 & 0.45 & 692.6 \\
\hline R.VPFGGVK.Q & 1 & $2.58 \mathrm{E}-02$ & 1.86 & 0.29 & 398.3 \\
\hline K.LHFDTAEPVK.I & 2 & 3.12E-02 & 2.29 & 0.43 & 522.1 \\
\hline gi|10383764| Hbn1p & & 1.18E-06 & 44.16 & & 20980.9 \\
\hline R.AVILTGETHK.K & 2 & $1.18 \mathrm{E}-06$ & 2.46 & 0.62 & 994.5 \\
\hline K.ETPTAFNSQPNR.A & 2 & $4.17 \mathrm{E}-05$ & 2.64 & 0.40 & 493.3 \\
\hline K.NDVEIFN.- & 1 & $9.42 \mathrm{E}-03$ & 1.52 & 0.27 & 328.2 \\
\hline K.TYIKNDVEIFN.- & 2 & $2.92 \mathrm{E}-02$ & 2.80 & 0.36 & 593.7 \\
\hline gi|6321332| Mlc1p & & $1.28 E-06$ & 42.19 & & 16434.4 \\
\hline K.LTDAEVDELLK.G & 2 & $1.28 \mathrm{E}-06$ & 3.76 & 0.59 & 1343.1 \\
\hline K.DSLGDYLR.A & 2 & 7.35E-04 & 2.79 & 0.46 & 787.8 \\
\hline R.YM*LTGLGEK.L & 2 & $2.52 \mathrm{E}-02$ & 2.17 & 0.38 & 321.2 \\
\hline K.VSVGDLR.Y & 2 & $3.56 \mathrm{E}-02$ & 2.23 & 0.31 & 711.9 \\
\hline gi|6319279| Cdc19p & & $1.62 E-06$ & 114.22 & & 54510.5 \\
\hline K.AIIVLSTSGTTPR.L & 2 & $1.62 \mathrm{E}-06$ & 4.04 & 0.68 & 2196.8 \\
\hline K.KGDTYVSIQGFK.A & 2 & $2.38 \mathrm{E}-05$ & 3.16 & 0.55 & 1393.3 \\
\hline K.VTDGVMVAR.G & 2 & $3.24 \mathrm{E}-05$ & 2.75 & 0.52 & 815.2 \\
\hline K.TNNPETLVALR.K & 2 & $7.20 \mathrm{E}-05$ & 2.97 & 0.29 & 735.3 \\
\hline R.TSIIGTIGPK.T & 2 & 2.85E-04 & 2.66 & 0.35 & 1076.1 \\
\hline R.LTSLNVVAGSDLR.R & 2 & $2.91 \mathrm{E}-03$ & 4.36 & 0.67 & 1295.3 \\
\hline R.TANDVLTIR.E & 2 & 7.61E-03 & 2.50 & 0.32 & 1425.6 \\
\hline R.INFGIEK.A & 2 & $9.34 \mathrm{E}-03$ & 2.10 & 0.12 & 540.5 \\
\hline K.AGAGHSNTLQVSTV.- & 2 & $1.79 \mathrm{E}-02$ & 2.94 & 0.56 & 940.1 \\
\hline R.EVLGEQGKDVK.I & 2 & 3.67E-02 & 3.10 & 0.42 & 781.9 \\
\hline
\end{tabular}


Supplementary Table 1. Continued.

\begin{tabular}{|c|c|c|c|c|c|}
\hline \multirow{2}{*}{ Peptide } & \multirow{2}{*}{$\mathbf{z}$} & \multirow{2}{*}{$\frac{\mathbf{P}(\text { pro) }}{\mathbf{P}(\text { pep) }}$} & \multirow{2}{*}{$\frac{\text { Score }}{\text { XC }}$} & \multirow{2}{*}{$\Delta \mathbf{C n}$} & \multirow{2}{*}{$\frac{\text { MW }}{\text { Sp }}$} \\
\hline & & & & & \\
\hline gi|6322794| Tma19p & & 1.83E-06 & 76.19 & & 18729.1 \\
\hline K.LQETNPEEVPK.F & 2 & $1.83 \mathrm{E}-06$ & 3.32 & 0.27 & 942.8 \\
\hline R.LQQTAFDK.K & 1 & $1.03 \mathrm{E}-03$ & 2.08 & 0.37 & 654.2 \\
\hline K.HGIVEEKI.- & 2 & $2.66 \mathrm{E}-03$ & 3.17 & 0.26 & 916.0 \\
\hline R.LQQTAFDKK.S & 3 & $2.28 \mathrm{E}-02$ & 3.48 & 0.40 & 1152.6 \\
\hline K.KVIGSFK.D & 2 & $5.32 \mathrm{E}-02$ & 2.31 & 0.07 & 624.8 \\
\hline K.VIGSFK.D & 1 & $1.98 \mathrm{E}-01$ & 1.88 & 0.29 & 428.4 \\
\hline K.SFLTYIK.G & 1 & $3.77 \mathrm{E}-01$ & 1.35 & 0.14 & 320.6 \\
\hline gi|6323387| Ilv5p & & 2.04E-06 & 158.23 & & 44340.7 \\
\hline K.AQALAVAIGSGYVYQTTFER.E & 2 & $2.04 \mathrm{E}-06$ & 4.55 & 0.64 & 1784.1 \\
\hline K.DLDVILVAPK.G & 2 & $4.41 \mathrm{E}-06$ & 3.79 & 0.54 & 1434.3 \\
\hline R.DNGLNVIIGVR.K & 2 & $5.86 \mathrm{E}-06$ & 3.97 & 0.43 & 1573.4 \\
\hline R.SLEFNSQPDYR.E & 2 & $1.12 \mathrm{E}-05$ & 3.13 & 0.51 & 571.3 \\
\hline K.AAIEDGWVPGK.N & 2 & $1.41 \mathrm{E}-05$ & 3.47 & 0.61 & 839.6 \\
\hline R.GINSSYAVWNDVTGK.A & 2 & $2.16 \mathrm{E}-05$ & 3.19 & 0.58 & 520.1 \\
\hline K.QINFGGTVETVYER.A & 2 & $2.43 \mathrm{E}-05$ & 3.37 & 0.55 & 778.9 \\
\hline K.NLFTVEDAIKR.G & 2 & 4.70E-05 & 2.66 & 0.51 & 946.0 \\
\hline K.DLTHVEPPK.D & 2 & $1.24 \mathrm{E}-04$ & 2.59 & 0.42 & 723.0 \\
\hline R.EVNSDLYGER.G & 2 & 3.77E-04 & 2.87 & 0.48 & 999.7 \\
\hline K.YGM*DYMYDACSTTAR.R & 2 & 4.27E-04 & 3.27 & 0.03 & 907.1 \\
\hline K.NLFTVEDAIK.R & 2 & $2.29 \mathrm{E}-03$ & 2.21 & 0.42 & 467.0 \\
\hline K.YGMDYM*YDACSTTAR.R & 2 & $4.21 \mathrm{E}-03$ & 3.16 & 0.57 & 838.0 \\
\hline K.ELDTIR.N & 1 & $5.12 \mathrm{E}-02$ & 1.36 & 0.23 & 110.1 \\
\hline K.LLDYFK.N & 1 & $5.22 \mathrm{E}-02$ & 1.84 & 0.14 & 569.9 \\
\hline gi|6323822| Ald2p & & 2.89E-06 & 40.20 & 9.29 & 55153.3 \\
\hline K.VGGFVLEASGQSNLK.D & 2 & $2.89 \mathrm{E}-06$ & 3.73 & 0.51 & 1414.4 \\
\hline R.ELGQSGVDTYLQTK.A & 2 & $3.17 \mathrm{E}-06$ & 3.47 & 0.47 & 856.8 \\
\hline R.GIYLSNLLK.L & 2 & $6.24 \mathrm{E}-04$ & 2.26 & 0.18 & 579.2 \\
\hline K.FTNYDDALK.L & 2 & $9.95 \mathrm{E}-03$ & 2.78 & 0.38 & 595.1 \\
\hline gi|6320255| Tpi1p & & $3.67 \mathrm{E}-06$ & 70.26 & & 26779.0 \\
\hline K.ASGAFTGENSVDQIK.D & 2 & $3.67 \mathrm{E}-06$ & 4.70 & 0.61 & 1754.6 \\
\hline R.QLNAVLEEVK.D & 2 & $1.66 \mathrm{E}-04$ & 2.62 & 0.35 & 486.5 \\
\hline K.KPQVTVGAQNAYLK.A & 2 & $7.50 \mathrm{E}-04$ & 3.53 & 0.56 & 1097.7 \\
\hline R.ILYGGSANGSNAVTFK.D & 2 & $1.80 \mathrm{E}-03$ & 3.09 & 0.48 & 1639.0 \\
\hline R.TFFVGGNFK.L & 2 & $5.64 \mathrm{E}-03$ & 2.20 & 0.38 & 424.9 \\
\hline K.TLDVVER.Q & 1 & $1.08 \mathrm{E}-01$ & 1.70 & 0.26 & 213.2 \\
\hline gi|6319326 $\mid$ Ade1p & & $8.75 E-06$ & 74.17 & & 34582.0 \\
\hline K.YIEAYETLTGSK.W & 2 & $8.75 \mathrm{E}-06$ & 3.38 & 0.58 & 993.8 \\
\hline K.LIPLEVIVR.G & 2 & $6.20 \mathrm{E}-05$ & 2.13 & 0.49 & 343.0 \\
\hline K.M*PQDIVDR.T & 2 & $5.37 \mathrm{E}-03$ & 2.45 & 0.09 & 783.9 \\
\hline K.MPQDIVDR.T & 2 & $5.47 \mathrm{E}-03$ & 3.12 & 0.23 & 987.4 \\
\hline K.FEFGIDEK.T & 1 & $2.41 \mathrm{E}-01$ & 1.81 & 0.13 & 465.6 \\
\hline R.VAELAVK.L & 1 & $9.92 \mathrm{E}-01$ & 1.52 & 0.21 & 338.4 \\
\hline
\end{tabular}


Supplementary Table 1. Continued.

\begin{tabular}{|c|c|c|c|c|c|}
\hline \multirow{2}{*}{ Peptide } & \multirow{2}{*}{$\mathbf{z}$} & $\mathbf{P}$ (pro) & Score & \multirow{2}{*}{$\boldsymbol{\Delta}$ Cn } & MW \\
\cline { 3 - 4 } & & $\mathbf{P}(\mathbf{p e p})$ & $\mathbf{X C}$ & & $\mathbf{S p}$ \\
\hline gi|6323386| Tal1p & & $\mathbf{1 . 2 0 E}-\mathbf{0 5}$ & $\mathbf{1 2 6 . 2 3}$ & & $\mathbf{3 7 0 1 3 . 5}$ \\
\hline K.TTEEQVENAVDR.L & 2 & $1.20 \mathrm{E}-05$ & 4.40 & 0.32 & 1953.4 \\
R.LSFDTQATIEK.A & 2 & $1.31 \mathrm{E}-05$ & 3.45 & 0.41 & 1655.7 \\
K.ASGTVVVADTGDFGIAK.F & 2 & $1.64 \mathrm{E}-05$ & 4.57 & 0.68 & 1910.4 \\
K.DYKGEADPGVISVK.K & 2 & $2.91 \mathrm{E}-05$ & 3.55 & 0.61 & 780.6 \\
K.TIVMGASFR.S & 2 & $6.29 \mathrm{E}-05$ & 2.56 & 0.41 & 603.5 \\
K.GEADPGVISVK.K & 2 & $2.02 \mathrm{E}-04$ & 3.02 & 0.58 & 1172.3 \\
R.LLVEFGK.E & 1 & $1.76 \mathrm{E}-03$ & 1.57 & 0.20 & 400.0 \\
K.IASTWEGIQAAK.E & 2 & $6.22 \mathrm{E}-03$ & 3.86 & 0.65 & 1685.4 \\
K.LMNSTEPFPR.V & 2 & $6.51 \mathrm{E}-03$ & 3.19 & 0.48 & 1443.4 \\
K.LM*NSTEPFPR.V & 2 & $4.24 \mathrm{E}-02$ & 2.65 & 0.38 & 505.0 \\
R.ILDWYK.S & 1 & $2.23 \mathrm{E}-01$ & 1.38 & 0.16 & 424.8 \\
\hline gi|6322633| Ura1p & & $\mathbf{1 . 7 7 E}-\mathbf{0 5}$ & $\mathbf{3 0 . 1 3}$ & $\mathbf{7 . 3 2}$ & $\mathbf{3 4 7 7 8 . 8}$ \\
\hline K.GYTSIDQFR.G & 2 & $1.77 \mathrm{E}-05$ & 2.28 & 0.53 & 720.3 \\
K.VFAFFK.K & 1 & $3.42 \mathrm{E}-02$ & 2.19 & 0.31 & 693.2 \\
K.VIGTGGIK.S & 1 & $5.95 \mathrm{E}-01$ & 1.68 & 0.29 & 297.6 \\
\hline gi|6324859| RdI1p & & $\mathbf{2 . 5 5 E}-\mathbf{0 4}$ & $\mathbf{4 0 . 1 4}$ & & $\mathbf{1 5 4 0 3 . 6}$ \\
\hline K.QIGIPKPDSAK.E & 2 & $2.55 \mathrm{E}-04$ & 2.32 & 0.34 & 275.5 \\
-.ELIFYCASGK.- & 1 & $5.24 \mathrm{E}-04$ & 2.66 & 0.22 & 263.4 \\
K.ELIFYCASGK.R & 2 & $2.37 \mathrm{E}-03$ & 2.80 & 0.47 & 887.1 \\
-.HDPNVVLVDVR.- & 2 & $2.55 \mathrm{E}-03$ & 2.84 & 0.23 & 693.0 \\
\hline gi|6323163| Pdc5p & & $\mathbf{1 . 2 0 E}-\mathbf{0 3}$ & $\mathbf{6 0 . 1 1}$ & & $\mathbf{6 1 8 7 3 . 1}$ \\
\hline R.NATFPGVQMK.F & 1 & $1.20 \mathrm{E}-03$ & 2.20 & 0.38 & 288.5 \\
K.LYEVKGMR.W & 2 & $2.50 \mathrm{E}-02$ & 2.04 & 0.40 & 708.0 \\
K.LYEVKGM*R.W & 2 & $3.49 \mathrm{E}-01$ & 1.86 & 0.23 & 317.3 \\
K.YLFER.L & 1 & $9.36 \mathrm{E}-01$ & 1.50 & 0.11 & 130.6 \\
\hline
\end{tabular}

Supplementary Table 2A. mRNAs with a logarithmic (to the basis of two) expression ratio of $\geq 0.59$ or $\leq-\mathbf{0 . 5 9}$ in all three biological replicates.

\begin{tabular}{|c|c|c|c|c|c|c|c|c|c|c|}
\hline \multirow{2}{*}{$\begin{array}{c}\text { Systematical } \\
\text { name }\end{array}$} & \multirow{2}{*}{ mRNA } & \multicolumn{3}{|c|}{ biological replicate 1 } & \multicolumn{3}{c|}{ biological replicate 2 } & \multicolumn{3}{c|}{ biological replicate 3 } \\
\cline { 3 - 11 } & & log2 & AveExpr R1 & FDR R1 & log2 & AveExpr R2 & FDR R2 & log2 & AveExpr R3 & FDR R3 \\
\hline \hline YMR116C & ASC1 & -7.35 & 10.48810301 & $0.00 \%$ & -7.46 & 10.38228062 & $0.00 \%$ & -6.93 & 10.43987511 & $0.00 \%$ \\
\hline YOL155C & HPF1 & -2.87 & 9.484003171 & $0.00 \%$ & -3.11 & 9.718780472 & $0.00 \%$ & -3.04 & 9.914801636 & $0.00 \%$ \\
\hline YPL095C & EEB1 & -1.97 & 8.822821964 & $0.00 \%$ & -1.56 & 9.505416597 & $0.00 \%$ & -1.97 & 9.415880825 & $0.00 \%$ \\
\hline YEL065W & SIT1 & -1.70 & 7.874400126 & $0.75 \%$ & -1.34 & 9.199065688 & $0.02 \%$ & -1.71 & 8.400562631 & $0.00 \%$ \\
\hline YMR058W & FET3 & -1.57 & 10.57125938 & $0.02 \%$ & -1.25 & 10.22387507 & $0.01 \%$ & -1.76 & 10.30773119 & $0.00 \%$ \\
\hline YDR345C & HXT3 & -1.53 & 12.09036161 & $0.00 \%$ & -1.04 & 11.96909997 & $0.16 \%$ & -0.92 & 12.35092901 & $0.07 \%$ \\
\hline
\end{tabular}


Supplementary Table 2A. Continued.

\begin{tabular}{|c|c|c|c|c|c|c|c|c|c|c|}
\hline \multirow{2}{*}{$\begin{array}{c}\text { Systematical } \\
\text { name }\end{array}$} & \multirow{2}{*}{ RNA } & \multicolumn{3}{|c|}{ biological replicate 1} & \multicolumn{3}{|c|}{ biological replicate 2} & \multicolumn{3}{|c|}{ biological replicate 3} \\
\hline & & $\log 2$ & AveExpr R1 & FDR R1 & $\log 2$ & AveExpr R2 & FDR R2 & $\log 2$ & AveExpr R3 & FDR R3 \\
\hline YKL216W & URAI & 1.27 & 11.18671392 & $0.01 \%$ & -2.22 & 10.90345975 & $.00 \%$ & -1.90 & 1.49214813 & $0.00 \%$ \\
\hline YIL169C & - & -1.18 & 7.413180634 & $.71 \%$ & -2.57 & 9.548169381 & $0.00 \%$ & -2.96 & 131550907 & $0.00 \%$ \\
\hline YLR214W & FRE1 & -1.16 & 7.66984228 & $0.56 \%$ & -1.36 & 8.323976358 & $0.00 \%$ & -0.74 & 52532 & $0.13 \%$ \\
\hline YLR136C & TIS11 & -1.16 & 7.511361362 & $0.06 \%$ & -1.18 & 7.520995693 & $1.10 \%$ & -0.80 & 219293451 & $.78 \%$ \\
\hline YLR327C & TMA10 & -1.14 & 10.41513847 & $0.06 \%$ & -1.27 & 4008 & $.01 \%$ & -0.95 & 1.47686906 & $.09 \%$ \\
\hline YOL052C-A & $D D R 2$ & 1.14 & 8.13 & $45 \%$ & -2.47 & 9.55 & $.00 \%$ & -2.32 & 028 & $.01 \%$ \\
\hline YKL096W-A & $C W P 2$ & -1.11 & 13.83650882 & $0.01 \%$ & -1.11 & 12.17846179 & $0.00 \%$ & -1.15 & 12.44018963 & $0.00 \%$ \\
\hline YDR343C & HXT6 & -1.09 & 7.634273622 & $1.15 \%$ & -1.85 & 8.853419699 & $0.01 \%$ & -2.15 & 9.226977125 & $0.00 \%$ \\
\hline YMR251W-A & HOR7 & -1.03 & 13.49074201 & $0.90 \%$ & -1.92 & 13.73753983 & $0.00 \%$ & -1.02 & 77984 & $0.00 \%$ \\
\hline YNL134C & - & -0.99 & 11.23699126 & $0.27 \%$ & -0.77 & 11.9 & $0.23 \%$ & -0.73 & 4756 & $0.39 \%$ \\
\hline YHL040C & ARNI & -0.99 & 8.027559024 & $0.59 \%$ & -1.16 & 8.213182217 & $0.00 \%$ & -1.31 & 8.396190083 & $0.00 \%$ \\
\hline YIL165C & - & -0.93 & 8.226515657 & $0.05 \%$ & -0.84 & .60171698 & $1.39 \%$ & -0.82 & 61189 & $0.02 \%$ \\
\hline YDR342C & HXT7 & -0.89 & 7.539780717 & $4.76 \%$ & -1.92 & 8.840881428 & $0.00 \%$ & -2.15 & 9.108275463 & $0.00 \%$ \\
\hline YOL143C & RIB4 & -0.86 & 10.30795397 & $0.02 \%$ & -1.22 & 11.25652953 & $0.01 \%$ & -1.70 & 1.26007493 & $0.00 \%$ \\
\hline YDL & PSAl & -0.80 & 12.1 & $3 \%$ & -0.61 & 1 & $59 \%$ & -0.66 & 1 & $13 \%$ \\
\hline YDR155C & CPRI & -0.80 & 12.28288291 & $4.15 \%$ & -0.82 & 13.73475207 & $.29 \%$ & -0.93 & 3.51901284 & $.09 \%$ \\
\hline YJL130C & $U R A 2$ & -0.79 & 10.86987687 & $0.07 \%$ & -0.85 & 11.48800117 & $0.09 \%$ & -1.12 & 58098 & $0.03 \%$ \\
\hline YOR374W & ALD4 & -0.79 & 10.0644473 & $1.82 \%$ & -1.40 & 9.700117218 & $0.01 \%$ & -0.59 & 9.953625869 & $1.86 \%$ \\
\hline YOL158C & ENB1 & -0.76 & 7.96850908 & $0.50 \%$ & -1.13 & 8.59916099 & $0.00 \%$ & -0.85 & 8.546274289 & $0.02 \%$ \\
\hline YDL181W & INHI & -0.75 & 3578 & $4 \%$ & -1.48 & 66522 & $.00 \%$ & -0.87 & 70513 & $0.09 \%$ \\
\hline YBL099W & $A T P 1$ & -0.73 & 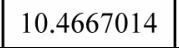 & - & -1.01 & $10.04 / 00502$ & $02 \%$ & 2 & 10.44886731 & $0.01 \%$ \\
\hline YJR121W & ATP2 & -0.68 & 9.941580734 & $2.78 \%$ & -1.02 & 10.58161374 & $2 \%$ & -1.03 & 99262 & $0.01 \%$ \\
\hline YGR279C & SCW4 & -0.67 & 11.5197365 & $2.26 \%$ & -0.65 & 11.58647549 & $60 \%$ & -0.69 & 1.66563144 & $.24 \%$ \\
\hline YDR134C & - & -0.66 & 13.965849 & $4.10 \%$ & -0.66 & 13.67631036 & $2.36 \%$ & -1.43 & 11.54810271 & $0.01 \%$ \\
\hline YPL154C & PEP4 & -0.66 & 11.17413385 & $0.10 \%$ & -0.88 & 11.93664391 & $0.02 \%$ & -0.74 & 11.79720311 & $0.03 \%$ \\
\hline YDR133C & - & -0.65 & 9.918979381 & $0.65 \%$ & -1.10 & 11.86111744 & $21 \%$ & -1.58 & 1.95204686 & $.01 \%$ \\
\hline YKL085W & $M D H I$ & -0.60 & 8.434229571 & $3.50 \%$ & -0.82 & | & $16 \%$ & -0.85 & 10.27572801 & $.01 \%$ \\
\hline YCR024C-A & $P M P 1$ & 0.60 & 638 & $\%$ & -0.71 & 42 & $\%$ & 0.74 & 61 & $2 \%$ \\
\hline YJL037W & IRC18 & 0.60 & 7.777944524 & $0.60 \%$ & 0.59 & 8.380674109 & $.14 \%$ & 0.69 & 8.379357858 & $0.40 \%$ \\
\hline YIR034C & LYSI & 0.63 & 9.390802174 & $1.71 \%$ & 0.82 & 11.8591187 & $0.10 \%$ & 0.79 & 11.34171178 & $0.01 \%$ \\
\hline YNL007C & SISI & 0.65 & 8.890378843 & $2.08 \%$ & 0.85 & 10.90645937 & $0.09 \%$ & 0.60 & 0.45344881 & $0.09 \%$ \\
\hline YOL105C & WSC3 & 0.65 & 8.452515126 & $2.56 \%$ & 1.22 & 8.641846915 & $0.00 \%$ & 0.73 & 8.251631975 & $0.28 \%$ \\
\hline YCL021W-A & - & 0.66 & 10.25495943 & $1.20 \%$ & 1.19 & 10.52140997 & $0.02 \%$ & 0.98 & 10.17619574 & $0.00 \%$ \\
\hline YDR271C & - & 0.70 & 667105 & $\%$ & 0.87 & 86226 & $\%$ & 1.11 & 688 & $04 \%$ \\
\hline YKR091W & SRL3 & 0.71 & 8.124 & $0.13 \%$ & 0.68 & 8.561403676 & $.53 \%$ & 0.70 & 8.289102519 & $0.10 \%$ \\
\hline YGR027W-A & - & 0.78 & 8.282 & $\%$ & 0.72 & 0178 & $0.54 \%$ & 0.71 & 114 & $2.05 \%$ \\
\hline YJR078W & $B N A 2$ & 0.79 & 8.051076569 & $0.09 \%$ & 1.06 & 8.667584895 & $0.01 \%$ & 0.70 & 8.52458776 & $0.04 \%$ \\
\hline
\end{tabular}


Supplementary Table 2A. Continued.

\begin{tabular}{|c|c|c|c|c|c|c|c|c|c|c|}
\hline \multirow{2}{*}{$\begin{array}{l}\text { Systematical } \\
\text { name }\end{array}$} & \multirow{2}{*}{ mRNA } & \multicolumn{3}{|c|}{ biological replicate 1} & \multicolumn{3}{|c|}{ biological replicate 2} & \multicolumn{3}{|c|}{ biological replicate 3} \\
\hline & & $\log 2$ & AveExpr R1 & FDR R1 & $\log 2$ & AveExpr R2 & FDR R2 & $\log 2$ & AveExpr R3 & FDR R3 \\
\hline YBL071W-A & KTI11 & 0.80 & 8.313290369 & $0.17 \%$ & 1.09 & 8.932311906 & $0.02 \%$ & 0.88 & 9.020197266 & $0.07 \%$ \\
\hline YOR143C & ТНI80 & 0.83 & 8.859598917 & $0.42 \%$ & 0.83 & 10.01783004 & $0.38 \%$ & 0.69 & 9.765317162 & $3.93 \%$ \\
\hline YOR132W & VPS17 & 0.84 & 9.872825798 & $0.30 \%$ & 0.59 & 10.87719276 & $1.23 \%$ & 0.83 & 10.78083628 & $1.65 \%$ \\
\hline YJR079W & - & 0.88 & 8.225844319 & $0.85 \%$ & 0.90 & 9.347228623 & $11 \%$ & 0.89 & 9.340645933 & $0.98 \%$ \\
\hline YMR045C & - & 0.96 & 10.94382076 & $1.94 \%$ & 0.83 & 12.03022032 & $0.52 \%$ & 1.05 & 1.73184478 & $0.00 \%$ \\
\hline YPL257W-B & - & 0.97 & 12.91896765 & $0.29 \%$ & 0.80 & 12.65890281 & $0.13 \%$ & 1.28 & 12.50960321 & $0.00 \%$ \\
\hline YGR234W & YHB1 & 0.98 & 11.9058922 & $0.03 \%$ & 1.49 & 12.63986334 & $0.00 \%$ & 1.63 & 12.9925406 & $0.00 \%$ \\
\hline YDR270W & $C C C 2$ & 0.99 & 12.20673708 & $2.33 \%$ & 0.81 & 13.01959829 & $2.78 \%$ & 0.91 & 13.05893648 & $3.73 \%$ \\
\hline YHR177W & - & 0.99 & 7.362127757 & $0.61 \%$ & 1.53 & 7.715902641 & $0.00 \%$ & 1.12 & 9175 & $0.92 \%$ \\
\hline YMR050C & - & 1.01 & 11.06769295 & $1.02 \%$ & 0.87 & 11.85010764 & $0.53 \%$ & 1.10 & 11.67239166 & $0.00 \%$ \\
\hline YGR170W & PSD2 & 1.01 & 10.49480646 & $1.39 \%$ & 0.69 & 11.59635597 & $1.39 \%$ & 0.93 & 11.51531761 & $4.52 \%$ \\
\hline YOL114C & - & 1.02 & 11.18462985 & $0.33 \%$ & 0.81 & 12.21653195 & $0.45 \%$ & 0.94 & 12.09919121 & $1.84 \%$ \\
\hline YOR343W-A & - & 1.02 & 12.55223142 & $1.67 \%$ & 1.55 & 13.38036625 & $0.01 \%$ & 1.60 & 12.37898062 & $1.17 \%$ \\
\hline YEL040W & UTR2 & 1.03 & 11.37452013 & $0.01 \%$ & 1.51 & 11.38237692 & $0.00 \%$ & 0.81 & 1422 & $.79 \%$ \\
\hline YDR034C-C & - & 1.05 & 13.10845518 & $1.26 \%$ & 0.93 & 12.83244139 & $0.03 \%$ & 1.05 & 12.30702604 & $0.43 \%$ \\
\hline YDR305C & HNT2 & 1.05 & 10.26577254 & $2.39 \%$ & 0.91 & 11.47534513 & $0.65 \%$ & 1.03 & 11.50798485 & $4.97 \%$ \\
\hline YDR326C & $Y S P 2$ & 1.07 & 11.52042644 & $2.33 \%$ & 0.92 & 12.58943451 & $1.35 \%$ & 1.06 & 12.59897236 & $4.65 \%$ \\
\hline YDR261C-C & - & 1.08 & 14.99663165 & $0.86 \%$ & 1.00 & 14.44963036 & $0.14 \%$ & 1.62 & 14.38478426 & $0.00 \%$ \\
\hline YOR343W-B & - & 1.09 & 11.43927732 & $0.63 \%$ & 1.43 & 13.20661797 & $0.43 \%$ & 1.35 & 12.19726428 & $2.84 \%$ \\
\hline YGR161C-D & - & 1.10 & 11.90127347 & 0.5070 & 0.66 & 11.92801286 & 1.0370 & 64 & 11.9128089 & $0.29 \%$ \\
\hline YOL103W-B & - & 1.11 & 12.22867236 & $0.13 \%$ & 0.83 & 2892 & $0.04 \%$ & 1.32 & 2583 & $0.00 \%$ \\
\hline YBR012W-B & - & 1.13 & 11.13285417 & $0.61 \%$ & 0.66 & 11.92239087 & $3.98 \%$ & 0.69 & 11.81977472 & $4.01 \%$ \\
\hline YCL020W & - & 1.13 & 12.1362403 & $1.19 \%$ & 0.98 & 12.46835428 & $0.02 \%$ & 0.90 & 11.90541476 & $0.15 \%$ \\
\hline YDR214W & AHAI & 1.17 & 9.438234071 & $0.00 \%$ & 1.17 & 9.972798134 & $.00 \%$ & 0.83 & 10.30171884 & $0.39 \%$ \\
\hline YPR158C-D & - & 1.23 & 12.03310965 & $0.06 \%$ & 0.71 & 12.27735622 & $\%$ & 1.02 & 12.08269827 & $0.00 \%$ \\
\hline YJL088W & $A R G 3$ & 1.23 & 9.635478843 & $0.12 \%$ & 1.08 & 12.3041303 & $05 \%$ & 0.68 & 11.92876643 & $0.10 \%$ \\
\hline YDR316W-B & - & 1.23 & 12.23798348 & $0.08 \%$ & 0.71 & 12.29694283 & $0.86 \%$ & 1.02 & 12.23506821 & $0.00 \%$ \\
\hline YFL010C & $W W M 1$ & 1.33 & 9.697360623 & $0.00 \%$ & 1.80 & 10.57116569 & $0.00 \%$ & 1.15 & 10.56749784 & $0.00 \%$ \\
\hline YGR027W-B & - & 1.33 & 12.5633935 & $0.03 \%$ & 1.12 & 12.74921608 & $0.12 \%$ & 1.32 & 12.68392625 & $0.00 \%$ \\
\hline YOR315W & $S F G 1$ & 1.37 & 8.333433227 & $0.00 \%$ & 1.66 & 8904 & $0.03 \%$ & 0.78 & 7745 & $0.10 \%$ \\
\hline YML039W & - & 1.38 & 12.55882626 & $0.04 \%$ & 0.79 & 12.72414174 & $4.80 \%$ & 1.08 & 12.66203689 & $3.98 \%$ \\
\hline YER138W-A & - & 1.38 & 11.30852991 & $1.07 \%$ & 2.53 & 13.6022948 & $0.18 \%$ & 1.54 & 12.18847911 & $0.05 \%$ \\
\hline YDR261C-D & - & 1.40 & 10.77537721 & $0.06 \%$ & 0.73 & 12.77270596 & $0.09 \%$ & 1.53 & 12.83888598 & $0.00 \%$ \\
\hline YOR142W-B & - & 1.45 & 12.11437375 & $0.96 \%$ & 1.14 & 11.92816147 & $3.54 \%$ & 1.19 & 11.8969615 & $0.00 \%$ \\
\hline YDR210W-B & - & 1.66 & 13.20676588 & $0.00 \%$ & 0.76 & 11.88831264 & $0.14 \%$ & 1.36 & 12.13217966 & $0.00 \%$ \\
\hline YLL053C & - & 1.70 & 8.151614805 & $0.00 \%$ & 2.39 & 8.452928274 & $0.00 \%$ & 1.72 & 8.294225782 & $0.00 \%$ \\
\hline YCL026C-B & $H B N 1$ & 1.73 & 9.145901104 & $0.00 \%$ & 1.75 & 9.919413435 & $0.00 \%$ & 1.27 & 10.46031349 & $0.68 \%$ \\
\hline
\end{tabular}


Supplementary Table 2B. mRNAs (referred to in discussion) with a mean logarithmic (to the basis of two) expression ratio of $\geq \mathbf{0 . 5 9}$ or $\leq \mathbf{- 0 . 5 9}$.

\begin{tabular}{|c|c|c|c|c|c|c|c|c|c|c|}
\hline \multirow{2}{*}{$\begin{array}{c}\text { Systematical } \\
\text { name }\end{array}$} & \multirow{2}{*}{ mRNA } & \multicolumn{3}{|c|}{ biological replicate 1 } & \multicolumn{3}{c|}{ biological replicate 2 } & \multicolumn{3}{c|}{ biological replicate 3 } \\
\cline { 3 - 25 } & & log2 & AveExpr R1 & FDR R1 & log2 & AveExpr R2 & FDR R2 & log2 & AveExpr R3 & FDR R3 \\
\hline \hline YIR019C & FLO11 & -0.55 & 8.129617143 & $3.17 \%$ & -0.40 & 8.182860765 & $11.50 \%$ & -1.08 & 8.186536509 & $0.43 \%$ \\
\hline YBL016W & FUS3 & 0.82 & 8.475104163 & $0.07 \%$ & 0.41 & 8.857863701 & $4.52 \%$ & 0.44 & 9.368586624 & $1.05 \%$ \\
\hline YCL027W & FUS1 & 0.70 & 8.398740922 & $2.32 \%$ & 1.04 & 9.48430735 & $0.02 \%$ & 0.36 & 9.046662618 & $42.34 \%$ \\
\hline
\end{tabular}

Supplementary Table 3. 5'UTR sequences confirmed by sequencing. The lengths of the respective candidate-5'UTRs were determined according to a previously generated tiling array transcriptome analysis of Saccharomyces cerevisiae (David et al., 2006)(www.ebi.ac.uk/huber-srv/queryGene). The displayed 5'UTR sequences were cloned and confirmed by sequencing.

\begin{tabular}{|c|c|c|}
\hline 5'UTR & length [bp] & sequence \\
\hline STE12 & 323 & $\begin{array}{l}\text { 5'-AAC AGC CTA AAA AAG ATT GAA CAA CTC TTC GCG GTC AGG TCT CGA } \\
\text { CAC CAT AAA TCG AAG TAC TCG TAC GCT AGT TTT CTC GCA CAT AGT } \\
\text { ACC ACT ACG TTC CTT TTA CAA TTA GAT TAC TTC TTT TTA GTT GAC TTT } \\
\text { TTT GAG ACG TTC GTG CCA TTC ATA AAA TAG GAA AAG ATA ACA GGT } \\
\text { AAG CAC TGA AGA CTT GTT TTA TAA GTG TCC CAA GCG AGA CCT AGA } \\
\text { GTG GAT ATT GAT ATT TCT CAA ACA AGA CTC GTC GAA GAA AAC ACA } \\
\text { CTT TTA TAG CGG AAC CGC TTT CTT TAT TTG AAT TGT CTT GTT CAC CAA } \\
\text { GG-3' }\end{array}$ \\
\hline PHD1 & 276 & $\begin{array}{l}\text { 5'- GCG GCC ATA CTC ATT AAA AAC CCC TCC CCA TTT TTC CTT TTT TTT } \\
\text { TTG TTT CCA TAT AGG AAG AAC TCT ACA GCT CGA ACA ATA CAT CAA } \\
\text { ATC AAT CAA GCA GTC GCT CTC GTT CTA TTG TGT GTT TCT CAC CAC } \\
\text { CTT ACA TAT CTC CCC TCA GTT CCC AGC CTA TAA CTT TGT GGT TCT CTT } \\
\text { CTT CTT TTC AAC TTC TTC TTC TTG ACA TTA TAC TTT AAT AAG ACC ATT } \\
\text { ACT TCT TTT TCT TTG CTG GAA TTC ATA ATT CAT TAA GCA GAA AAT-3' }\end{array}$ \\
\hline TEC1 & 64 & $\begin{array}{l}\text { 5'-ATT CCT CCC ATA TCG ACA AGA AGA ATA ATC CAC CTA TTT CAA CAA } \\
\text { TTC TGA TAC CTG TTTAAC C-3' }\end{array}$ \\
\hline$R A P 1$ & 115 & $\begin{array}{l}\text { 5'- CCA TCA ATA CAC GTT TTA AAC AAA ACA AAC CCA TAG CCC AAA } \\
\text { AGG TAG TAA ACA CAA ACC GTT GTA TAC GCA ACC GCC CTA CAT AAG } \\
\text { ACA CTA TTT GCG TAC AGA TTA TCT CAA T-3' }\end{array}$ \\
\hline FLO8 & 167 & $\begin{array}{l}\text { 5'-ATT GAA AAA GTG ACC ATT TTT TAC TCC TGT TCA AGC GCA TTT GCT } \\
\text { TTG ATA CCA TTT TGT TTG CCG AAG ACA CGG TGA GTT GAC GTT AGT } \\
\text { AAG TCA CTG AGG CTA TAA AAA ATA AAC ACG AAG ACG TTT ATA GAC } \\
\text { ATA AAT AAA GAG GAA ACG CAT TCC GTG GTA GA-3' }\end{array}$ \\
\hline
\end{tabular}




\section{Curriculum vitae}

NAME:

GEBURTSDATUM:

GEBURTSORT:

NATIONALITÄT:

FAMILIENSTAND:

SCHULbILdUNG:

1986 - 1990:

1990 - 1992:

1992 - 1999:

1999 - 2000:
Nicole Rachfall

08.09.1980

Göttingen

deutsch

ledig
Grundschule, Adolf-Reichwein Grundschule in Göttingen

Orientierungsstufe, Orientierungsstufe I in Hann. Münden

Gymnasium, Grotefend-Gymnasium in Hann Münden

WisSENSChAFTLiChe AUSBILDUNG:

$2000-2006:$

Grund- und Hauptstudium der Biologie (Diplom) an der Georg-August-Universität zu Göttingen

Aug. 2004 - Dez. 2004 Praktikum als wissenschaftliche Assistantin am Department of Biology, Georgetown University, Washington, D.C., USA

Mai 2005: Diplomprüfungen (Hauptfach: Mikrobiologie; Nebenfächer: Humangenetik und Botanik)

Sept. 2005 - Mai. 2006: Diplomarbeit am Institut für Mikrobiologie und Genetik bei Prof. Dr. Gerhard H. Braus

Thema: „Proteom-Änderungen von Saccharomyces cerevisiae Wildtyp- und $\Delta c p c 2 / \Delta a s c 1-Z e l l e n$ unter Aminosäuremangel"

Sept. 2006 - Sept. 2010: Doktorarbeit am Institut für Mikrobiologie und Genetik der Georg-August-Universität zu Göttingen bei Prof. Dr. Gerhard H. Braus

Thema: „Translational control by the ribosomal protein Asc1p/Cpc2p in Saccharomyces cerevisiae" 
